\title{
USE OF CHITOSAN FOR THE REMOVAL OF METAL. ION CONTAMINANTS AND PROTEINS FROM WATER
}

CENTRE FOR NEWFOUNDLAND STUDIES

TOTAL OF 10 PAGES ONLY MAY BE XEROXED 


Use of chitosan for the removal of metal ion contaminants and proteins from water

By

\section{${ }^{\circ}$ DONA ASHOKA SRIYANI GAMAGE}

A thesis submitted to the School of Graduate Studies

in partial fulfillment of the requirements

for the degree of Master of Science

Environmental Science Programme

Memorial University of Newfoundland

May 2003

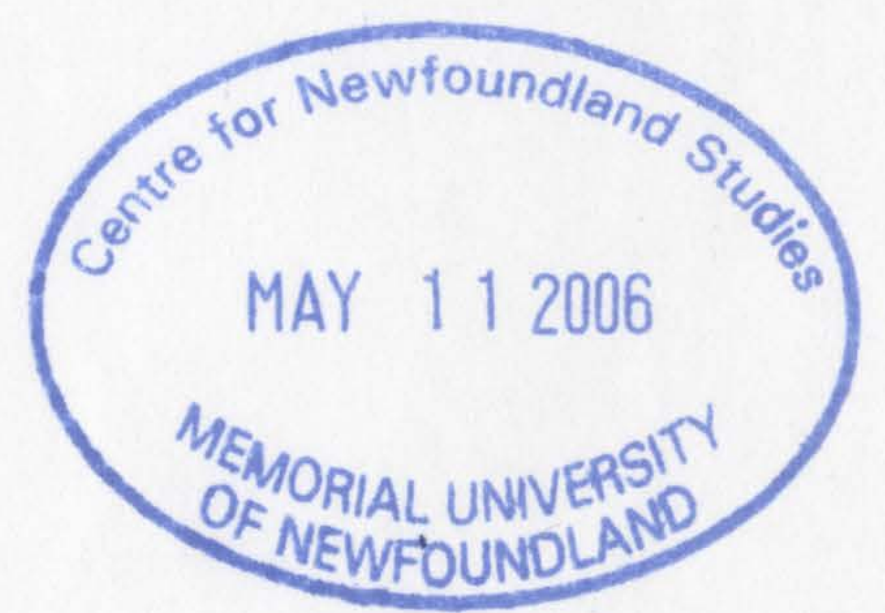


Library and

Archives Canada

Published Heritage

Branch

395 Wellington Street

Ottawa ON K1A ON4

Canada
Bibliothèque et

Archives Canada

0-494-06602-4

Direction du

Patrimoine de l'édition

395, rue Wellington

Ottawa ON K1A 0N4

Canada
Yourfile Votre référence

ISBN:

Our file Notre retèrence

ISBN:
NOTICE:

The author has granted a nonexclusive license allowing Library and Archives Canada to reproduce, publish, archive, preserve, conserve, communicate to the public by telecommunication or on the Internet, loan, distribute and sell theses worldwide, for commercial or noncommercial purposes, in microform, paper, electronic and/or any other formats.

The author retains copyright ownership and moral rights in this thesis. Neither the thesis nor substantial extracts from it may be printed or otherwise reproduced without the author's permission.
AVIS:

L'auteur a accordé une licence non exclusive permettant à la Bibliothèque et Archives Canada de reproduire, publier, archiver, sauvegarder, conserver, transmettre au public par télécommunication ou par l'Internet, prêter, distribuer et vendre des thèses partout dans le monde, à des fins commerciales ou autres, sur support microforme, papier, électronique et/ou autres formats.

L'auteur conserve la propriété du droit d'auteur et des droits moraux qui protège cette thèse. $\mathrm{Ni}$ la thèse ni des extraits substantiels de celle-ci ne doivent être imprimés ou autrement reproduits sans son autorisation.
In compliance with the Canadian Privacy Act some supporting forms may have been removed from this thesis.

While these forms may be included in the document page count, their removal does not represent any loss of content from the thesis.
Conformément à la loi canadienne sur la protection de la vie privée, quelques formulaires secondaires ont été enlevés de cette thèse.

Bien que ces formulaires aient inclus dans la pagination, il n'y aura aucun contenu manquant. 


\section{ABSTRACT}

Chitin is the second most abundant natural biopolymer after cellulose and is distributed in the shells of crustacea and cuticle of insects and also in the cell wall of some fungi. Chitosan is the deacetylated product of chitin. Chitosan has been used in a number of fields such as agriculture, the food industry and medicine. Both chitin and chitosan are recognized as excellent metal ligands, forming stable complexes with many metal ions. In particular, chitosan is considered one of the best natural chelators for transition metal ions and an effective protein coagulating agent.

The processing discards of shellfish pose major technological problems, mainly due to their insolubility in water and resistance to biodegradation. D irect $\mathrm{u}$ se of $\mathrm{crab}$ processing discards is generally discouraged due to the obnoxious odour of putrefying shells, therefore, value-added utilization of their discards is of paramount importance.

In the treatment of crab processing discards to extend their usable shelf-life, five different chemical treatments were used. Fresh samples of crab processing discards were treated by dipping in $1 \%$ formaldehyde, formic acid, acetic acid, sodium bicarbonate or sodium hydroxide solution. Experiments were conducted at two temperatures ranges; 4$7^{\circ} \mathrm{C}$ and $20-25^{\circ} \mathrm{C}$. The samples were evaluated for sensory characteristics by a seven membered panel and the results were recorded. Chitin isolated from crab processing discards was deacetylated in order to produce three types of chitosan (Types 1, 2 and 3). Chitosans so prepared were evaluated for their capacity to chelate single metal ion solutions containing $\mathrm{Co}^{2+}, \mathrm{Fe}^{2+}, \mathrm{Ni}^{2+}, \mathrm{Cd}^{2+} \mathrm{Mn}^{2+}, \mathrm{Zn}^{2+}$ and $\mathrm{Cu}^{2+}$. Then, the three chitosan types were tested for their capacity to chelate metal ions in samples of water obtained from a zinc minining site, Buchans, Newfoundland. Ethylenediaminetetraacetic acid (EDTA) was used as the reference chelating agent. The capacity to chelate single metal ions by chitosan and EDTA was determined by a colourimetric method and metal chelation capacity of wastewater was determined by inductively coupled plasma-mass spectrometry (ICP-MS) at three $\mathrm{pH}$ levels (5,6 and 7). Chelation and recovery of metals from aqueous solutions using a column containing chitosan was also determined by ICP- 
MS. Ethylenediaminetetraacetic acid was used to recover metal ions that were chelated by chitosan in the column. Chitosan served as an effective coagulating agent in removing proteins from waste water.

Out of the tested treatments, $1 \%$ formaldehyde served best in controlling the foul odour development both at $4-7^{\circ} \mathrm{C}$ and $20-25^{\circ} \mathrm{C}$ followed by formic acid. Due to possible carcinogenicity of formaldehyde, formic acid could be best utilized in controlling foul odour of crab wastes. At all $\mathrm{pH}$ levels tested, EDTA exhibited the highest chelation capacity. At $\mathrm{pH} \mathrm{5,} \mathrm{chitosan} \mathrm{served} \mathrm{best} \mathrm{for} \mathrm{metal} \mathrm{ion} \mathrm{chelation} \mathrm{and} \mathrm{pH} 7$ was best for metal mixtures in waste water. Metal chelation by a column method for single metal ions showed over $98 \%$ chelation both at 50 and $100 \mathrm{ppm}$ except for $\mathrm{Co}^{2+}$ while gave a metal recovery of $52-97 \%$. For mixtures of metal ions, except $\mathrm{Co}^{2+}$, exhibited $94 \%$ chelation and metal recovery was $24-90 \%$. Chitosan Type 1 showed the best protein flocculation ability followed by Types 2 and 3 chitosan.

Encouraging results for metal chelation and recovery by the prepared chitosan and protein flocculation reveal that crustacean processing discards can be converted to useful environmentally friendly material for wastewater purification. 


\section{ACKNOWLEDGEMENTS}

I wish to express my sincere gratitude to Dr. F. Shahidi for providing invaluable guidance and financial support throughout my MSc programme. I also wish to extend my thanks to my supervisory committee members, Dr. N. Gogan, Chair Environmental Science Programme and Dr. A. Martin for their guidance and valuable suggestions. I wish to express my sincere thanks to Dr. Sue Ellen Maher, Environmental toxicologist and Mr. George Neary, Asarco Incorporated, Buchans, Newfoundland for providing me with wastewater samples. Thanks are extended to Mrs. Lakmali Hewa, Department of Earth Science for assisting me with ICP-MS analyses. I am also grateful to Dr. M-S. Heu for assisting me with column chromatography analysis and valuable suggestions. Special thanks are due to Dr. S.P.J.N. Senanayake, Mr. M.A Khan and Mr. J.A.L.P. Jayakody as well as other colleagues in Dr. Shahidi's research team. My Deepest gratitude is due to my husband Madhujith for his enormous support, encouragement and dedication and my little son Hasith from whom the time devoted to this work was withdrawn. I wish to express my deepest appreciation to my loving parents for their blessing and encouragement without which this work not have been successful. 


\section{TABLE OF CONTENTS}

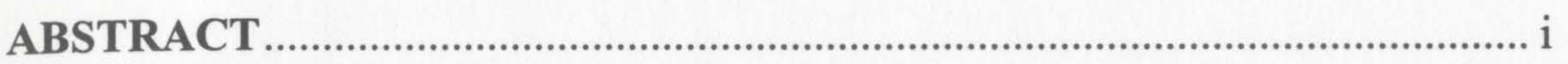

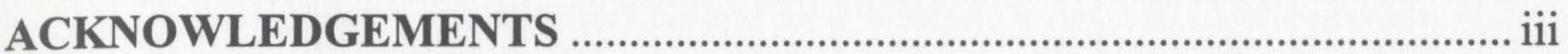

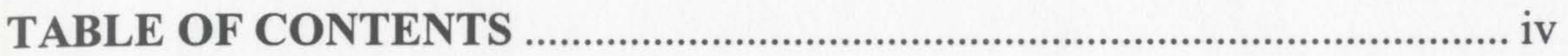

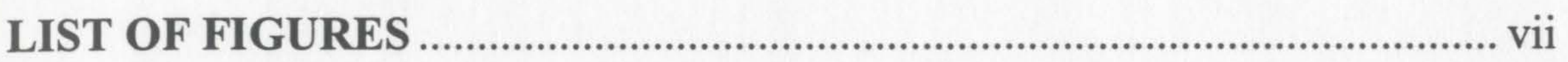

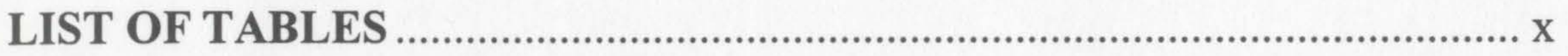

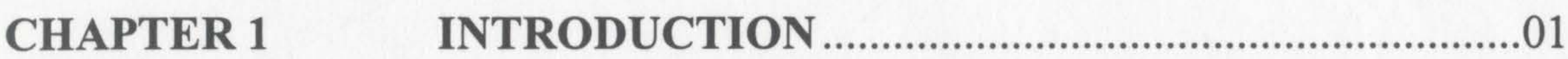

CHAPTER 2 LITERATURE REVIEW …...........................................04

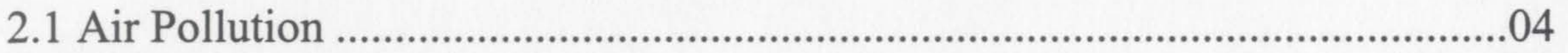

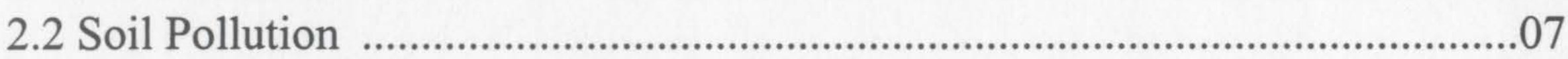

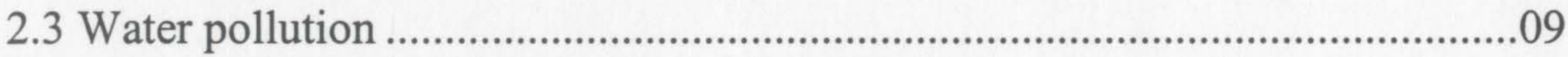

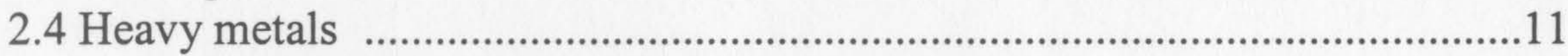

2.4.1 Heavy metals in environmental pollution ......................................... 12

2.4.1.1 Heavy metals in the atmosphere .........................................12

2.4.1.2 Heavy metals in soil ..........................................................14

2.4.1.3 Heavy metals in water ......................................................16

2.4.2 Heavy metal toxicity and human health........................................... 19

2.4.3 Analytical procedures for determination of heavy metals .................22

2.4.3.1 Spectroscopic methods....................................................... 23

2.4.3.2 Atomic emission spectrometry ........................................... 23

2.4.3.3 Atomic absorption spectroscopy........................................ 24

2.4.3.4 Inductively coupled plasma-mass spectrometry ................25

2.4.3.5 Voltammetry ...................................................................... 25

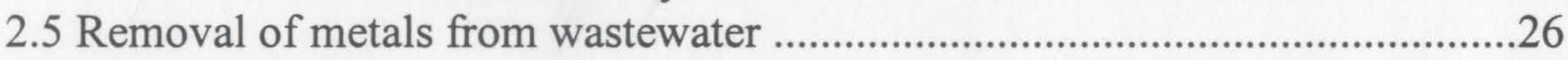

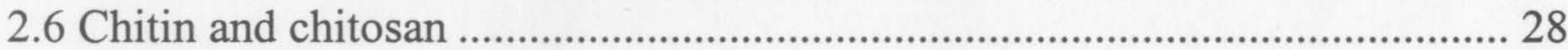

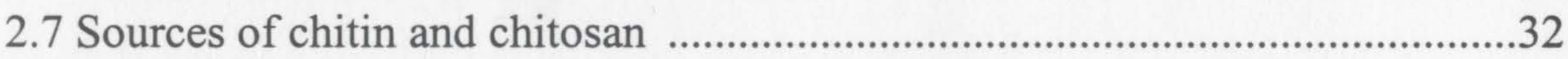

2.8 Preparation of chitin and chitosan from shellfish processing discards ........... 36

2.8.1 Preparation of chitin from shellfish processing discards ................. 37

2.8.1.1 Preparation of raw materials ............................................ 38

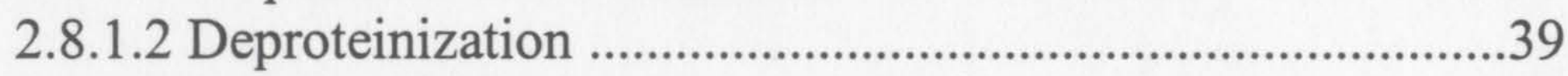

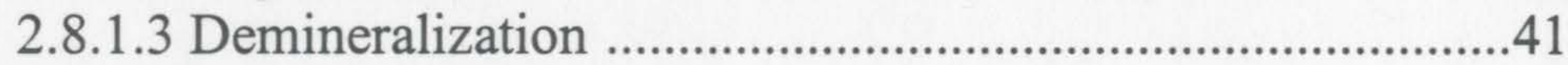

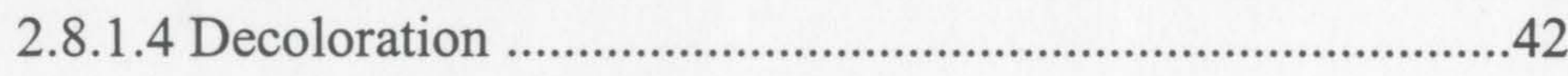

2.8.2 Production of chitosan from chitin ....................................................43

2.9 Physiochemical properties of chitin and chitosan .............................................4 


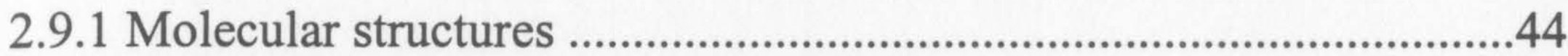

2.9.2 Molecular weight of chitin and chitosan ...........................................49

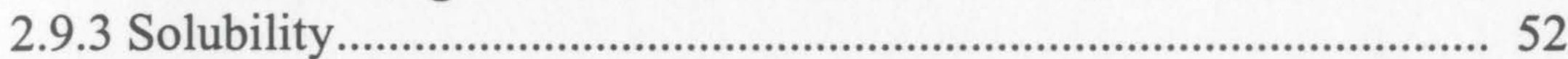

2.9.4 Chemical reactions of chitin and chitosan ......................................... 53

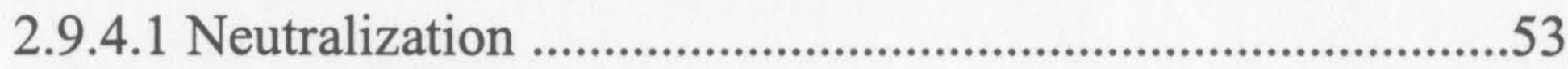

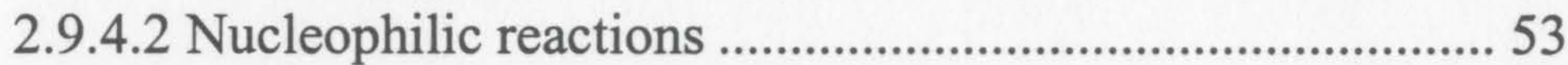

2.9.4.3 Acid- or base-assisted hydrolysis ......................................56

2.9.4.4 Sulphation reactions........................................................... 56

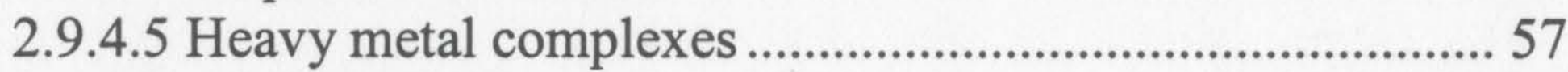

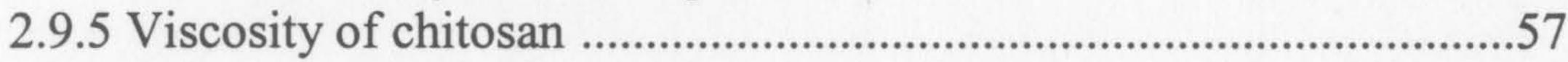

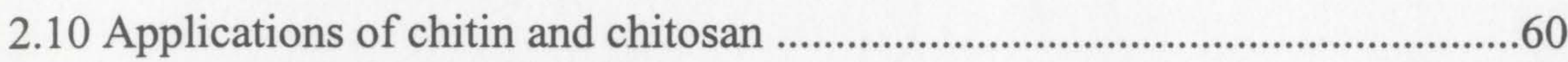

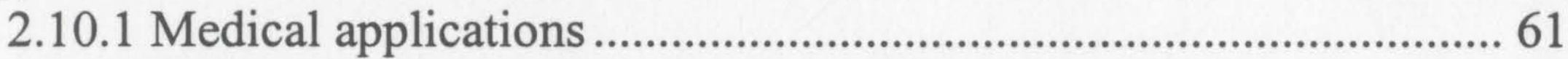

2.10.2 Pharmaceutical and biotechnological applications .........................63

2.10.3 Food and nutritional applications....................................................... 64

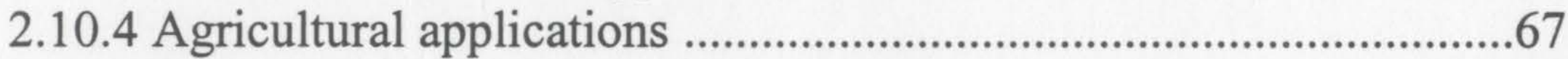

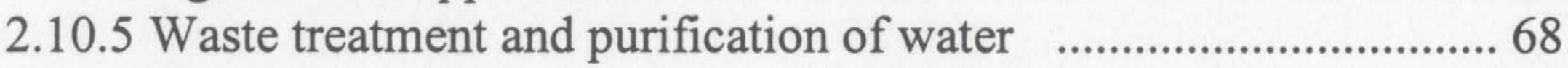

2.11 Seafood processing discards as environmental pollutants …….....................70

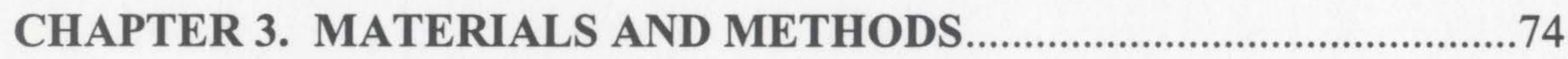

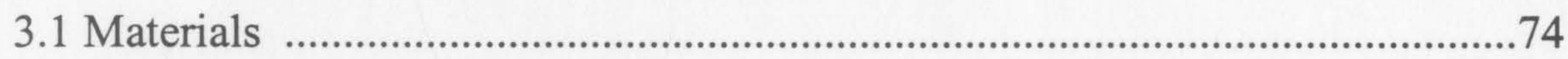

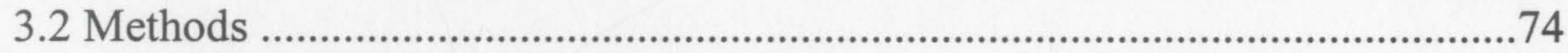

3.2.1 Suitability of chemical treatments in

extending shelf life of crab processing discards .................................. 74

3.2.2 Proximate composition of crab processing discards .............................75

3.2.2.1 Moisture content .................................................................... 75

3.2.2.2 Ash content ...........................................................................

3.2.2.3 Crude protein content.......................................................... 76

3.2.2.4 Lipid content .......................................................................76

3.2.3 Preparation of chitin and chitosan and

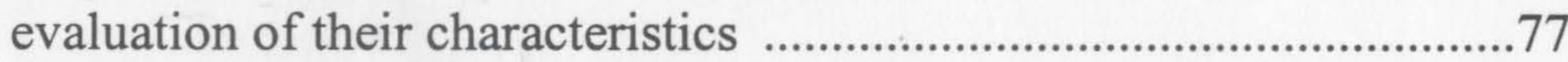

3.2.4 Metal chelation capacity of chitosan ...................................................... 81

3.2.5 Determination of heavy metals in waste water samples by inductively coupled plasma mass spectrometry (ICP-MS)...................82

3.2.6 Metal chelation capacity and recovery of metals from aqueous solutions using small-sized columns

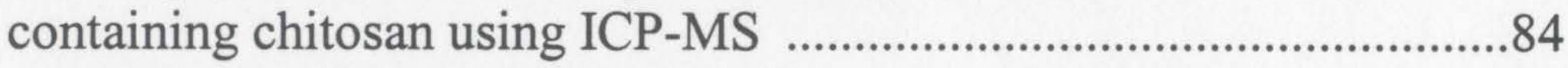

3.2.6.1 Column preparation ............................................................. 84

3.2.6.2 Metal chelation and recovery of single metals from aqueous solutions ...............................................84

3.2.6.3 Metal chelation and recovery of multiple metals from aqueous solution. ..............................................86

3.2.7 Determination of protein flocculation by chitosans .......................... 86 


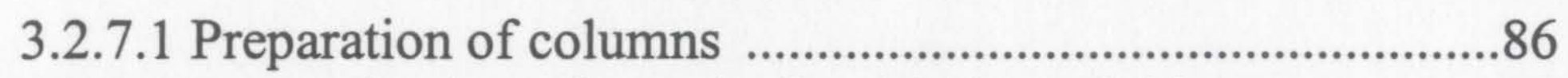

3.2.7.2 Determination of protein flocculation of chitosan ............ 87

3.2.7.3 Determination of protein by Lowry's method ..................87

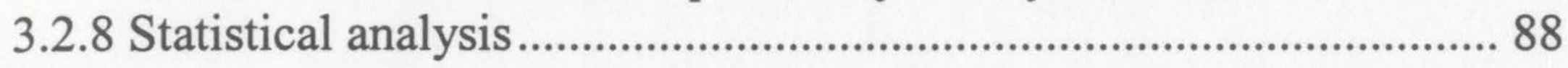

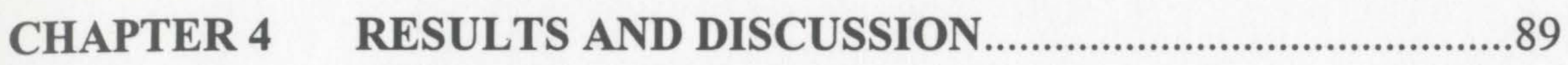

4.1 Suitability of chemical treatments for extending the shelf life of crab processing discards ......................................................... 89

4.2 Proximate analysis of crab wastes and isolation of Chitin ............................ 94

4.3 Production and characteristics of chitosan extracted from crab processing discards ......................................................... 96

4.4 Metal chelation capacity of chitosans

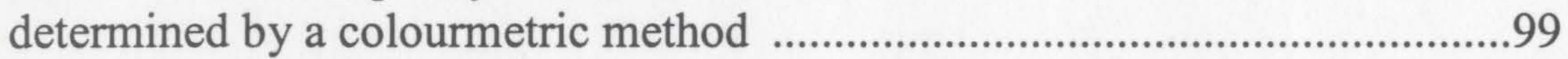

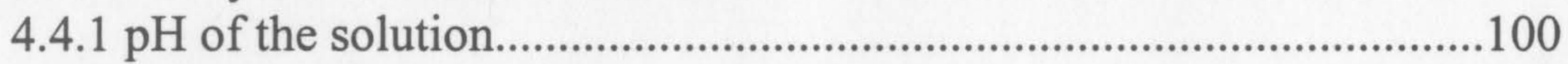

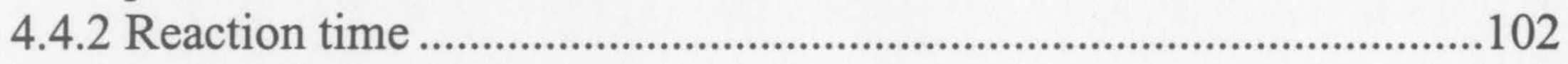

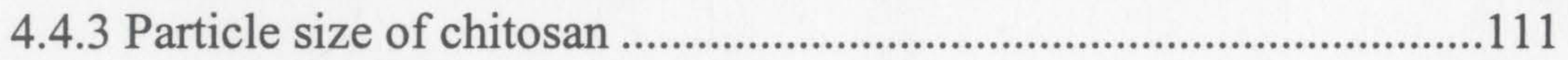

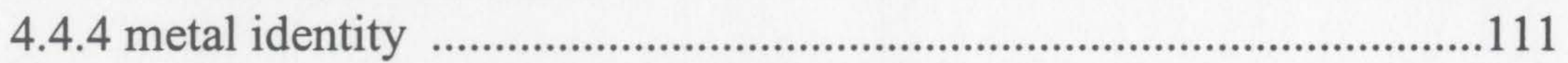

4.5 Determination of heavy metals in waste water samples by inductively coupled plasma mass

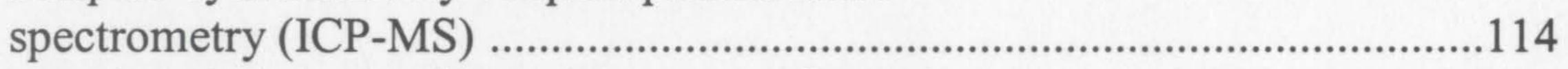

4.6 Metal chelation capacity and recovery of metals from aqueous solutions using a chitosan columns ........................................121

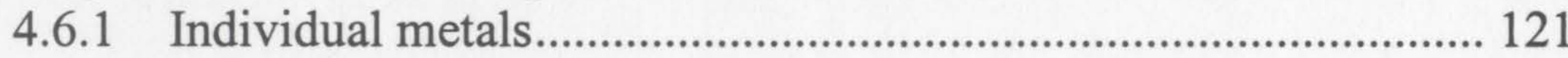

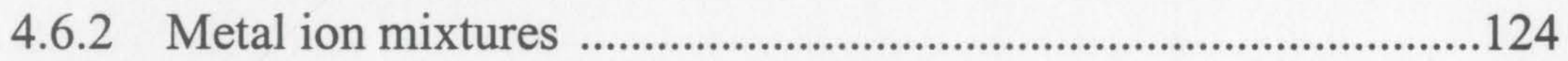

4.7 Determination of protein flocculation by chitosan ....................................... 126

5.0 CONCLUSIONS AND RECOMMENDATIONS …...............................131

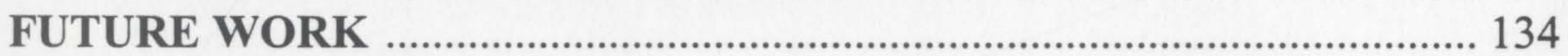

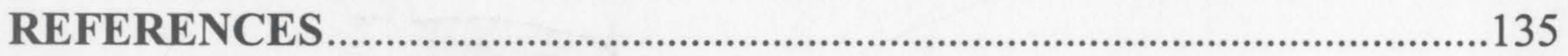

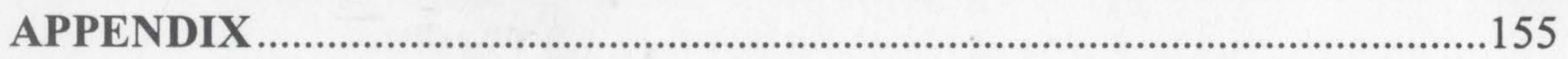




\section{LIST OF FIGURES}

Figure 2.1 Chemical structures of chitin, chitosan and cellulose 30

Figure 2.2 Chemical derivatives of chitin and chitosan. 31

Figure 2.3 Antiparallel and parallel chain arrangements of chitin. .50

Figure 2.4 Preparation of water-soluble chitin and chitosan derivatives. .54

Figure 2.5a The neutralization reaction of chitin/chitosan 58

Figure 2.5b Nucleophilic reactions of chitosan 58

Figure 2.6a The degradation reaction of chitosan by use of nitrous acid 59

Figure 2.6b Sulphation of chitosan .59

Figure 3.1 A simplified flow diagram of chitin and chitosan preparation 79

Figure 4.1 The binders of $\mathrm{Cu}^{2+}$ by the tetramethylmurexide. 101

Figure 4.2 Metal chelation capacity of $\mathrm{Cd}^{2+}$ by chitosans and EDTA under three different $\mathrm{pH}$ conditions over time

Figure 4.3 Metal chelation capacity of $\mathrm{Co}^{2+}$ by chitosans and EDTA under three different $\mathrm{pH}$ conditions over time 104

Figure 4.4 Metal chelation capacity of $\mathrm{Cu}^{2+}$ by chitosans and EDTA under three different $\mathrm{pH}$ conditions over time

Figure 4.5 Metal chelation capacity of $\mathrm{Fe}^{2+}$ by chitosans and EDTA under three different $\mathrm{pH}$ conditions over time 106

Figure 4.6 Metal chelation capacity of $\mathrm{Mn}^{2+}$ by chitosans and EDTA under three different $\mathrm{pH}$ conditions over time

Figure 4.7 Metal chelation capacity of $\mathrm{Ni}^{2+}$ by chitosans and EDTA under three different $\mathrm{pH}$ conditions over time 108

Figure 4.8 Metal chelation capacity of $\mathrm{Zn}^{2+}$ by chitosans and EDTA under three different $\mathrm{pH}$ conditions over time 
Figure 4.9 Metal chelation capacities of three types of chitosan after $3 \mathrm{~h}$....... 112

Figure 4.10 Metal chelation capacities of three types of chitosan after $6 \mathrm{~h}$........ 113

Figure 4.11 Effectiveness of chitosan in metal ions chelation from waste water at $\mathrm{pH} 5$

Figure 4.12 Effectiveness of chitosan in metal ions chelation from waste water at $\mathrm{pH} 6$.

Figure 4.13 Effectiveness of chitosan in metal ions chelation from waste water at $\mathrm{pH}$

Figure 4.14 Protein flocculation capacity of chitosan using different concentrations of bovine serum albumin

Figure A.1 Dependence of the absorbance of diisopropylethylamine (DIPEA)picrate concentration at $358 \mathrm{~nm}$ on the concentration of DIPEA-picrate

Figure A.2 Dependence of the absorbance ratio of (A) $\mathrm{Fe}^{2+}$ and (B) $\mathrm{Co}^{2+}$ concentration at $460 \mathrm{~nm} / 530 \mathrm{~nm}$ on the concentration of metal solutions - $\mathrm{pH} 5$

Figure A.3 Dependence of the absorbance ratio of (A) $\mathrm{Ni}^{2+}$ and (B) $\mathrm{Mn}^{2+}$ concentration at $460 \mathrm{~nm} / 530 \mathrm{~nm}$ on the concentration of metal solutions- $\mathrm{pH} 5$ 164

Figure A.4 Dependence of the absorbance ratio of (A) $\mathrm{Cu}^{2+}$ and (B) $\mathrm{Zn}^{2+}$ concentration at $460 \mathrm{~nm} / 530 \mathrm{~nm}$ on the concentration of metal solutions $-\mathrm{pH} 5$.

Figure A.5 Dependence of the absorbance ratio of $\mathrm{Cd}^{2+}$ concentration at $460 \mathrm{~nm} / 530 \mathrm{~nm}$ on the concentration of metal solutions- $\mathrm{pH} 5$

Figure A.6 Dependence of the absorbance ratio of (A) $\mathrm{Ni}^{2+}$ and (B) $\mathrm{Zn}^{2+}$ concentration at $460 \mathrm{~nm} / 530 \mathrm{~nm}$ on the concentration of metal solutions - $\mathrm{pH} 6$

Figure A.7 Dependence of the absorbance ratio of (A) $\mathrm{Mn}^{2+}$ and (B) $\mathrm{Cd}^{2+}$ concentration at $460 \mathrm{~nm} / 530 \mathrm{~nm}$ on the concentration of metal solutions $-\mathrm{pH} 6$ 168

Figure A.8 Dependence of the absorbance ratio of (A) $\mathrm{Cu}^{2+}$ and (B) $\mathrm{Co}^{2+}$ concentration at $460 \mathrm{~nm} / 530 \mathrm{~nm}$ on the concentration of metal solutions $-\mathrm{pH} 6$ 
Figure A.9 Dependence of the absorbance ratio of $\mathrm{Fe}^{2+}$ concentration at $460 \mathrm{~nm} / 530 \mathrm{~nm}$ on the concentration of metal solutions $-\mathrm{pH} 6 \ldots . .170$

Figure A.10 Dependence of the absorbance ratio of (A) $\mathrm{Ni}^{2+}$ and (B) $\mathrm{Mn}^{2+}$ concentration at $460 \mathrm{~nm} / 530 \mathrm{~nm}$ on the concentration of metal solutions $-\mathrm{pH} 7$

Figure A.11 Dependence of the absorbance ratio of (A) $\mathrm{Cu}^{2+}$ and (B) $\mathrm{Zn}^{2+}$ concentration at $460 \mathrm{~nm} / 530 \mathrm{~nm}$ on the concentration of metal solutions $-\mathrm{pH} 7$

Figure A12 Dependence of the absorbance ratio of (A) $\mathrm{Fe}^{2+}$ and (B) $\mathrm{Co}^{2+}$ concentration at $460 \mathrm{~nm} / 530 \mathrm{~nm}$ on the concentration of metal solutions $-\mathrm{pH} 7$

Figure A.13 Dependence of the absorbance ratio of $\mathrm{Cd}^{2+}$ concentration at $460 \mathrm{~nm} / 530 \mathrm{~nm}$ on the concentration of metal solutions $-\mathrm{pH} 7 \ldots .174$

Figure A.14 Dependence of the absorbance of bovine serum albumin at $660 \mathrm{~nm}$ on the concentration of protein in the solutions. 


\section{LIST OF TABLES}

Table 2.1 Maximum contaminant levels for potentially toxic metals in drinking water. 21

Table 2.2 Chitin content of selected crustaceans and molluscan organs 34

Table 2.3 Deacetylation conditions in chitosan production .45

Table 2.4 Characteristics of chitin 46

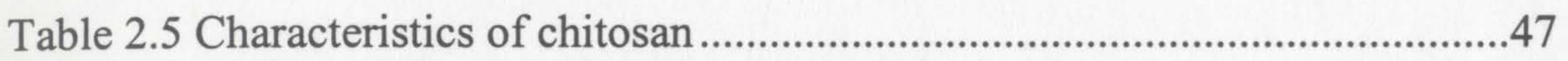

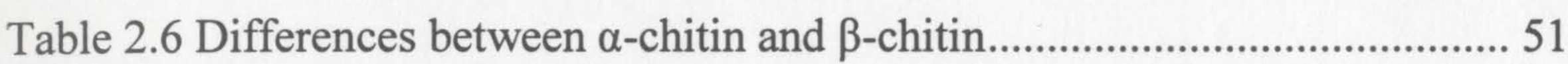

Table 2.7 Common solvents for chitin and chitosan..............................................55

Table 3.1 Limit of detection of elements for ICP-MS ….....................................85

Table 4.1 Sensory evaluation of crab processing discards treated with different reagent and stored at $4-7^{\circ} \mathrm{C}$................................92

Table 4.2 Sensory evaluation of crab processing discards treated with different reagent and stored at $20-25^{\circ} \mathrm{C}$

Table 4.3 Characteristics of three different types of chitosans (Types 1,2 and 3) prepared from crab shells.

Table 4.4 Elements present in the waste water samples from zinc mining site (Buchans, Newfoundland) as determined by ICP-MS and their concentrations

Table 4.5 Summary of guidelines for protection of aquatic life and dinking water

Table 4.6 Comparison of metal chelation and recovery of chitosan. 125

Table 4.7 Comparison of metal chelation and recovery of chitosan for mixtures of metal ions

Table A.1 Sensory evaluation of crab waste at cold room temperature $\left(4-7^{\circ} \mathrm{C}\right)$

Table A.2 Sensory evaluation of crab waste at cold room temperature $\left(20-25^{\circ} \mathrm{C}\right)$ 
Table A3 Chelation capacity \% of chitosan and EDTA over 24 hour at $\mathrm{pH} 5$

Table A4 Chelation capacity \% of chitosan and EDTA over 24 hour at $\mathrm{pH} 6$

Table A5 Chelation capacity \% of chitosan and EDTA over 24 hour at $\mathrm{pH} 7$

Table A6 Effectiveness of chitosan in metal ion chelation from industrial waste water.

Table A7 Protein flocculation capacity of chitosan using different concentrations of bovine serum albumin. 


\section{CHAPTER 1 \\ INTRODUCTION}

Heavy metals belong to the group of elements described geochemically as trace elements, because they collectively comprise $<1 \%$ of the rock in the earth's crust (Alloway, 2001). Heavy metals are released into the aqueous environment through a variety of sources such as metal smelter effluents, textiles, microelectronics and usage in fertilizers and plastics. It is well known that most trace metals display strong bioactivities. The heavy metals play a dual role as essential nutrients and toxic chemicals in plant production and human health (Harada and Hatanka, 1988). The hazards associated with the pollution of water bodies caused by heavy metals have led to the development of various wastewater reclamation technologies (Bassi et al., 2000). Heavy metals at low concentrations are difficult to remove. Chemical precipitation, reverse osmosis, and other available methods become inefficient when heavy metal contaminants are present in trace amounts in a large volume of solution. Adsorption is one of few alternatives available in such a situation (Huang et al., 1996). The use of adsorbents (eg. activated carbon, low cost industrial products and microbial materials) has received extensive attention (Huang et al., 1996). All of these technologies have their inherent advantages and limitations. For instance, activated carbon still requires complexing agents to improve its performance in removing inorganic matters. On the other hand, ion-exchange resins are effective, but expensive.

The use of chelation ion exchange for wastewater remediation has been gaining attention in the recent past. Chelation ion exchange, in contrast to simple ion exchange, takes advantage of removing only toxic metal ions while the harmless ions move on into 
the environment (Deans and Dixon, 1992). Some of the best chelation ion-exchange materials consist of different biopolymers and their derivatives because of the variety of functional groups, such as $\mathrm{OH}$ and $\mathrm{NH}_{2}$ (Bassi et al., 2000). Biopolymers are attracting increasing interest for their capacity as effective scavengers of heavy metals, thus making them environmentally safe (Huang et al., 1996). Such materials include cellulose, alginates, proteins, chitin and chitin derivatives.

Chitin (ploy[ $\beta$-(1-4)-2-acetoamido-2-deoxy-D-glucopyranose]), a polymer of $N$ acetyl-D-glucosamine is one of the most abundant organic materials produced annually by biosynthesis in animals, particularly in crustacea, mollusks and insects, and in certain fungi. Its derivative chitosan (ploy[ $\beta$-(1-4)-2-amino-2-deoxy-D-glucopyranose]), a polymer of D-glucosamine, has reactive amino groups which are responsible for complex formation between metal ions and the polymer chain. Chitosan is a heteropolymer made of D-glucosamine and a small fraction of N-acetyl-D-glucosamine residues (Roberts, 1992). Therefore, the adsorption ability of chitosan is found to be much higher than that of chitin, which has relatively fewer amino groups. Chitosan also has many other useful features, including hydrophilicity, biocompatibility, biodegradability, antibacterial property, and a remarkable affinity for many proteins (Bassi et al., 2000). Reclamation of proteins yields not only economically valuable products, but also the pretreatment of food, industrial wastewater which is becoming a common requirement prior to discharge to the municipal sewer systems (Selmer-Olsen et al., 1996). Chitosan, with its partial positive charge, can be used for coagulation and recovery of proteinaceous materials present in such food processing operation (Knorr, 1991). 
The processing of shellfish waste poses major technological problems as shells are largely water insoluble and very resistant to natural biodegradation (Healy et al., 1994). Direct use of these discards for land manuring, or spreading, is generally discouraged by the uniquely o bnoxious odours of putrefying shells. Therefore, valueadded utilization of shell discards is of importance. Hence, the uses of chitin and chitosan have been explored for wastewater treatment such as removal of metals, recovery of precious metals and removal of proteinaceous materials from industrial wastewater.

Most previous studies have dealt with examining the capabilities of chitosan to adsorb metal ions and coagulation of proteinacous materials from industrial wastewater. However, little attempt has been made to understand the characteristics of different chitosans obtained by adapting different deacetylation times.

The objectives of the present study are to evaluate the efficacy of different chemicals for extending the shelflife of fresh crab processing discards prior to future processing. Preparation of chitosan from locally available crab discards was also attempted. In addition, the potential of chitosans produced under different conditions in chelating metal ions and flocculation of proteins was investigated. Finally, industrial wastewater containing a wide variety of metal ions was investigated. 


\section{CHAPTER 2 \\ LITERATURE REVIEW}

The environment, including the atmosphere, earth, water and space are affected by various activities of man; hence, the composition and the complex nature of the environment change. Over the past 200 years, a rapid increase in population worldwide has necessitated the need for even greater use of fuel and development of industrial chemicals, fertilizers, pesticides and pharmaceuticals to sustain and improve the quality of life (Chakrabarty et al., 1988). Although many of these chemicals are utilized or destroyed, a high percentage of them is released into the atmosphere, water and soil; all of which represents a potential environmental hazard (Alexander, 1995). Unfortunately, it is n ot feasible to r eplace a 11 industrial p rocesses that g enerate polluting $w$ astes $w$ ith clean alternatives (Betts, 1991). Diverse environmental impacts are usually associated with high contaminant concentration formed in close proximity to input sources. Environmental pollution is classified into various groups, namely air pollution, water pollution (i.e., industrial effluent pollution and domestic effluent pollution), soil pollution and noise pollution.

\subsection{Air Pollution}

Amongst the various types of pollution, air pollution is of greater importance. A large variety and quantity of contaminants are released into the environment. Once released, these contaminants may become widely dispersed via the fluid dynamics of surface water and atmosphere. The atmosphere is responsible for the long-range dissemination of contaminants over regional, hemispherical and global scales due to its 
dynamic nature and ability to move contaminants rapidly (Rahn and Lowenthal, 1984; Johnes et al., 1989).

Through the process of atmospheric transport and deposition, toxic chemicals have found their way to remote environments far from emission sources (Eurtz, 1990). Many of these chemicals are toxic and persistent, thus, can bioaccumulate and remain biologically active for long periods of time. Airborn pollutants can be broadly defined as chemicals occurring in the atmosphere in concentration and exposure duration that may pose a threat to human health and the environment. This broad definition includes an array of chemicals ranging from criteria pollutants (e.g. ozone, sulphur dioxide), which have resulted in well-documented biological effects at local and regional scales, to the greenhouse gases (e.g. methane, chlorofluorocarbons) with their implications for global warming and stratospheric ozone depletion. Another group of chemicals, often referred to as air toxic or airborne contaminants, includes a large number and variety of chemical species broadly categorized as industrial organic, agricultural pesticide, trace metal and metalloid. These contaminants have strong anthropogenic emission sources and are known to be transported long distances (hundreds to thousands of kilometres) on the troposphere before being deposited into remote environments (Moser et al., 1992).

Although humans have been responsible for emitting contaminants into the atmosphere for thousands of years, air pollution has increased exponentially, both in quantity and variety as a result of industrial revolution. Anthropogenic contaminants emanate from a host of different industrial, urban, and agricultural sources such as 
chemical, metal, plastic, pulp and paper industries, fossil fuel processing plants, motor vehicles and aircrafts, municipal waste incinerators, agricultural practices such as pesticide usage and field burning, and small business practices, including dry cleaning among others (Freedman and Hutchinson, 1981). Emissions of toxic chemicals into the atmosphere may occur directly through deliberate or inadvertent release from industrial or urban sources or indirectly through volatilization following deliberate or accidental discharge of chemicals into water or soil. Considerable amounts of toxic chemicals enter the atmosphere from wind drift and volatilization during and following application of agricultural pesticides (Waddel and Bower, 1988).

Although numerous toxic chemicals are released from anthropogenic sources, organochlorine compounds and several trace metals are of particular concern. Organochlorines are significant environmental contaminants due to their chronic toxicity, their proven ability for bioaccumulation and biomagnification in the food chain, and the large quantities that have been manufactured, used, and released into the environment (Stickel, 1975; Harrison, 2001). Organochlorines represent a large class of chemicals that include synthetic organics and their by-products such as polychlorinated biphenyls (PCBs), hexachlorobenzene (HCB), polychlorinated dibenzodioxins (PCDD), and polychlorinated dibenzofurans (PCDF), and pesticides such as dichlorodiphenyltrichloroethane (DDT), hexachlorocyclohexane $(\mathrm{HCH})$ and toxapene.

All trace metals, even those with essential biochemical functions, have the potential to produce adverse biological effects at excessive levels of exposure. However, 
trace metals such as mercury, cadmium, lead, and arsenic are of particular environmental concern b ecause they a re b iologically nonessential and a re toxic to most organisms at relatively low concentrations (Nriagu, 1988). The deposition of persistent synthetic organics and trace metals into terrestrial ecosystems not only results in increasing concentration of these contaminants in vegetation and soil, but also increases the risk to organisms at higher tropic levels such as herbivores, detrivores, and carnivores (Stickel, 1975; Martin and Caughtrey, 1981; Buckely, 1982).

\subsection{Soil Pollution}

Soil is an essential component of the terrestrial ecosystem because the growth of plants and biogeochemical cycling of nutrients depend upon it. Of the total area of the world's land $\left(13.07 \times 10^{9}\right.$ ha), only $11.3 \%$ is cultivated for crops; $34 \%$ account for forest and woodlands, $24.6 \%$ account for permanent grazing and $31 \%$ account for other land including urban industries and roads (World Resources Institutes, 1994-95). From a resource perspective, soil is vitally important for the production of food, fibre crops and timber, and it is therefore essential that the total productive capacity of the world's soils not be impaired. Pollution, along with other types of degradation, such as erosion and the continuing spread of urbanization pose a threat to the sustainability of soil resources. Soil pollution can also be a hazard to human health when potentially toxic substances are moved through the food chain or reach the ground water used for drinking purposes, among others (Alloway, 2001). 
In comparison with air and water, soil is more variable and complex in composition and hence, it functions as a sink for pollutants, a filter which retards the passage of chemicals to the ground water, and a bioreactor in which many organic pollutants can be decomposed. As a consequence of its occurrence at the interface between the land and the atmosphere, soil is the recipient of a diverse range of polluting chemicals transported into the atmosphere. Further introduction of pollutants to the soil occurs as a result of agricultural and waste disposal practices, but in general, the most severe pollution usually arises from industrial and urban used lands (Alloway, 2001). Old industrial sites are generally characterized by being very heterogeneous, both with regard to the distribution of pollutants and also to the properties of the soil material that control the behaviour of these chemicals. In contrast, atmospherically deposited pollutants tend to be more evenly by distributed with gradual changes in concentration, which tend to decrease with distance for the source. The upper horizons of the soil are contaminated to the greatest extent by atmospheric deposition of pollutants (Alloway, 2001).

Soil pollutant sources include the following: heavy metals, hydrocarbon pollutants such as benzene, toluene, ethylbenzene and xylene; toxic organic micropollutants such as polycyclic aromatic hydrocarbons, polyheterocyclic hydrocarbons, polychlorinated biphenyls, polychlorinated dibenzodioxins, polychlorinated dibenzofurans and pesticide residues and metabolites; nutrient-rich wastes such as sewage sludge and livestock manures; radionuclides; as well as other industrial chemicals and pathogenic organisms. Pollutants reach the soil by four main pathways: these include atmospheric deposition of 
particulates (washout or dry deposition), sorption of gases (e.g. volatile organic compounds) from the atmosphere fluvial transport and desorption/sorption from floodwaters, and placement (agricultural, amendments, dumping, injection, surface spreading etc). Placement of pollutants can occur in many ways. The most obvious being the spreading of wastes, such as sewage sludges or metal rich manures from cattle, pigs or poultry. The spraying of pesticides onto crops and soils is a good example of placement although they may subsequently be further dispersed into the environment. Industrially-contaminated land with its associated demolition of old buildings and manufacturing plants, the redevelopment of sites, leakages of stored chemicals, and accumulation of wastes provides other examples of the placement of contaminants into the soil (Alloway, 2001).

Soil pollution gives rise to toxicological problems in humans, livestock, crops and ecosystems and may also cause damage to structures and services. This can happen directly through contact with the soil itself or indirectly through soil pollution causing groundwater to become contaminated and thus giving toxicological and structural problems (Alloway, 2001). Large areas of soil and groundwater in the northern part of France are contaminated by trace metals as a result of former or contemporary processing of metal ions (Godin et al., 1985).

\subsection{Water pollution}

Water is certainly the most important substance on earth, as it is the medium through which all life has evolved. The pollution of natural waters by both biological and 
chemical contaminants is a worldwide problem. Only very few areas, whether in developed or developing countries, do not suffer from some form of water pollution. Pollution of water directly affects humans through drinking water while the aquatic life (plants and animals) is also affected. There are well in excess 1500 potential pollutants discharged to freshwaters (Mason, 2000). Water $\mathrm{c}$ an $\mathrm{b}$ ecome $\mathrm{c}$ ontaminated from $\mathrm{b}$ oth natural and anthropogenic sources (Fawell and Stanifield, 2001). All surface waters contain natural organic matter in the form of humic substances, which are large complex carbohydrates. The sources of contamination fall into two categories as point and diffuse sources; industrial or waste discharges being point sources while run-off from agricultural 1 and and from $\mathrm{h}$ ard surfaces b eing diffused sources (Fawell and $\mathrm{S}$ tanfield, 2001). Inorganic contaminants, examples being lead, arsenic, nitrate, aluminum and fluoride, and organic contaminants such as disinfectant by-products, pesticides, endocrine disrupters, polycyclic aromatic hydrocarbons and tri- and tetra-chloroethene, are among some of the most studied water pollutants.

Among the various means of environmental pollution, heavy metals released to the environment through various sources such as metal smelters, textile, microelectronic, fertilizer and pesticide manufacturing (Ross, 1994; Prasad and Hagemeyer, 1999) play an important role. The following sections discuss the different types of pollutants, role of heavy metals as an environmental pollutant, removal of heavy metal ions from wastewater as a means of reducing environmental pollution by heavy metals and the use of chitosan in removing heavy metals from wastewater. 


\subsection{Heavy metals}

Heavy metals belong to the group of elements described geochemically as trace elements, because they collectively comprise $<1 \%$ of the rock in the earth's crust (Alloway, 2001). These a re $\mathrm{n}$ atural $\mathrm{c}$ onstituents of the e arth's $\mathrm{c}$ rust and are p resent in varying concentrations in all ecosystems. All trace elements are toxic to living organisms at excessive concentrations, but some are essential for the normal growth and reproduction by either plants or animals at low, but critical, concentrations. These elements are referred to as essential trace elements or micronutrients and their deficiency may lead to diseases and even death of the plant or animal. The essential trace elements include cobalt ( $\mathrm{Co}$; bacteria and animals), chromium ( $\mathrm{Cr}$; animals), copper $(\mathrm{Cu}$; plants and animals), selenium (Se; animals) and zinc ( $\mathrm{Zn}$; plants and animals). In addition, boron (B; plants), chlorine ( $\mathrm{Cl}$; plants), iron (Fe; plants and animals), iodine (I; animals) and silicon ( $\mathrm{Si}$; plants and animals probably) are also essential trace elements but are not dense enough to be classified as h eavy m etals. O ther elements including silver ( $\mathrm{Ag})$, arsenic (As), barium $(\mathrm{Ba})$, cadmium $(\mathrm{Cd})$, mercury $(\mathrm{Hg})$, titanium $(\mathrm{Ti})$, lead $(\mathrm{Pb})$ and antimony ( $\mathrm{Sb}$ ) have not been known to exert any essential function, but similar to essential trace elements cause toxicity when present above a certain tolerance level. The most important heavy metals with regard to potential hazard and occurrence in contaminated soils include $\mathrm{As}, \mathrm{Cd}, \mathrm{Cu}, \mathrm{Cr}, \mathrm{Hg}, \mathrm{Pb}$ and $\mathrm{Zn}$ (Alloway, 2001).

Heavy $m$ etals a re s table and persistent e nvironmental c ontaminants s ince m any cannot be degraded or destroyed. Therefore, they tend to accumulate in soils, seawater, freshwater, and s ediments. E xcessive levels of metals in the $\mathrm{m}$ arine environment $\mathrm{c}$ an 
affect marine biota and pose risk to human consumers of seafood. Heavy metals are also known to have adverse effects on the environment and human health. However for the sake of human health and that of the natural environment, particular attention must be paid to heavy metals that persist in the environment and in the tissue of plants and animals and which bioaccumulate in the food chain (Harrison, 2001).

\subsubsection{Heavy metals in environmental pollution}

Heavy metals occur naturally in rocks, soils, sediments and waters, but their anthropogenic component has increased greatly since the industrial revolution. This increase has caused serious environmental problems that have affected the food chain and consequently the organisms, including humans (Forstner, 1990).

\subsubsection{Heavy metals in the atmosphere}

Heavy metals are emitted from traffic and industrial sources into the atmosphere and spread over wide regions. Although heavy metal deposition has decreased considerably during the last 20 years in many parts of the world, there are many areas where the long-term accumulation of heavy metals, often associated with exposure to sulphur dioxide, has damaged the ecosystem. For instance, there are extensive damage areas surrounding the metallurgical industry complexes in the Kola Peninsula located in the NW of Russia. Coniferous trees efficiently filter pollutant particles from the air (Salemaa et al., 2001). Stand throughfall and plant litter increases the load of heavy metals and sulphur on the forest floor (Heinrich and Mayer, 1980; Derome and Nieminess, 1988; Nieminen et al., 1999). 
Potentially toxic metals are emitted to the atmosphere as gases, aerosols and particles. They are ingested by organisms during respiration in high concentrations in proximate areas to a source and in lesser concentrations at more distant ones. Emitted metals are carried to the ecosystem at the earth's surface via atmospheric deposition. They enter the food web from the air, mix with soils and sediments and may create a health hazard. There are natural contributions of metals to the atmosphere from volcanic eruptions, hot springs and wildfires. These come in bursts and cause temporal distortion in atmospheric contents of potentially toxic elements that are then dispersed and diluted. Volatile e lements such as m ercury a re e mitted to the a tmosphere $\mathrm{n}$ aturally from s oils, buried mineral deposits or subsurface rocks with high mercury contents (Siegel, 2002).

By far the major anthropogenic loading of metals in the atmosphere is from coal and oil-burning electrical power plants as well as from coal, oil and wood used in home heating and from sulphur smelting operations. For example, Pirrone et al. (1996) estimated that $40 \%$ of the mercury in the atmosphere over the former USSR originated from coal combustion. The masses of metals emitted to the atmosphere from these sources are enormous (Siegel, 2002).

Potentially toxic metals from atmospheric deposition on a land surface are integrated with soil. T hey can become $\mathrm{p}$ art of the recharge to aquifers or r unoff into surface water. Depending on an element's mobility in soils and vegetation, the capacity to accumulate one or more metals or discriminate against their uptake, potentially toxic 
metals can access the food/water web. In addition, once in soils or associated waters the metals may be moved by erosion and in solution to fluvial systems (Siegal, 2002).

\subsubsection{Heavy metals in soil}

Soil provides the nutrient-bearing environment that sustains plant growth. Essential nutrient metals and other metals in food crops are translocated through soil into the food web. Natural contents of potentially toxic elements in soils are generally low unless the soil developed from rock with high contents of one or more elements to from ore-bearing rock metal in soils that may be greatly enhanced by human activities (Siegel, 2002).

Although metals such as copper, nickel and zinc are essential nutrients for living organisms (Alloway, 1995), they may be toxic at higher concentrations. Metal content in soil is determined by the nature of the parent material and by inputs of metals from sources such as sewage sludge, mining, smelting impurities in agricultural and horticultural materials, and fossil fuel combustion. Atmospheric deposition contamination arises where sewage sludge, metal-containing pesticides or fertilizers are used extensively. Owing to its relatively high concentration of metals, sewage sludge is a major potential source of metals in agricultural soils to which it is applied to improve fertility (Smith et al., 1989) and physical conditions (Pagliai et al., 1981). Coniferous forests are effective for trapping heavy metal aerosols because of the high adsorption surface area that their canopies present for interception (Lindberg and Turner, 1988). The humus layer of coniferous forest soils has often been found to be effective in 
retaining heavy metals, particularly lead and copper (Tyler, 1978; Bergkvist, 1987; Derome and Nieminen, 1988; Bergkvist et al., 1989). Zinc, being less strongly adsorbed by organic matter, and a plant nutrient subject to uptake and cycling, tends to show a weak depth-gradient in the soil and correlation with deposition (Anderson et al., 1991). Heavy metals are often associated with accessory minerals in acidic igneous rocks which dominate in the boreal zone (Koljonen, 1992).

High levels of metals are usually found in superficial soils and vegetation in areas affected by mining activities, metal factories and traffic emissions. Accurate measurements of the total metal contents in polluted soils are required to assess the potential risk of these areas; however, only soluble, exchangable and chelated metal species in the soils are the labile fractions available for plants (Kabata-Pendias, 1993). Heavy metal uptake by plants in contaminated soils has been extensively studied. However, in some cases the variability of soils and plants has prevented the obtaining of a direct relationship between the total metal concentration in the soil and plants (Voutsa et al., 1996; Shallari et al., 1998). Contaminated soils become a secondary environmental danger in two respects: (1) contamination of crops and vegetables which are particularly important when soils are used for agriculture or gardening; and (2) contamination of drained water by metal migration in gravitational waters (Denaix et al., 2001).

Many c ountries have e stablished g uidelines limiting the loading of p otentially toxic elements to soils (Sheppard et al., 1992). Potentially toxic elements can be 
classified into elements posing a threat mainly to human health (e.g. cadmium, lead and mercury) and those mainly of concern as phytotoxins (e.g. boron, copper, nickel and zinc) (Alloway, 1995). Intake of food is a potential human exposure pathway particularly where much food is locally sourced or home grown on contaminated soils (Webber,1992).

\subsubsection{Heavy metals in water}

Natural waters in streams and rivers, ponds and lakes, and aquifers and springs have a chemical element content that reflects the chemistry of rocks through or over which they flow. Thus, water chemistry can vary greatly in nature with rock compositions. In addition, during flow, factors such as temperature, $\mathrm{pH}$, redox potential, adsorption capacity and bacterial activity may bring about changes to the water chemistry. High values of contaminant metals in water can be natural and may represent a rock type change or the existence of mineralization. The high values can also originate from industrial activities (e.g. acid mine drainage, effluent from chemical, plastics, metal plating, wood preserving), or leachate from waste disposal sites (Siegel, 2002).

Heavy metals are released into the aqueous environment through a variety of sources such as metal smelters, effluents from plastics, textiles, microelectronics, wood preservative-producing industries, as well as through the usage of fertilizers and pesticides (Ross, 1994; Prasad and Hagemeyer, 1999). Natural waters also contain toxic metals depending upon the bed rock (Gerger, 1999). 
Heavy metal contamination in aquatic systems is one of the most critical environmental issues today (Nriagu et al., 1998; Silva et al., 1999). Aquatic organisms may bioaccumulate anthropogenic organic compounds and trace metals from water and sediments, and it is used as an aid in the monitoring of aquatic pollutants (Phillips, 1980).

Contamination of groundwater by metal ions can occur as a result of municipal or industrial chemicals. Increased usage of groundwater resources and increase of inputs of nonpoint surface pollutants into groundwater zones may cause contamination and general deterioration of groundwater quality (Yang et al., 2000).

Contamination of soils and groundwater contamination by trace metals is becoming one of the major environmental concerns because these natural resources may impact human health through the food chain. Sources of trace metals are closely related to industrial and human activities, such as smeltering, wastewater from mining and manufacturing industries and solid wastes, among others. Trace metals such as $\mathrm{Cd}, \mathrm{Cr}$, $\mathrm{Cu}, \mathrm{Hg}, \mathrm{Pb}$ and $\mathrm{Zn}$ are mainly considered as being responsible for soil and groundwater pollution from the viewpoints of phytotoxicity of undesirable entrance into the food chain. Trace metal levels in arable soils are similar to their natural abundance, which is relatively safe for crop growth. Metals cause an adverse effect on nutrition availability properties of the soil by changing the ionic speciation and distribution in soil solution and decreasing the buffering capacity and urease activity. Where soils are subject to metal contamination, high metal content in crops may inhibit nutrient uptake and crop growth, 
thus resulting in a yield decrease. Metal contents in major crops grown in unpolluted areas have been reported to be lower than pollution standards (Yang et al., 2000).

Trace metal concentration in groundwater is in general similar to the natural abundance and lower than the pollution standards due to the geochemcial or chemical characteristics in groundwater; its impacts are known to be limited. A more detailed data base is necessary to describe the current status and impact of trace metals in groundwater (Yang et al., 2000).

Drinking water is derived from three basic sources: lowland rivers and reservoirs, upland reservoirs, and groundwater. Lowland surface water sources contain a high level of natural and anthropogenic organic and inorganic matter and are much more prone to pollution. They receive the highest level of treatment in order to remove microorganisms, particulate matter and chemical contaminants. Upland sources usually suffer less from anthropogenic contamination but they contain high levels of naturally occurring organic matter form decaying vegetation. This in combination with iron is the cause of brown coloration seen in many upland streams. There can also, on occasion, be microbiological contamination from farm animals and wildlife. They are usually low in inorganic constituents and are therefore soft. Groundwaters are usually low in organic matter and are less vulnerable to both microbiological and chemical contamination. They frequently contain high levels of inorganic substances from the rocks through which the water is percolated (Fawell and Stanfield, 2001). 
Maximum contaminant levels (MCLs) for potentially toxic metals and other inorganic and organic components in water and foods have been set by various organizations. These entities include the W orld Health Organization (WHO), the Pan American Health Organization (PAHO), and the Environmental Protection Agency (EPA) in the United States and the European Health Union.Table 2.1 shows a compilation of the MCLs established for potentially toxic metals in potable water. Data are also available from global and national organizations for allowable concentration of heavy metals in the atmosphere, in agricultural soils, in food and in the workplace (Seigel, 2002).

\subsubsection{Heavy metal toxicity and human health}

A toxic material is a substance that has an adverse effect on health. Many chemicals could be classified as toxic, but their toxicity level may be different. The level of toxicity of substances is r elated to the amount that c auses an adverse e ffect and to some extent the type of effect (Nriagu, 1988). Many chemical elements may also be essential or at least beneficial to human health, but they also can become toxic when taken in excess. Some elements may have either antagonistic or synergistic effects on the biological properties of other elements; that is, a toxic element may either be helpful in reducing the toxic effects of another, or add to its toxic effect. For example, selenium is antagonistic to mercury and reduces its toxicity. Some toxic elements are used therapeutically for specific purposes, despite their toxic risks (Ferguson, 1990). 
The toxic effects of an element are measured by its dose-response relationship, where the response is the sign of an adverse effect; doses are either acute or chronic. An acute dose is a large amount of a toxic material which produces a rapid onset of effects, often intense and can result in death. A chronic dose is usually a lesser amount but continued over a longer period of time. Therefore, toxic material has a chance to build up in a gradual manner for the onset of symptoms. At times symptoms and the effects may also differ (Ferguson, 1990).

Metals have a variety of effects on the human body, mostly at the cellular level. Some metals disrupt biochemical reactions while others block essential biological processes including the adsorption of nutrients. Some metals accumulate in the body and give rise to t oxic c oncentrations a fter m any years of exposure while o thers (including arsenic, beryllium, cadmium and chromium) are carcinogens.

Exposure to methyl mercury and high levels of lead can cause gross developmental deformities (Friberg et al., 1986). Exposure to high levels of mercury, gold and lead has also been associated with the development of autoimmunity, in which the immune system starts to attack its own cells mistaking them for foreign invaders. Lead is particularly toxic to the brain, kidneys, reproductive and cardiovascular systems. Exposure can cause impairment in intellectual functioning, kidney damage, infertility, miscarriage and hypertension (Glover-Kerkvlient, 1995). Environmental lead exposure has been linked to a reduced IQ in children and to elevated blood pressure in adults, although the cause-effect relationship for the latter is not especially strong (Hare, 1986). 
Table 2.1 Maximum contaminant levels (also, action levels or maximum allowable concentrations) for potentially toxic metals in drinking water ${ }^{1}$.

\begin{tabular}{lll}
\hline Metal ion & Content in water $(\mathrm{mg} / \mathrm{L})$ & Content in air $\left(\mu \mathrm{g} / \mathrm{m}^{3}\right)$ \\
\hline $\mathrm{As}$ & 0.01 & 0.01 \\
$\mathrm{Be}$ & 0.004 & 0.01 \\
$\mathrm{Cd}$ & 0.003 & $0.001-0.005^{*} ; 0.01-0.02^{* *}$ \\
$\mathrm{Co}$ & 1.0 & 10 \\
$\mathrm{Cr}$ & 0.05 & 100 \\
$\mathrm{Cu}$ & 1.0 & $0.012^{*} ; 0.257^{* *}$ \\
$\mathrm{Fe}$ & 0.2 & 6000 \\
$\mathrm{Hg}$ & 0.001 & $0.01-0.02$ \\
$\mathrm{Mn}$ & 0.05 & $0.05^{*} ; 0.3^{* *}$ \\
$\mathrm{Mo}$ & 0.04 & $0.1-3.2^{*} ; 10-30^{* *}$ \\
$\mathrm{Ni}$ & 0.02 & $0.002^{*} ; 0.15^{* *}$ \\
$\mathrm{~Pb}$ & 0.0015 & $0.2-2$ \\
$\mathrm{Sb}$ & 0.005 & $0.02-0.07$ \\
$\mathrm{Se}$ & 0.01 & 0 \\
$\mathrm{Tl}$ & 0.002 & $\mathrm{NI}$ \\
$\mathrm{Zn}$ & 5.0 & \\
\hline
\end{tabular}

${ }^{1}$ Complied from several sources such as WHO, EPA, EC and others. Contents in air are given for some of the metals in concentrations as noted.

*Rural.

**Urban.

NI, not issued by health authorities

Adapted from Siegel (2002) 


\subsubsection{Analytical procedures for determination of heavy metals}

The essence of speciation studies is to identify and quantify the many species that make up the heavy metal concentration. This may further lead to the understanding of the biological and agrochemical cycling of the elements of concern. Biological cycling involves the transport, adsorption, and precipitation of the element in the water system. There are two main techniques that have been applied in heavy metal monitoring, normally biological and chemical methods.

Biological monitoring involves surveillance by using the response of living organisms to the environment. This is carried out with the use of indicator species. Indicator species are those species or species assembly that have particular requirements for a known set of physical or chemical variables (Hellawell, 1986). Some of the desirable characteristics of indicator species used in biological monitoring include narrow and specific environmental tolerances, taxonomic soundness and composition distribution variability, well known ecological characteristics and suitability for experimental studies. Some forty years ago, colorimetry, spectrography and polarography were the dominating methods for quantitative determination of metals. Atomic absorption spectrophotometry was then in the introduction stages for metal analysis (Papp, 1994). The direct analytical techniques that have been successfully utilized in trace metal speciation include atomic absorption spectroscopy (AAS), inductively coupled plasma mass-spectrometry (ICPMS) and electrochemical techniques such as anodic or cathodic stripping voltametry (ASV-CSV) (Florence, 1989; Papp, 1994). 


\subsubsection{Spectroscopic methods}

Colorimetry and adsorption spectrophotometry colorimetry, the first modern method to be developed for metal analysis, is based on the formation of coloured complexes between metals and organic compounds, whose absorbance can be measured in a colorimeter or spectrophotometer, after their extraction into a suitable solvent. (Piscator and Vouk, 979). Colorimetric methods still have many applications as the more modern methods are not suitable, or in some cases have not yet been worked out. For some metals, the limitations of colorimetric assays are the labour intensive preparatory work required to isolate specific complexes (Taylor and Pollard, 1994). Such work is expensive, time-consuming and entails a high risk of contamination, as well as occupational hazard to the analysts. Accuracy and precision, especially when several manual sample preparation steps are involved, will depend on the analyst's skill (Taylor and Pollard, 1994).

\subsubsection{Atomic emission spectroscopy}

Atomic emission spectroscopy is based on the extraction of metals by flame or by electric discharge. The excited atoms then lose their acquired energy by emitting photons on returining to their ground state. This emission can be recorded on a spectrometer or spectrograph which has a monochromator that separates the emitted radiation according to $w$ avelengths (i.e. the energy of photons). A spectrum is o btained and a very wide range of metals can be more or less quantitatively determined. Atomic emission spectroscopy is especially useful for multielement analysis. Atomic emission 
spectroscopy is also used in the metal industry for quality control of products (Piscator and Vouk, 1979; Pollard, 1994).

\subsubsection{Atomic absorption spectroscopy (AAS)}

The basic principle behind AAS is that metals in the ground state will absorb radiation from a light beam with the same spectral composition as the light emitted by the element in consideration. The decrease in intensity as compared to a blank corresponds to the concentration of the metal. There are two main methods for atomization of samples: the flame method and the furnace method, the latter also known as electrothermal atomic absorption. Atomic absorption spectroscopy has found a number of applications and has been especially useful for the determination of $\mathrm{Pb}, \mathrm{Cd}$ and $\mathrm{Hg}$ in biological materials and in exposure m edia as w ell a s for the d etermination of $\mathrm{m}$ any essential e lements (Papp, 1994; Piscator and Vouk, 1979). Special modifications are r equired for highly volatile metals such as $\mathrm{Hg}$ and As (Pistor and Vouk, 1979). Atomic absorption spectroscopy has been used to demonstrate the ability to quantify chromium in a broad range of material at concentrations ranging from parts per hundred (i:e. percent) to parts per billion (Kaltz and Salem, 1994). One limitation of atomic absorption spectroscopy is that atomic absorption is not suitable for multielement analysis. Also, some non-specific absorption may occur due to the presence of other atoms and molecules in the flame salts such as sodium chloride and phosphate (Piscator and Vouk, 1979). Atomic absorption spectroscopy, however, is facing stiff competition from some newer techniques such as plasma emission and ICP-MS. As these techniques reach maturity, AAS, in particular flame AAS, may be relegated to a complementary role (Papp, 1994). 


\subsubsection{Inductively coupled plasma-mass spectrometry(ICP-MS)}

This t echnique in h eavy m etal m ultielement a nalysis involves i onization of the analyte elements present in a sample in the ICP. In this method, freshwater samples are preferably filtered using disposable filters and acidified with high purity $0.2 \mathrm{M} \mathrm{HNO}_{3}$ and then placed in a clean sample container. The ions are then extracted into a MS, separated and detected. By scanning through the mass range within milliseconds, the ICP-MS acts as a highly sensitive multielemental technique allowing determination of about 30 elements per minute with detection limits of 0.1 to $10 \mu \mathrm{g} / \mathrm{L}$ (Kishi, 1997). The ICP has found applications as an ion source for mass spectrometery, and the ICP- MS technique has been employed for the determination of trace metals in biological and environmental materials (Kartz and Salem, 1994).

\subsubsection{Voltammetry}

This is an electroanalytical technique in which the current at an electrode is measured as a function of the potential, or voltage applied at the electrode. The potential is varied in some systematic manner and the resulting current-potential plot is called a voltammogram. This can be used to analyze any chemical species that is electroactive; hence, its applicability in heavy metal speciation of stripping voltammetry (Taylor, 1994). Stripping voltammetry can be carried out in two ways, namely cathode stripping voltammetry (CSV) and anode stripping voltammetry (ASV). Anodic stripping voltammetry is probably the most sensitive technique for $\mathrm{Pb}$ in very low levels and avoidance of contamination (Taylor, 1994). Advantages of ASV are the possibility of 
simultaneous determination of four metals $(\mathrm{Pb}, \mathrm{Cd}, \mathrm{Cu}, \mathrm{Zn})$ in one sample (Harrison and Laxen, 1981).

\subsection{Removal of metals from wastewater}

The presence of toxic substances in wastewater has always been a matter of concern. This concern has become much more pressing with the intentional or unintentional release of an ever-larger variety of substances into the environment. The treatment of wastes containing toxic material may be technically difficult and/or expensive. $\mathrm{M}$ anufacturers or $\mathrm{p}$ rivatized $\mathrm{w}$ ater $\mathrm{u}$ tilities $\mathrm{m}$ ay $\mathrm{b}$ e r eluctant $\mathrm{to} \mathrm{m}$ ake $\mathrm{l}$ arge capital investments in wastewater treatment facilities (James, 2001).

Discharge of metals to the aquatic environment has been a major cause of concern and the treatment of these wastes has consequently attracted considerable attention. Wastes containing metals may arise from a variety of industrial and agricultural operations including tanneries, paint manufacture, battery manufacture, and pig wastes; however, but the main source being from metal processing. The sources of waste in metal processing are numerous and also extremely variable both in quantity and quality. Metals in the wastes may occur as large particles of pure metals in suspension or as metallic ions and complexes in solution. The technique m ost commonly employed in treating m etal processing wastes is precipitation using $\mathrm{pH}$ adjustment (James, 2001).

Conventional methods for the removal of metals from industrial waste solution such as chemical precipitation or oxidation, filtration, electrochemical treatment, ion 
exchange, application of membrane technology and evaporation recovery may be ineffective and expensive, especially when metals are present at low concentrations (Volseky, 1987). A part from their e conomical and e cological disadvantages, only i on exchange is able to remove trace levels of metal ions (Deans and Dixon, 1992). However, the effectiveness of ion exchange in removing metal ions from aqueous media is also suppressed by the presence of large quantities of metals ions from aqueous systems by various hydrophytic species (Moffat,1995). The vulnerability of these hyperaccumulators to high levels of toxic metal has ruled out the possibility of using them to clean wastewaters with high levels of heavy metals.

The reclamation of wastewaters through a process known as chelating ion exchange seems to be a better alternative to the existing remediation technologies. In contrast to simple ion exchange, chelating ion exchange permits the removal of the heavier toxic metals ions while permitting harmless ions to move into the environment (Deans and Dixon, 1992). Some of the best chelation exchange materials are biopolymers. Cellulose, alginates, proteins, chitin and chitin derivatives, which are particularly effective in adsorbing metals ions due to the presence of several functional groups such as $-\mathrm{OH}$ and $-\mathrm{NH}_{2}$ that can reduce metal ion concentrations to the order of $\mu \mathrm{g}$ per gram from mg per gram levels (Kurita et al., 1979; Deans and Dickson, 1992). Several investigators have reported the heavy metal binding capacities of chitin and chitosan (Muzzarelli et al., 1989; Bassi et al., 1999; Lasko and Hurst, 1999). 


\subsection{Chitin and chitosan}

The name "chitin" is derived from the Greek word "Chiton" meaning a coat of nail (Lower, 1984). It was apparently first used in 1811 by French scientist Henri Braconnot (Muzzarelli, 1977; Brine, 1984), who isolated the substance from mushrooms. In 1823, Odier found this same compound in the cuticle of insects (Muzzarellli, 1977). Chitin is the major component of the exoskeleton of invertebrates, crustaceans, insects and the cell wall of fungi and yeasts (Knorr, 1984; Lower, 1984; Tan et al., 1996). It is the second most abundant natural polymer on earth after cellulose (Brzeski, 1987; Ornum, 1992) and is a linear homopolymer of 2-acetamido-2-deoxy- $\beta$-D-glucan, having 1000-3000 basic units (Austin et al., 1981; Lower, 1984). These units are linked together by $\beta$ (1-4) glycosidic bonds (Ornum, 1992; Simpson et al., 1994). Chitin is also known as $\mathrm{N}$-acetyl-D-glucosamine polymer and is one of the most abundant polysaccharide that contains amino sugars (Bough, 1977; Austin et al., 1981; Kumar and Jayachandran, 1993). Chitosan is the name used for the low acetyl substitute form of chitin. Chitosan polymers are composed of primarily of glucosamine, 2-amino-deoxy- $\beta$-D-glucose, known as $(1 \rightarrow 4)-2$-amino-2-deoxy- $\beta$-D-glucose (Shahidi et al., 1999) (Figure 2.1). Chitosan is derived from chitin by deacetylation in the presence of alkali which is a copolymer of glucosamine and some $\mathrm{N}$-acetylglucosamine residues, of which the proportion of the former usually exceeds $80 \%$ (Arvanoyannis et al., 1998). Chitosan was first discovered by Rouget in 1859 (Muzzarelli, 1977) when he boiled chitin in a concentrated solution of potassium hydroxide. 
Chitosan is the simplest derivative that can be prepared from chitin and is the least expensive usable derivative of it (Ornum, 1992). Unlike most polysaccharides, the presence of positively charged amino groups regularly located along a polymer chain of chitosan allows the molecule to bind to negatively charged surfaces via ionic or hydrogen bonding (Muzzarelli, 1973; Rha, 1984; Shahidi, 1995).

Research on chitin and chitosan accelerated in the early to mid 1900's and the first patent pertaining to chitin and chitosan was granted in the 1930s to G.W. Rigby, an employee of the Du Pont de Nemours and Company in the United States (Winterowd and Stanford, 1995). However, commercialization of chitin-based products was hampered by a lack of adequate manufacturing facilities and competition from synthetic polymers (Averbach, 1981; Subasinghe, 1999). However after the 1970s, industrial exploitation of chitin and its derivatives has been emerging and expanding (Kaye, 1985) (Figure 2.2). Furthermore, advancement in research and small-scale production of chitin and chitosan have expanded the number and variety of potential applications such as medical, cosmetic, agricultural and food-related uses (Winterword and Sandford, 1995). Both chitin and chitosan have been identified as being biocompatible, non-antigenic, a lmost non-toxic and biofunctional (Hirano et al., 1990; Li et al., 1992). The United States Food and Drug Administration (FDA) approved chitosan as a feed additive in 1983. Use of chitosan for potable water purification has been approved by the United States Environmental Protection Agency (EPA) up to a maximum level of $10 \mathrm{mg} / \mathrm{L}$ (Knorr, 1986). In addition, environmental problems and cost for disposal of shellfish processing discard have 
Figure 2.1 Chemical structures of chitin, chitosan and cellulose 


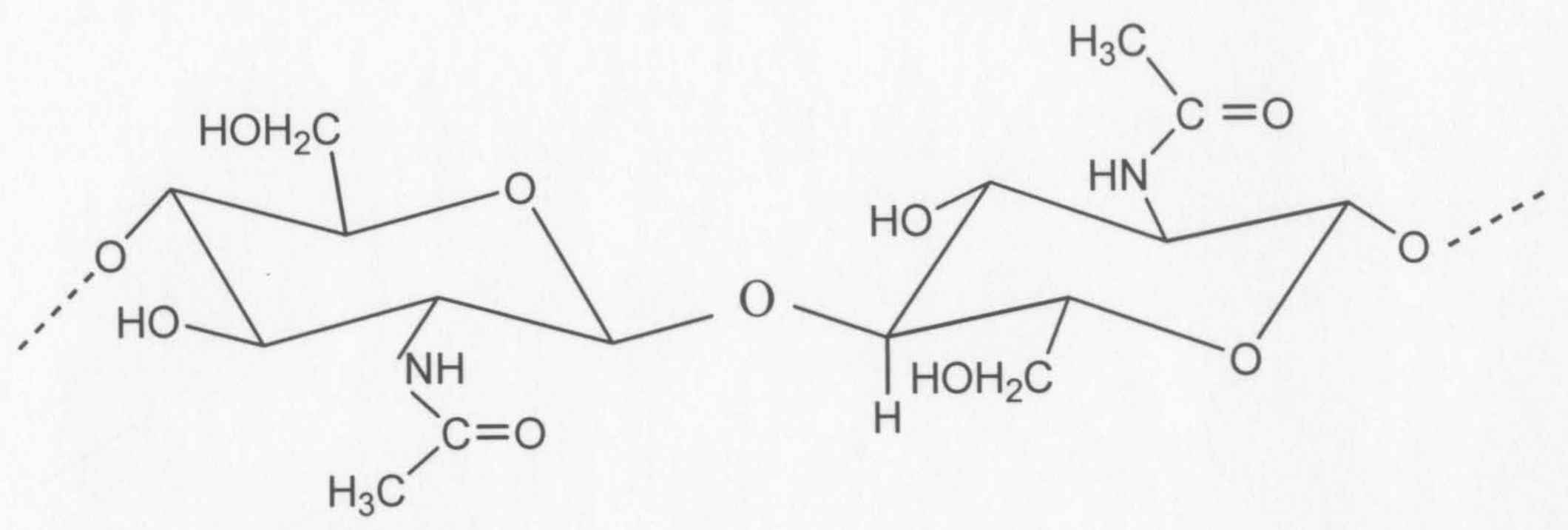

Chitin

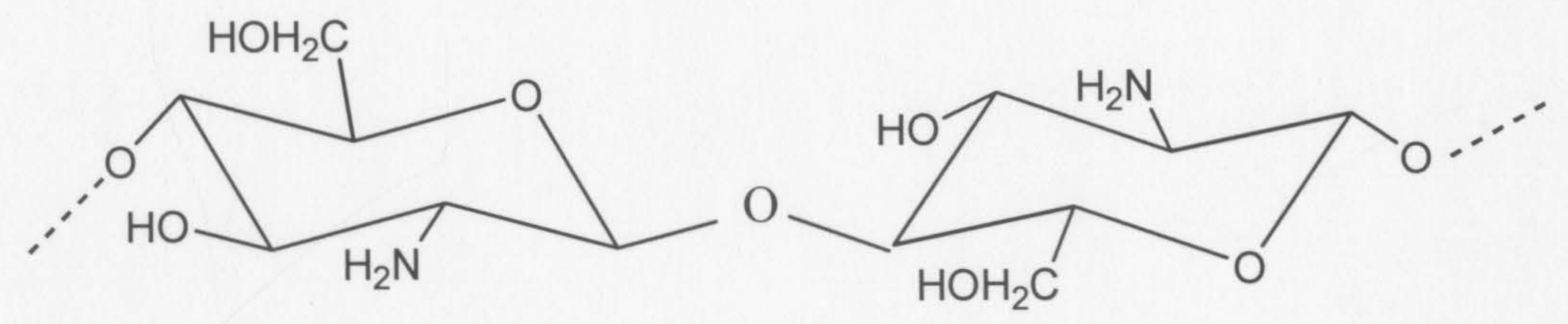

Chitosan

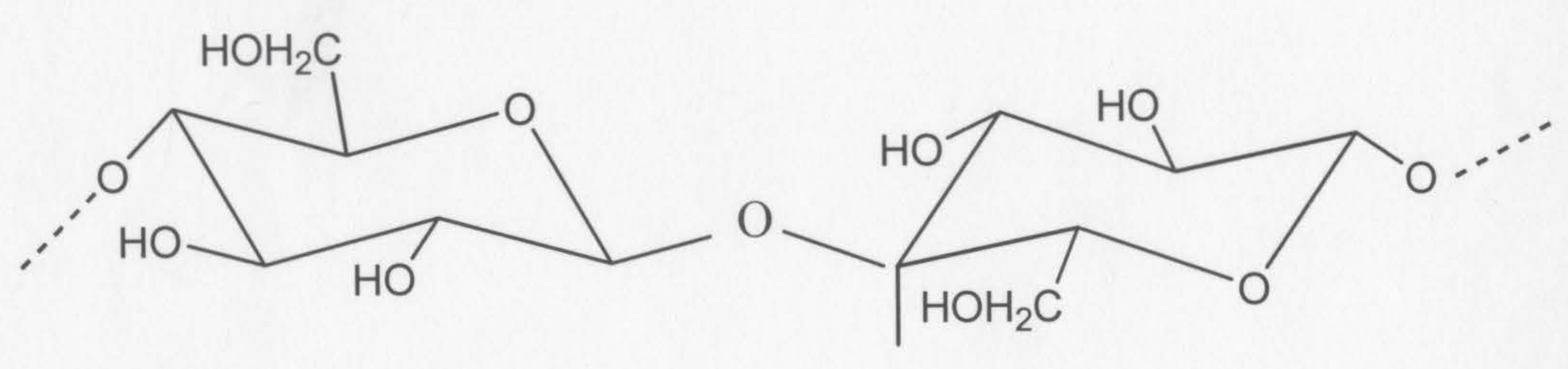

Cellulose 
Figure 2.2 Chemical derivatives of chitin and chitosan adapted from Peter (1995) 


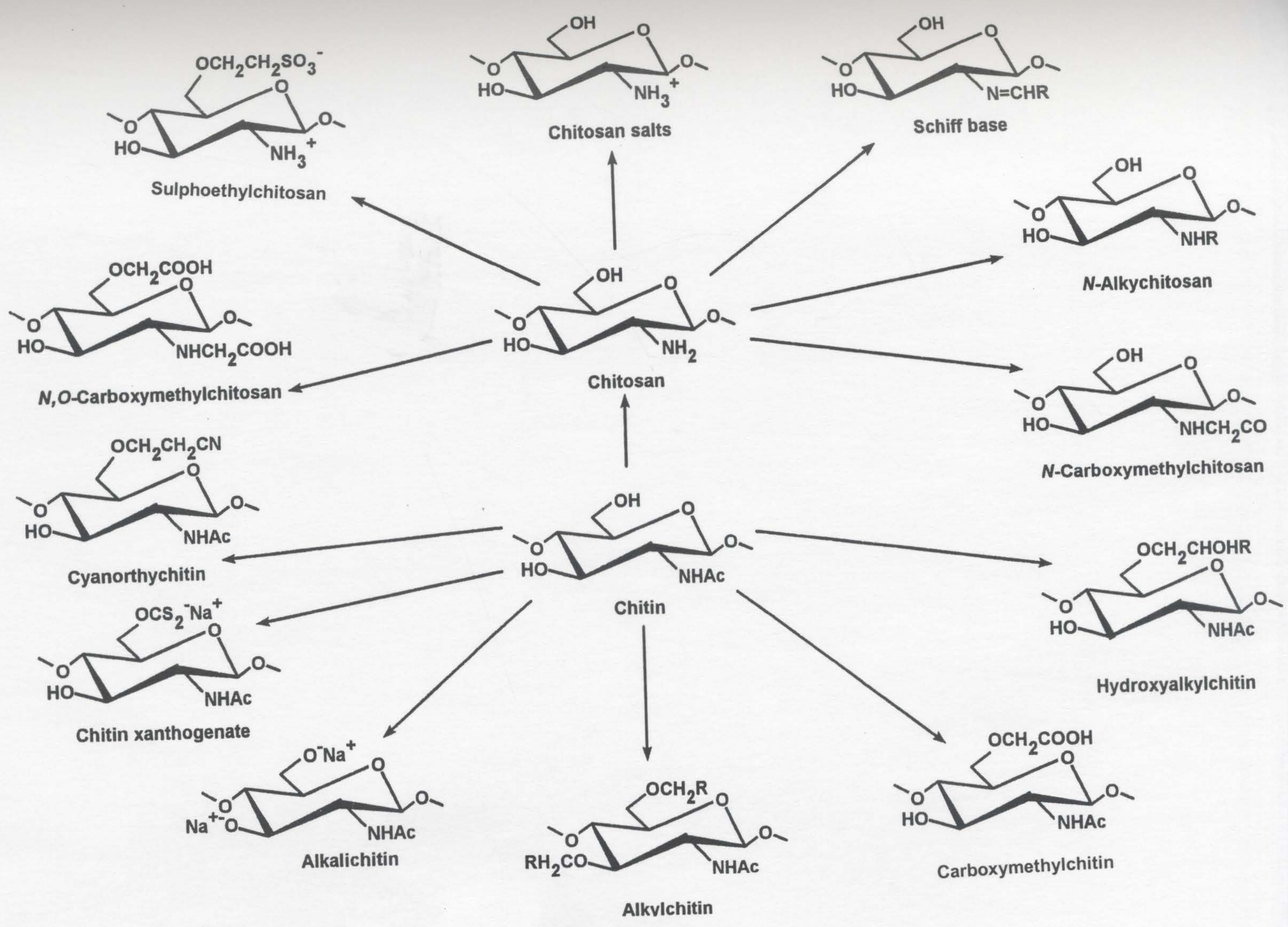


become a pressing problem. On the other hand environmentally safe substitutes for many plastic or polymeric products are in demand (Ashford et al., 1976; Berkeley, 1979; Shahidi and Synowiecki, 1991). Although not always accessible, the enormous abundance of chitin and its unusual chemical properties which can be readily modified, are factors underlying the current interest in developing its commercial potential (Winterowd and Sandford, 1995).

\subsection{Sources of chitin and chitosan}

Chitin is a w aste product of the s eafood p rocessing industry with an estimated volume of 100,000 metric tonnes annually on a worldwide basis (Muzzarelli, 1999). Nearly $10 \%$ of the g lobal landings of sea products consist of species rich in chitinous materials (Subasninghe, 1999). These include, species such as shrimp, crab, lobster, squid, krill, and crawfish, among others. The annual production of species containing chitin is approximately 13 million metric tonnes (FAO, 1999). Chitin occurs in association with protein and inorganic materials, mainly $\mathrm{CaCO}_{3}$, pigments and lipids (Austin et al., 1981; Knorr, 1984; Gopalkumar, 1997) in the exoskeleton of crustaceans, insects and mollusks (Knorr, 1984; Lower, 1984). Chitin constitutes more than half of the total organic matter in chitinous structures. Higher concentrations of up to $85 \%$ are found in arthropods which are able to synthesize chitin. There is no apparent relationship between the proportion of chitin and the degree of calcification, hardness or flexibility of the structure, as shells of gastropoda and lamellibranchia contain only small amounts of chitin (Muzzarelli, 1977). Certain fungi, algae, diatoms and protozoa also contain chitin and sometimes chitosan as cell wall and cellular constituents (Berkeley, 1979; Austin et 
al., 1981). The body parts and processing discards of crustaceans, insects and mollusks contain approximately $10-55 \%$ chitin on a dry weight basis (Table 2.2 ).

Since chitin and chitosan do not accumulate in the environment, chitinases and chitosanase must play a significant role in biochemical cycling of limiting elements including nitrogen (Bade and Wick, 1988). The biosynthesis of chitin takes place in the membrane-bound protein complex via the catalytic action of chitin synthase (EC 2.4.1.16) and by the addition of uridine diphosphate- $N$-acetyl-D-glucosamine to acceptors such as $\mathrm{N}$-acetylglucosamine (G/CNAC) to afford $\mathrm{N}$-acetylchitooligosaccharide. Chitin synthase has been found in crustaceans, insects and microorganisms (Koga, 1998).

The natural pathway of chitin metabolism includes enzyme-catalyzed hydrolysis by chitinases (Peter, 1995) to $\mathrm{N}$-acetyl-chitooligosaccharide in an endo- or randomsplitting fashion. This enzyme is found in many organisms, and plays a characteristic role in higher plants, seaweeds and mammals, insects and crustaceans, cell organisms, as well as spiders and snails (Koga, 1998). The chitinases (EC 3.2.1.14) give $N, N^{\prime}$ diacetylchitobiose and $N, N^{\prime}, N^{\prime \prime}$-triacetylchitotriose as the final products (Peter, 1995). Chitin- $N$-deacetylase (EC 3.5.1.41) catalyses the $N$-deacetylation reaction of chitin into chitosan (Muzzarelli, 1977; Cohen, 1993; Hirano, 1996). Chitosanase (EC 3.2.1.132) hydrolyzes chitosan similarly to chitinase. This enzyme has been found mainly in microorganisms and is limited in certain plant such as orange (Koga, 1998). 
Table 2.2 Chitin content of selected crustaceans and molluscan organs.

\begin{tabular}{ll}
\hline Organism & Chitin content, \%
\end{tabular}

\section{Crustaceans}

$\underline{\mathrm{Crab}}$

Blue crab

$14.9^{\mathrm{a}}$

Stone crab

$18.1^{\mathrm{a}}$

Red crab

$27.6^{\mathrm{a}}$

Horseshoe crab

$26.4^{\mathrm{a}}$

Snow crab-claws

$24.0^{\mathrm{b}}$

Snow crab-legs

$32.0^{\mathrm{b}}$

\section{Shrimp}

Brine shrimp

$27.2^{\mathrm{a}}$

Tiger shrimp-carapace

$35^{\mathrm{b}}$

Tiger shrimp-shell

$37^{\mathrm{b}}$

\section{Molluscan organs}

Squid pen ( $\beta$ chitin)

$30-35^{\mathrm{b}}$

Krill-crude deproteinnized shell

$34-49^{\mathrm{b}}$

Krill-dried concentrated waste

$25^{\mathrm{b}}$

Clamshell

$6.1^{\mathrm{c}}$

Oyster shell

$3.6^{\mathrm{c}}$

All values are on a dry weight basis.

Data adapted from ${ }^{\mathrm{a}}$ Austin et al. (1981); ${ }^{\mathrm{b}} \mathrm{Knorr}$ (1984); and ${ }^{\mathrm{c}}$ Subasinghe (1999). 
Diatoms which have protein-free chitin appendages are conceivable practical sources of very pure chitin. For special applications, requiring exceptionally high quality and pure chitin in r elatively s mall quantities, d iatoms might e ventually s erve as a viable source (Ashford et al., 1976; Gopakumar, 1997). The vast majority of fungi including members of the ascomycetes, basidiomycetes, deuteromycetes and mastigomycetes have walls which contain chitin and glucans or mannans, whereas those of zygomycetes contain both chitin and chitosan (Bartinicki-Garcia, 1968; Gopakumar, 1997). In addition, large quantities of fungi, currently grown in fermentation systems for producing organic acids, antimicrobials, and enzymes, constitute a potential source for chitin production (Ashford et al., 1976; Rha, 1984). It is estimated that fungi could provide $3.2 \times 10^{4}$ metric tonnes of chitin annually (Brine, 1984). Chitosan occurs naturally in fermented foods such as tempeh, tofu and even in aged beef, and is already part of the diet of people of many parts of the world (Bough, 1977; Berkeley, 1979).

Since the biodegradation of chitin is very slow in crustacean waste, accumulation of large quantities of shell discards from processing of crustaceans has become a major concern in the seafood industry (Shahidi ad Synowiecki, 1991; Martin, 1998). The techniques which are available for disposal of processing by-products include ocean dumping, incineration or disposal to landfill sites (Revah-Moiseer and Carroas, 1981; Shahidi, 1994). Pollution from wastes has become a serious problem because solid waste disposal and discharge of processing discards are tightened by regulation and are quite costly in most places (Shoemaker, 1991; Martin, 1998). However, environmental restrictions and a better understanding of the potential value of applications have resulted 
in efforts to find uses for these materials (Healy et al., 1994). Direct use of crab wastes for land manuring or spreading is generally discouraged by the uniquely obnoxious odour of putrefying shells. Therefore, value-added utilization of chitin, chitosan and their derivatives in different fields is of utmost interest (Brzeski, 1987; Shahidi et al., 1999). The constituents of crustacean shells include approximately $13-42 \%$ protein and $14-30 \%$ chitin (Shahidi and Synowiecki, 1991; Ferrer et al., 1996).

\subsection{Preparation of chitin and chitosan from shellfish processing discards}

A variety of procedures have been developed over the years for the preparation of chitin and chitosan. Some of these form the basis of chemical processes for industrial production of chitosan from crab, shrimp, lobster or crawfish, which are the richest sources of chitin (in general $20-30 \%$ on dry basis) as well as being the only chitinous matter presently available in quantities sufficient to support a commercial chitin/chitosan industry (Johnson and Peniston, 1982; Ornum, 1992; Selmer-Olsen, 1996). Crustacean shell waste consists mainly of protein (30-40\%), minerals (30-50\%) and chitin (30-40\%). These proportions may vary among species and with the season (Green and Kramer, 1984). Thus, the methods of chitin/chitosan preparation can vary with sources in order to address compositional differences. Further, physical and chemical characteristics of chitin and chitosan a ccordingly differ $w$ ith s pecies and preparation m ethod (Brine and Austin, 1981). 


\subsubsection{Preparation of chitin from shellfish processing discards}

Shellfish processing discards, chitin is associated with proteins, lipids, pigments and mineral deposits (Roberts, 1992; Simpson et al., 1994). Therefore, the raw material has to be pretreated to remove non-chitionous components (Brzeski, 1987; Simpson et al., 1994). The entire manufacturing process may be divided into four different steps: (1) preparation of sample, (2) removal of mineral fraction or demineralization, (3) removal protein fraction or deproteinization, (4) and removal of carotenoid pigments or decoloration.

These four basic steps are continuously monitored so that removal of interfering components is best achieved. For example, careful control of time, concentration of chemicals and temperature is necessary in order to ensure that the highest molecular weight chitin/chitosan is obtained (Ornum, 1992). Nevertheless with careful control of the above parameters, it might be possible to produce chitosan with molecular weights of $80,000-1,000,000$ Da with reproducible properties (Averbach, 1981).

The order of deproteinization and demineralization steps can be conducted in a reverse order, i.e. demineralization, followed by deproteinization. However, if protein recovery is an objective, its extraction before demineralization is preferred so as to maximize protein yield and quality (Johnson and Peniston, 1982). Demineralization is achieved using a dilute $\mathrm{HCl}$ solution (Shahidi, 1995). The acid treatment is important for the removal of minerals in order to ensure an ash content of less than $0.1 \%$ in the product (Kaye, 1985). Although the resultant calcium chloride may be used in the pulp and paper 
manufacturing, the dehydration process required for its recovery is commercially unattractive (Shahidi, 1995). The yield of chitin varies depending on the raw materials and species used. Yield of crawfish shell portion and whole meal were $25-28 \%$ and $17 \%$ respectively (No et al., 1989). Crab waste contains $17-32 \%$ chitin whereas squid pen contains $30-35 \%$ chitin on a dry weight basis (Knorr, 1984; Shahidi and Synowiecki, 1991).

\subsubsection{Preparation of raw materials}

Washing of shellfish processing discards is important for the removal of soluble organics and adhered proteins whereas grinding is necessary to increase the surface area and to obtain uniform size particles. Carotenoproteins, by-products from shellfish processing, have potential for use as a feed supplement in aquaculture (Simpson and Haard, 1985; Ramaswamy et al., 1991; Shahidi and Synowiecki, 1991; Shahidi, 1994) or as a potential colorant and possibly a flavourant in food products (Simpson and Haard, 1985). Extraction of carotenoid pigments with organic solvents or oil achieves a good recovery, but the product so obtained is devoid of protein and hence has decreased stability due to oxidation (Haard, 1992). Shahidi and Synowiecki (1991) have shown the possibility of extracting carotenoid pigments prior to the deproteinization step. Fish oil was used for extracting carotenoids directly from shell discards; the best recovery of carotenoids (74\%) was achieved when the ratio of discards to oil was $1: 2(\mathrm{w} / \mathrm{v})$ and the extraction temperature was adjusted to $60^{\circ} \mathrm{C}$. 


\subsubsection{Deproteinization}

Crustacean shell waste is usually ground and treated with a dilute $\mathrm{NaOH}$ solution $(1-10 \%)$ at elevated temperatures $\left(65-100^{\circ} \mathrm{C}\right)$ in order to dissolve the protein present. Deproteinzation may be achieved using different alkali concentrations, time, temperature and solid-to-solvent ratios (No and Mayers, 1995). Nevertheless, a large variation exists for deproteinzation conditions (Roberts, 1992).

Hackman (1954) extracted protein from lobster shells with $1 \mathrm{M} \mathrm{NaOH}$ at $100^{\circ} \mathrm{C}$. Anderson et al. (1978) also treated shrimp shells with $3 \% \mathrm{NaOH}$ at $100^{\circ} \mathrm{C}$. No et al. (1989) extracted protein from crawfish shell waste with $3.5 \% \mathrm{NaOH}$ at $65^{\circ} \mathrm{C}$. Optimal deprotienization also can be accomplished by treatment with $1 \% \mathrm{KOH}$ for shrimp and $2 \%$ $\mathrm{KOH}$ for crab shell at $90^{\circ} \mathrm{C}$ (Shahidi and Synowiecki, 1991). Exceptions to the above are seen in methods of Whistler and BeMiller (1962) and Brzeski (1982) involving deproteinization with $10 \% \mathrm{NaOH}$ at room temperature, and with $3.5 \% \mathrm{NaOH}$ at $25^{\circ} \mathrm{C}$, respectively. Cosio et al. (1982) carried out the deproteinization process at $\mathrm{pH} 11.5$ and $30^{\circ} \mathrm{C}$. Reaction time usually ranges from 0.5 to $12 \mathrm{~h}$ depending on the preparation method, although Hackman (1954) and Whistler and BeMiller (1962) attempted to extract proteins for several days. Prolonged alkaline treatment under several conditions for isolation of proteins, from the carapace of horseshoe crab (Limulus polyphemus), which contained a low amount of protein was considered. Austin et al. (1981) indicated that some other chitin, which may require harsh acidic or temperature conditions for to isolation, yield dextrorotatory products. Recovered protein from the deproteinization step m ay b e utilized as a growth m edium for microorganism or by the food and feed 
industries in selected applications (Bough et al., 1978; Johnson and Peniston, 1982; No and Meyers, 1992). Limitations with alkali treatments include the requirement of large amounts of alkali which results in deacetylation and a decrease in the molecular size of the product explained above (Simpson et al., 1994).

A number of researchers have attempted to remove proteins from shellfish by enzymatic digestion for production of chitin that has been minimally deacetylated. Commercially-available enzymes from plant and animal sources have also been used (Muzzarelli, 1973). Possibility of using the enzyme Rhozyme- 62 at $60^{\circ} \mathrm{C}$ for $6 \mathrm{~h}$ at $\mathrm{pH}$ 7.0 for deproteinization of crustaceans shell waste was described by Bough et al. (1978). Simpson et a l. (1994) r eported that o ut of v arious proteolytic enzymes, chymotrypsin, papain and bacterial protease best served deproteinization of crustacean shells. Chymotrypsin was most effective, achieving a degree of deproteinization comparable to that of chemical deprotienzation. Enzymatic deproteinization of the shells for the production of protein hydrolysate during isolation of chitin from shrimp (Crangon crangon) processing discards was recently reported (Synoweicki and Al-Khateeb, 2000). This method was found suitable for isolation of chitin containing $4 \%$ protein impurities. The hydrolysate so obtained had an adequate essential amino acid index and protein efficiency ratio. Enzyme treatment did not affect the chitosan structure, however, complete removal of protein was not achieved (No and Meyers, 1995).

The recovered protein can be used as high-grade additive to livestock starter feed, thus resulting in a decreased manufacturing cost of chitin (Johnson and Peniston, 1982). 
The profile of amino acids recovered from shrimp and crab processing discards were favourable, except for lysine and tryptophan (Shahidi and Synowiecki, 1991).

\subsubsection{Demineralization}

Demineralization is conventionally accomplished by extraction w ith dilute $\mathrm{HCl}$ (up to $10 \%$ ) at room temperature in order to dissolve the calcium carbonate and provide calcium chloride (No and Meyers, 1995). Demineralization is also important for the removal of endotoxins which are present in the shell processing discards (Roberts, 1992). Demineralization can be achieved using a variety of either inorganic or organic acids including $\mathrm{HCl}, \mathrm{HNO}_{3}, \mathrm{H}_{2} \mathrm{SO}_{3}, \mathrm{CH}_{3} \mathrm{COOH}$ and $\mathrm{HCOOH}$ (Roberts, 1992) in different concentrations, time, temperature and solid-to-solvent ratio (No and Meyers, 1995). However, Chen and Tsai (1998) demonstrated that only the $\mathrm{HCl}$ concentration and solution-to-solid ratio were important whereas the effect of temperature for demineralization of shrimp shell waste was unimportant. Shahidi and Synowiecki (1991) observed that ash content of deproteinzed shell waste from shrimp and crab on a dry weight basis was 42 and $45 \%$, respectively. After $30 \mathrm{~min}$ of demineralization at $20^{\circ} \mathrm{C}$ [2.55\% $\mathrm{HCl}$ solution, of shell to acid ratio of $1: 20(\mathrm{w} / \mathrm{v})]$, the ash content in chitin from shrimp and crab discards decreased to 0.10 and $0.25 \%$, respectively. One of the disadvantages of using $\mathrm{HCl}$ for demineralization is that $\mathrm{HCl}$ at concentrations above 1.25 $\mathrm{M}$ adversely affects the viscosity of the final product due to depolymerization of the chitin chain (Muzzarelli, 1977). To avoid this, certain methods have been developed using mild acids to minimize degradation. Austin et al. (1981) used ethylenediaminetetraacetic acid (EDTA) for decalcification of crustacean shells. 
Demineralization can usually be achieved in 2 to $3 \mathrm{~h}$ with proper agitation (Johnson and Peniston, 1982). A prolonged demineralization step, even $24 \mathrm{~h}$, results in only a very slight drop in the ash content, but can bring about polymer degradation (Brzeski, 1982). For demineralization, it is also important that the amount of acid be stoichiometrically equal or greater than all minerals present in the shells to ensure complete reaction (Johnson and Peniston, 1982; Shahidi and Synowiecki, 1991).

\subsubsection{Decoloration}

Decoloration is an important unit operation for the production of a white coloured chitin with added commercial value. The exoskeleton of crustaceans contains coloured matters, principally carotenoids, the main components being astaxanthin, astacene, canthaxanthin, lutein and $\beta$-carotene (Roberts, 1992). They do not appear to be complexed with either the inorganic material or the protein since treatments which remove these components do not remove carotenoids (Roberts, 1992). There are two steps involved in decoloration of shellfish processing discards: they are extraction of pigments using the necessary reagents and bleaching using appropriate chemicals. Decoloration of chitin can be achieved using organic solvents such as acetone, chloroform, ether or ethanol (Simpson et al., 1994; No and Meyers, 1995). The second step is mainly important for commercial chitin preparation (Simpson et al., 1994) when acetone, sodium hypochlorite solution (No et al., 1989) and hydrogen peroxide (Brine and Austin, 1981) have been used as the bleaching agents. The colour of chitin recovered from shellfish processing discards may vary from white to pink (No and Meyers, 1995). 


\subsubsection{Production of chitosan from chitin}

Chitosan is a natural product derived from chitin. In order to obtain chitosan from chitin, alkali treatment $\mathrm{m}$ ay be carried out to remove some or all of the acetyl groups from the chitin polymer; this process is known as deacetylation. Although amides can in principle be hydrolyzed under either acidic or basic conditions, the use of acid hydrolysis is precluded because of the susceptibility of the glycosidic linkages in chitin to acid hydrolysis (Muzarelli, 1977; Roberts, 1992). Horton and Lineback (1965) reported that the trans-arrangement of the $\mathrm{C}(2)-\mathrm{C}(3)$ substituents in chitin increases the resistance of the $\mathrm{C}(2)$-acetamido group to alkaline hydrolysis; therefore, severe treatments are required to bring about deacetylation.

Conversion of chitin to chitosan is achieved by treatment with concentrated $\mathrm{NaOH}$ or $\mathrm{KOH}$ solution (40-50\%) generally at $100^{\circ} \mathrm{C}$ or higher. Deacetylation of chitin can be achieved with different reagents, concentrations, time and temperature as well as the ratio of the weight of raw material to the volume of the extraction solution (Table 2.3). Other factors affecting the extent of deacetylation include concentration of the alkali, temperature of deacetylation, time of reaction, previous treatment of the chitin, particle size and density of the chitin (No and Meyers, 1995).

Some limitations to this chemical method are high energy cost, use of high volumes of concentrated $\mathrm{NaOH}$ and production of a liquid waste containing protein and non-protein nitrogenous compounds (Simpson et al., 1994; Hirano, 1996). Deaceytlation may also be achieved by biological means using chitin deacetylase-producing 
microorganisms such as Mucor rouxi, M. meehei, Absidia butleri and Aspergillus niger (Haard et al., 1994; Simpson et al., 1994). Some problems associated with enzymatic methods are low yield and variation with age of fungal culture (Simpson et al., 1994).

Mima et al. (1983) established a method for the preparation of chitosan products with a desired degree of deacetylation of up to $100 \%$ without any serious depolymerization. Effective deacetylation was readily attained by intermittently washing the intermediate product in water two or more times and using alkali treatment for less than $5 \mathrm{~h}$ in $47 \% \mathrm{NaOH}$ at $110^{\circ} \mathrm{C}$. Application of thermo-mechano-chemical technology to chitin deacetylation was evaluated by Pelletier et al. (1990) as an alternative method for chitosan production. This process consists of a cascade reactor unit opening under reduced alkaline conditions of $10 \%(\mathrm{w} / \mathrm{v}) \mathrm{NaOH}$. Sudden decompression of the aqueous alkaline suspension of m ercerized chitin (at $4^{\circ} \mathrm{C}$ for $24 \mathrm{~h}$ ) resulted in a near complete deacytylation of chitin (Pelletier et al., 1990). Chitosan is sold commercially in the form of a solution, flake and fine powder, and more recently in bead and fibre forms (Kumar and Jayachanndran, 1993).

\subsection{Physiochemical properties of chitin and chitosan}

\subsubsection{Molecular structures}

Chitin and chitosan are known to exhibit polymorphism (Muzzarelli, 1977). Chitin exists in three polymorphic forms with various degrees of crystallinity (Muzzarelli, 1985). These crystalline structures of chitin are evidenced by $\mathrm{x}$-ray diffraction studies which 
Table 2.3 Deacetylation conditions in chitosan production.

\begin{tabular}{lllllll}
\hline Source & Atmosphere & $\begin{array}{l}\text { Alkali } \\
(\%)\end{array}$ & $\begin{array}{l}\text { Temp } \\
\left({ }^{\circ} \mathbf{C}\right)\end{array}$ & $\begin{array}{l}\text { Time } \\
(\mathbf{h})\end{array}$ & $\begin{array}{l}\text { Ratio w/w } \\
\text { or w/v) }\end{array}$ & $\begin{array}{l}\text { Deacetylation } \\
\text { \% }\end{array}$ \\
\hline Lobster & $\mathrm{A} / \mathrm{N}^{\mathrm{a}}$ & $\mathrm{KOH}, 35$ & $40-100$ & $0.5-15$ & $1: 100$ & $65-81.2$ \\
& & & & & & \\
$\mathrm{Crab}$ & $\mathrm{N}$ & $\mathrm{NaOH}, 47$ & 60 & $2 \times 1-4^{*}$ & - & $57-90$ \\
& $\mathrm{~A}$ & & 110 & $1 \times 1-3^{*}$ & - & $78-96$ \\
& & & & $1 \times 3^{* *}$ & - & 99 \\
\multirow{5}{*}{ Shrimp } & $\mathrm{N}$ & $\mathrm{KOH}, 39^{\mathrm{b}}$ & reflux & 20 & $1: 17$ & - \\
& $\mathrm{N}$ & $\mathrm{NaOH}, 50$ & 100 & $0.5-5$ & - & $68-78$ \\
\multirow{4}{*}{ Krill } & $\mathrm{A}$ & $\mathrm{NaOH}, 50$ & $145-150$ & $1 / 12$ & $1: 10$ & - \\
& $\mathrm{A}$ & $\mathrm{NaOH}, 50$ & 60 & $2^{* * *}$ & $1: 4$ & - \\
\multirow{2}{*}{ Squid } & $\mathrm{A}$ & $\mathrm{NaOH}, 50$ & $80-96$ & $1 / 3$ & - & $56-68$ \\
& $\mathrm{~N}$ & $\mathrm{KOH}, 39^{\mathrm{b}}$ & reflux & 20 & $1: 17$ & - \\
& & $\mathrm{NaOH}, 40$ & 80 & $3 \times 1-3 *$ & $1: 20$ & $80-97$ \\
\hline
\end{tabular}

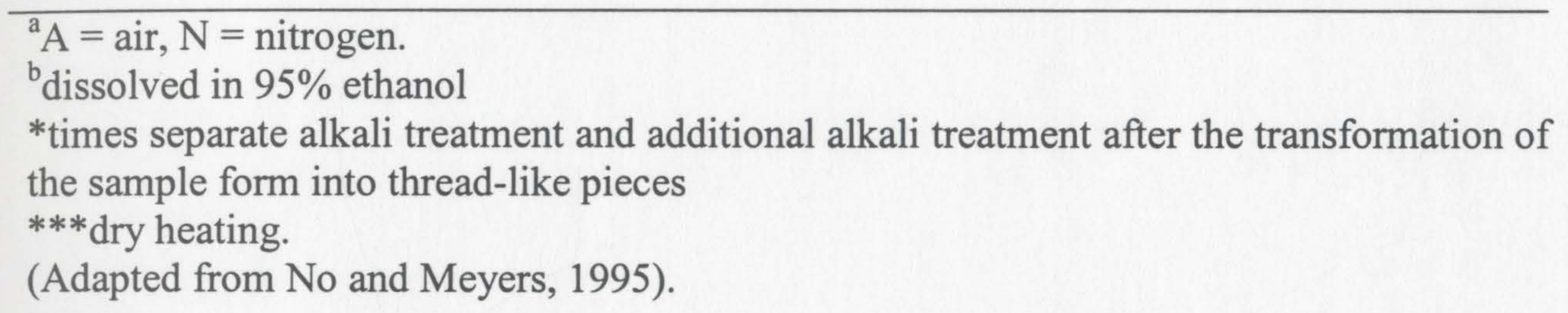


Table 2.4 Characteristics of chitin.

\begin{tabular}{|c|c|c|}
\hline Specification & Description & Reference \\
\hline \multirow[t]{4}{*}{ Nitrogen ( \%) } & $7.01^{\mathrm{a}}$ & No et al. (1989) \\
\hline & 6.14-6.96 & Brezski (1982) \\
\hline & $6.29,6.42$ & Shahidi and Synowiecki (1991) \\
\hline & 6.27 & Synowiecki et al. (1981) \\
\hline Fat $(\%)$ & $0.1-0.2$ & Brezski (1982) \\
\hline \multirow[t]{5}{*}{ Ash ( \%) } & 0.1 & No et al. (1989) \\
\hline & up to 3 & Brezski (1982) \\
\hline & $<0.17$ & Mima et al. (1983) \\
\hline & $0.09,0.10$ & Shahidi and Synowiecki (1991) \\
\hline & 0.06 & Synowiecki et al. (1981) \\
\hline \multirow[t]{2}{*}{ Acetyl value ( \%) } & 19.6 & No et al. (1989) \\
\hline & $15.9-19.7$ & Brine and Austin (1981) \\
\hline \multirow[t]{3}{*}{ Deacytylation (\%) } & 7.5 & No et al. (1989) \\
\hline & $42-58$ & Brezski (1982) \\
\hline & 0.08 & Kurita et al. (1993) \\
\hline \multirow[t]{2}{*}{ Solubility $(\%)^{\mathrm{b}}$} & 26.4 & No et al. (1989) \\
\hline & $28-99$ & Brine and Austin (1981) \\
\hline Optical rotation ${ }^{\mathrm{b}}$ & $-38-+48$ & Brine and Austin (1981) \\
\hline \multirow[t]{4}{*}{ Colour } & White & No et al. (1989) \\
\hline & & Mima et al. (1983) \\
\hline & & Kurita et al. (1993) \\
\hline & Creamy white to & \\
\hline Residual amino acids & $\begin{array}{l}\text { light pink } \\
6.5\end{array}$ & $\begin{array}{l}\text { Brezsk1 }(1989) \\
\text { No et al }(1989)\end{array}$ \\
\hline$(\mathrm{mg} / \mathrm{g})$ & $58.91-47.21$ & Shahidi and Synowiecki (1991) \\
\hline Molecular weight $(\mathrm{Da})$ & $0.56-19.6 \times 10^{6 \mathrm{~b}}$ & Brine and Austin (1981) \\
\hline
\end{tabular}


Table 2.5 Characteristics of chitosan

\begin{tabular}{lll}
\hline Specification & Amount & Reference \\
\hline Nitrogen, (\%) & $7.06-7.63$ & Brezski (1982) \\
& $7.80^{\mathrm{a}}-7.88^{\mathrm{a}}$ & Anderson et al. (1978) \\
Ash, (\%) & $7.74-7.97$ & Bough et al. (1978) \\
& $<1$ & Brezski (1982); Bough et al. (1978) \\
Colour & $<0.01$ & Alimuniar and Zainuddin, (1992) \\
& White & Anderson et al. (1978); Alimuniar and \\
& & Zainuddin (1992) \\
& & \\
& Pinky white & Brezski (1982) \\
Molecular weight, (Da) & Tan & Anderson et al. (1978) \\
& $>5.0 \times 10^{5}$ & Mima et al. (1983) \\
& $0.7-1.5 \times 10^{6}$ & Bough et al. (1978) \\
\hline
\end{tabular}

${ }^{a}$ corrected for ash content. 
show three polymorphic forms of $\alpha$-chitin, $\beta$-chitin, $\gamma$ - chitin (Roberts, 1992; Shimojoh, 1998). The chitin of insect and crustacean cuticle occurs in the form of microfibrills typically $10-25 \mathrm{~nm}$ in diameter and $2-3 \mu \mathrm{m}$ in length. These natural forms of chitin are known to differ from each other in orientation of the polysaccharide chains within the microfibrills, namely $\alpha$ - (antiparallel), $\beta$ - (two parallel, one antiparallel) $\gamma$ - (random orientation) chitin. The most abundant form is $\alpha$-chitin (Peter, 1995). Generally, the individual chains assume an essentially linear structure which undergoes one full twist every $10.1-10.5 \AA$ units along the chain axis (Winterowed and Sandford, 1995). Because each glycosidic unit in the chain is chiral and all units are connected by an oxygen atom that links $\mathrm{C}(1)$ of one glycosidic unit to $\mathrm{C}(4)$ of an adjacent unit, a distinct "left" and "right" direction can be assigned to each polymer chain (Muzzarelli, 1977; Roberts, 1992). Chitin and chitosan are internally cross-linked to a much greater degree than cellulose; each $\mathrm{N}$-acetylglucosamine residue in chitins is linked by an estimated eight hydrogen bonds to residues in the surrounding chains which gives this material an exceptionally high tensile strength in three dimensions compared to cellulose or starch (Bade and Wick, 1988). Figure 2.3 shows an illustration of the parallel and antiparallel polymer arrangement of chitin.

As it is easy to access $\alpha$-chitin compared to the o ther two p olymorphic forms, most of the research has been carried out on $\alpha$-chitin (Shimojoh et al., 1998). However, chitin isolated from squid pen has a $\beta$-structure in contrast to the ordinary $\alpha$-chitin. Deacetylation of squid chitin takes place much easier than that of $\alpha$-chitin because of the loose arrangement of chitin molecules (Kurita, 1997). According to Bade (1997), 
depending on these chain arrangements, there are four different orders of chitin present in nature, such as linear primary structure in which monomers are linked to each other by covalent $\beta$-(1-4)-glycosidic bonds, three dimensional secondary structure which consists of primary chitin chains linked to form microfibrills, tertiary and quarternary structures with macrofibrills and sheets, respectively. Differences between $\alpha$-chitin and $\beta$-chitin are listed in Table 2.6.

\subsubsection{Molecular weight of chitin and chitosan}

The molecular weight of natural chitin is normally g reater than $1,000 \mathrm{kDa}$ and that of commercially available chitosan varies from 100 -over $1,000 \mathrm{kDa}$ (Lower, $1984 ; \mathrm{Li}$ et a l., 1992). S everal external forces d uring the m anufacturing process $\mathrm{c}$ an a ffect the molecular weight of chitosan. Factors such as high temperature (above $280^{\circ} \mathrm{C}$ ) bring about degradation of chitosan and the polymer chains rapidly break down; dissolved oxygen concentration and shear stress may cause these alterations (Muzzarelli, 1977; $\mathrm{Li}$ et a l., 1992). Chitin p repared from b lue, $\mathrm{r}$ ed and $\mathrm{s}$ tone $\mathrm{c}$ rab s howed m olecular w eight variations that appeared to be closely related to the method of decalcification (Brine and Austin, 1981).

The maximum degree of depolymerization occurred when $\mathrm{HCl}$ was used for decalcification, followed by $\mathrm{CH}_{3} \mathrm{COOH}$ and $\mathrm{H}_{2} \mathrm{SO}_{3}$ with minimal degradation occurring during EDTA decalcification process (Rutherford and Austin, 1978; Brine and Austin, 1981). There are many methods to determine the molecular weight of chitin and chitosan, such as viscometry (Roberts 
Figure 2.3 Antiparallel (A) and parallel (B) chain arrangements of chitin. 


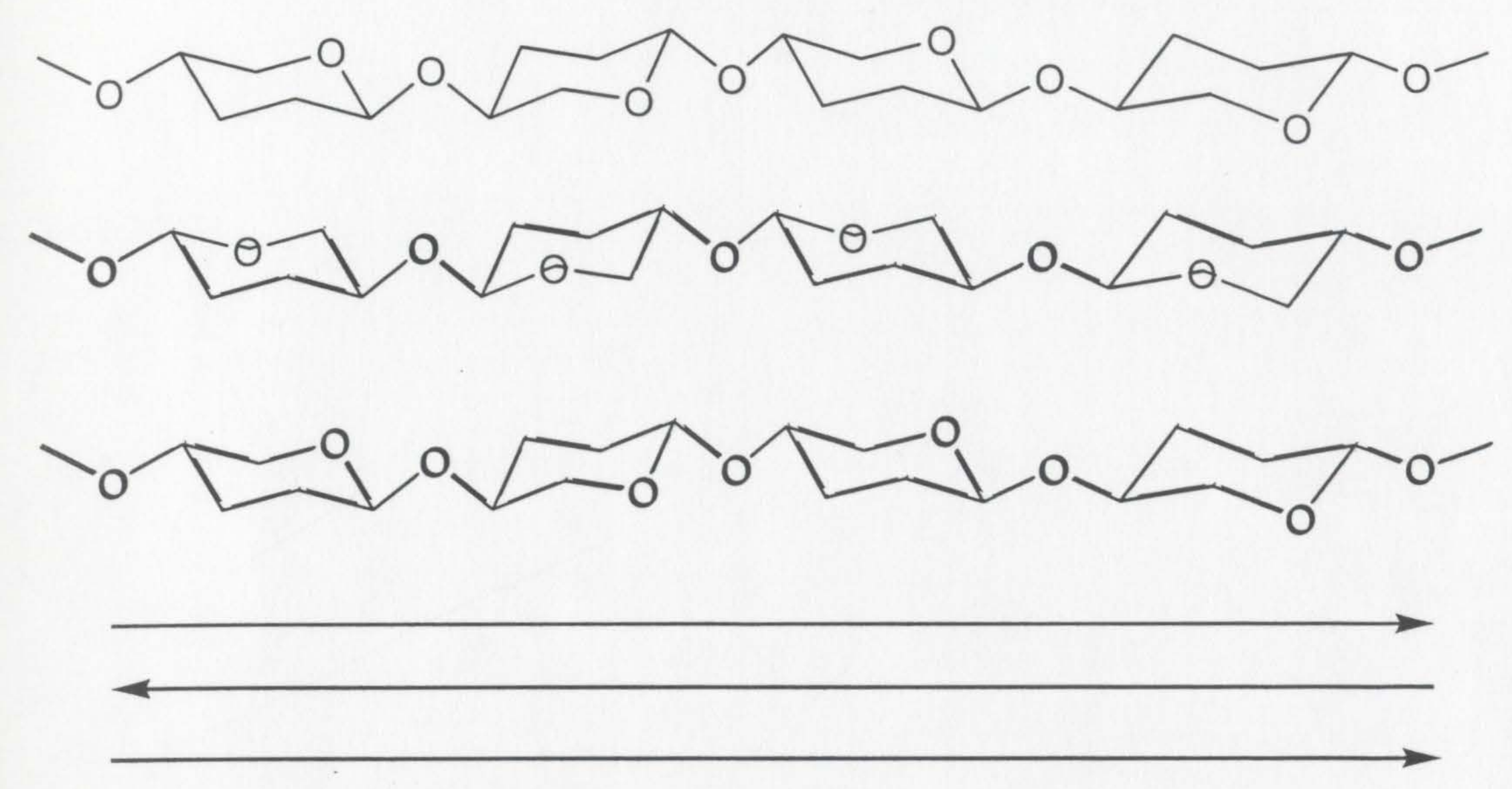

(A)

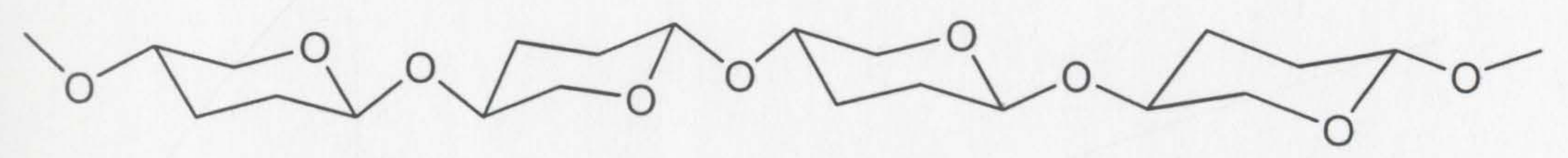

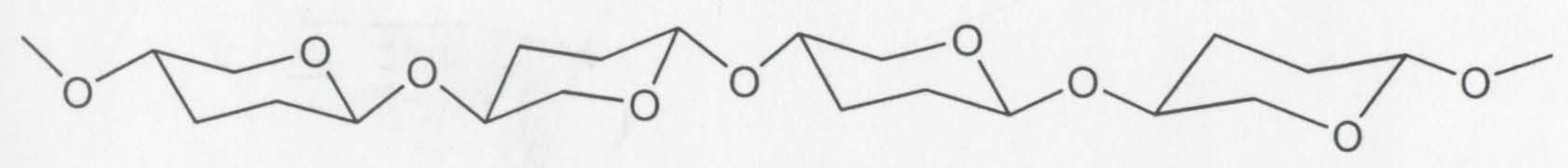

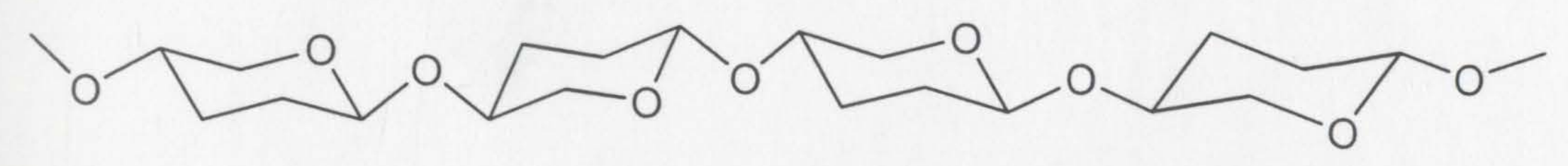

(B) 
Table 2.6 Differences between $\alpha$-chitin and $\beta$-chitin.

$\alpha$-chitin $\quad \beta$-chitin

Major sources-shrimp and crab shell

Molecules are packed and antiparallel

Less affinity for organic solvents and

water

Deacetylation is relatively slow

Quite resistant to modification reactions

Cannot undergo various reactions efficiently under mild condition
Major source-squid pen

Molecules are packed parallel

High affinity for organic solvents and water Deacetylation is relatively fast

Susceptible to modification reactions

Can undergo reactions efficiently under mild conditions

Adapted from Kurita, (1997). 
and Domszy, 1982), laser light scattering technique (Muzzarelli et al., 1987), and gel permeation chromatography (Wu and Bough, 1976). Of these, viscometry is widely used because of its speed and simplicity (Maghami and Roberts, 1988).

\subsubsection{Solubility}

Chitin is insoluble in water, dilute aqueous salt solutions and all common organic solvents. It is depolymerized by strong mineral acids, but is partially soluble in mixtures of dimethylacetamide (DMAC) and $\mathrm{LiCl}$ (No and Meyers, 1995). Brine and Austin (1981) reported variations in the solubility $(28-99 \%)$ of chitin from different species using a number of preparation methods. These workers noted that lower solubility resulted from incomplete removal of protein, and that molecular weight and acetyl content were not the controlling factors for solubility of chitin in 5\% LiCl-DMAC solvent. Chitin is insoluble in aqueous solutions because its microcrystalline regions are stabilized by hydrogen bonds (Claesson and Ninham, 1992). Furthermore, various studies have been conducted to produce water-soluble derivatives of chitin and chitosan using chemical modification techniques (Dung et al., 1994; Sugimoto et al., 1998). Production of acid derivatives may cause harmful effects, such as in cosmetics, medicine and certain foods (Li et al., 1992). Sugimoto et al. (1998) used polyethylene glycol (PEG) in order to improve solubility of chitin and chitosan in water (Figure 2.4).

The chitosan-PEG hybrid did not precipitate from aqueous solution by the addition of organic solvents such as methanol and acetone, because the chitosan-PEG 
hybrid had a high hydrophilicity and some chitosan-PEG hybrids dissolved in water (Sugimoto, 1998). Table 2.7 lists some of the solvents for chitin and chitosan. It can be seen that while there are relatively few solvents for chitin, nearly all aqueous acids dissolve chitosan.

\subsubsection{Chemical reactions of chitin and chitosan}

\subsubsection{Neutralization}

Chitin and chitosan can both be considered as weak bases; as such, they undergo the typical neutralization reactions of alkaline compounds. In these reactions the nonbonding pair of electrons on the primary amine group of glucosamine units performs the role of donating electrons. Thus, the primary amine groups become positively charged (Figure 2.5a). Chitin units may also include amino groups, but to a much lesser degree than chitosan.

\subsubsection{Nucleophilic reactions}

The non-bonding pair of electrons on the primary amine groups makes chitosan a potent nucleophile that can react readily with most aldehydes (Kurita et al., 1988). Formaldehyde and glutaraldehyde are excellent cross-linking agents for chitosan. Acyl chlorides react vigorously with chitosan to form the corresponding amide derivative (Hirano et al., 1976). The primary amine groups in chitin preparations also have the potential to participate in reactions with electrophiles, but in many cases are inaccessible due to the crystalline and intractable nature of chitin. It should be noted that the primary 
Figure 2.4 Preparation of water-soluble chitin and chitosan derivatives Adapted from Sugimoto et al. (1998). 


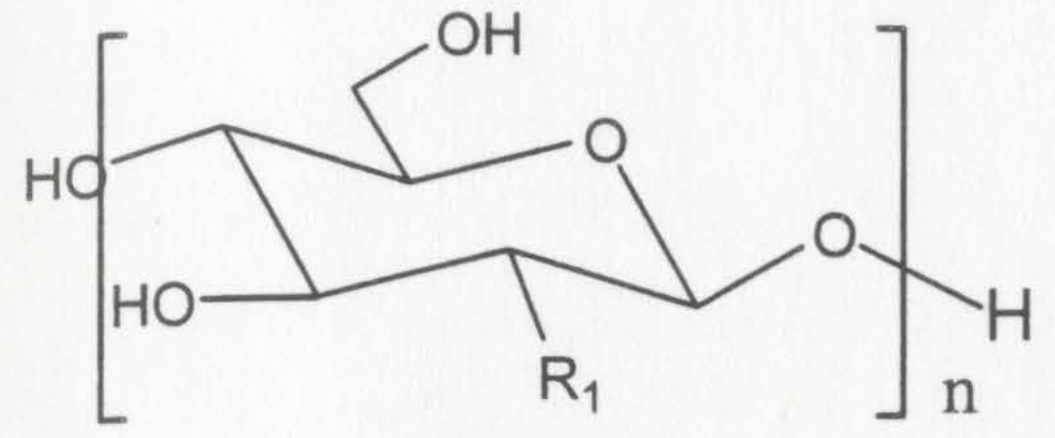

$\mathrm{R}_{1}=\mathrm{NH}_{2}$ or $\mathrm{NHCOCH}_{3}$

$\mathrm{AcOH}, \mathrm{MeOH}, \mathrm{pH}$ 4.6-5.6
$\mathrm{HO}-\mathrm{CH}_{2} \mathrm{CH}_{2} \mathrm{O}\left(\mathrm{CH}_{2} \mathrm{CH}_{2} \mathrm{O}\right)_{\mathrm{m}} \mathrm{CH}_{3}$

Poly(ethylene glycol) monoethyl ether $\mathrm{Ac}_{2} \mathrm{O}, \mathrm{DMSO}, \mathrm{CHCl}_{3}$

$\mathrm{OHC} \mathrm{CH}_{2}\left(\mathrm{CH}_{2} \mathrm{CH}_{2} \mathrm{O}\right)_{\mathrm{m}} \mathrm{CH}_{3}$

1 PEG -aldehyde<smiles>[R2]C1C(O)C(CO)C(C)C(O)C1OC</smiles>

n $\mathrm{N}=\mathrm{CHCH}_{2} \mathrm{O}\left(\mathrm{CH}_{2} \mathrm{CH}_{2} \mathrm{O}\right)_{\mathrm{m}} \mathrm{CH}_{3}$

NaCN-BH 3 AcOH, MeOH, pH 6.5<smiles>[R3]C1C(O)C(O)C(O)C(O)C1OC</smiles>

n

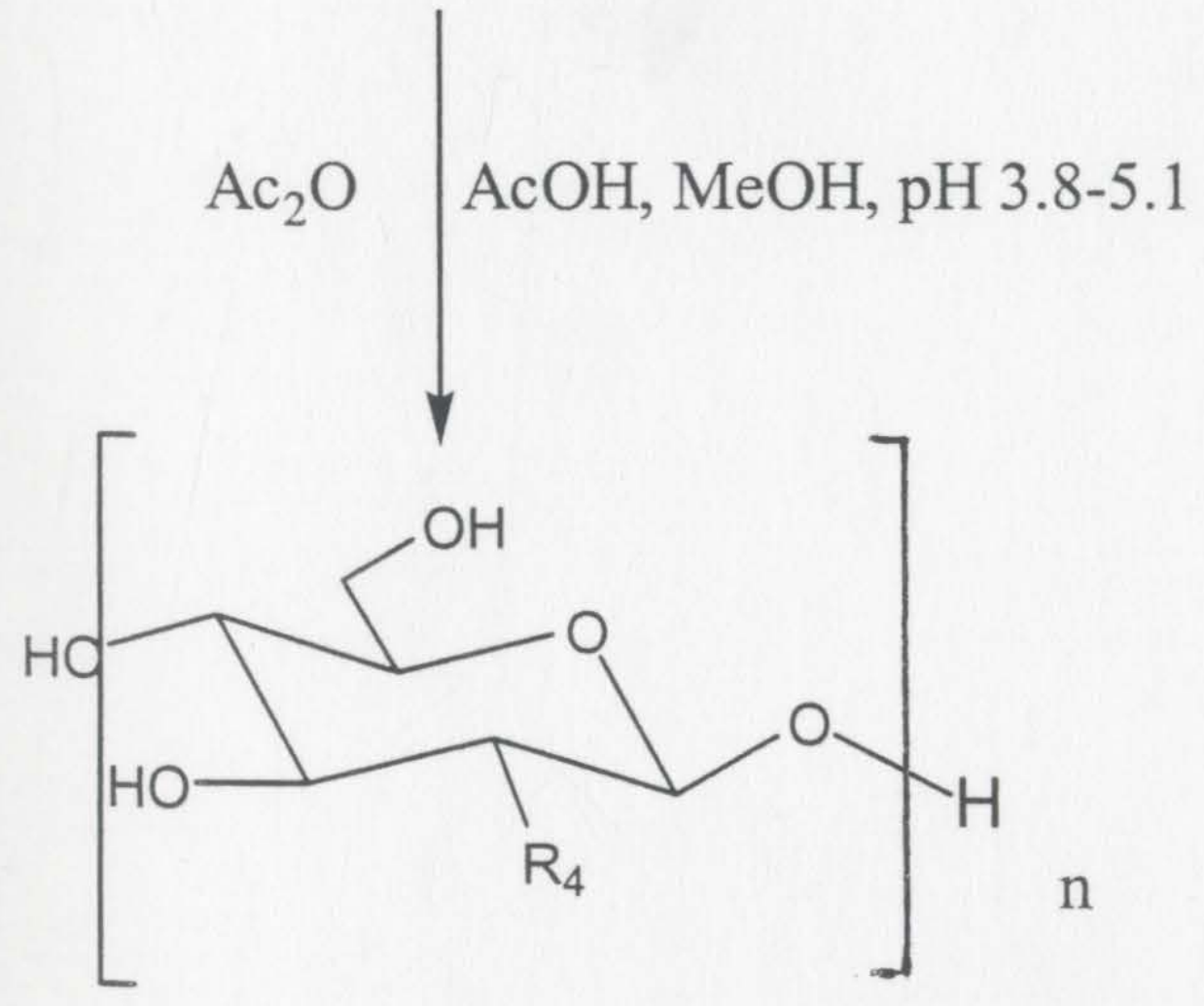

$\mathrm{R}_{3}=\mathrm{NH}_{2}, \mathrm{NHCOCH}_{3}$ or

$\mathrm{NHCH}_{2} \mathrm{CH}_{2} \mathrm{O}\left(\mathrm{CH}_{2} \mathrm{CH}_{2} \mathrm{O}\right)_{\mathrm{m}} \mathrm{CH}_{3}$

2 Chitosan-PEG hybrid
$\mathrm{R}_{4}=\mathrm{NHCOCH}_{3}$ or

$\mathrm{NHCH}_{2} \mathrm{CH}_{2} \mathrm{O}\left(\mathrm{CH}_{2} \mathrm{CH}_{2} \mathrm{O}\right)_{\mathrm{m}} \mathrm{CH}_{3}$ 
Table 2.7 Common solvents for chitin and chitosan.

\begin{tabular}{ll}
\hline Chitin solvents & Chitosan solvents
\end{tabular}

Dimethylformamide, lithium chloride

formic acid, water

Diethylformamide, lithium chloride

acetic acid, water

Hexafluoroisopropanol

lactic acid, water

Hexafluoroacetone, sequihydrate

glutamic acid, water

1,2-Chloroethanol, sulphuric acid hydrochloric acid, water

Adapted from Winterowd and Sanford (1995). 
amine sites on chitin and chitosan are more nucleophilic than the primary hydroxyl groups at the $\mathrm{C}(6)$ position (Figure 2.5b) (Winterowd and Sandford, 1995).

\subsubsection{Acid- or base-assisted hydrolysis}

Chitin and chitosan are susceptible to acid- or base-catalyzed hydrolysis. Under acidic or alkaline conditions, acetic acid can be liberated as the $\mathrm{N}$-acetylamino groups at C(2) are converted to primary amines (Muzzarelli, 1977). Acidic conditions also result in some degree of depolymerization as hydrolysis of the $\beta$-glycosidic linkages takes place (Madhaven and Ramachandran, 1974). Depolymerization occurs to a lesser extent in alkaline environments. Chitosan can also be degraded by treatment with nitrous acid (Figure 2.6a) (Alan and Peyron, 1989).

\subsubsection{Sulphation reactions}

Although the majority of reactions of chitin and chitosan involves the primary amine group, it is possible to modify selectively their hydroxyl groups as well. This can be accomplished by protecting the amine group through the formation of polysaccharide formate or acetate and subsequent reaction of the salt with an electrophile (Muzzarelli, 1977). The hydroxyl group at $C(6)$ is more reactive than that at $C(3)$ and is therefore derivatized preferentially. The sulphation reactions as shown in Figure $2.6 \mathrm{~b}$, is a common example of this type of reaction. These reactions may also be carried out on chitin. The resultant products have blood anticoagulant properties similar to those of heparin (Wolform and Shen-Han, 1959). 


\subsubsection{Heavy metal complexes}

Both chitin and chitosan are able to form complexes with many of the transition metals (Muzzarelli, 1973). Complexes are not formed between chitin and chitosan and metals from groups 1 or 2 . The heavy metal/polymer complexes are believed to form as a result of dative bonding. This involves the donation of the non-bonding pair of electrons from the nitrogen and/or the oxygen of the hydroxyl groups to a heavy metal ion. Cupric ion seems to form one of the strongest metal complexes with chitosan in the solid state. Ferrous ion is also capable of binding to chitosan (Winterowd and Sandford, 1995).

\subsubsection{Viscosity of chitosan}

Viscosity is defined as resistance to flow or resistance to an applied force. It may also be defined as the shear stress divided by the shear rate. Shear stress is the applied force (pouring, mixing, pumping, chewing, swallowing) and shear rate is a value expressing how fast the liquid flows (Singh and Heldman, 1993). The viscosity of chitosan seems to be a major factor that determines its application in many fields (Kaye, 1985).

Chitosan in solution exhibits a polyelectrolytic effect. In the absence of salt there is an abnormal increase in the viscosity of the more dilute solutions because of an enlarged effective volume due to charge repulsion and stretching out of the molecules. When sufficient salt is added to neutralize this charge effect, the viscosity behaviour is 
Figure 2.5a The neutralization reaction of chitosan.

Figure 2.5b Nucleophilic reactions of chitosan

(adapted from Winterowd and Sandford, 1995). 


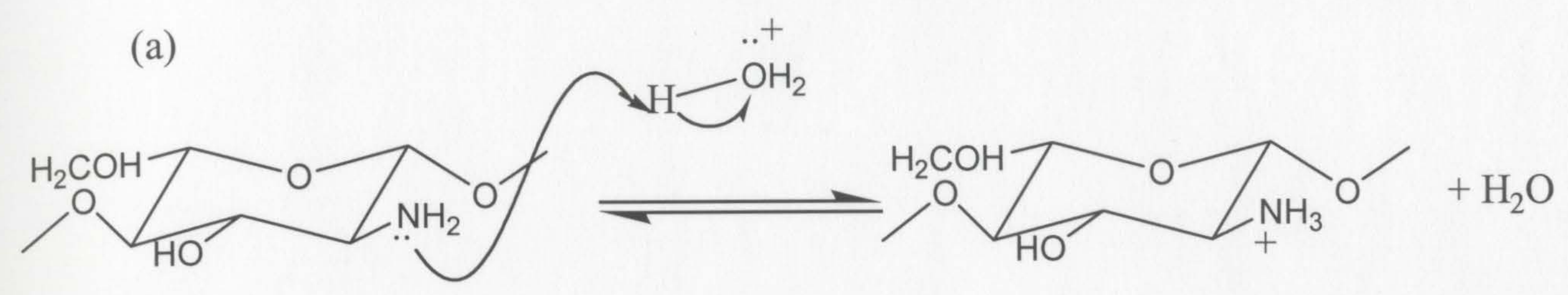

(b)

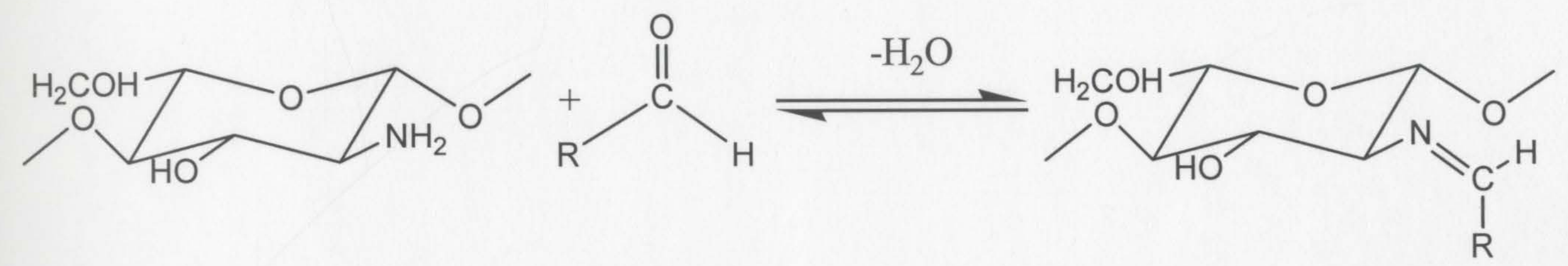

Aldehyde

imine

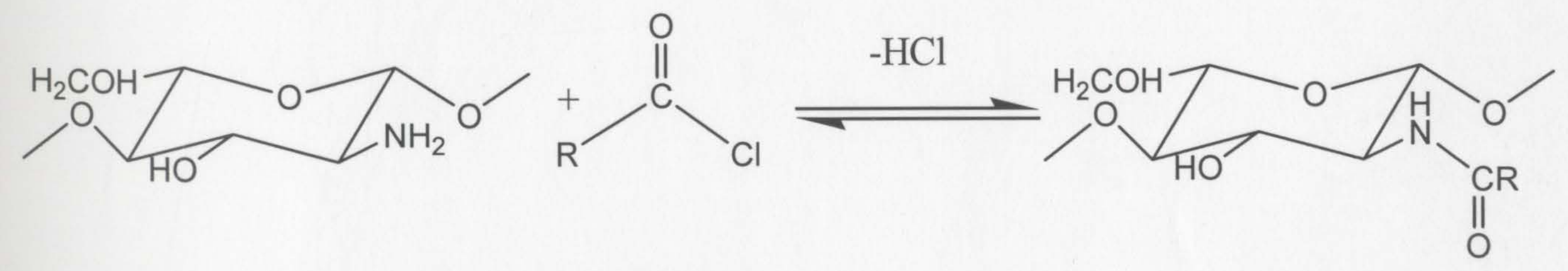

Acyl chloride amide 
Figure 2.6a The degradation reaction of chitosan by use of nitrous acid

Figure 2.6b Sulphation of chitosan

(Adapted from Winterowd and Sandford, 1995). 
(a)
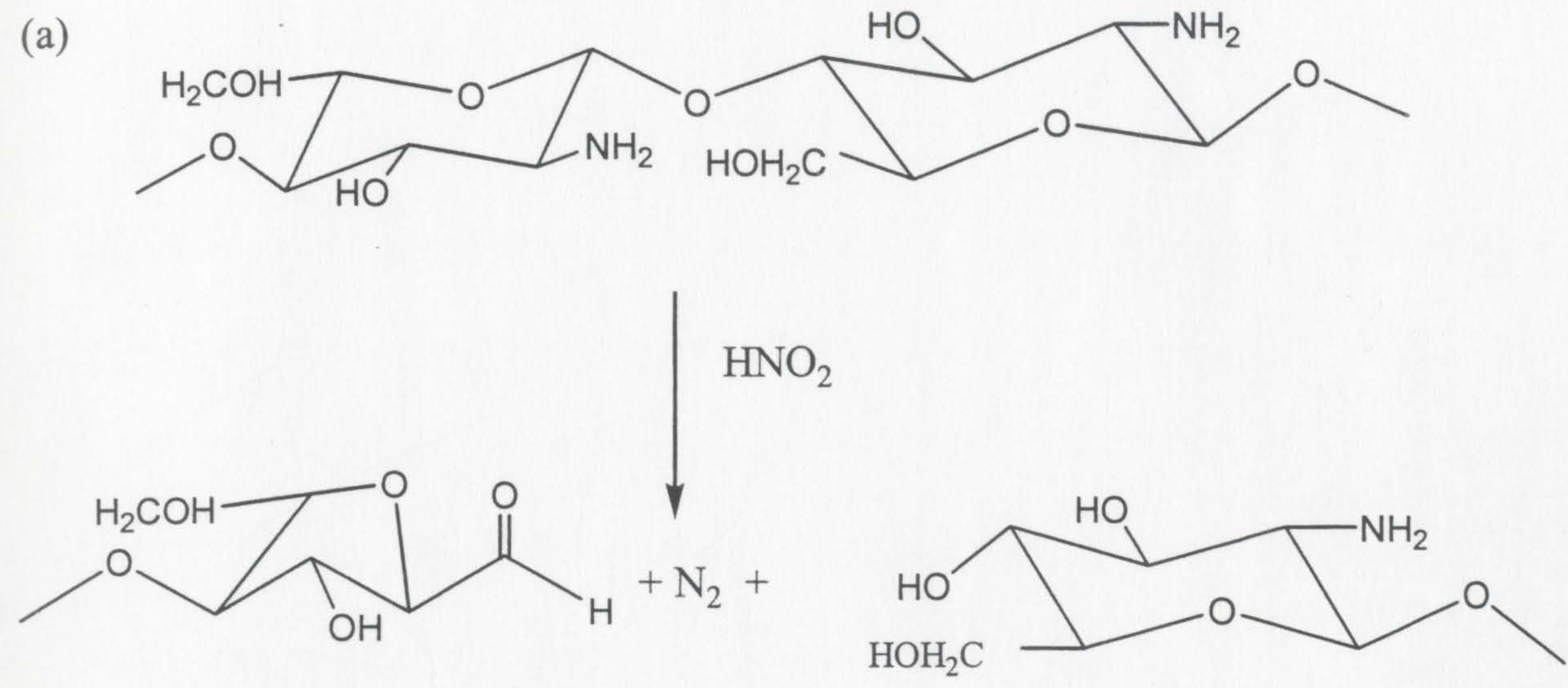

(b)

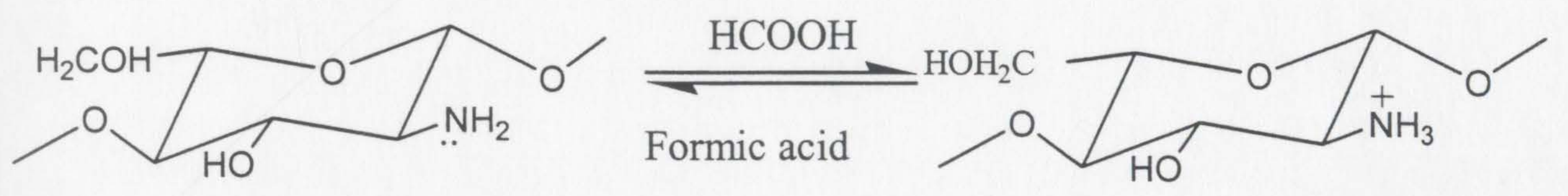<smiles>O=CO</smiles>

dissolve in formamide

2 chlorosulphonic acid

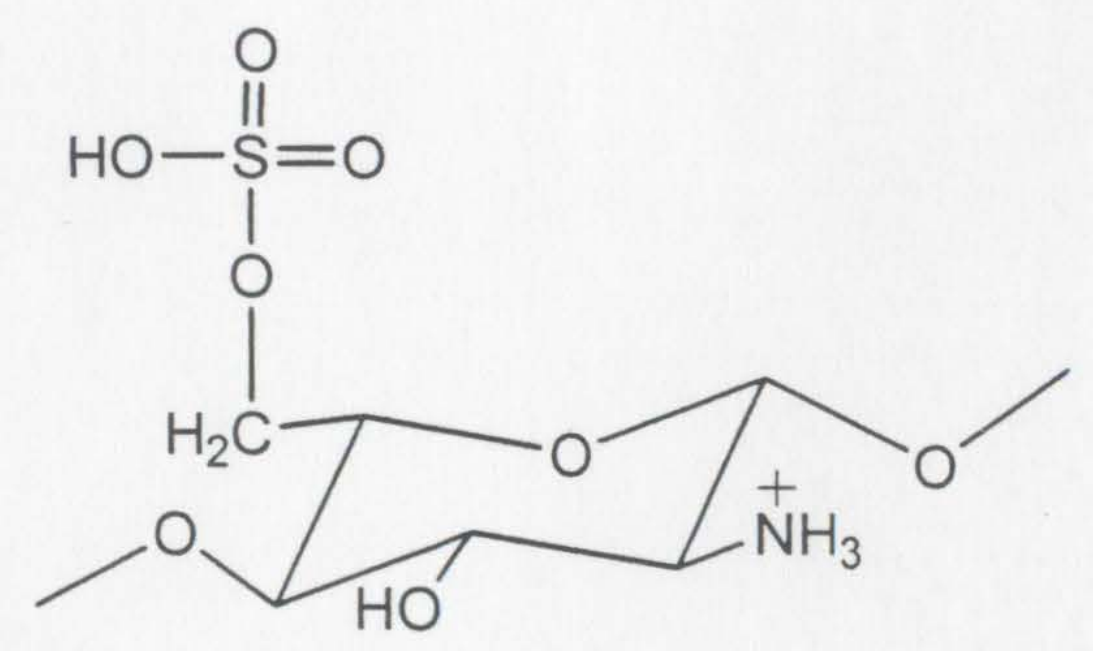<smiles>O=CO</smiles> 
normal. For this reason, the solvent system of $0.2 \mathrm{M} \mathrm{CH}_{3} \mathrm{COOH}$ and $0.1 \mathrm{M} \mathrm{CH}_{3} \mathrm{COONa}$ is preferred for viscosity measurements (Muzzarelli, 1977).

The viscosity of the chitosan in solution is influenced by many factors, such as the degree of polymer deacetylation, molecular weight, concentration, ionic strength, $\mathrm{pH}$ and temperature. In general, as the temperature rises, the viscosity of the polymer solution decreases. However, a $\mathrm{pH}$ change in the polymer solution may give different results depending on the type of acid employed (Li et al., 1992).

The intrinsic viscosity, [ $\eta$, of a liner chain polymer such as chitosan depends on the molecular weight $\left(\mathrm{M}_{\mathrm{w}}\right)$ described by the Mark-Houwink equation, where " $\mathrm{K}$ " and " $\mathrm{a}$ " are constants; $[\eta]=\mathrm{KM}_{\mathrm{w}}{ }^{\mathrm{a}}$ (Roberts, 1992). The viscosities and rheological properties of cations may be measured with a rotational viscometer that measures torque (the resistance to a spindle or cylinder rotating at a given speed in a fluid). Shear rates (spindle speeds) may be changed, so one can obtain both reading at a given shear rate and have plots of shear stress versus shear rate (Roberts, 1992).

\subsection{Applications of chitin and chitosan}

Chitin and chitosan offer a wide range of applications, including clarification and purification of $\mathrm{w}$ ater and b everages, a pplications in $\mathrm{p}$ harmaceuticals and cosmetics, as well as agricultural, food and biotechnological uses (Knorr, 1991). Recent efforts for the use of chitin and chitosan have intensified since efficient utilization of marine biomass resource has become an environmental priority. Early applications of chitin and chitosan 
include the treatment of wastewater and heavy metal adsorption agents in the industry, immobilization of enzymes and cells, resins for chromatography, functional membrane in biotechnology, seed coating and animal feed in agriculture, artificial skin, absorbable surgical suture, and wound healing accelerators in the medical field. Therefore, chitin and chitosan have been develop for new physiological materials lately as because they possess antitumour activity by immuno-enhancing antibacterial activity, hypocholeterolemic activity and antihypersensitive action (Jeon et al., 2000).

\subsubsection{Medical applications}

The interest in chitin and chitosan for medical, ecological and pharmaceutical industries is evident in many publications and has been clearly indicated in several instances. Chitosan membranes have been proposed as artificial kidney membranes possessing high mechanical strength in addition to permeability to urea and creatine; they are impermeable to serum proteins and probably they are unique in offering the advantage of preventing emission of toxic metals into the blood stream, as currently happens with other membranes (Muzzarelli, 1977). Chitin and chitosan have been shown to have both material and bioactive properties that might be beneficial to enhance wound repair. Chitin is "physiologically" soluble because lysozyme, present in large amounts in recent and healing wounds, acts on it. Chitin derivatives suitable as healing accelerators are ethers and esters of salts. Examples are as follows: hydroxyethylchitin; carboxymethylchitin and its zinc salt; methylchitin and ethylchitin; chitin acetate, nitrate, citrate and phosphate; as well as,$N$-formyl-, $N$-acetyl-, $N$-propionyl- and other acyl derivatives (Howling et al., 2001; Muzzarelli, 1977). It was reported that the wound 
recovering material composed of polyelectrolytic complexes of chitosan and sulphonated chitosan speed up wound healing and give a good-looking skin surface (Lahiji et al., 2000). Chitosan has the ability to promote wound healing; this is due to the tendency to form polyelectrolytic complexes with polyanion heparin, which possesses anticoagulant and angiogenic properties. By forming a complex with heparin and actin to lengthen the half-life of growth factors, chitosan supports tissue growth and improves wound healing (Lahiji et al., 2000). Chitosan is a very attractive candidate for burn treatment. This is true since $\mathrm{chitosan}$ can form tough, w ater-absorbent, b iocompatible films. These films can be formed directly on the burn by application of an aqueous solution of chitosan acetate. The solution, although acidic, provides a cool and pleasant soothing effect when applied to the open wounds of burn patients. Deacetylated chitin, or chitosan, has been shown to aggressively bind to a variety of mammalian and microbial cells. This property of chitosan may lead to a variety of medical applications. These possible applications will use chitosan as a haemostatic, bacteriostatic and spermicidal agent.

In recent years chitosan has been introduced as a material in nutritional supplement markets, especially as a weight loss aid and a cholesterol-lowering agent (Shahidi et al., 1999; Subasinghe, 1999). The mechanism behind this apparent effect of chitosan has been suggested to be its effect on the lipid transport mechanism in the gut, wherein free fatty acids (released from consumed fat), cholesterol, bile salts and other components form mixed micelles that comprise an essential step in the fat absorption process. Apparently the positively charged chitosan can bind to free fatty acids and bile salt components and disrupt lipid absorption (Sugano et al., 1980). 


\subsubsection{Pharmaceutical and biotechnological applications}

Chitosan has been extensively examined in the pharmaceutical industry for its potential in the development of controlled release drug delivery systems (Illum, 1998). This is due to its unique polycationic character and its gel- and film- forming properties. Such systems should allow the control of the rate of drug administration and prolong the duration of the therapeutic effect as well as perhaps the targeting of the drug to specific sites (Illum, 1998).

Chitin, 6-O-carboxymethylchitin, 6-O-(2-hydroxyethyl)chitin and 6-O-ethylchitin in the form of membranes have been used as enzymatically decomposable pharmaceutical carriers (Muzzarelli, 1977). Sawayanagi et al. (1982) reported that chitosan had excellent properties as disintegrant for direct compression of tablets where the addition of $50 \%$ chitosan resulted in rapid disintegration. The degree of deacetylation determined the extent of moisture absorption (Sawayanagi et al., 1982). Chitosan, if added to tablets in a concentration higher than $5 \%$, was superior to cornstarch and microcrystalline cellulose as a disintegrant. The efficiency was dependent on chitosan crystallinity, degree of deacetylation, molecular weight and particle size (Ritthidej et al., 1994).

Akbuga (1993) studied the influence of physicochemical characteristics of drugs on their release characteristics from chitosan maleate matrix tablets and found that the drug solubility, degree of ionization and the molecular weight of the drug were the main factors of importance. A controlled release system has been produced by film coating of 
theophylline granules with a polyelectrolyte complex of chitosan and sodium tripolyphosphate (Kawashima et al., 1985). The rate of release of drug could be controlled by $\mathrm{pH}$. At low $\mathrm{pH}$ values, reduced charge of the anionic tripolyphosphate reduced the electrostatic interaction in the complex and the network in the film loosened. Miyazaki et al. (1981) investigated the solubility of dried chitosan gels as vehicles for the sustained release of the poorly soluble drugs such as indomethacin and papaverine hydrochloride. Recently, chitosan, in the form of capsules, has been used for the specific delivery of insulin to the colon (Tozaki et al., 1997).

Chitosan may also be used for biotechnological uses such as a carrier for enzymes and cells, porous beads for bioreactors, and a resin for chromatography and membrane materials. Immobilization technology has the potential for providing high cell densities and high product concentrations in a cell culture system. Enzymes immobilized as chitosan gels include $\alpha$-chymotrypsin, $\alpha$-galactosidase, invertase, $\beta$-galactosidase, $\alpha$ amylase, lactose and cyclodextrin glucanotransferase (Li et al., 1997).

\subsubsection{Food and nutritional applications}

Chitosan offers a wide range of food applications including bioconversion for the production of value-added food products, preservation of foods from microbiological deterioration, formation of biodegradable films, recovery of waste material from food processing industries, purification of water and clarification and deacidification of fruit juices (Shahidi et al., 1999). The growing consumer demand for foods without chemical preservatives has focused efforts in the discovery of new natural antimicrobials (Wang, 
1992). Antomicrobial activity of chitosan and its derivatives against different groups of microorganisms such as bacteria, yeast and fungi has received considerable attention in recent years (Yalpani et al., 1992). Because of the positive charge on the $\mathrm{C}(2)$ of the glucosamine monomer at a $\mathrm{pH}$ below, chitosan is more soluble and has better antimicrobial activity than chitin (Chen et al., 1998). Sudharshan et al. (1992) studied the antimicrobial effect of water-soluble chitosans such as chitosan lactate, chitosan glutamate and chitosan hydroglutamate and chitosan derived from Absidia coerulea fungi, on different bacterial cultures. They observed that chitosan glutamate and chitosan lactate were bactericidal against both Gram-positive and Gram-negative bacteria in the range of one to five log cycle reductions within one hour. Chitosan reduced the in vitro growth of numerous fungi with the exception of zygomycetes; that is, the fungi containing chitosan as a major component of its cell walls (Allan and Hadwiger, 1979).

The $u$ se of edible films and coatings to extend the shelf 1 ife and improve the quality of fresh, frozen and fabricated foods has been examined (Kester and Fennama, 1986). Chitin and chitosan possess film-forming properties and hence have been successfully used as food wraps (Shahidi et al., 1999). The use of $N, O$ carboxymethylchitin films to preserve fruits over long periods has been approved in both Canada and the USA (Davides et al., 1989). Due to its ability to form semi-permeable films, chitosan coatings modify the internal atmosphere as well as decrease transpiration loss and delay the ripening of fruits (El Ghaouth et al., 1992). The feasibility of using a chitosan powder in a fluorescence sensor for monitoring lipid oxidation in muscle food was studied by Weist and Karel (1992). The primary amino groups of chitosan form a 
stable fluorosphere with volatile aldehydes such as malondialdehyde, which is derived from the breakdown of fats (Weist and Karel, 1992).

The United Status Food and Drug Administration (USFDA) approved the use of chitosan as a feed additive in 1983 (Knorr, 1986). Chitosan is also used in the food industry as a food quality enhancer in certain countries. Japan produces dietary cookies, potato chips and noodles enriched with chitosan because of its hypocholesterolemic effect (Hirano, 1989). Furthermore, vinegar products containing chitosan are manufactured and sold in Japan, again because of their cholesterol lowering ability. The non-digestibility in the upper gastrointestinal (GI) tract, high viscosity, polymeric nature and high water binding properties, together with low water binding in the lower GI tract, are all responsible for the effective hypocholesterolemic potential of chitin and chitosan dietary fibres (Muzzarelli, 1996; Muzzarelli, 1997).

Hirano et al. (1990) demonstrated the nutritional significance of chitinous polymers in animals and indicated the effectiveness of chitin and chitosan as feed additives. Razdan and Pettersson (1994) observed increased high density lipoprotein (HDL) concentrations after feeding a chitosan-containing diet to broiler chickens. This could be attributed to enhanced reverse cholesterol transport in response to intestinal losses of dietary fats. The effect of chitin, chitosan and cellulose as dietary supplements on the growth of cultured red sea bream, Japanese eel and yellow tail has been investigated by Kono et al. (1987). Due to the ability of forming an ionic bond at low $\mathrm{pH}$, it can bind in vitro to difficult types of anions such as bile acids or free fatty acids 
(Muzzarelli, 1996). Large proportions of these bound lipids are thus excreted. Bound triacylglycerols would escape hydrolysis by the lipase, promoting the excretion of fatty materials including cholesterol, sterols and triacylglycerols (Zacour et al., 1992; Muzzarelli, 1997). Inside the digestive tract, chitosan forms micelles with cholesterol, both endogenous and from dietary sources, in the alkaline fluids in the upper part of the intestine, resulting in the depression of absorption of dietary cholesterol and circulation of cholic acid to the liver. Because of the formation of cholic acid from blood cholesterol in the trends to decrease blood cholesterol concentration. Large intestinal microbials, which secrete chitinases, can digest these micelles; hence, the formed bile acids and sterols are excreted as free forms into faeces without absorption (Hirano and Akiyama, 1995).

\subsubsection{Agricultural applications}

Chitosan has many potential applications in agriculture because it is naturally occurring and biodegradable; therefore, it should not cause pollution problems. One application that is widely employed at present is seed coating ( $\mathrm{Li}$ et al., 1997). Hadwiger and coworkers (1985) found that chitosan treatment in coating seeds had many beneficial effects, such as inhibition of fungal pathogens in the vicinity of the seeds and enhancement of plant-resistant responses against diseases. Kokalis-Burelle (2001) reported that chitin contributes significantly to soil enrichment. He found that chitin can control plant pathogens, pathogenic nematodes and can provoke the development of host plant resistance against these pathogens. In addition to directly treating plants with chitosan, this polymer $\mathrm{h}$ as b een employed for i mproving s oil p roperties and preparing 
hydroponic fertilizes (Li et al., 1997). Simther-Kopperl (2001) reported that when chitin decomposes it produces ammonia, which takes part in the nitrogen cycle. Furthermore, chitin is a main constituent in geochemical cycling of both carbon and nitrogen. Concerns about the environment have aroused great interest in the excessive use of agrochemicals such as fertilizers, herbicides and pesticides. Thus to reduce environmental damage caused by agrochemicals, the use of chitosan in controlledreleased systems has gained momentum (Li et al., 1997).

\subsubsection{Waste treatment and purification of water}

Both chitin and chitosan are recognized as excellent metal ligands, forming stable complexes with many metal ions (Muzzarelli, 1973; Kurita et al., 1979). In particular, chitosan is considered as one of the best natural chelators for transition metals. Hence, chitin and chitosan have been utilized for waste water treatment, such as removal of toxic metals and radionuclides, recovery of precious metals, and recycling of metals from industrial wastewater for reuse and in order to reduce operational costs (Chui et al., 1996). Chitosan can be utilized as a tool for the purification of water because of its high sorption capacity (Jeuniaux, 1986). The capacity of chitin and chitosan to form complexes with metal ions has been exploited in Japan for water purification (Simpson et al., 1994). The $\mathrm{NH}_{2}$ group of chitosan is of interest due to its ability to form coordinate covalent bonds with metal ions. Chitosan powder and dried films have more potential use in metal ion complexing because they will release most of their free amino groups above the $\mathrm{pKa}$ of the $\mathrm{NH}_{2}$ group of chitosan (Tirmizi et al., 1996). 
The use of commercially available chitosan for potable water purification has been approved by the United States Environmental Protection Agency (USEPA) up to a maximum level of $10 \mathrm{mg} / \mathrm{L}$ (Knorr, 1984). The effectiveness of cross-linked $\mathrm{N}$ carboxymethylchitosan in removing lead and cadmium from drinking water has been demonstrated by Muzzarelli et al. (1989). A study of the metal binding capacity of chitosan has shown good binding with metals such as copper and vanadium (Micera et al., 1986). Chitosan as a means of removing soluble silver from industrial waste streams has also been demonstrated (Lasko and Hurst, 1999). Commercially available chitosan's potential in the adsorption of heavy metals such as zinc, copper, cadmium and lead from aqueous solutions under various physicochemical conditions was investigated by Bassi et al. (2000). A new technique for preconcentration of trace elements and matrix elimination with a chitosan-based chelating resin was proposed as a useful pretreatment prior to measurements by ICP-MS. A small volume of the sample solution $(80 \mu \mathrm{L})$ was discretely introduced into the nebulizer of ICP-MS using a segment flow injection (SFI) system; a maximum of fifteen elements were simultaneously measured by this single injection (Lee et al., 2000).

Chitosan is an excellent coagulating agent and flocculent due to the high density of amino groups on the polymer chain that can interact with negatively charged substances, such as proteins, solids and dyes, among others (Goosen, 1997). Wu et al. (1978) investigated the effectiveness of different chitosans for removing proteins from cheese whey. They found that the effectiveness in coagulating solids and proteins was inversely proportional to the molecular weight of the polymer. It is recognized that 
chitosan with its partial positive charge can be used for coagulation and recovery of proteinaceous solids present in such food-processing wastewater (Knorr, 1991). Chitosan was a lso u tilized a a c oagulant for a mino a cids from $\mathrm{c}$ rawfish processing $\mathrm{w}$ astewater (No and Meyers, 1989) and flocculation of microalgae at a chitosan concentration between 10 and $80 \mathrm{mg} / \mathrm{L}$ (Lubian, 1989).

Adsorption of dyestuff from processing effluents onto chitin has been reported by McKay et al. (1982) and the dye binding properties of chitin have been investigated by Knorr (1983). Dye binding was between 0.7 and $0.8 \mathrm{mg}$ dye per gram chitin and chitosan. The kinetics of sorption of dyes on chitosan and the effects of temperature, particle size of chitosan, and $\mathrm{pH}$ of the dye solution have been examined by Venkatrao et al. (1986).

\subsection{Seafood processing discards as environmental pollutants}

The term shellfish, includes both molluscs and crustaceans and few other invertebrates such as sea urchins. Over the past two decades the shellfish industry has experienced a significant increase in processing volume with a corresponding increase in the available by-products, most of which are not presently utilized. The waste from shellfish processing plants is a serious concern for processors if strict environmental regulations are enforced (Brzeski,1987).

The most important commercially harvested crustaceans in Canada are crab, shrimp and lobster. In the crustacean industry, processing discards may account for up to $80 \%$ of the landed catch. These materials are mainly shells, viscera, heads and adhered 
meat. The major components of shells are proteins, chitin and minerals, as well as small amounts of flavourant proteins and carotenoid pigments (Hansen and Illanes, 1994; Shahidi et al., 1992; Ferrer et al., 1996).

Spoilage of muscle foods, such as shellfish, results from changes brought about by the following: (1) biological reactions such as oxidation of lipids; (2) reactions due to activities of the fish's own enzymes; and (3) the metabolic activities of microorganisms. The predominance of these in any given food and under different storage conditions depends on several factors, including the chemical composition of the fish and shellfish. Chemically, shellfish has four major components: proteins, lipids, carbohydrates (chitin) and moisture (Ashie et al., 1996). The relative proportions of all these components give fish and shellfish their characteristic structure, flavour, texture, colour and nutritional value. Besides these macrocontaminants, there are vitamins and other minor components, some of which become important in the spoilage process. One such group, generally referred to as extractives (i.e., extractable into water or aqueous solution), comprises primarily free amino acids, sugars and volatile nitrogenous bases such as ammonia, trimethylamine $N$-oxide (TMAO), creatine, taurine, the betaines, uric acid, anserine, carnosine and histamine (Jay, 1986).

In the pos-tmortem animal, enzymes from spoilage microorganisms primarily metabolize the extractive fraction of the fish muscle, producing a wide variety of volatile compounds resulting in off-flavours and off-odours. Trimethylamine $\mathrm{N}$-oxide, which is found in a large number of marine fish and shellfish, is broken down to trimethylamine (TMA) by either endogenous enzymes or the bacterial enzyme, trimethylamine oxidase 
(Phillippy, 1984). Trimethylamine $\mathrm{N}$-oxide may also be decomposed to dimethylamine (DMA) and formaldehyde. The reactions involved are:
$\mathrm{AH}_{2}+\left(\mathrm{CH}_{3}\right)_{3} \mathrm{NO}$
$\longrightarrow\left(\mathrm{CH}_{3}\right)_{3} \mathrm{~N}+\mathrm{H}_{2} \mathrm{O}+\mathrm{A}$
TMAO
TMA
$\left(\mathrm{CH}_{3}\right)_{3} \mathrm{NO}$
$\left(\mathrm{CH}_{3}\right)_{2} \mathrm{NH}+\mathrm{HCHO}$
DMA
formaldehyde

Where $\mathrm{A}$ is an oxidized substrate and $\mathrm{AH}_{2}$ is the reduced form of the substrate Trimethylamine reacts with lipids in the fish muscle to produce the characteristic fishy odour of low-quality fish. When the oxygen supply is depleted, many of the spoilage bacteria utilize TMAO as a terminal hydrogen acceptor, thus allowing them to grow under anaerobic conditions. This could be one reason why seafoods spoil more rapidly than other muscle foods. It has also been suggested that the formaldehyde produced in the above reaction cross-links with muscle proteins, contributing to the tough texture that develops during frozen storage (Sikorski et al., 1976).

Other compounds produced as a result of microbial activity are hydrogen sulphide, dimethyl sulphide and methyl mercaptan from sulphur-containing amino acids; various amines and ammonia from amino acids; lower fatty acids from sugars such as glucose and ribose; carbonyl compounds from lipids; and indole, skatole, putrescine and 
cadaverine from proteins. Indole production has also been correlated with the strong odour of decomposition which is characteristic of shrimp spoilage (Ashie et al., 1996).

Despite the presence of valuable components in the discards, little developments of industrial scale have occurred in North America. Although some composting of processing discards has taken place, discards are generally dumped in-land or hauled into the ocean. Nonetheless, meal and silage production has also been used as a possible means of waste utilization (Shahidi, 1994). The processing of shellfish waste poses major technological problems, as shells are largely water insoluble and very resistant to natural biodegradation (Healy et al., 1994). The constituents of such shells include protein and chitin, which are worthy of further processing.

Chitin is a biopolymer which could have many market applications. Chitosan is made either by chemical or biochemical deacetylation of chitin (Ornum, 1992). Chitin and chitosan can be used for agricultural, food, industrial and medical applications. Crab and shrimp fishery are of utmost importance to the economy of Newfoundland and Labrador. Therefore, value-added utilization of their discards is of importance (Shahidi and Synowiecki, 1991; Ferrer et al., 1996). 


\section{CHAPTER 3 \\ MATERIALS AND METHODS}

\subsection{Materials}

Fresh samples of crab processing discards, comprised of intact cephalothoraxes and abdominal exoskeletons were collected from a local source in Newfoundland. Reagents, namely sodium hydroxide $(\mathrm{NaOH})$, formaldehyde $(\mathrm{HCHO})$, formic acid $(\mathrm{HCOOH})$, acetic acid $\left(\mathrm{CH}_{3} \mathrm{COOH}\right)$, hydrochloric acid $(\mathrm{HCl})$, sulphuric acid $\left(\mathrm{H}_{2} \mathrm{SO}_{4}\right)$, acetone, potassium chloride $(\mathrm{KCl})$, hexamine, cadmium nitrate tetrahydrate $\left(\mathrm{Cd}\left(\mathrm{NO}_{3}\right)_{2} \cdot 4 \mathrm{H}_{2} \mathrm{O}\right)$, cupric sulphate $\left(\mathrm{CuSO}_{4}\right)$, ferrous sulphate $\left(\mathrm{FeSO}_{4}\right)$, zinc chloride $\left(\mathrm{ZnCl}_{2}\right)$, manganese chloride tetrahydrate $\left(\mathrm{MnCl}_{2} \cdot 4 \mathrm{H}_{2} \mathrm{O}\right)$, nitric acid $\left(\mathrm{HNO}_{3}\right)$, chloroform, methanol, sodium hypochlorite $(\mathrm{NaOCl})$, sodium carbonate, sodium tartarate and bovine serum albumin were obtained from Fisher Scientific Co. (Nepean, ON). Sodium bicarbonate $\left(\mathrm{NaHCO}_{3}\right)$, tetramethylmurexide (TMM), nickel(II) sulphate hexahydrate $\left(\mathrm{NiSO}_{4} \cdot 6 \mathrm{H}_{2} \mathrm{O}\right)$, silver nitrate $\left(\mathrm{AgNO}_{3}\right)$, Folin \& Ciocalteu's phenol reagent, ethylenediaminetetraacetic acid (EDTA), boric acid, picric acid (PA) and cobalt(II) chloride hexahydrate $\left(\mathrm{CoCl}_{2} \cdot 6 \mathrm{H}_{2} \mathrm{O}\right)$ were obtained from Sigma-Aldrich Canada Ltd. (Oakville, ON). ICP-MS standards were obtained from SCP Science (St. Laurent, PQ). Wastewater samples were obtained from Asarco Inc (Buchans, NL).

\subsection{Methods}

\subsubsection{Suitability of chemical treatments in extending shelf life of crab waste}

Fresh samples of crab processing discards were treated by dipping them seperately in a $1 \%(\mathrm{w} / \mathrm{v})$ solution of formaldehyde, formic acid, acetic acid, sodium 
bicarbonate and sodium hydroxide. Experiments were conducted at cold room temperature $\left(4-7^{\circ} \mathrm{C}\right)$ and at room temperature $\left(20-25^{\circ} \mathrm{C}\right)$ separately. A control without any treatment was used for comparative purposes. The samples were evaluated for odour characteristics by a panel of 7 untrained panelists. Panelists were asked to judge the odour of the crab processing discards and to record the results on a 5-point scale [1excellent (no foul odour), 2-good, 3-moderate, 4-bad, 5-very bad (foul odour)].

\subsubsection{Proximate composition of crab processing discards}

\subsubsection{Moisture content}

Two to 3 grams of ground crab processing samples were dried in a pre-weighed aluminium pan (Fisher) and placed in a forced-air convection oven (Fisher Isotemp 300). Samples were maintained at $105 \pm 1{ }^{\circ} \mathrm{C}$ until a constant mass was obtained. The moisture content was then calculated as percent ratio of the weight difference of the sample before and after drying to that of the original material (AOAC, 1990).

\subsubsection{Ash content}

Approximately 3 to $5 \mathrm{~g}$ of ground crab processing discards samples were accurately weighed into clean, dry, pre-weighed porcelain crucibles and charred over a Bunsen burner. The charred samples were heated in a muffle furnace (Blue M. Electro Co., Blue Island, IL) and maintained at $550 \pm 1^{\circ} \mathrm{C}$ until a gray ash was obtained. Crucibles were subsequently cooled in a desiccator and weighed. Ash content was calculated as percent ratio of the mass of the ash obtained after ignition to that of the original material (AOAC, 1990). 


\subsubsection{Crude protein content}

Approximately 0.3-0.4 g of ground crab processing discards sample were weighed onto nitrogen-free weighing paper and transferred into a of Büchi digestion tube (Büchi 321, Büchi Laboratories, Fawil, Switzerland). The sample was digested with $20 \mathrm{~mL}$ of concentrated $\mathrm{H}_{2} \mathrm{SO}_{4}$ acid and two Kjeltab tablets (Profamo Analytical Service Inc., Dorval, PQ) for 45 min to obtain a clear solution. The digested samples were diluted with $50 \mathrm{~mL}$ of distilled water followed by the addition of $150 \mathrm{~mL}$ of a $25 \%$ (w/v) sodium hydroxide solution. The samples were steam distilled (Büchi 321, Büchi Laboratories,

Fawil, Switzerland) to release the nitrogen in the form of ammonia, which was trapped in a $50 \mathrm{~mL}$ solution of $4 \%(\mathrm{w} / \mathrm{v})$ boric acid containing N-Point indicator (EM Science, Gibbstown, NJ) in a receiving flask. Steam distillation was continued for 6 min and the contents in the receiving flask were titrated against a $0.1 \mathrm{~N}$ standard solution of sulphuric acid to determine the content of nitrogen (AOAC, 1990). The crude protein content of samples was calculated using a factor of 6.25 .

$$
\text { Percentage } \mathrm{N}=\frac{\left(\mathrm{V}_{\text {sample }}-\mathrm{V}_{\text {blank }}\right) \times \mathrm{N} \times 14.0067 \times 100}{\mathrm{~W}}
$$

Where, $\mathrm{V}_{\text {sample }}=$ volume of titrate for sample $(\mathrm{mL})$

$\mathrm{V}_{\text {blank }}=$ volume of titrant for blank $(\mathrm{mL})$

$\mathrm{N} \quad=$ normality of the $\mathrm{H}_{2} \mathrm{SO}_{4}$ solution used in the titration

$\mathrm{W}=$ weight of the sample $(\mathrm{mg})$

\subsubsection{Lipid content}

Total lipid content of samples was determined using the procedure described by Bligh and Dyer (1959). Briefly, Approximately $25 \mathrm{~g}$ of ground crab processing discards samples were accurately weighed and then extracted over a $3 \mathrm{~min}$ period with a mixture 
of $25 \mathrm{~mL}$ of chloroform and methanol followed by homogenization using a Polytron homogenizer (Model PT-3000, Brinkmann Instruments, Canada Ltd., Rexdale, ON). Approximately $25 \mathrm{~mL}$ of distilled water were added and the mixture was then filtered through a Büchner funnel under suction. The filtrate was allowed to separate overnight in a separatory funnel. Ten millilitres aliquots were transferred into a pre-weighed round bottom flask and the solvent was removed using a Büchi Rotorvapor (461,Büchi Laboratories, Fawil, Switzerland). The flask was then placed in the a forced-air convection oven at $80^{\circ} \mathrm{C}$ for $1 \mathrm{~h}$. After cooling in a desiccator the round bottom flask containing the lipids was weighed and the total lipid content determined gravimetrically.

\subsubsection{Preparation of chitin and chitosan and evaluation of their characteristics}

Chitin was isolated from crab processing discards using a modified version of the methods of Mima et al. (1993) and Shahidi and Synoweicki (1991). Deproteinization and demineralization steps were carried out with 20 volumes of $4 \%(\mathrm{w} / \mathrm{v}) \mathrm{NaOH}$ at $60^{\circ} \mathrm{C}$ for $3 \mathrm{~h}$ and 10 volumes of $10 \%(\mathrm{v} / \mathrm{v}) \mathrm{HCl}$ at $25^{\circ} \mathrm{C}$ for $2 \mathrm{~h}$, respectively. The alkali and acid treatments were repeated twice. Chitin residue, firmly complexed with the carotenoid pigments, was extracted with 20 volumes of acetone and dried for $2 \mathrm{~h}$ at ambient temperature, followed by bleaching with $0.32 \%(\mathrm{v} / \mathrm{v})$ sodium hypochlorite solution (containing $5.25 \%$ available chlorine) for $5 \mathrm{~min}$ with a solid-to-solvent ratio of $1: 10(\mathrm{w} / \mathrm{v})$. Chitosan was prepared by alkali treatment of chitin using 10 volumes of $50 \%$ (w/v) $\mathrm{NaOH}$ in distilled water at $100{ }^{\circ} \mathrm{C}$ for 4,10 and $20 \mathrm{~h}$ under a nitrogen atmosphere (Mima et al., 1983). The reactants were immediately filtered under vacuum after alkali treatment, washed with hot-deionized water to neutral $\mathrm{pH}$ and lyophilized for $72 \mathrm{~h}$ at - 
$49^{\circ} \mathrm{C}$ and $62 \times 10^{-3}$ mbar (Freezone 6, Model 77530, Labconco, Kansas City, MO). According to the deacytelation times three types of chitosan were obtained (Type 1, Type 2 and Type 3). A simplified flow diagram of chitin and chitosan preparation is given in Figure 3.1. Moisture, total nitrogen and ash contents were then determined. Particle sizes of chitosan types were determined by passing a sample of chitosan through a series of sieves with four sizes r anging from 250-1000 microns (250, 350 and $500 \mathrm{~m}$ icronsGilson Company Inc.,Worthinton, OH; 1000 microns- Tyler Co. of Canada Ltd., St. Catherines, ON). Apparent viscosity (at $2 \mathrm{~N} / \mathrm{m}^{2}$ ) of a $1 \%(\mathrm{w} / \mathrm{v})$ chitosan level in a $1 \%$ $(\mathrm{v} / \mathrm{v})$ acetic acidsolution at $25^{\circ} \mathrm{C}$ was measured using a rotational viscometer (ColeParmer Co., Vernon Hills, IL). Measurments were made in triplicate using a No 5 spindle at $50 \mathrm{rpm}$ on solutions at $25^{\circ} \mathrm{C}$ with values reported in centipose (cP) units. The degree of acetylation of chitosan was measured according to the picric acid method of Neugebauer et al. (1989). Dried and finely powdered chitosan (10-15 mg) was placed in a small column for liquid chromatography, and the weight of the polymer was determined accurately by weighing the column before and after its introduction. In order to remove residual salts from the amino groups, a preliminary washing step was included; the polymer in the column was exposed for $15 \mathrm{~min}$ to $0.1 \mathrm{M}$ diisopropylethylamine (DIPEA) in methanol, and then washed with methanol $(10 \mathrm{~mL})$. Binding of picric acid to the amino groups was performed by introducing $0.1 \mathrm{M}$ picric acid in methanol $(1.0 \mathrm{~mL})$ and then allowing the reaction to proceed for $6 \mathrm{~h}$. The column was subsequently washed with methanol $(30 \mathrm{~mL})$ at a rate of $0.5 \mathrm{~mL} / \mathrm{min}$ in order to remove the unbound picric acid 
Figure 3.1 A simplified flow diagram of chitin and chitosan preparation 

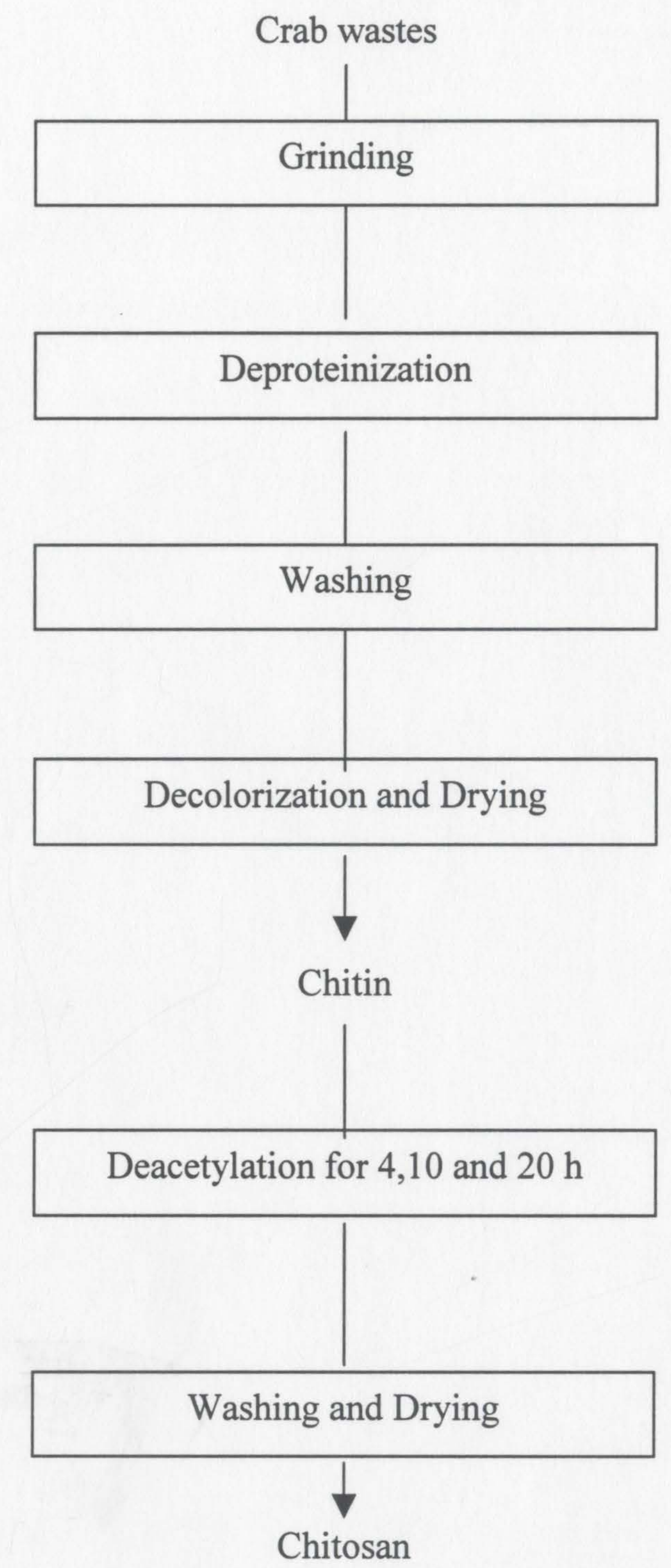

Type 1, Type 2 and Type 3 
completely. The bound picric acid was then quantitatively removed from the chitinchitosan a mino groups as subsequently d escribed. D iisopropylethylamine in m ethanol $(0.1 \mathrm{M}, 1.0 \mathrm{~mL})$ was introduced into the column and allowed to stand for $30 \mathrm{~min}$ and then eluted with methanol. The concentration of DIPEA-picrate in the eluate was measured at $358 \mathrm{~nm}$ using a Hewlett-Packard diode array spectrophotometer (Model 8452A, Agilent Technologies, Wilmington, DE). A standard curve was prepared using different concentrations of DIPEA-picrate salt in methnolic solutions (Figure A1 in appendix). The fraction of amino groups acetylated (degree of $\mathrm{N}$-acetylation, da) was calculated using the formula $\mathrm{da}=\mathrm{m}-161 \mathrm{n} / \mathrm{m}+42 \mathrm{n}$ where, $\mathrm{m}=$ mass of chitosan sample $(\mathrm{mg})$, $\mathrm{n}=$ mmoles of picric acid eluted from sample, $161 \mathrm{Da}=$ molecular weight of $\mathrm{D}$ glucosamine unit, and $42 \mathrm{Da}=$ molecular weight of $N$-acetyl-D-glucoamine less the molecular weight of D-glucosamine.

The molecular weight of chitosan was expressed as the viscosity molecular weight (Mv) using a ViscoTek model Y-500 relative viscometer (Viscotek Co., Houston, TX). Chitosan solution in $0.1 \mathrm{M}$ acetic acid- $0.2 \mathrm{M}$ sodium chloride was diluted to give four concentrations ranging from 0.05 to $2 \mathrm{~g} / \mathrm{L}$, which were used for determination of specific viscosity $\left(\eta_{\mathrm{sp}}\right)$ at $25^{\circ} \mathrm{C}$. Specific viscosity was determined as follows:

$\eta_{s p}=\left(\eta-\eta_{s}\right) / \eta_{s}$, where $\eta$ and $\eta_{s}$ are the solution and the solvent viscosity, respectively. The values of intrinsic viscosity $(\eta)$, of a liner chain polymer such as chitosan depends on the molecular weight $\left(\mathrm{M}_{\mathrm{w}}\right)$ described by the Mark-Houwink equation, where " $\mathrm{K}$ " and "a" are constants; $[\eta]=\mathrm{Km}_{\mathrm{w}}{ }^{\mathrm{a}}$ (Roberts, 1992). 


\subsubsection{Metal chelation capacity of chitosan}

Three different types of chitosan flakes (Type 1, Type 2 and Type 3) were used. Ethylenediaminetetraacetic acid was used as a reference chelating agent. For determination of metal chelation capacity, $\mathrm{Fe}^{2+}, \mathrm{Co}^{2+}, \mathrm{Ni}^{2+}, \mathrm{Mn}^{2+}, \mathrm{Cu}^{2+}, \mathrm{Zn}^{2+}$ and $\mathrm{Cd}^{2+}$ were selected. Each experiment was replicated three times.

Chitosan $(0.01 \mathrm{~g})$ was weighed into seven beakers and $100 \mathrm{~mL}$ of the solution containing $400 \mu \mathrm{M}$ metal ions were added separately. Metal solutions were prepared in hexamine- $\mathrm{HCl}$ buffer (pH 5) containing $10 \mathrm{mM} \mathrm{KCl}$. The metal ion-chitosan mixtures were held for $24 \mathrm{~h}$ and the supernatants of metal ions were collected at $0,1,3,6$ and $24 \mathrm{~h}$, respectively. At the same time EDTA and metal ion mixtures were kept for $24 \mathrm{~h}$ and supernatant of metal ion mixtures were collected at $0,1,2,3,6$ and $24 \mathrm{~h}$, respectively. Tetramethymurexide (TMM, 1mM) as an indicator was dissolved in hexamine- $\mathrm{HCl}$ buffer (pH 5) containing $10 \mathrm{mM} \mathrm{KCl}$. The metal ions in the supernatant were estimated using a colorimetric method (Asakura et al., 1990; Terasawa et al., 1991). These experiments were carried out at $\mathrm{pH} 6$ and 7.

The determination of chelation capacity of metal ions was carried out by the method described by Askura et al. (1990). To two millilitres of supernatant of metal ion solutions, $0.2 \mathrm{ml}$ of TMM were added. Absorbance was read at 460 and $530 \mathrm{~nm}$ using a the HP diode array spectrophotometer and absorbance ratios $\mathrm{A}_{460 \mathrm{~nm}} / \mathrm{A}_{530 \mathrm{~nm}}$ were calculated. The absorbance ratios were then converted to the corresponding free metal 
ion concentrations using a standard curve (Figure A2 in appendix to Figure A13). Metal ion chelating capacities of chitosans were calculated using the following equation.

Metal chelating capacity, $\%=\mathrm{C}_{\text {Initial }}-\mathrm{C}_{\text {Final }} \times 100$

$$
\mathrm{C}_{\text {Initial }}
$$

Where $\mathrm{C}_{\text {Initial }}$ and $\mathrm{C}_{\text {Final }}$ refer to the initial and final millimolar concentration of metal ion, respectively.

\subsubsection{Determination of heavy metals in waste water samples by inductively coupled plasma-mass spectrometry (ICP-MS)}

Samples of chitosan ( $0.01 \mathrm{~g}$ of Type 1, 2 and 3 ) were mixed with $50 \mathrm{~mL}$ industrial waste water (obtained from a zinc mining site in Buchans, NL) in centrifuge tubes. Industrial wastewater samples were adjusted at different $\mathrm{pH}$ levels

$(\mathrm{pH} \mathrm{5,6}$ and 7). The original wastewater sample was used as a control. Industrial wastewater sample-chitosan mixtures were held for $3 \mathrm{~h}$ at room temperature $\left(22^{\circ} \mathrm{C}\right)$. The contents were then centrifuged for $5 \mathrm{~min}$ at $4000 \mathrm{xg}$ (ICE Centra M5, International Equipment Co., Needham Heights, MA) and supernatants were collected. Supernatants were filtered through a $0.45 \mu \mathrm{m}$ filter (Millipore Corporation, Bedford, MA). The metal ions, namely $\mathrm{Co}^{2+}, \mathrm{Ni}^{2+}, \mathrm{Mn}^{2+}, \mathrm{Fe}^{2+}, \mathrm{Cu}^{2+}, \mathrm{Zn}^{2+}, \mathrm{Cr}^{2+}, \mathrm{Pb}^{2+}, \mathrm{Ag}^{+}, \mathrm{Hg}^{2+}$ and $\mathrm{Mo}^{2+}$ were analyzed for residual metal concentrations using ICP-MS (HP 4500, Agilent). The concentrations of the aforementioned metal ions in the original industrial wastewater were separately analyzed using ICP-MS as a control. 
Before the samples were introduced to the ICP-MS, supernatants were acidified with $\mathrm{HNO}_{3}$ and (one litre water sample should have $25 \mathrm{~mL}$ of $8 \mathrm{M} \mathrm{HNO}_{3}$ acid added to it) rinsed with ultra pure water.

The HP 4500 ICP-MS was used to acquire raw data from unknown water samples, known reference materials and calibration solutions. Water samples were diluted ten fold with approximately $0.2 \mathrm{M} \mathrm{HNO}_{3}$. Samples were introduced to the ICPMS via $10 \mathrm{~mL}$ test tubes arranged in a CETEC autosampler (Agilent, Palo Alto,CA). This enables automated runs of up to $30 \mathrm{~h}$ in length. Data was acquired for 39 elements, namely $\mathrm{Li}, \mathrm{Be}, \mathrm{Mg}, \mathrm{Al}, \mathrm{Si}, \mathrm{P}, \mathrm{S}, \mathrm{Cl}, \mathrm{Ca}, \mathrm{Ti}, \mathrm{V}, \mathrm{Cr}, \mathrm{Mn}, \mathrm{Fe}, \mathrm{Co}, \mathrm{Ni}, \mathrm{Cu}, \mathrm{Zn}, \mathrm{As}, \mathrm{Se}, \mathrm{Br}$, $\mathrm{Rb}, \mathrm{Sr}, \mathrm{Mo}, \mathrm{Ag}, \mathrm{Cd}, \mathrm{Sn}, \mathrm{Sb}, \mathrm{I}, \mathrm{Cs}, \mathrm{Ba}, \mathrm{La}, \mathrm{Ce}, \mathrm{Hg}, \mathrm{Ti}, \mathrm{Pb}, \mathrm{Bi}$ and $\mathrm{U}$. The data for elements used as internal standards were also acquired. Five calibration standards were analyzed and one blank per cycle was used for background correction. The blank was followed by 7 unknown and one water reference material ran as an unknown for quality control purposes. Raw data in counts per seconds (cps) format was exported from the ICP-MS data acquisition package for concentration calculation using inhouse created spreadsheet-based software. Matrix and drift correction was accomplished with the use of internal standards, which were continuously added to the sample introduction system via online dilution. All standards were prepared using ICP standard solutions (SCP Science, St. Laurent, PQ for elements of interested. High purity distilled acids were used to dilute these standards to required concentrations. All limits of detection (LOD) for elements of interested were quoted at the ppb $(\mu \mathrm{g} / \mathrm{kg})$ levels. Table 3.1 shows the LOD of elements for ICP-MS. 
For ICP-MS, A r w as u sed as the plasma carrier and a uxiliary gas with sample uptake and a rate of $1 \mathrm{~mL} / \mathrm{min}$ was employed. A sample acquisition time of $579.79 \mathrm{~s}$ with rinse time of $180 \mathrm{~s}\left(0.5 \mathrm{M} \mathrm{HNO}_{3}\right), 10 \mathrm{~s}$ integration time, and one repetition were employed.

3.2.6 Metal chelation capacity and recovery of metals from aqueous solutions using small-sized columns containing chitosan by ICP-MS

Removal and recovery of metal ions from aqueous solutions was done according to a modified version of the method explained by Chui et al. (1996).

\subsubsection{Column preparation}

Ten grams of chitosan (Type 1) were taken into a $500 \mathrm{~mL}$ beaker containing 200 $\mathrm{mL}$ of deionized water $(\mathrm{pH} 7)$. The mixture was stirred for $24 \mathrm{~h}$ at ambient temperature. The pre-soaked chitosans were packed into five glass columns $(15 \mathrm{~cm} \times 0.9 \mathrm{~cm})$.

\subsubsection{Metal chelation and recovery of single metals from aqueous solutions}

Samples of 50ppm and 100ppm of $\mathrm{Ni}^{2+}, \mathrm{Co}^{2+}, \mathrm{Cd}^{2+}, \mathrm{Cu}^{2+}$ and $\mathrm{Ag}^{+}$prepared by dissolution in $\mathrm{pH} 7$ deionized water from the corresponding salt Ten millilitres of metal ion solutions were eluted from each separate column at neutral $\mathrm{pH}$ at a rate of $2 \mathrm{~mL} / \mathrm{min}$, and at room temperature $\left(22^{\circ} \mathrm{C}\right)$. Twenty millilitres of deionized water $(\mathrm{pH} 7)$ were passed through each column to wash the remaining metal ions, and the eluate was collected. The 
Table 3.1 Limit of detection of elements for ICP-MS.

\begin{tabular}{ll}
\hline Element & Limit of detection, ppb \\
\hline $\mathrm{Ag}$ & 0.09 \\
$\mathrm{As}$ & 2.00 \\
$\mathrm{Cd}$ & 0.04 \\
$\mathrm{Co}$ & 0.03 \\
$\mathrm{Cr}$ & 0.08 \\
$\mathrm{Cu}$ & 0.02 \\
$\mathrm{Fe}$ & 0.03 \\
$\mathrm{Hg}$ & 1.00 \\
$\mathrm{Mn}$ & 0.02 \\
$\mathrm{Mo}$ & 0.03 \\
$\mathrm{Ni}$ & 0.10 \\
$\mathrm{~Pb}$ & 0.30 \\
$\mathrm{Zn}$ & 1.00 \\
\hline
\end{tabular}


combined eluates were used for ICP-MS analysis. Ten millilitres of a $0.1 \mathrm{M}$ solution of EDTA were used to desorb each metal ion from the column and the eluate was collected again. Twenty millilitres of deionized water were passed through the column to wash the remaining EDTA, and the eluate was collected. The amount of metal ions recovery in the eluate was similarly determined by ICP-MS using the procedure given in section 3.2.5. Metal chelation capacity and recovery values were then calculated.

\subsubsection{Metal chelation and recovery of multiple metals from aqueous solution}

Samples of 50 and $100 \mathrm{ppm}$ of each of $\mathrm{Ni}, \mathrm{Co}, \mathrm{Cd}, \mathrm{Cu}$ and $\mathrm{Ag}$ metal ion mixture was dissolved in $\mathrm{pH} 7$ deionized water. Metal chelation capacity and recovery values were calculated using the method described in section 3.2.5.

\subsubsection{Determination of protein flocculation by chitosans}

Three types of chitosan (Type 1, Type 2 and Type 3) were selected in this experiment.

\subsubsection{Preparation of columns}

The c olumn p reparation $\mathrm{w}$ as d one as described in s ection 3.2.6.2. T hree glass columns were used for protein flocculation and the dimensions of each column was $4 \mathrm{~cm}$ x $0.9 \mathrm{~cm}$. The experiment was carried out in triplicate. 


\subsubsection{Determination of protein flocculation of chitosan}

Bovine serum albumin (BSA) was dissolved in deionized water to obtain different concentrations $(2-8 \mathrm{mg} / \mathrm{mL})$. Solutions of BSA were passed through the three chitosan columns at a flow rate of $12 \mathrm{~m} \mathrm{~L} / \mathrm{min}$ and $5 \mathrm{~mL}$ of eluted solutions were collected in three glass tubes. The content of protein in each tube was measured using the method described by Lowry et al. (1951).

\subsubsection{Determination of protein by Lowry's method}

Reagents $\mathrm{A}, \mathrm{B}$ and $\mathrm{C}$ were prepared as follows: for reagent $\mathrm{A}, \mathrm{Na}_{2} \mathrm{CO}_{3}$ was dissolved in $0.1 \mathrm{M} \mathrm{NaOH}$ to obtain a $2 \%(\mathrm{w} / \mathrm{v})$ solution; for reagent $\mathrm{B}, \mathrm{CuSO}_{4}$ was dissolved in $1 \%(\mathrm{w} / \mathrm{v})$ sodium tartarate to obtain a $0.5 \%(\mathrm{w} / \mathrm{v})$ solution; and reagent $\mathrm{C}$ was prepared by using $50 \mathrm{~mL}$ of solution A with $1 \mathrm{~mL}$ of solution $\mathrm{B}$.

Three millilitres of reagent $\mathrm{C}$ were transferred to a glass tube. The sample $(0.3 \mathrm{~mL})$ was added to the glass tube and shaken vigorously. Lowry's solution $(0.3 \mathrm{~mL}$; half diluted Folin \& Ciocalteu's phenol reagent) was added and it was shaken vigorously. The mixtures were kept for $20 \mathrm{~min}$ at ambient temperature. Absorbance of the mixture was read at $660 \mathrm{~nm}$. Analytical linearity range of the Lowry's method was $10 \mu \mathrm{g}$ to 1.00 mg protein (Lowry et al., 1951). Working standards (Figure A14) were prepared using BSA at concentration ranging between 50 and $700 \mu \mathrm{g} / \mathrm{mL}$. 


\subsubsection{Statistical analysis}

All experiments in this study were replicated at least three times. Data were reported as mean \pm standard deviation (SD). Analysis of variance (ANOVA) was performed and differences in mean values determined using Tukey's studentized range test at $\mathrm{p}<0.001$ or 0.05 and employing ANOVA and least significance difference procedures of statiatical analysis system (Snedecor and Cochran, 1980; SAS, 1990). A simple linear regression was also performed using the same software in the general linear model. 


\section{CHAPTER 4 RESULTS AND DISCUSSION}

\subsection{Suitability of chemical treatments for extending the shelf life of crab processing discards}

The effectiveness of methods and storage conditions to control fish and shellfish spoilage depends largely on the mechanisms involved. Thus, an understanding of postmortem biochemical changes in fish and shellfish and their relationship with various factors and spoilage mechanisms involved is essential in order to formulate and rationalize effective strategies for controlling deterioration processes (Ashie et al., 1996).

Shellfish processing discards pose major technological problems, as shells are largely water insoluble and very resistant to natural biodegradation (Healy et al., 1994). The scrapped exoskeletons and other parts of processed shellfish such as American lobster (Homarus americanus), snow crab (Chinocetes opilio) and shrimp (Pandalus borealis) constitute $30-80 \%$ of their total weights. The processing discards from the crustacean industry are mainly shells, viscera, heads and adhered meat. The major components of shells are proteins, chitin and minerals, as well as small amounts of flavourant proteins and c arotenoid pigments (Shahidi et al., 1992; Hansen and Illanes, 1994; Ferrer et al., 1996). Direct use of the crab waste for land manuaring or spreading is generally discouraged by the uniquely obnoxious odours of putrefying shells.

When the wastes are buried or land filled decomposition of the fresh wastes occurs under the anaerobic conditions that generate particularly malodorous compounds. Anaerobic composting of fish wastes therefore poses problems of smell, transport, 
application and aesthetic utilization without adverse environmental impacts. The impacts may be mainly d ue to most of the nitrogen in the product b eing in forms that $\mathrm{c}$ an be easily volatilized or washed away, not in the form of the stable humus that is generated by aerobic composting (Hayes et al., 1994). Low technology land burial and open surface dumping of seafood wastes is likely to be prohibited and regulations enforced in more and more jurisdictions, due to the nuisances of malodours and scavengers, and the eventual c ontamination of s urface and g round water (Hayes et a l., 1994). In order to prevent development of putrefying odours and extend shelf-life, five chemical spraying treatments of crab processing discards were employed. The chemical treatments were $1 \%$ $(\mathrm{v} / \mathrm{v})$ solutions of formaldehyde, formic acid, acetic acid, sodium hydroxide and sodium bicarbonate.

Crab processing discards, which had been treated with all five treatments and the control, remained acceptable up to 5 days of storage under the cold room temperatures $\left(4-7^{\circ} \mathrm{C}\right)$ without developing any putrefying odour. Acceptability percentage was calculated based on the scores given by the panelists for the first three categories; that is, excellent, good and moderate, in terms of odour (Table A1 in appendix). Acceptability percentage was calculated by adding these three catagories (Acceptability $\%=$ Excellent $\%$ + Good $\%$ +Moderate\%). Formaldehyde- and formic acid-treated samples could be kept for 11 days and 7 days, respectively, without any foul smell developing (Table 4.1 and Table A2 in appendix). After 14 days all treatments were unable to prevent the development of putrefying odours. The efficiency of treatments was, however, in following order. 
formaldehyde $>$ formic acid $>\mathrm{NaHCO}_{3}>$ acetic acid $>\mathrm{NaOH}>$ Control

According to Table 4.2 and Table A2 in the appendix, crab waste treated with all five treatments as well as the control could be kept for only 2-3 days at room temperature $\left(20-25^{\circ} \mathrm{C}\right)$ without developing any putrefying odour. Formaldehyde- and formic acidtreated s amples, h owever, c ould b e kept for 3 and 2 days, r espectively. T he order of efficiency of other treatments was as follows:

formaldehyde $>$ formic acid $>$ acetic acid $>\mathrm{NaHCO}_{3}>\mathrm{NaOH}>$ Control

Foul odour is produced mainly due to microbial activities and enzymatic degradation of crab meat residues attached to the shells. The volatile compounds produced are mainly alcohols, aldehydes, ketones and hydrocarbons (Pan and Kau, 1994). Microbial activities in crab wastes produce a number of odorous gases leading to an objectionable smell. Formaldehyde and formic acid can act as antimicrobial compounds and reduce microbial activity (Merck Index, 1996).

Low-temperature storage prevents spoilage or contaminating microorganisms from metabolizing, growing, and causing spoilage without necessarily killing them. The refrigeration process usually results in an initial reduction in the microbial population followed by a gradual decline during storage, with the survival of spoilage microorganisms (Ashie et al., 1996). Crab processing discards can be held longer at 4$7^{\circ} \mathrm{C}$ than $20-25^{\circ} \mathrm{C}$. 
Table 4.1 Sensory evaluation ${ }^{1}$ of crab processing discards treated with different reagents and stored at $4-7^{\circ} \mathrm{C}$.

\begin{tabular}{lllllll}
\hline & \multicolumn{5}{c}{ Treaments $^{2}$} \\
\hline $\begin{array}{l}\text { Storage } \\
\text { time, days }\end{array}$ & Formaldehyde & $\begin{array}{l}\text { Formic } \\
\text { acid }\end{array}$ & Acetic acid & $\begin{array}{l}\text { Sodium } \\
\text { bicarbonate }\end{array}$ & $\begin{array}{l}\text { Sodium } \\
\text { hydroxide }\end{array}$ & Control \\
\hline 0 & 100 & 100 & 100 & 100 & 100 & 100 \\
1 & 100 & 100 & 100 & 100 & 100 & 100 \\
2 & 100 & 100 & 100 & 100 & 100 & 100 \\
3 & 100 & 100 & 100 & 100 & 100 & 100 \\
4 & 100 & 100 & 100 & 100 & 100 & 100 \\
5 & 100 & 100 & 100 & 100 & 100 & 100 \\
6 & 100 & 100 & 100 & 43 & 100 & 43 \\
7 & 100 & 100 & 57 & 57 & 57 & 29 \\
8 & 100 & 71 & 29 & 43 & 0 & 0 \\
9 & 100 & 29 & 0 & 0 & 0 & 0 \\
10 & 100 & 0 & 0 & 0 & 0 & 0 \\
11 & 100 & 0 & 0 & 0 & 0 & 0 \\
12 & 71 & 0 & 0 & 0 & 0 & 0 \\
13 & 29 & 0 & 0 & 0 & 0 & 0 \\
14 & 0 & 0 & 0 & 0 & 0 & 0 \\
\hline
\end{tabular}

${ }^{1}$ Number of untrained panelists $=7$

(Acceptability $\%=$ Excellent $\%+$ Good $\%+$ Moderate $\%$ )

${ }^{2}$ Treatments were applied to crab processing discards at a $1 \%(\mathrm{v} / \mathrm{v})$ level. 
Table 4.2 Sensory evaluation ${ }^{1}$ of crab processing discards treated with different reagents and stored at $20-25^{\circ} \mathrm{C}$.

\section{${ }^{2}$ Treatments}

\begin{tabular}{lllllll}
\hline $\begin{array}{l}\text { Storage } \\
\text { Time, days }\end{array}$ & Formaldehyde & $\begin{array}{l}\text { Formic } \\
\text { acid }\end{array}$ & Acetic acid & $\begin{array}{l}\text { Sodium } \\
\text { bicarbonate }\end{array}$ & $\begin{array}{l}\text { Sodium } \\
\text { hydroxide }\end{array}$ & Control \\
\hline 0 & 100 & 100 & 100 & 100 & 100 & 100 \\
1 & 100 & 71 & 71 & 58 & 58 & 29 \\
2 & 86 & 43 & 0 & 0 & 0 & 0 \\
3 & 14 & 0 & 0 & 0 & 0 & 0 \\
4 & 0 & 0 & 0 & 0 & 0 & 0 \\
\hline
\end{tabular}

${ }^{1}$ Number of untrained panelists $=7$

(Acceptability \% = Excellent $\%$ + Good $\%$ + Moderate $\%$ )

${ }^{2}$ Treatments were applied to crab processing discards at a $1 \%(\mathrm{v} / \mathrm{v})$ level. 
Although samples treated with formaldehyde were best in terms of off-odour prevention at both $4-7^{\circ}$ and $20-25^{\circ} \mathrm{C}$, formaldehyde may act as a carcinogen (Merck Index, 1996). Most adults react to formaldehyde at a concentration of 0.5 to $1.5 \mathrm{ppm}$ in the air. Infants, the elderly, those with specific allergic reactions, and individuals with respiratory problems may react to even lower levels. Symptoms of formaldehyde exposure include nausea, vomiting, abdominal pain, or diarrhea (Merck Index, 1996). When the reaction is allergic, symptoms may include minor respiratory irritation and watery eyes. Extreme cases of exposure or chronic exposure has been linked to respiratory cancer (Sittig, 1991).

According to the current Occupational Safety and Health Administration (OSHA, 2001), the permissible exposure limit (PEL) for formic acid is $5 \mathrm{ppm}$ in the air. Inhalation of formic acid results in coughing and bronchitis. Extensive exposure can produce depression of the central nervous system, severe metabolic acidosis and nephropathy (Seiler et al., 1988).

\subsection{Proximate analysis of crab wastes and isolation of chitin}

The chemical composition of crab (C. opilio) processing discards is crude protein, $21.5 \pm 0.53 \%$; ash, $43.7 \pm 0.1 \%$; lipid, $0.35 \pm 0.1 \%$ and chitin $35.3 \pm 1.9 \%$ (all measurements are in dry weight basis). Crab processing discards comprise a composite of $\mathrm{d}$ ried $\mathrm{w}$ aste of $\mathrm{s}$ hell, $\mathrm{c}$ ephalathrorax, legs and $\mathrm{claws.}$ Non-chitinous p rotein $\mathrm{w}$ as the main component which should be removed effectively to obtain a high quality chitin (Austin et al., 1981). For isolation of chitin, a deproteinization step was included 
followed by demineralization to remove inorganic matters. Crab processing discards were ground and treated with $4 \%(\mathrm{w} / \mathrm{v}) \mathrm{NaOH}$ at a solid-to-solvent ratio of $1: 20(\mathrm{w} / \mathrm{v})$ at elevated temperatures $\left(65-100^{\circ} \mathrm{C}\right)$ for $3 \mathrm{~h}$ in order to dissolve the protein present, similar to that used by No and Mayers (1995). Prolonged alkaline treatment under severe conditions causes depolymerization and deacetylation of chitin (No and Mayers, 1995). Demineralization was accomplished by extraction with $10 \%(\mathrm{v} / \mathrm{v}) \mathrm{HCl}$ solution at a solidto-solvent ratio of $1: 10(\mathrm{w} / \mathrm{v})$ at room temperature for $2 \mathrm{~h}$ in order to dissolve calcium salts, similar to that used by No et al. (1989) and No and Mayers (1995). A prolonged demineralization time of $24 \mathrm{~h}$ resulted in only a very slight drop in the ash content, but this can cause polymer degradation (Brzeski, 1982). For demineralization, it is important that the amount of acid be stoichiometrically equal or greater than all minerals present in the shells to ensure complete reaction with inorganic salts (Shahidi and Synowiecki, 1991). Acid and alkali treatments may produce a coloured chitin product because of the carotenoids remaining in the preparations. When a bleached chitinous product is desired, pigments can be removed using appropriate solvents (No and Mayers, 1995). Chitin was treated with acetone at a 1:20 (w/v) solid-to-solvent ratio and dried at ambient temperature, followed by bleaching with $0.32 \%$ sodium hypochlorite. No et al. (1989) prepared a white coloured crawfish chitin using an acetone wash, followed by bleaching with $0.315 \%(\mathrm{v} / \mathrm{v})$ sodium hypochlorite. The yield of chitin from crab processing discards was 27.8\%. Austin et al. (1981) and Shahidi and Synowiecki, (1991) reported isolation of $14-30 \%$ chitin from crab processing discards. 


\subsection{Production and characteristics of chitosan extracted from crab processing discards}

Chitosan was prepared by alkali treatment of chitin using a 1:10 (w/v) solid-tosolvent ratio of $50 \%$ (w/v) sodium hydroxide in distilled water at $100^{\circ} \mathrm{C}$ for 4,10 and $20 \mathrm{~h}$ under a nitrogen atmosphere (Mima et al., 1983). According to the length of deacetylation time, three types of chitosan were obtained (Types 1, 2 and 3 ). The degree of deacetylation was $86.4,89.3$, and $91.3 \%$ for chitosans prepared from chitin under deacetylation times of 4,10 , and $20 \mathrm{~h}$, respectively. The large positive charge density due to the high degree of deacetylation (86.4-91.3\%) makes crab chitosan unique for industrial applications, because chitosan properties are highly dependent on charge density. Li et al. (1992) and Muzzarelli (1985) reported that the term chitosan could be used only when the degree of d eacetylation is a bove $70 \%$ and nitrogen content in the product is higher than $7 \%$ by weight. Table 4.3 shows that the viscosity average molecular weight $\left(\mathrm{M}_{\mathrm{v}}\right)$ of chitosan decreased with increasing deacetylation time. However, a very high deacetylation rate of chitin polymers was not observed in this study by increasing the deacetylation time from 10 to $20 \mathrm{~h}$. The procedure used for deacetylation in this investigation was similar to that of Mima et al. (1983) who produced $96 \%$ deacetylation with alkali treatment at $110^{\circ} \mathrm{C}$.

Characteristics of chitosans prepared with different deacetylation times are presented in Table 4.3. P reparation of chitosan samples (Types 1, 2 and 3 ) $\mathrm{shown}$ in Table 4.3 involved deacetylation of $\mathrm{chitin}$ for 4,10 and $20 \mathrm{~h}$. T he chitosans p repared from the snow crab processing discards showed variations in their viscosity which seem 
to be closely related to the d uration of d eacetylation time. $\mathrm{T}$ he highest $\mathrm{v}$ iscosity was observed when deacetylation was carried out for $4 \mathrm{~h}$, followed by those prepared over a 10-20 $\mathrm{h}$ period. As shown in Table 4.3, the nitrogen contents of chitosans were dependent on deacetylation time and were $7.52,7.64$ and $7.73 \%$ respectively, for samples prepared over 4,10 , and $20 \mathrm{~h}$, confirming a more effective deacetylation over longer periods. The corresponding apparent viscosity values were 360,57 , and $14 \mathrm{cP}$.

As shown in T able 4.3 there $\mathrm{w}$ as a substantial difference in molecular weights measured by the viscometric method for Types 1,2 and 3 chitosan. The Type 1 chitosan prepared upon deacetylation for $20 \mathrm{~h}$ had a molecular weight 1.45 times lower than that of the Type 2 product prepared over a $10 \mathrm{~h}$ period. These molecular weight differences were less than those observed for viscosity values. The molecular weight was not linearly related to viscosity. Since both the viscosity and molecular weight were determined in solution, all observations made were based on solution behaviour of chitosan types. Viscometry is one of the simplest and most rapid methods for determining the reactive molecular weights of polymers, although it is not an absolute method (Maghami and Roberts, 1988). Furthermore, Maghami and Roberts (1988) observed that viscometric constants " $\mathrm{K}_{\mathrm{m}}$ " and " $\mathrm{a}$ " in the Mark-Houwink equation remained uncharged for a series of chitosans with $N$-acetyl contents of $0-40 \%$. 
Table 4.3 Characteristics of three different types of chitosans (Types 1,2 and 3) prepared from crab shells ${ }^{a}$.

\begin{tabular}{lccc}
\hline Properties & Type 1 & Type 2 & Type 3 \\
\hline Deacetylation time ${ }^{b}(\mathrm{~h})$ & 20 & 10 & 4 \\
Moisture (\%) & $3.75 \pm 0.21$ & $3.95 \pm 0.34$ & $4.50 \pm 0.30$ \\
Nitrogen (\%) & $7.70 \pm 0.19$ & $7.63 \pm 0.08$ & $7.55 \pm 0.10$ \\
Ash (\%) & $0.30 \pm 0.00$ & $0.25 \pm 0.02$ & $0.30 \pm 0.03$ \\
Colour & cream white & cream white & cream white \\
Apparent viscosity (cP) & $14.0 \pm 0.34$ & $57.0 \pm 0.96$ & $360 \pm 0.53$ \\
Degree of deacetylation (\%) & $91.3 \pm 1.3$ & $89.3 \pm 1.2$ & $86.4 \pm 2.1$ \\
Mv $^{c}$ (Dalton) & $6.60 \times 10^{5}$ & $9.60 \times 10^{5}$ & $1.80 \times 10^{6}$ \\
\hline
\end{tabular}

${ }^{a}$ Results are expressed as mean value of three determinations \pm standard deviation.

${ }^{b}$ Deacetylation for preparation of chitosans Types 1,2 and 3 was achieved using a $50 \%$ (w/v) $\mathrm{NaOH}$ solution at $100^{\circ} \mathrm{C}$ for 4,10 and $20 \mathrm{~h}$, respectively.

${ }^{c}$ Viscosity molecular weight 


\subsection{Metal chelation capacity of chitosans determined by a colourimetric method}

The chemical definition of metal chelation can be defined as firm binding of metal ions with an organic molecule (ligand), which gives a ring structure (Muzzarelli, 1977). The resulting ring structure protects the mineral from entering into unwanted chemical reactions. Capacity of adsorption of metal ions expressed as a percentage is referred to as chelation capacity.

Tetramethylmurexide (TMM) is a chelating agent with an absorption maximum at $530 \mathrm{~nm}$. However, shifting of the absorption maximum to $460 \mathrm{~nm}$ occurs when metal ions are chelated by tetramethylmurexide (Figure 4.1). The ratio of absorbance at 460 $\mathrm{nm}$ to that at $530 \mathrm{~nm}$ is linearly correlated with the metal ion concentration (Askura et al.,1990). When a known concentration of metal ion is added to a buffered solution of chitosan, some of the metal ions chelates with chitosan while leaving any untreated or free metal ion in the solution. When TMM is added to the solution, it chelates the remaining metal ions, and the characteristic absorbance maximum shifts from $530 \mathrm{~nm}$ to $460 \mathrm{~nm}$. The untreated metal ions can then be determined from the calibration line and the concentration of metal ions chelated by chitosan is calculated by subtracting the free ion concentration from that initially present (Askura et al., 1990) (Table A3-A5 in appendix). The slope of the standard curve became sharp as the $\mathrm{pH}$ of the system increased, because high $\mathrm{pH}$ conditions favour TMM-metal complex formation. The reason for using the hexamine buffer system in this study was due to the weak interaction of hexamine with metallic ions, which would be advantageous to the stability of the metal ligand complex (Kohn and Furda, 1967). The metal chelation capacity depends on the 
type of chitosan (e.g. Type 1, 2 or 3 ) $\mathrm{pH}$, reaction time and the metal type at its initial concentration.

\subsection{1 $\mathrm{pH}$ of the solution}

According to the metal chelation capacity values at $\mathrm{pH} 5$, all three types of chitosan tested showed the same chelation pattern (Type $1>$ Type $2>$ Type 3 ) for $\mathrm{Zn}^{2+}$, $\mathrm{Cu}^{2+}, \mathrm{Fe}^{2+}$ and $\mathrm{Cd}^{2+}$ while $\mathrm{Ni}^{2+}, \mathrm{Mn}^{2+}$ and $\mathrm{Co}^{2+}$ showed different patterns. Metal chelation capacities at $\mathrm{pH} 6$ for $\mathrm{Zn}^{2+}, \mathrm{Ni}^{2+}, \mathrm{Fe}^{2+}$ and $\mathrm{Mn}^{2+}$ showed the same pattern (Type1 > Type $2>$ Type 3 ) at $6 \mathrm{~h}$, while $\mathrm{Cu}^{2+}, \mathrm{Co}^{2+}$ and $\mathrm{Cd}^{2+}$ showed different patterns. However, there was no significant difference $(p<0.05)$ between the three types of chitosan at $3 \mathrm{~h}$ except for $\mathrm{Fe}^{+2}$. Considering $\mathrm{pH} 7, \mathrm{Co}^{+2}$ and $\mathrm{Zn}^{+2}$ showed the highest chelation capacity at $3 \mathrm{~h}$ (Type 1 chelation capacity was higher than those of types 2 and 3). Chelation capacity of the three types of chitosan chelators were significantly different $(p \leq 0.05)$ from that of EDTA.

Generally, the adsorption of metal ions by chitosans is expected to be $\mathrm{pH}$ sensitive (Roberts, 1992). Adsorption of $\mathrm{Zn}^{2+}, \mathrm{Cu}^{2+}, \mathrm{Cd}^{2+}, \mathrm{Co}^{2+}, \mathrm{Ni}^{2+}, \mathrm{Fe}^{2+}$ and $\mathrm{Mn}^{2+}$ on chitosan flakes in solutions was studied at three $\mathrm{pH}$ levels (Figure 4.2 - Figure 4.8). The uptake of metal ions by chitosan showed a decrease as the $\mathrm{pH}$ increased from 5 to 7 . This could be due to the $\mathrm{pH}$ dependance of complex formed between chitosan and metals and the $\mathrm{pH}$ complex formation of the remaining metal ions and TMM, which was also $\mathrm{pH}$ dependent. Some researchers have observed that $\mathrm{pH} 5$ is best for metal chelation $\left(\mathrm{Cu}^{2+}\right.$ 
Figure 4.1 The binders of $\mathrm{Cu}^{2+}$ by tetramethylmurexide. Adapted from Terasawa et al. (1991) 


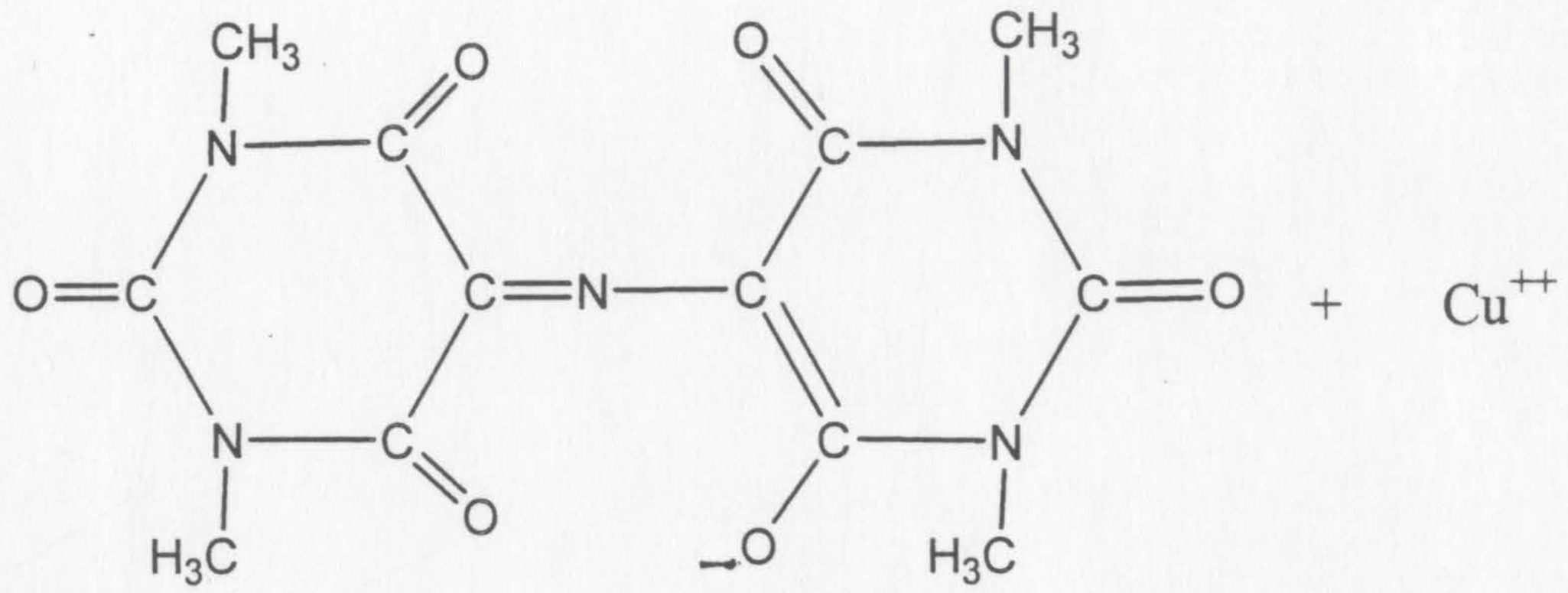

Tetramethylmurexide

$530 \mathrm{~nm}$ (purple)

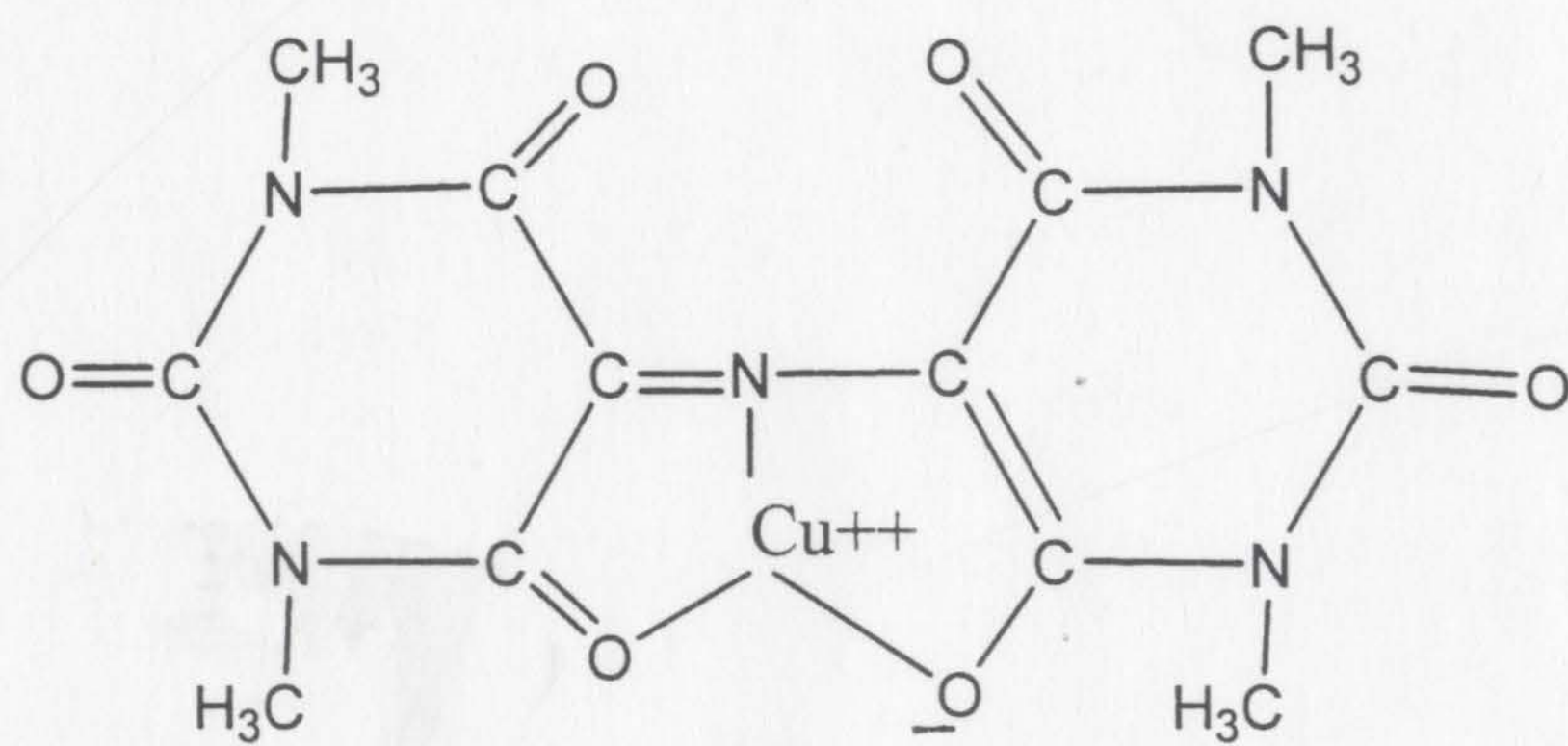

Tetramethylmurexide $-\mathrm{Cu}^{++}$

$480 \mathrm{~nm}$ (orange) 
$\mathrm{Zn}^{2+}$ and $\mathrm{Fe}^{2+}$ ) of plant phenolic compounds using the TMM method (Asakura et al., 1990; Terasawa et al., 1991; Wettasinghe and Shahidi, 2002). Bassi et al. (2000) observed that the uptake of metal ions by chitosan increased as the $\mathrm{pH}$ rose from 4 to 7 using atomic absorption spectrophotometry. This could be due to the better availability of amino groups at higher $\mathrm{pH}$ values. The reduced adsorption of metal ions under acidic $\mathrm{pH}$ conditions could be attributed to the fact that at a lower $\mathrm{pH}$, the metal ions that would coordinate with the lone pair electrons of nitrogen would have to compete with $\mathrm{H}_{3} \mathrm{O}^{+}$for an active site (Jha et al., 1988). Muzzarelli and Tubertini (1969) observed a decrease in the uptake capacity for many metal ions by chitin and chitosan when solution $\mathrm{pH}$ decreased from 7 to 2.5 . However, hexavalent chromium uptake by chitosan decreased as the $\mathrm{pH}$ increased from 3 to 5 (Udaybhaskar et al., 1990). The correspondence between rising $\mathrm{pH}$ and adsorption of metal ions was not found above $\mathrm{pH}$ 7. The experimentally observed decrease in metal removal at higher $\mathrm{pH}$ values may be explained by rapid changes in protonated and unprotonated forms of chitosan (Udaybhaskar et al., 1990). According to Bassi et al. (2000), the maximum decrease in the uptake of metal ions was found at $\mathrm{pH} 6$ and 7, but when using a colourimetric method, the maximum decrease of metal ions was found at $\mathrm{pH} 5$.

\subsubsection{Reaction time}

The chitosan used reduced the concentration of metal ions regardless of the contact time. However, changing the contact time between chitosan and metal ions had a significant $(p \leq 0.05)$ effect on the chelation capacity of chitosans. The maximum chelation capacity was achieved at $\mathrm{pH} 5$ by all three types of chitosan upon $6 \mathrm{~h}$ standing 
Figure 4.2 Metal chelation capacity of $\mathrm{Cd}^{2+}$ by chitosans and EDTA under three different $\mathrm{pH}$ conditions over time. 

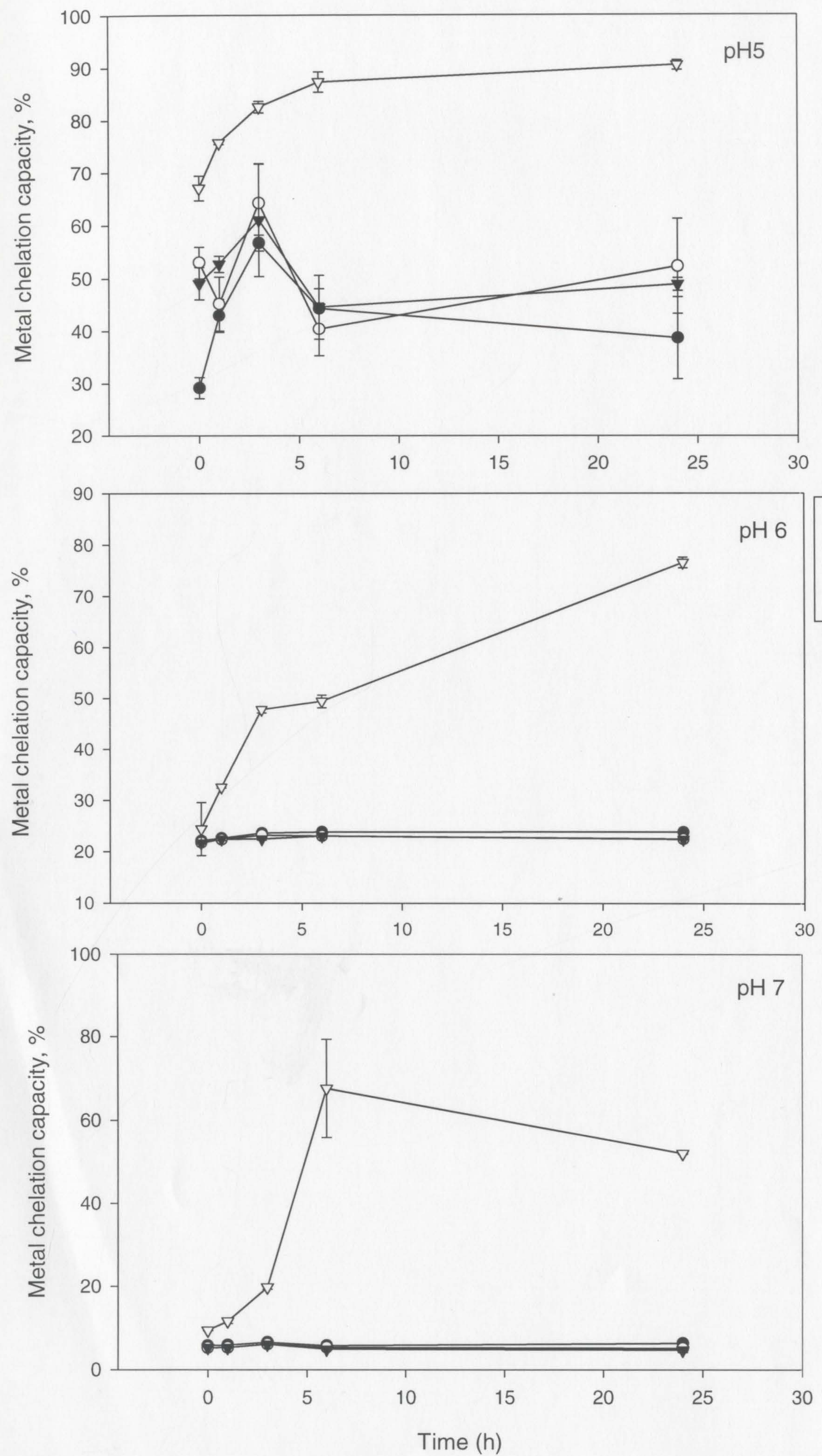
Figure 4.3 Metal chelation capacity of $\mathrm{Co}^{2+}$ by chitosans and EDTA under three different $\mathrm{pH}$ conditions over time. 

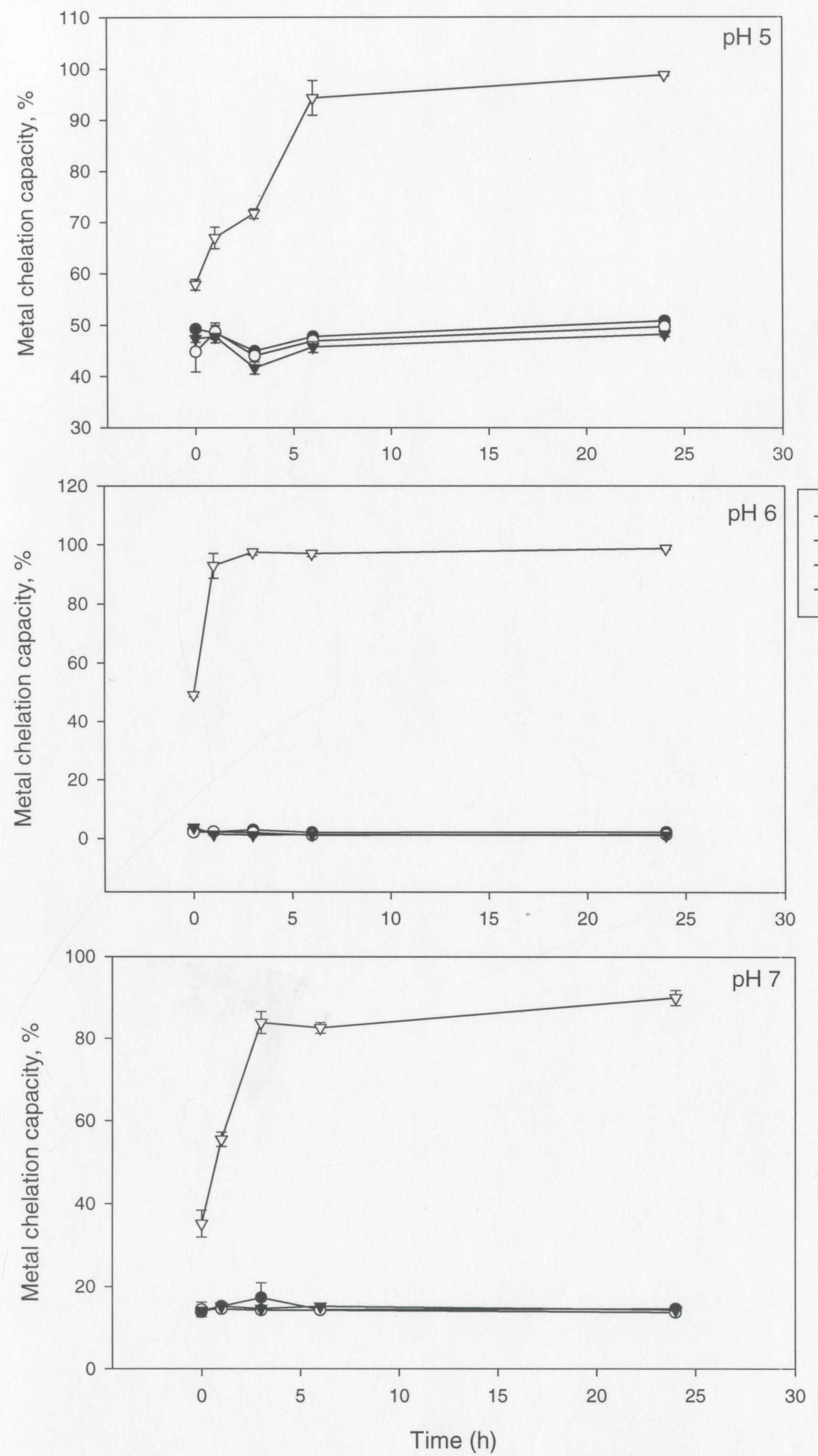
Figure 4.4 Metal chelation capacity of $\mathrm{Cu}^{2+}$ by chitosans and EDTA under three different $\mathrm{pH}$ conditions over time. 

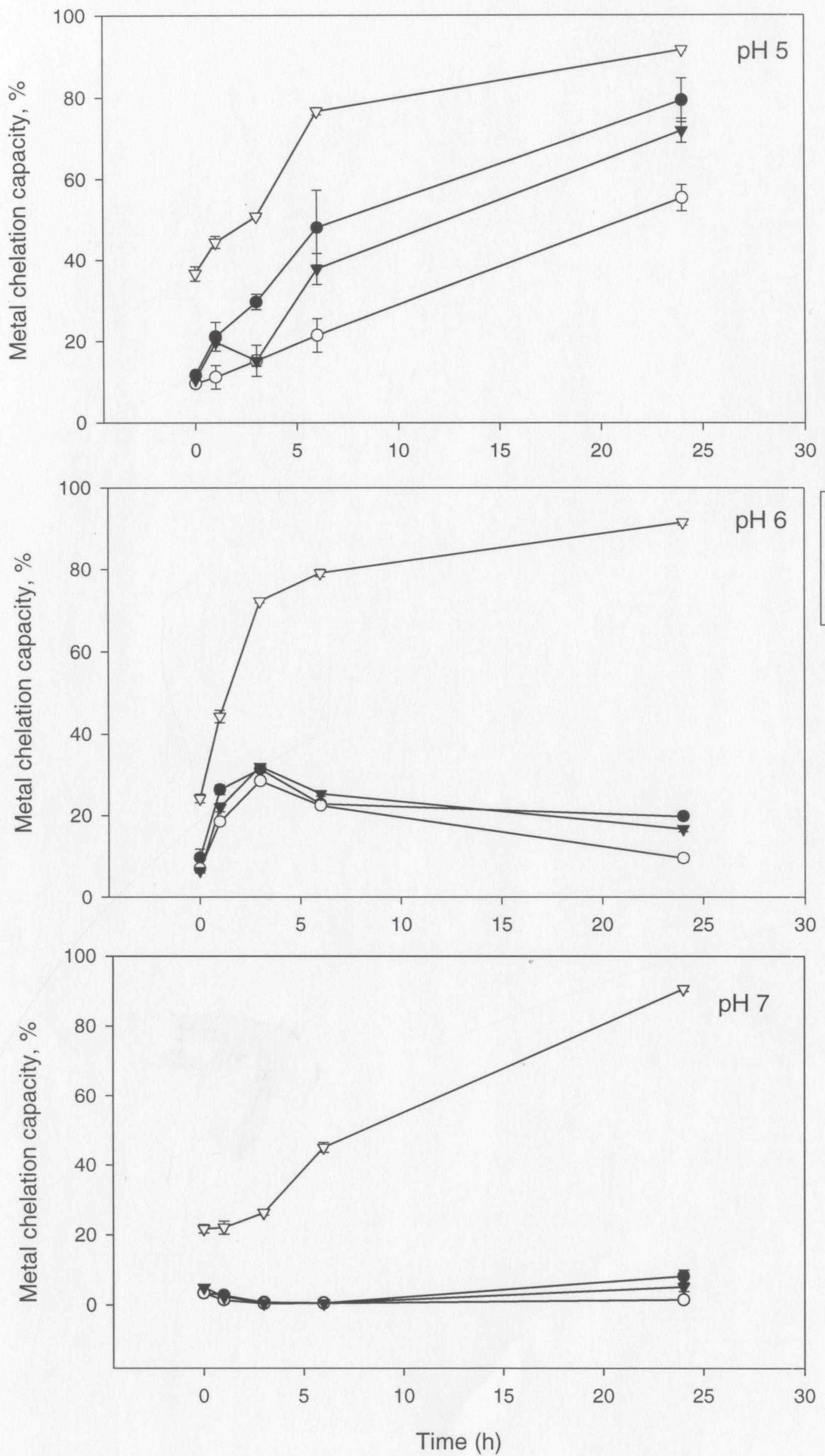
Figure 4.5 Metal chelation capacity of $\mathrm{Fe}^{2+}$ by chitosans and EDTA under three different $\mathrm{pH}$ conditions over time. 

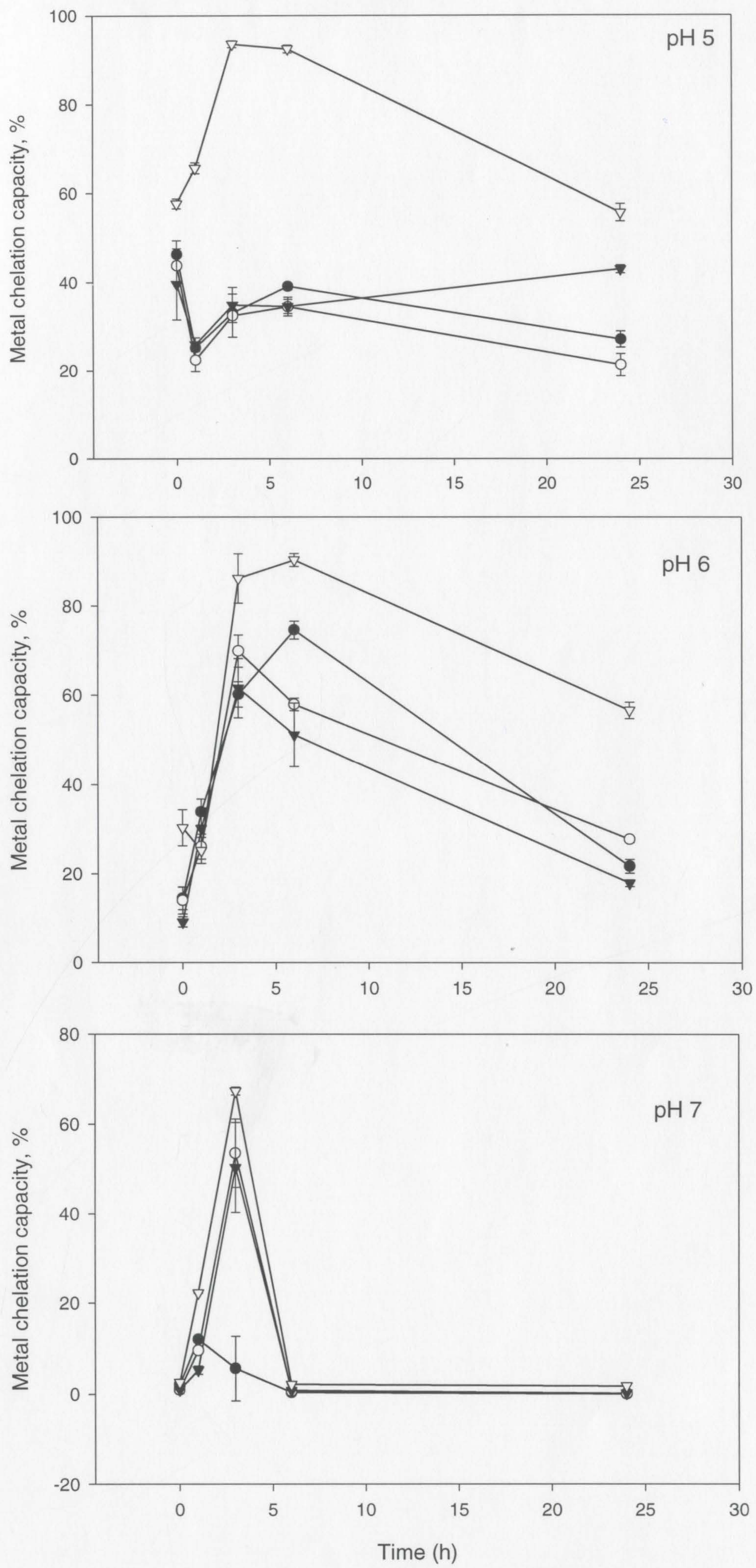
Figure 4.6 Metal chelation capacity of $\mathrm{Mn}^{2+}$ by chitosans and EDTA under three different $\mathrm{pH}$ conditions over time. 

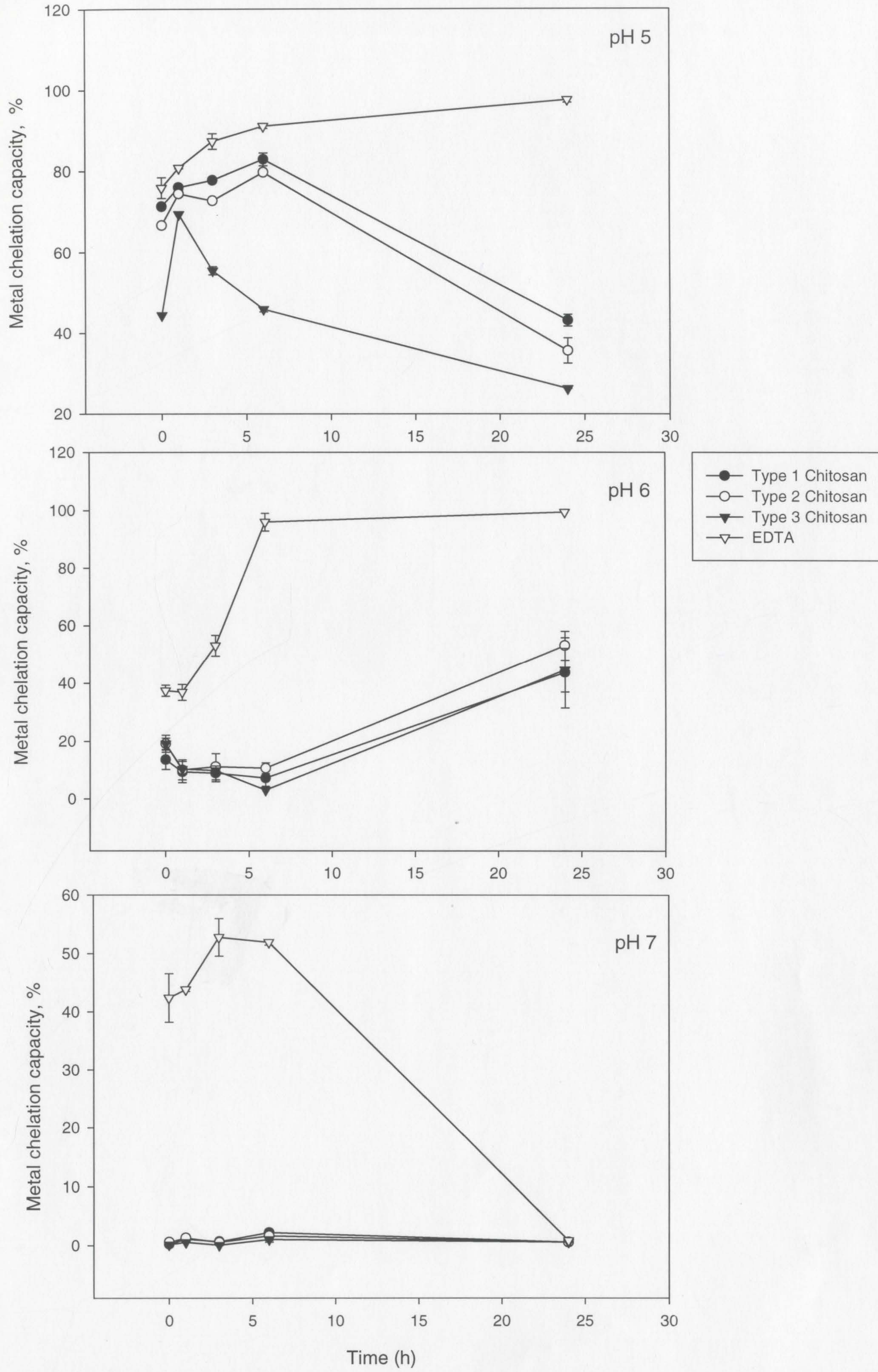
Figure 4.7 Metal chelation capacity of $\mathrm{Ni}^{2+}$ by chitosans and EDTA under three different $\mathrm{pH}$ conditions over time. 

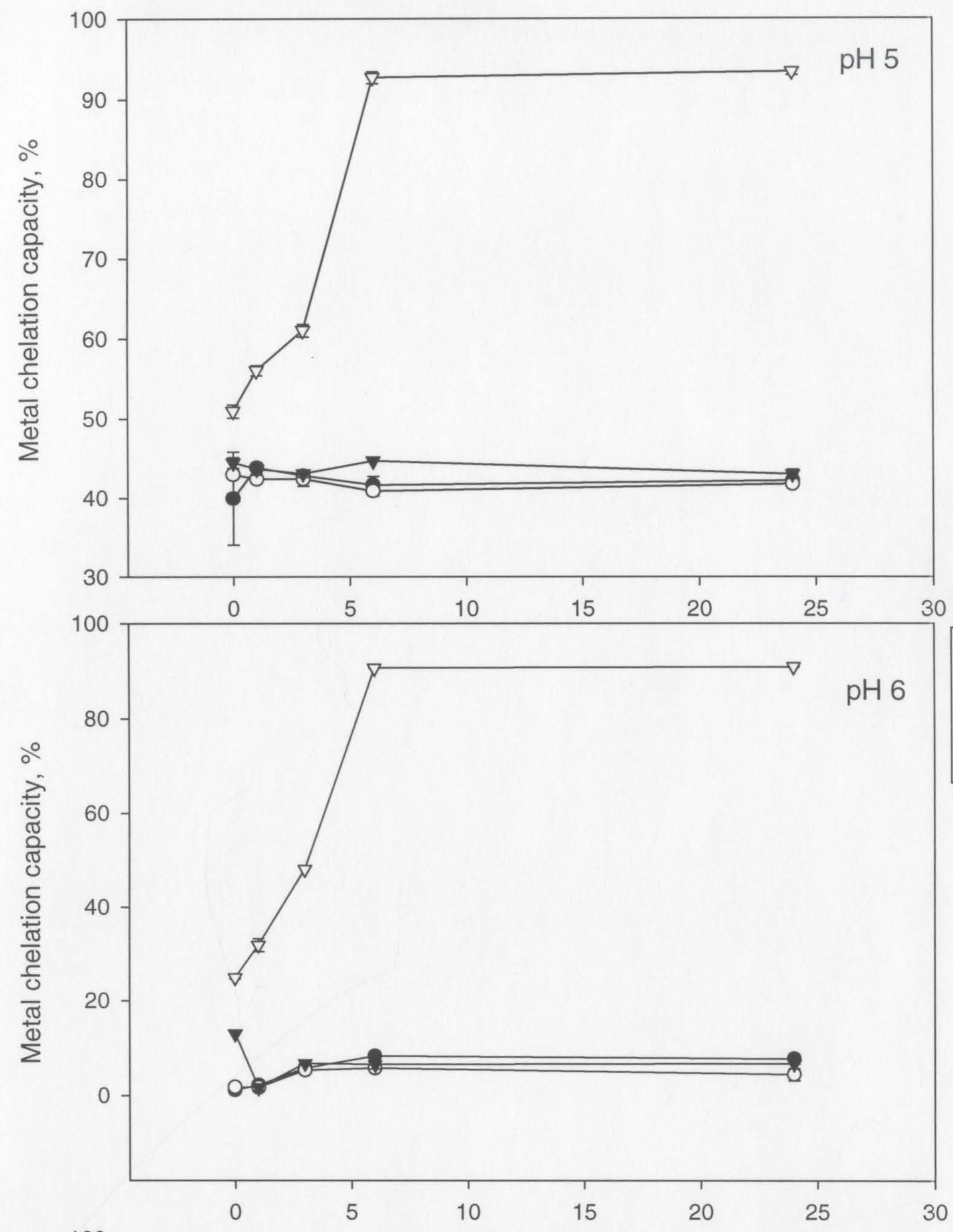

$\longrightarrow$ Type 1 Chitosan
-0 Type 2 Chitosan
$\rightarrow-$ Type 3 Chitosan
$\rightarrow-$ EDTA

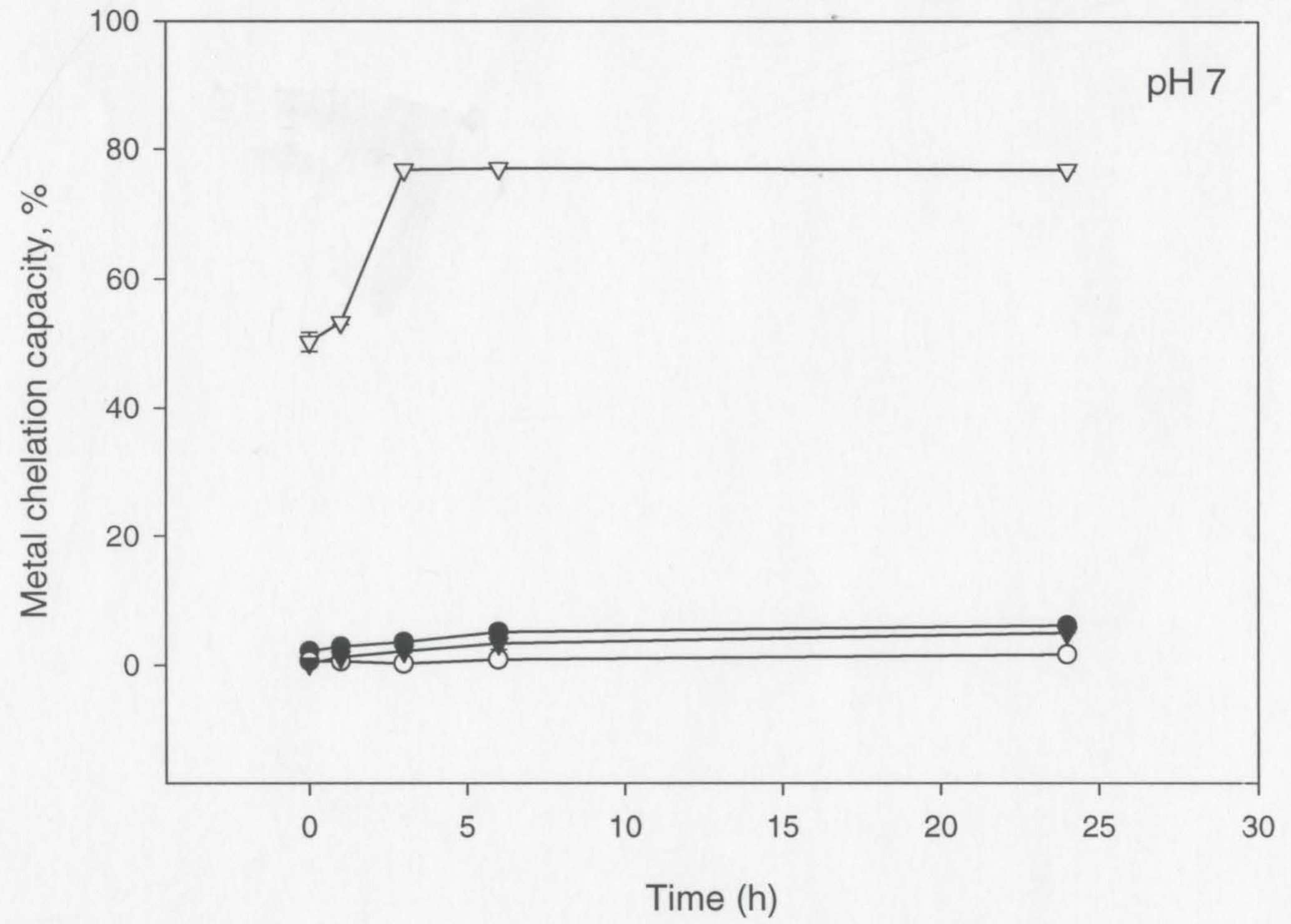


Figure 4.8 Metal chelation capacity of $\mathrm{Zn}^{2+}$ by chitosans and EDTA under three different $\mathrm{pH}$ conditions over time. 

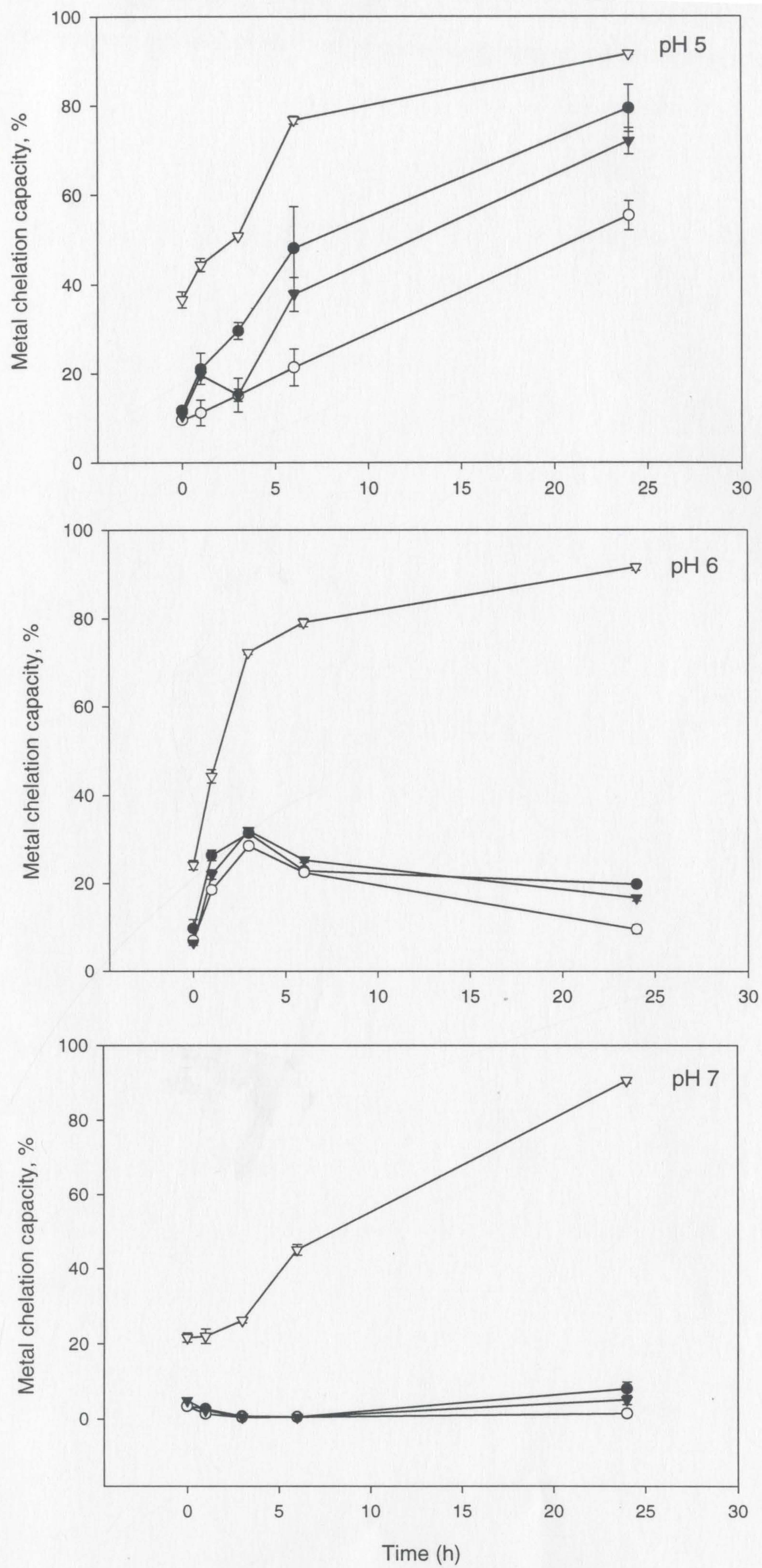
with $\mathrm{Zn}^{2+}, \mathrm{Mn}^{2+}, \mathrm{Ni}^{2+}, \mathrm{Co}^{2+}$ and $\mathrm{Fe}^{2+}$. The maximum chelation capacity was achieved after $3 \mathrm{~h}$ of standing at $\mathrm{pH} 6$ by all three types of chitosan with $\mathrm{Zn}^{2+}, \mathrm{Cd}^{2+}, \mathrm{Cu}^{2+}, \mathrm{Co}^{2+}$ and $\mathrm{Fe}^{2+}$. The maximum chelation capacity was achieved after $3 \mathrm{~h}$ of standing at $\mathrm{pH} 7$ by all three types of chitosan with $\mathrm{Fe}^{2+}, \mathrm{Co}^{2+} \mathrm{Cu}^{2+}$ and $\mathrm{Cd}^{2+}$ (Figures 4.2-4.7). Figures 4.2-4.8 show that the amount of chitosan used under different reaction times exhibited a considerable uptake of metal ions. The increase in the adsorbed metal ion contents leveled off after $6 \mathrm{~h}$ of standing at $\mathrm{pH} 5\left(\mathrm{Zn}^{2+}, \mathrm{Mn}^{2+}, \mathrm{Ni}^{2+}, \mathrm{Co}^{2+}\right.$ and $\left.\mathrm{Fe}^{2+}\right)$ and $3 \mathrm{~h}$ of standing at $\mathrm{pH} 6\left(\mathrm{Zn}^{2+}, \mathrm{Cd}^{2+}, \mathrm{Cu}^{2+}, \mathrm{Co}^{2+}\right.$ and $\left.\mathrm{Fe}^{2+}\right)$, indicating the attainment of adsorption equilibrium. Longer reaction times $(>3 \mathrm{~h})$ between chitosan and metal solutions were reported and indicated no result in an increase in metal ion uptake (Dean and Dixon, 1992; Peniche-Cocas et al., 1992; Bassi et al., 2000). Bassi et al. (2000) observed that shaking of the mixture of chitosan flakes and metal ions did not to affect the adsorption capacity of chitosan for metal ions. Ethylenediaminetetraacetic acid in comparison with different chitosan types showed the highest chelation capacity, as it is known to be a strong chelating agent (Juang et al., 1999). Interaction between EDTA and metal ions in natural aquatic systems has been investigated by several researchers. For example, Barica et al. (1973) examined the effects of EDTA on increased metal concentrations in lake water as a result of solubilization from associated metalcontaminated sediments. In the present study, out of three chitosans examined Type 1 showed the best chelation capacity. 


\subsubsection{Partical size of chitosan}

Experimental results show that the chelation capacity increased with decreasing particle size (Type $1>$ Type $2>$ Type 3 ). Particle size of the Type 1 product was $350-500$ microns, Type 2, 350-1000 microns and Type 3, 500-1000 microns. According to Huang et al. (1996), the number of adsorption sites per unit mass increased with decreasing particle size. Chitosan can be considered as a microporous material. After chitosan was crushed into small particles, adsorption sites on the chitosan chain increased thus allowing better binding of metal ions. According to Roberts (1992) the adsorpion capacity was found to be independent of particle size but to decrease with increasing temperature.

\subsubsection{Metal identity}

Upon chelation, the polymers assume typical colours: yellow for $\mathrm{Fe}^{2+}$, pink for $\mathrm{Co}^{2+}$, green for $\mathrm{Ni}^{2+}$ and blue for $\mathrm{Cu}^{2+}$. A number of metal ions including $\mathrm{Zn}^{2+}, \mathrm{Mn}^{2+}$ and $\mathrm{Cd}^{2+}$ while being effectively chelated did not develop any colour as expected. The order of metal ions chelation of chitosan at $\mathrm{pH} 5$ was $\mathrm{Cu}^{2+}>\mathrm{Fe}^{2+}>\mathrm{Ni}^{2+}>\mathrm{Co}^{2+}>\mathrm{Zn}^{2+}>$ $\mathrm{Cd}^{+2}>\mathrm{Mn}^{+2}$. The order of metal chelation at $\mathrm{pH} 6$ was $\mathrm{Fe}^{2+}>\mathrm{Co}^{2+}>\mathrm{Cd}^{2+}>\mathrm{Ni}^{2+}>\mathrm{Cu}^{2+}>$ $\mathrm{Zn}^{2+}>\mathrm{Mn}^{2+}$ and $\mathrm{pH} 7 \mathrm{w}$ as $\mathrm{Fe}^{2+}>\mathrm{Co}^{2+}>\mathrm{Cd}^{2+}>\mathrm{Ni}^{2+}>\mathrm{Cu}^{2+}>\mathrm{Zn}^{2+}>\mathrm{Mn}^{2+}$. Thus, different patterns were obtained at different $\mathrm{pH}$ values. However, the order found for the adsorption of metal ions by chitosan appears to vary in different studies. According to Peter (1995), the chelation order was $\mathrm{Zn}^{2+}>\mathrm{Ni}^{2+}>\mathrm{Cu}^{2+}>\mathrm{Cd}^{2+}>\mathrm{Co}^{2+}>\mathrm{Mn}^{2+}>\mathrm{Fe}^{+2}$. 
Figure 4.9 Metal chelation capacities of three types of chitosan after $3 \mathrm{~h}$. 

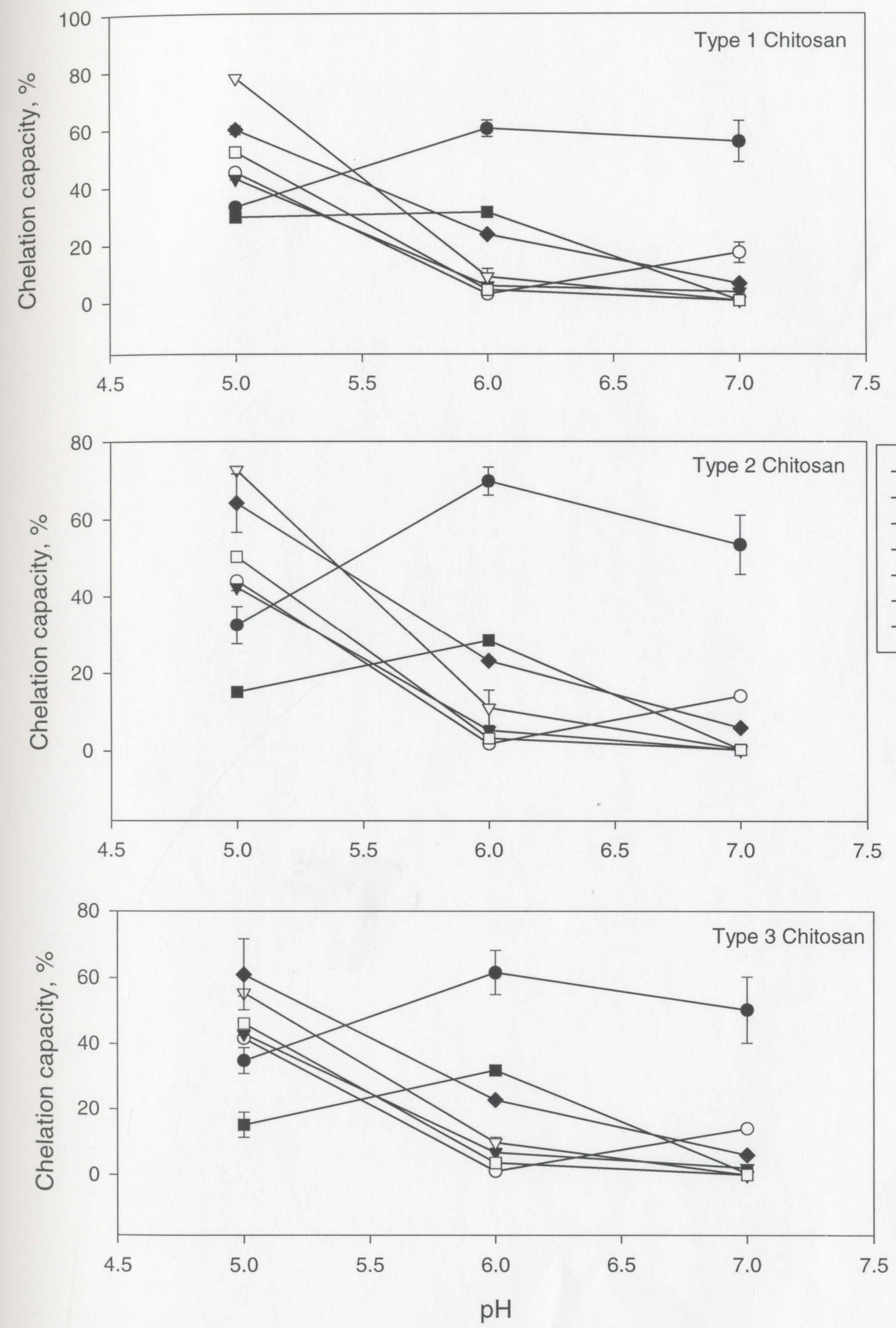
Figure 4.10 Metal chelation capacities of three types of chitosan after $6 \mathrm{~h}$. 

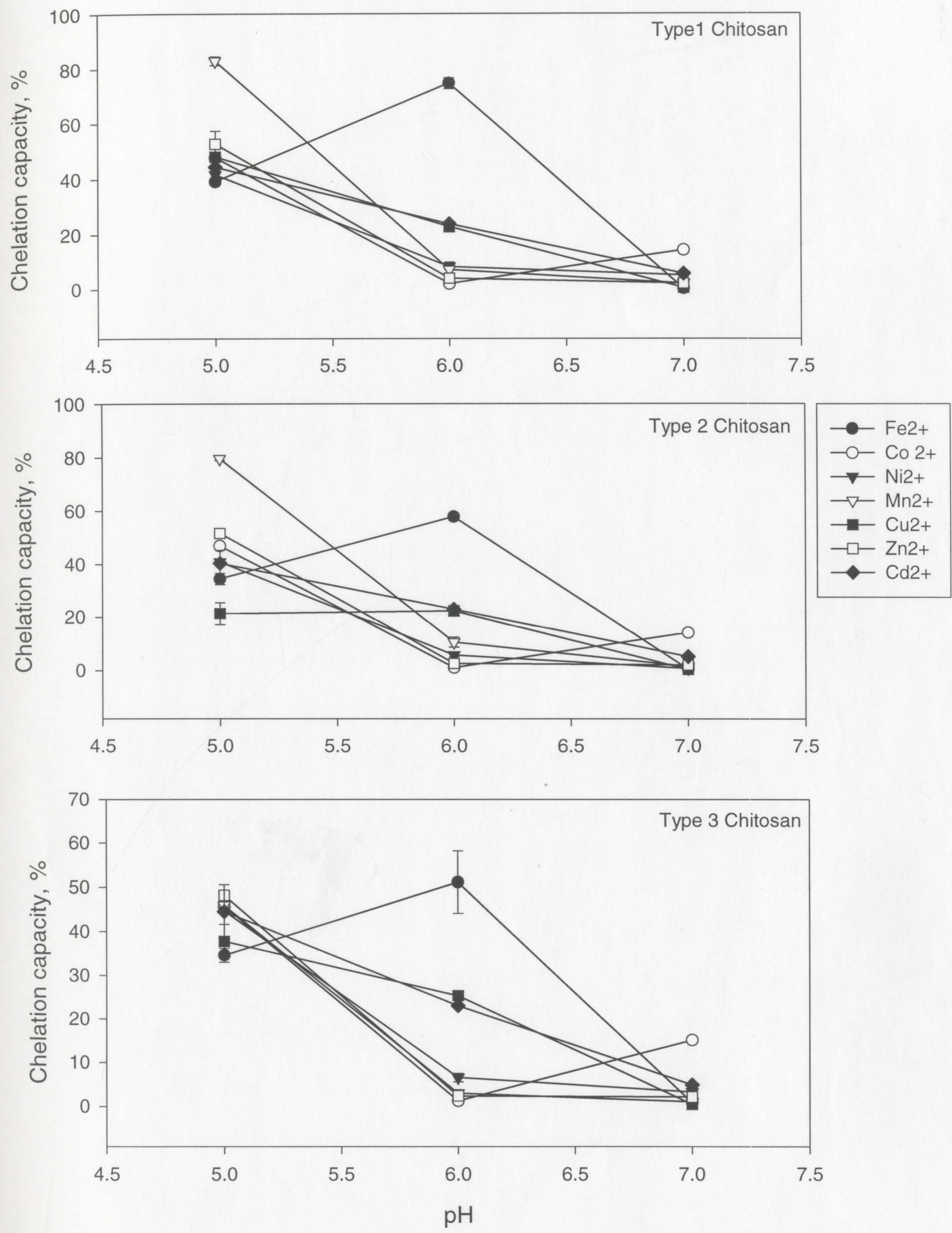
A colorimetric method is was for measuring metal chelation capacity using the absorption ratio of $460_{\mathrm{nm}} / 530_{\mathrm{nm}}$ for all metal ions. Several authors have employed the same $460_{\mathrm{nm}} / 530_{\mathrm{nm}}$ absorption ratio for $\mathrm{Zn}^{2+}, \mathrm{Cu}^{2+}$ and $\mathrm{Fe}^{2+}$ metal ions (Asakura et al., 1990; Terasawa et al., 1991; Wettasinghe and Shahidi, 2002).

\subsection{Determination of heavy metals in waste water samples by inductively coupled plasma mass spectrometry (ICP-MS)}

Mining activities result in pollution of aquatic systems. Water samples from a zinc mining site were analyzed using ICP-MS, which is a powerful detection system for elemental analysis at very low concentrations (trace and ultratrace level) (Lee et al., 2000). Since ICP-MS has a very low detection limit and a very wide analytical concentration range, it is often used for elemental analysis (Harada and Hatanaka, 1998) and studies on environmental materials (Yamasaki and Tsumura, 1992; Lee et al., 2000). Elements present in the water samples collected from a zinc mining site (Buchans, NL) are included in Table 4.4. The average $\mathrm{pH}$ of the waste water samples collected was 6.26.5 .

Wastewater samples obtained from the zinc mining site, Buchans, NL, contained excessive amounts of $\mathrm{Mn}^{2+}, \mathrm{Co}^{2+}, \mathrm{Cd}^{2+}, \mathrm{Hg}^{2+}, \mathrm{Pb}^{2+}, \mathrm{Cu}^{2+}$ and $\mathrm{Zn}^{2+}$ based on the Canadian water quality guidelines (1999) for protection of fresh water. Figures 4.11 to 4.13 show the effectiveness of chitosan in metal ion chelation from wastewater at different $\mathrm{pH}$ levels. Out of the three $\mathrm{pH}$ conditions used, $\mathrm{pH} 7$ was the best for chelation of multiple metal ions. Considering the three types of chitosan, Type 1 was significantly 
Table 4.4 Elements present in the wastewater samples from the zinc mining site (Buchans, NL) as determined by ICP-MS and their concentrations.

\begin{tabular}{lc}
\hline Elements & Concentration, ppb or $\mu \mathrm{g} / \mathrm{L}$ \\
\hline $\mathrm{Mg}$ & 1191.1 \\
$\mathrm{Al}$ & 19.40 \\
$\mathrm{~S}$ & 110.35 \\
$\mathrm{Ca}$ & 14700.00 \\
$\mathrm{Cl}$ & 1669.00 \\
$\mathrm{Cr}$ & 0.70 \\
$\mathrm{Fe}$ & 161.50 \\
$\mathrm{Mn}$ & 158.50 \\
$\mathrm{Co}$ & 0.47 \\
$\mathrm{Ni}$ & 1.11 \\
$\mathrm{Cu}$ & 15.39 \\
$\mathrm{Zn}$ & 1330.00 \\
$\mathrm{As}$ & 0.43 \\
$\mathrm{Mo}$ & 1.40 \\
$\mathrm{Ag}$ & 0.03 \\
$\mathrm{Cd}$ & 4.99 \\
$\mathrm{Hg}$ & 0.59 \\
$\mathrm{~Pb}$ & 32.93 \\
$\mathrm{U}$ & 0.02 \\
\hline
\end{tabular}


Figure 4.11 Effectiveness of chitosan in metal ion chelation from wastewater at $\mathrm{pH} 5$. 


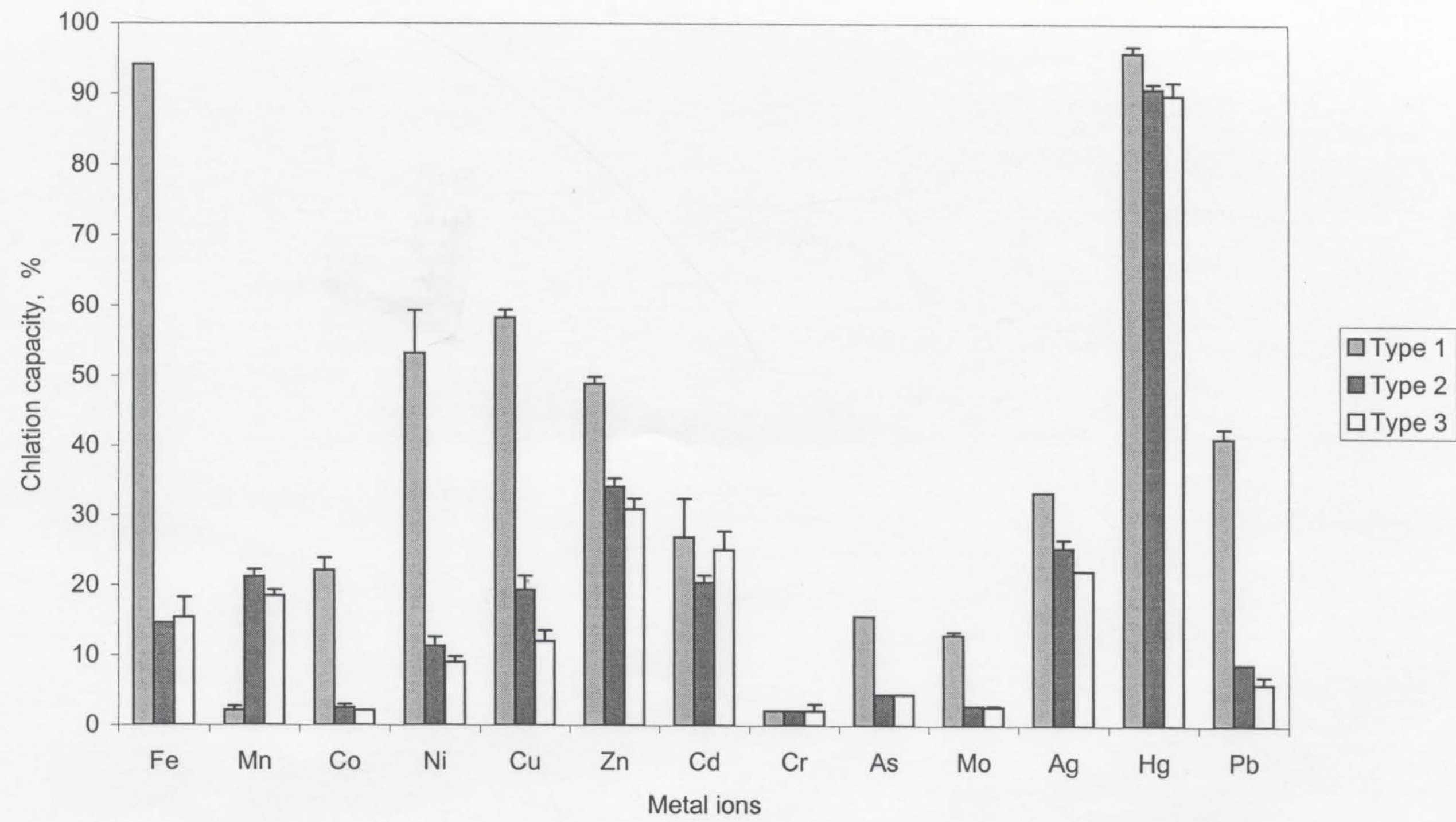


Figure 4.12 Effectiveness of chitosan in metal ion chelation from wastewater at pH 6. 


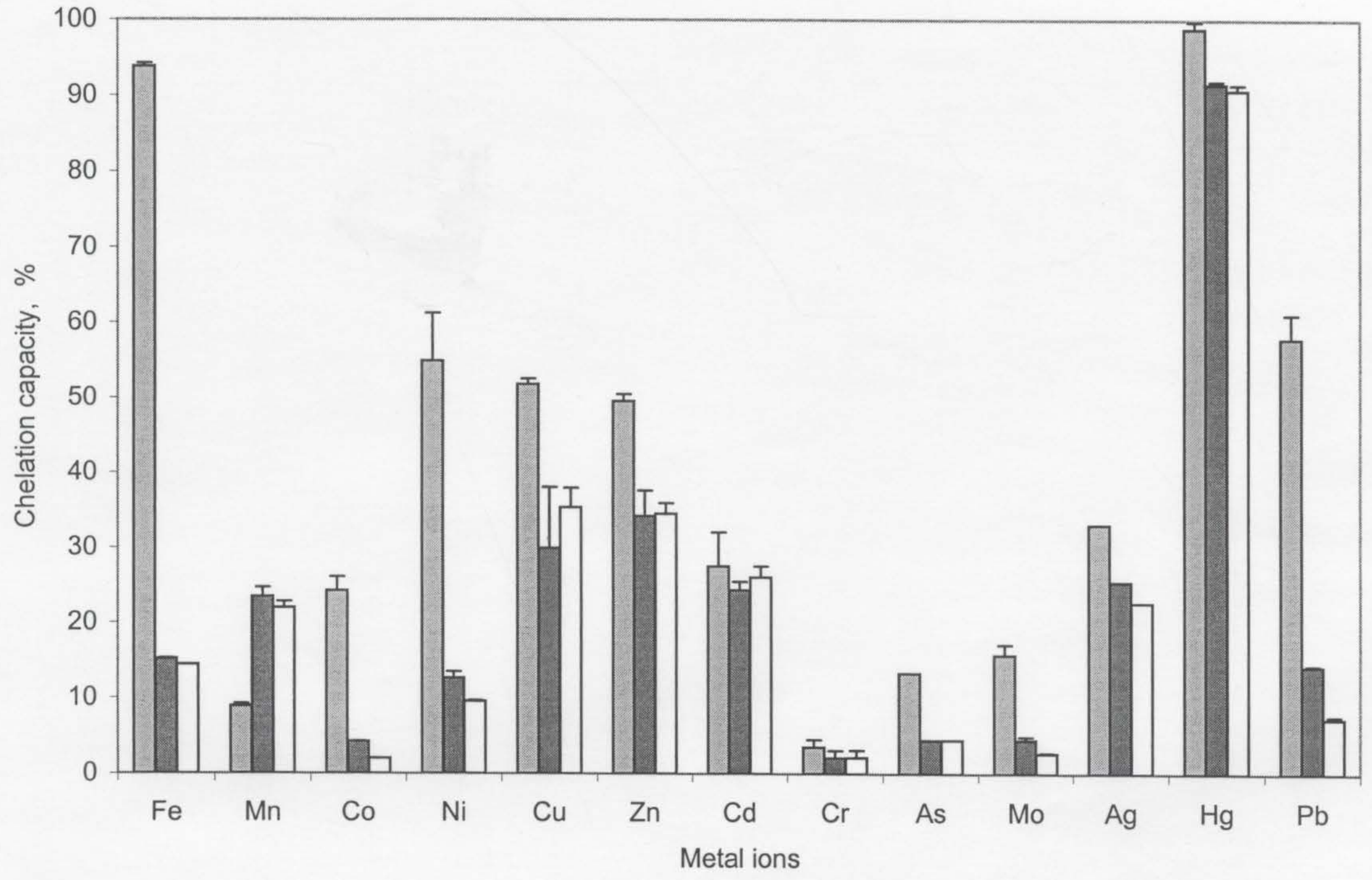


Figure 4.13 Effectiveness of chitosan in metal ion chelation from wastewater at $\mathrm{pH} 7$. 


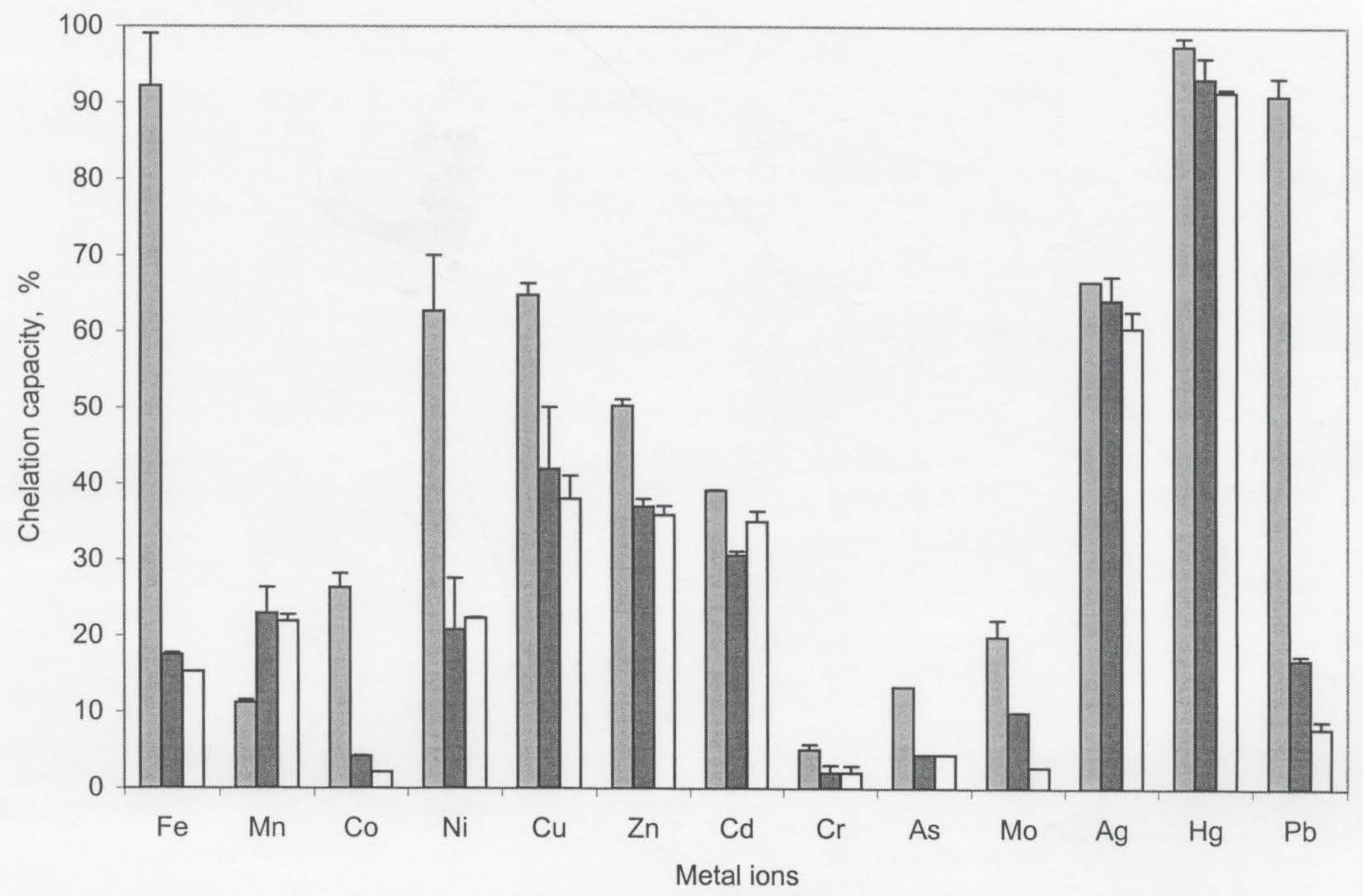

Type 1

口Type 2

口Type 3 
$(p<0.05)$ different from Types 2 and 3 (Table A6 in appendix). Chitosan Type 1 was best for metal chelation followed by Type 2 and 3. Chitosans Type 2 and 3 showed the same chelation pattern. Of the metal ions tested, $\mathrm{Hg}^{2+}$ was best chelated under all $\mathrm{pH}$ conditions by all three types of chitosan. Ferrous ions were best chelated at $\mathrm{pH} 5$. The order of chelation capacity percentage of metal ions was in the decreasing order of: $\mathrm{Hg}^{2+}$ $>\mathrm{Pb}^{2+}>\mathrm{Fe}^{2+}>\mathrm{Cu}^{2+}>\mathrm{Ni}^{2+}>\mathrm{Zn}^{2+}>\mathrm{Cd}^{2+}>\mathrm{Co}^{2+}>\mathrm{Mn}^{+2}$.

According to the Canadian water quality guidelines (1999), the wastewater sample tested contained high amounts of $\mathrm{Zn}^{2+}$ (Table 4.5). Using chitosan (Type 1, Type 2 and 3) the concentration of zinc ions could be reduced upto $50 \%$. However, it is still higher than the level suggested in the Canadian water quality guidelines, (1999) for protection of aquatic life. Therefore, multiple passage through chitosan might be necessary. Zinc is an essential element mediating a variety of metal enzymes and the biosynthesis of nucleic acids and polypeptides. The non-stoichiometric accumulation of heavy metals by the carrier protein metal thionein could lead to zinc deficiencies in humans. Symptoms of zinc deficiency include delayed healing, suppression of enzymatic activity, and immune response (Moore and Ramaoorthy, 1984). Toxicity symptoms of zinc include nausea, vomiting and diarrhea, in several cases with blood, and abdominal cramps (Elinder and Piscator, 1979).

The toxicity of zinc ions to aquatic plants is highly variable, with $\mathrm{LC}_{50}$ 's (lethal concentration) ranging from 0.0075 to $50 \mathrm{mg} / \mathrm{L}$. LC values usually refer to the concentration of a chemical in air, but in environmental studies it can also mean the 
concentration of a chemical in water. The concentration of a chemical in water that kills $50 \%$ of the test animals in a given time is referred to as the $\mathrm{LC}_{50}$ value. Part of the extreme inconsistency is due to the ability of many species to adapt to high zinc levels in water. In addition, physicochemical factors may significantly influence the bioavailability of zinc. Under most circumstances, mercury and copper are more toxic to aquatic plants than chromium, cadmium, nickel, lead and arsenic which may be more or less toxic, depending on the conditions considered (Moore and Ramamoorthy, 1984). Acute toxicity of zinc to freshwater invertebrates is relatively low. Although the $48-96 \mathrm{~h}$ $\mathrm{LC}_{50}$ 's generally range from 0.5 to $5 \mathrm{mg} / \mathrm{L}$, some species are particularly sensitive to zinc. Considering fish, the $48-96 \mathrm{~h} \mathrm{LC}_{50}$ for zinc usually falls within 0.5 to $5.0 \mathrm{mg} / \mathrm{L}$ (500-5000 $\mu \mathrm{g} / \mathrm{L})$, physicochemical and biological factors may extend the range from 0.09 to $>100 \mathrm{mg} / \mathrm{L}$. Susceptibility to zinc poisoning is largely species dependent (Moore and Ramamoorthy, 1984). Zinc toxicity of soil decreased considerably after ageing but there was a parallel increase in $\mathrm{pH}$ of more than one unit (Lock and Janssen, 2002).

Research has been done on the use of chitosan for the removal of some heavy metal ions from actual industrial waste water. Masri and Randall (1978) investigated chitosan binding of lead, copper, nickel, cadmium and zinc ions from a number of different industrial waste solutions. The use of commercially available chitosan for potable water purification has been approved by the USEPA up to a maximum level of $10 \mathrm{mg} / \mathrm{L}$ (Knorr, 1984). It not only removes toxic metal ions such as those of $\mathrm{Cd}$ and $\mathrm{Pb}$ when present in the environment, but it also prevents accidental contamination by radioactive isotopes such as cobalt-60. Chitosan also eliminates undesirable though harmless metal ions such 
as $\mathrm{Fe}^{2+}$, which are known to impart unpleasant organoleptic properties (Muzzarelli et al., 1989).

Apart from the advantage of reusing the industrial waste, chitosan has the capability of adsorbing either metal ions or complexing metal ions at the same time. Under alkaline conditions, chitosan exhibits a strong cation exchange behaviour to remove metal ions from industrial wastewater. In acidic condition, chitosan causes anion exchange sites to be made available to bind the nickel- cyanide anion. Adjustment of $\mathrm{pH}$ may be on developed to replace the conventional process for cyanide wastewater treatment. The density of adsorption sites on chitosan increased with decreasing particle size (Huang et al., 1996).

\subsection{Metal chelation capacity and recovery of metals from aqueous solutions using a chitosan column.}

\subsubsection{Individual metals.}

Out of the metal ions investigated there was no significant $(p<0.05)$ difference in metal chelation ability of chitosan between 50 and 100 ppm metal concentration, except for $\mathrm{Co}^{2+}$. According to Deans and Dixon (1992), a significantly reduced adsorption efficiency of chitosan was noticed upon raising the initial concentrations of copper and lead ions from 10 to $100 \mathrm{ppm}$. Increasing metal ion concentration in the solutions seems to reduce the external diffusion of the adsorbate and enhance intraparticular diffusion (Jasson-Charrier et al., 1996). Chitosan removed over $99 \%$ of metal ions from 50 ppm metal solutions, except for $\mathrm{Co}^{2+}$ and over $98 \%$ from $100 \mathrm{ppm}$ (Table 4.6). 
Table 4.5 Summary of guidelines for protection of aquatic life and dinking water.

\begin{tabular}{lll}
\hline $\begin{array}{l}\text { Metal } \\
\text { ions }\end{array}$ & $\begin{array}{l}\text { Canadian water quality } \\
\text { guideline for protection of } \\
\text { aquatic life* }\end{array}$ & $\begin{array}{l}\text { Drinking } \\
\text { water } \\
\text { MCL** }\end{array}$ \\
\hline $\mathrm{Cr}^{3+}$ & 1 & 50 \\
$\mathrm{Fe}^{2+}$ & 300 & 200 \\
$\mathrm{Mn}^{2+}$ & - & 50 \\
$\mathrm{Co}^{2+}$ & - & 1000 \\
$\mathrm{Ni}^{2+}$ & $25-150$ & 20 \\
$\mathrm{Cu}^{2+}$ & - & 1000 \\
$\mathrm{Zn}^{2+}$ & 30 & 5000 \\
$\mathrm{As}^{2+}$ & 5 & 50 \\
$\mathrm{Mo}^{2+}$ & 73 & 40 \\
$\mathrm{Ag}^{+}$ & 0.1 & - \\
$\mathrm{Cd}^{2+}$ & 0.017 & 3 \\
$\mathrm{Hg}^{2+}$ & 0.1 & 1 \\
$\mathrm{~Pb}^{2+}$ & $1-7$ & 1.5 \\
\hline
\end{tabular}

*Adapted from Canadian water quality guideline (1999); values are given in ppb or $\mu \mathrm{g} / \mathrm{L}$.

**MCL-Maximum contamination levels for potentially toxic metals in dinking water; Adapted from Siegel (2002). 
The lone pair electrons present on the amino nitrogen can establish dative bonds with transition metal ions. Some hydroxyl groups in chitosan may function as second donors; hence, deprotonated hydroxyl groups can be involved in coordination with metal ions (Micera et al., 1989). Acidic $\mathrm{pH}$ would favour protonation of the amino sites, resulting in reversal of charges, and may greatly diminish the metal chelating ability of chitin and chitosan (Chui et al., 1996). Hence, neutral pH was maintained in the chitosan columns for metal adsorption. When comparing the uptake capacity for the metal ions, the performance of chitosan, as expressed by the order of its affinity, was in the order of $\mathrm{Ag}^{+}>\mathrm{Cu}^{2+}>\mathrm{Ni}^{2+}>\mathrm{Cd}^{2+}>\mathrm{Co}^{2+}$ for $50 \mathrm{ppm}$ and $\mathrm{Ag}^{+}>\mathrm{Co}^{2+}>\mathrm{Cu}^{2+}>\mathrm{Cd}^{2+}>\mathrm{Ni}^{2+}$ for 100 ppm. The amount of metal adsorbed by chitosan was directly proportional to the increase in metal ion concentration, demonstrating a linear relationship (Chui et al., 1996). In the present study there was no significant difference between solutions containing 50 and 100 ppm of single metal ions.

EDTA could satisfactorily recover $52-97 \%$ and $56-97 \%$ of $\mathrm{Ni}^{2+}, \mathrm{Co}^{2+}, \mathrm{Cd}^{2+}$ and $\mathrm{Cu}^{2+}$ from solutions containing 50 and $100 \mathrm{ppm}$ of metal ions, respectively. Chui et al. (1996) found that metal removing efficiency of chitosan was over $93 \%$ for $\mathrm{Cu}^{2+}$ and $\mathrm{Cr}^{3+}$ from aqueous metal solutions ranging in concentration from 20 to $100 \mathrm{ppm}$. In this study, the r emoval e fficiencies of $\mathrm{chitosan}$ ranged from 82 to $99 \%$ depending on the concentration of $\mathrm{Ni}^{2+}$ in solution. The recovery efficiencies of $\mathrm{Ni}^{2+}$ and $\mathrm{Cu}^{2+}$ were 66$100 \%$ for Type 1 chitosan. 
Chelation formulations based on EDTA are used in a wide variety of applications in agriculture, food processing and water treatment industries to sequester metal ions (Gonsior et al., 1997). Concern has arisen that EDTA, because of its high binding constants with metals, has the potential to solubilize metals from solid phases (i.e. sediments and colloidal particulates). This process could occur by several possible interrelated mechanisms affecting overall metal ion speciation. The chelatant may complex free metal ions in solution, thus shifting precipitation and sorption equilibria toward increased dissolution of metals. Alternatively, EDTA could interact directly with solid phases by complexing metal ions present in, and/or adsorbed to precipitated solids and minerals (Gonisor et al., 1997). Because of wide spread usage, high water solubility and slow biodegradation rate, EDTA has been detected in various water sources, including waste water treatment plant effluents and river waters in both the USA and Europe (Alder et al. 1990). Concentrations of EDTA measured in river water typically range from 0.01 to $0.1 \mu \mathrm{M}$, similar to the concentration of several metal ions (Xue et al., 1995).

\subsubsection{Metal ion mixtures}

Considering metal ion mixtures, chitosan can remove $89 \%$ of $\mathrm{Ni}^{2+}, \mathrm{Cd}^{2+}, \mathrm{Cu}^{2+}$ and $\mathrm{Ag}^{+}$ from aqueous metal ion solutions (Table 4.7). For the metal mixture, there is a significant difference $(\mathrm{p}<0.05)$ between 50 and $100 \mathrm{ppm}$ for all metal ions. Order of metal chelation for $50 \mathrm{ppm}$ was as follows: $\mathrm{Ag}^{+}>\mathrm{Cd}^{2+}>\mathrm{Ni}^{2+}>\mathrm{Cu}^{2+}>\mathrm{Co}^{2+}$. The metal chelating ability of chitosan for $\mathrm{Ag}^{+}$was higher than that for other metal ions. 
Table 4.6 Comparison of metal chelation and recovery of chitosan Type 1.

Metal ion

Chelation, \%

Recovery, \%

\begin{tabular}{lllll} 
& $50 \mathrm{ppm}$ & $100 \mathrm{ppm}$ & $50 \mathrm{ppm}$ & $100 \mathrm{ppm}$ \\
\hline $\mathrm{Ni}^{2+}$ & $99.6 \pm 0.01^{\mathrm{c}}$ & $98.9 \pm 0.00^{\mathrm{a}}$ & $87.0 \pm 10.9^{\mathrm{cd}}$ & $97.9 \pm 1.69^{\mathrm{d}}$ \\
$\mathrm{Co}^{2+}$ & $76.6 \pm 0.17^{\mathrm{a}}$ & $99.7 \pm 0.00^{\mathrm{d}}$ & $52.2 \pm 0.00^{\mathrm{b}}$ & $84.7 \pm 3.18^{\mathrm{c}}$ \\
$\mathrm{Cd}^{2+}$ & $99.1 \pm 0.01^{\mathrm{b}}$ & $99.1 \pm 0.00^{\mathrm{b}}$ & $79.8 \pm 0.21^{\mathrm{c}}$ & $74.3 \pm 1.56^{\mathrm{b}}$ \\
$\mathrm{Cu}^{2+}$ & $99.9 \pm 0.06^{\mathrm{c}}$ & $99.5 \pm 0.00^{\mathrm{c}}$ & $97.5 \pm 2.26^{\mathrm{d}}$ & $56.2 \pm 0.51^{\mathrm{a}}$ \\
$\mathrm{Ag}^{+}$ & $99.9 \pm 0.00^{\mathrm{c}}$ & $99.9 \pm 0.00^{\mathrm{d}}$ & $0.08 \pm 0.00^{\mathrm{a}}$ & $0.00 \pm 0.00$
\end{tabular}

Results reported are mean vales of three determinations \pm standard deviation

Means in each column sharing the same superscript are not significantly $(p>0.05)$ different from one another. 
Ethyelenediaminetetraacetic acid could recover $61-89 \%$ of $\mathrm{Ni}^{2+}, \mathrm{Cd}^{2+}$ and $\mathrm{Cu}^{2+}$ at $50 \mathrm{ppm}$ and $77-90 \%$ for $\mathrm{Cd}^{2+}, \mathrm{Cu}^{2+}, \mathrm{Co}^{2+}$ and $\mathrm{Ni}^{2+}$ at $100 \mathrm{ppm}$. Considering metal recovery, there was a significant $(\mathrm{p}<0.05)$ difference between 50 and $100 \mathrm{ppm}$.

Chitin and chitosan have been explored for wastewater treatment, such as removal of toxic metals and radionuclides, recovery of precious metals, and recycling of metals from industrial wastewater for reuse and to reduce operational costs (Rorrer and Hsien, 1993; Coughlin, 1990).

\subsection{Determination of protein flocculation by chitosan}

Chitosan, with its partial positive charge, can effectively function as a polycationic coagulating agent in wastewater treatment (Peniston and Johnson, 1970). Chitosan as a coagulating agent for wastewater streams is particularly effective in removing protein from wastes; the coagulated by-products could serve as a source of protein in animal feed (Bough, 1976). In the present study three types of chitosan were used for determination of protein flocculation. In order to determine protein flocculation ability of chitosan, BSA solutions were passed through the three glass columns at a rate of $12 \mathrm{~mL} / \mathrm{min}$.

Of three types of chitosan used, Type 1 showed the best flocculation ability followed by Types 2 and 3 (Table A7 and Figure 4.14). Considering Type 1 chitosan; protein flocculation was high between 2 and $4 \mathrm{mg} / \mathrm{mL}$ protein concentration. The flocculation percentage was reduced with increasing protein concentrations thereafter. 
Table 4.7 Comparison of metal chelation and recovery of chitosan Type 1 for mixtures of metal ions.

\begin{tabular}{lllll}
\hline Metal ion & \multicolumn{3}{c}{ Chelation, \% } & \multicolumn{2}{c}{ Recovery, \% } \\
& $50 \mathrm{ppm}$ & $100 \mathrm{ppm}$ & $50 \mathrm{ppm}$ & $100 \mathrm{ppm}$ \\
\hline $\mathrm{Ni}^{2+}$ & $94.3 \pm 0.66^{\mathrm{b}}$ & $97.2 \pm 0.07^{\mathrm{b}}$ & $62.3 \pm 0.18^{\mathrm{b}}$ & $90.9 \pm 9.16^{\mathrm{a}}$ \\
$\mathrm{Co}^{2+}$ & $71.6 \pm 2.61^{\mathrm{a}}$ & $99.4 \pm 0.39^{\mathrm{c}}$ & $24.1 \pm 0.09^{\mathrm{a}}$ & $89.4 \pm 14.5^{\mathrm{a}}$ \\
$\mathrm{Cd}^{2+}$ & $94.8 \pm 0.55^{\mathrm{b}}$ & $99.1 \pm 0.02^{\mathrm{c}}$ & $61.2 \pm 0.07^{\mathrm{b}}$ & $77.9 \pm 15.5^{\mathrm{a}}$ \\
$\mathrm{Cu}^{2+}$ & $89.8 \pm 6.52^{\mathrm{b}}$ & $95.8 \pm 0.12^{\mathrm{a}}$ & $70.4 \pm 1.31^{\mathrm{c}}$ & $84.3 \pm 10.0^{\mathrm{a}}$ \\
$\mathrm{Ag}^{+}$ & $99.4 \pm 0.00^{\mathrm{b}}$ & $99.6 \pm 0.03^{\mathrm{c}}$ & $85.0 \pm 0.02^{\mathrm{d}}$ & $0.86 \pm 0.17^{\mathrm{a}}$ \\
\hline $\begin{array}{l}\mathrm{Results} \text { reported are mean vales of three determinations } \pm \text { standard deviation } \\
\text { Means in each column sharing the same superscript are not significantly (p>0.05) } \\
\text { different from one another. }\end{array}$ & &
\end{tabular}


Type 2 showed the same flocculation efficiency for all concentrations of protein employed. In the present study $\mathrm{pH} 7$ was used for determination of protein flocculation. The effects of $\mathrm{pH}$ and concentration of chitosan on reduction of turbidity in wastewater have been reported by several research groups (No and Mayers, 1989). The effect of $\mathrm{pH}$ on reduction of turbidity in crawfish waste water showed that lowest turbidity of 597 NTU (Nephelometric Turbidity Unit) at $\mathrm{pH}$ 6, and at $\mathrm{pH} 7$ the turbidity was reduced to 610 NTU (No and Mayers, 1989). According to the Jun et al. (1994), the lowest turbidity can be achieved by treatment of water containing proteins with an optimum concentration of chitosan at $\mathrm{pH}$ 5.8. The mechanism of flocculating lipids and proteins from food processing wastes is due to the pKa of the amino group of the glucosamine residues which is about 6.3 (Muzzarelli, 1985); hence, chitosan is polycationic at acidic $\mathrm{pH}$ values (Hwang and Damodaran, 1995; Fernandez and Fox, 1997). In contrast to chitin, chitosan is soluble at $\mathrm{pH}$ below 6.3 and higher $\mathrm{pH}$ values (Senstand and Mattiasson, 1989).

Chitosan is an excellent coagulating agent and flocculant due to the high density of amino groups on the polymer chain that can interact with negatively charged substances such as proteins, solids and dyes (Li et al., 1997). Wu et al. (1978) investigated the effectiveness of different chitosans for removing proteins from cheese whey. They found that the effectiveness of chitosan in coagulating solids and proteins was inversely proportional to its molecular weight. In the present study, Type 1 chitosan had a lower molecular weight $\left(6.6 \times 10^{5} \mathrm{Da}\right)$ than Type $2\left(9.6 \times 10^{5} \mathrm{Da}\right)$ and Type $3\left(1.8 \times 10^{6} \mathrm{Da}\right)$, as determined by. The present results support those of previous workers (Wu, 1978; Li et 
al., 1997), in that chitosan Type 1 had the highest protein flocculation ability when compared to Type 2 and Type 3 chitosans.

Proteins and fats can be reclaimed from wastewaters by a multitude of physical/chemical and biological techniques. Reclamation of proteins yields not only economically valuable products, but also the pretreatment of food industry w astewater which is becoming a common requirement prior to discharge to the municiple sewer systems (Selmer-Olsen et al., 1996). The most widely researched application for chitosan is perhaps its use as a coagulant for suspended matter in food processing wastes. Chitosan has been used to treat the waste effluents of a wide number of food process operations including egg breaking, vegetable, shrimp, cheese, meat, beer and apple juice processing. In these operations, chitosan was demonstrated to be a very good coagulating agent. The minimum reduction of suspended solids reported was $70 \%$ (Enriquez and Flick, 1989). 
Figure 4.14 Protein flocculation capacity of chitosan using different concentrations of bovine serum albumin. 


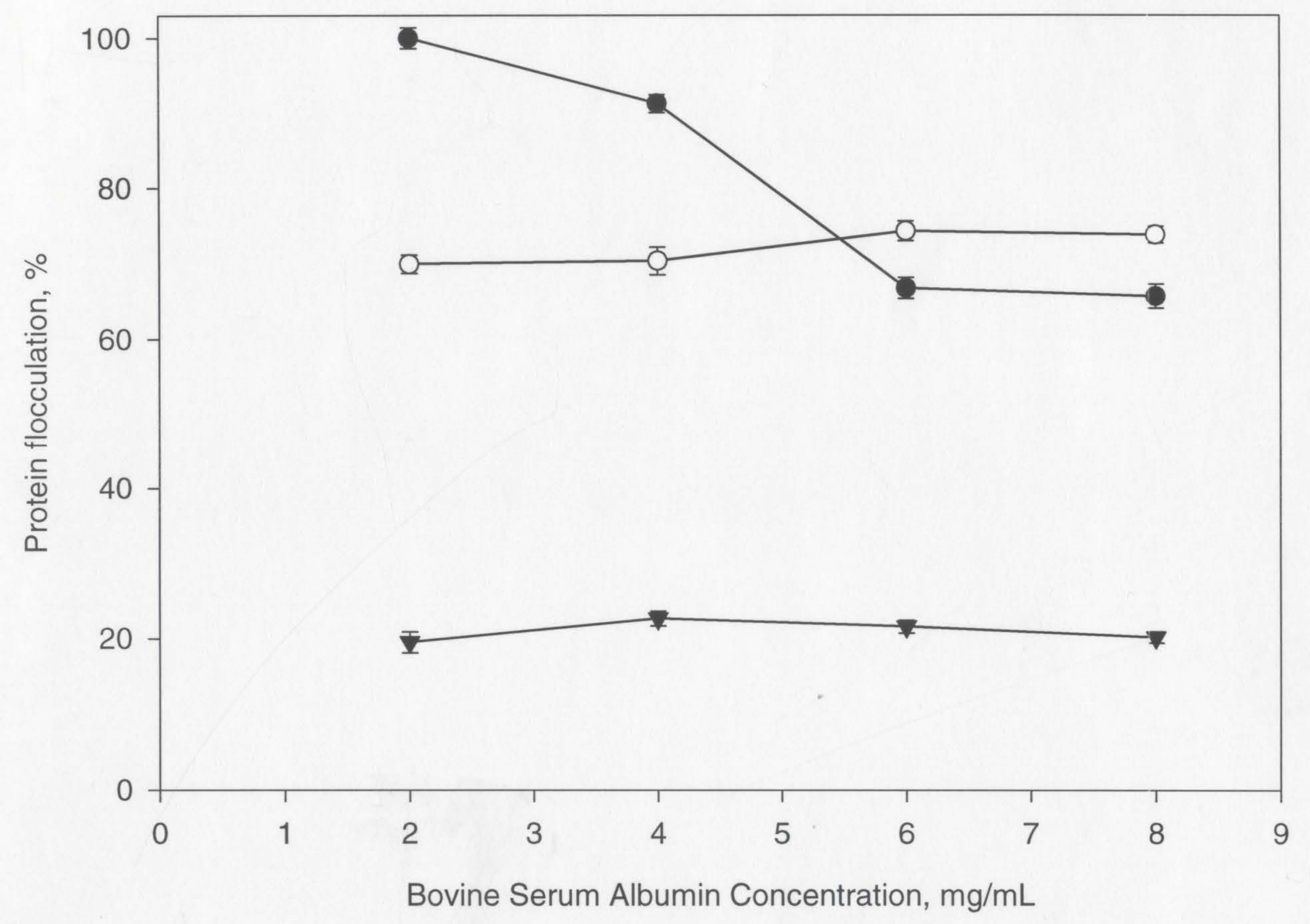

- Type 1 Chitosan
- - Type 2 Chitosan
$\longrightarrow-$ Type 3 Chitosan 


\subsection{CONCLUSIONS AND RECCOMMENDATIONS}

Formaldehyde served best in controlling the foul odour development both at 4$7^{\circ} \mathrm{C}$ and $20-25^{\circ} \mathrm{C}$. Formic acid could also be utilized in controlling foul odour development at a $1 \%(\mathrm{v} / \mathrm{v})$ level considering its safety aspects.

Chitosan was effective in the removal of metal ions including $\mathrm{Mn}^{2+}, \mathrm{Cd}^{2+}, \mathrm{Zn}^{2+}$, $\mathrm{Fe}^{2+}, \mathrm{Ni}^{2+}, \mathrm{Co}^{2+}$ and $\mathrm{Cu}^{2+}$ from wastewater samples obtained from a zinc mining site, Buchans, NL. Based on the colorimetric estimations, chitosan Type 1 performed better than Type 2 and Type 3 in its capacity to remove metal ions from single metal ion solutions. Ethylenediaminetetraacetic acid displayed the highest chelation capacity compared to all three chitosan types with single metal ions at all three $\mathrm{pH}$ values ( $\mathrm{pH} \mathrm{5,6}$ and 7). The highest chelation capacity was observed at $\mathrm{pH} 5$ followed by $\mathrm{pH} 6$ and $\mathrm{pH} 7$ with single metal ions. Type 1 chitosan served best for the removal of individual metal ions and metal ion mixtures compared to Types 2 and 3 chitosan. Removal of metal ions $\left(\mathrm{Hg}^{2+}, \mathrm{Fe}^{2+,} \mathrm{Ag}^{+}, \mathrm{Ni}^{2+}, \mathrm{Pb}^{2+}, \mathrm{Cu}^{2+}\right.$ and $\left.\mathrm{Zn}^{2+}\right)$ from industrial wastewater was most effective at $\mathrm{pH} 7$ as measured by ICP-MS. Mercury was most chelated the best under all $\mathrm{pH}$ conditions with all three types of chitosan.

Chitosan packed in columns removed more than $98 \%$ of $\mathrm{Ni}^{2+}, \mathrm{Cd}^{2+}, \mathrm{Cu}^{2+}$ and $\mathrm{Ag}^{+}$ from aqueous solutions at both 50 and $100 \mathrm{ppm}$ levels of metal ion concentrations. Out of the metal ions tested, there was no significant difference among metal chelation both at 50 and $100 \mathrm{ppm}$ metal concentration for single metal ions and metal mixtures, except for $\mathrm{Co}^{2+}$. More than $89 \%$ of metal ion mixtures were removed by 
chitosan from aqueous solutions of $\mathrm{Ni}^{2+}, \mathrm{Cd}^{2+}, \mathrm{Cu}^{2+}, \mathrm{Ag}^{+}$at both $50 \mathrm{ppm}$ and $100 \mathrm{ppm}$ levels. EDTA satisfactorily removed $52-97 \%$ and $56-97 \%$ of $\mathrm{Ni}^{2+}, \mathrm{Co}^{2+}, \mathrm{Cd}^{2+}$ and $\mathrm{Cu}^{2+}$ when used at 50 and $100 \mathrm{ppm}$, respectively. Ethylenediaminetettracetic acid could recover $61-89 \%$ of $\mathrm{Ni}^{2+}, \mathrm{Cd}^{2+}$ and $\mathrm{Cu}^{2+}$ at $50 \mathrm{ppm}$ metal concentrations and 77$90 \%$ for $\mathrm{Cd}^{2+}, \mathrm{Cu}^{2+}, \mathrm{Co}^{2+}$, and $\mathrm{Ni}^{2+}$ for $100 \mathrm{ppm}$ concentrations of metal ion mixtures.

In the protein flocculation study, Type 1 chitosan exhibited the best flocculation ability followed by Types 2 and 3 chitosans. Considering Type 1, protein flocculation was highest between 2 and $4 \mathrm{mg} / \mathrm{mL}$ protein. The flocculation percentages were reduced with increasing protein concentration after $4 \mathrm{mg} / \mathrm{mL}$. Type 2 showed the same flocculation percentages for 2 to $8 \mathrm{mg} / \mathrm{mL}$ protein.

Chitosans were effective in the removal of metal ions from wastewater samples. Chitosan Type 1 performed better than Types 2 and 3 in removing single metal ions, as measured a by a colorimetric method. A three hour reaction time and $\mathrm{pH} 5$ yielded satisfactory results in removing metal ions from single metal ion solutions. However, $\mathrm{pH} 7$ may be recommended for removal of metal ions from mixtures. The present study established that chitosan can effectively remove metal ions and proteins from waste and contaminated waters. Chitosan can be used at a rate of $0.2 \mathrm{~g} / \mathrm{L}$ wastewater. High efficiency of metal removal for metal ion mixtures can be achieved using Type 1 chitosan, over a $3 \mathrm{~h}$ period at $\mathrm{pH} 7$. In general, wastewaters rich in protienaceous material increase biological oxygen demand (BOD). The present study 
reveals that chitosan is not only a metal remover but also good as a protein flocculating agent. High efficiency of protein flocculation can be achieved by using the Type 1 chitosan at neutral $\mathrm{pH}$ at less than $4 \mathrm{mg} / \mathrm{mL}$ protein in the wastewater.

Based on the above, it is suggested that crustacean shellwaste serves best for production of chitosan which may in turn be used as an environmentally friendly material for wastewater purification. 


\section{FUTURE WORK}

The major commercial application of chitosan is its use in industrial wastewater treatment and recovery of a feed grade protein from food-processing plant $d$ ischarges. Chitosan prepared from crab chitin has been extensively studied for its metal chelation potential, but not widely employed in wastewater treatment. Acid solubility of chitosan is a disadvantage from a practical stand point of view for metal collection as regular chitosan may dissolve in acidic wastewater. Cross-linking can change the solubility characteristics of chitosan for use in acidic media. Therefore, it is important to conduct further studies with cross-linked and non cross-linked chitosan for metal chelation and metal recovery from wastewater. Since chitosan carries a partial positive charge, it effectively functions as a polycationic coagulating agent in wastewater treatment. Further research on the evaluation of coagulating and recovery of protenaceous material in wastewater discharge from food processing plants is necessary. It is also important to study the metal chelation characteristics and protein flocculation ability of chitosan prepared from other crustacean sources, especially squid which has a different chitin and hence chitosan crystallization pattern.

Increasing demand for chitin and chitosan may, however, lead to exploitation of natural resources such as crab, shrimp, lobster and squid. Thus, planning of large scale utilization of chitin must also include their production via biotechnological means in order to address a possible shift in the ecological balance in the marine environment. 


\section{REFERENCES}

Akbuga, J. (1993). The effect of the physicochemical properties of a drug on its release from chitosan malate tablets. Int. J. Pharm. 100, 257-261.

Alder, A.C., Siegrist, H., Gujer, W. and Giger, W. (1990). Behaviour of NTA and EDTA in biological wastewater treatment. Water Res. 24, 733-742.

Alexander, M. (1995). How toxic are toxic chemicals in soil? Environ. Sci.Technol.29, 2713-2717.

Alimunair and Zainuddin (1992). An economical technique for producing chitosan. In Advances in Chitin and Chitosan. eds. C.J. Brine, P.A. Sandford and J.P. Zikakis. Elsevier Applied Science, Essex, UK. pp. 627-629.

Allan, C.R., and Hadwiger, L.A. (1979). The fungicidal effect of chitosan on fungi of varying cell wall composition. Exp. Micol. 3, 285-287.

Allan, G.G. and Peyron, M. (1989). The kinetics of the depolymerization of chitosan by nitrous acid. In Chitin and Chitosan: Sources, Chemistry, Biochemistry, Physical Properties, and Applications. eds. G. Skjak-Braek, T. Anthonsen and P. Sandford. Elsevier Applied Science, New York, NY. pp. 443-438.

Alloway, B. J. (1995). Soil process and the behavior of metals. In Heavy Metals in Soils. ed. B.J. Alloway. Blackie Academic and Professional, Glasgow, UK. pp. 3-10.

Alloway, B.J. (2001). Soil Pollution and land contamination. In Pollution Causes, Effects and Control. Chapter 14, $4^{\text {th }}$ Edition, ed. R.M. Harrison. The Royal Society of Chemistry, Cambridge, UK. pp 352-377.

Anderson, C.G. Depablo, N. and Romo, C.R. (1978). Antarctic Krill (Euphausia superba) as a source of chitin and chitosan. In Proceedings of the First International Conference on Chitin and Chitosan. eds. R.A.A. Muzarrelli and E.R. Pariser. MIT Sea Grant Programme, Cambridge, MA. pp. 54-58.

Andersson, A., Nilsson, A. and Hakanson, L. (1991). Metal concentrations of the Mor layer in Sweden as influenced by deposition and soil parent material. Naturvardsverket, Solna. ISBN, PP. 91-620, 3990-3.

AOAC. (1990). Official Methods of Analysis, $15^{\text {th }}$ ed. Association of Official Analytical Chemists', Washington, DC.

Arvanitoyannis, I.S., Nakayama, A. and Aiba, S. (1998). Chitosan and gelatin based edible films: State diagrams, mechanical and permeation properties. Carbohyd. Polym. 37, 371-382. 
Asakura, T., Namakura, Y., Inoue, N., Murata, M. and Homma, S. (1990).

Characterization of zinc chelating compounds in instant coffee. Agric. Biol. Chem. 54, 855-862.

Ashford, N.A., Hattis, D.B., Murray, A.E. and Seo, K. (1976). Industrial applications of chitin and chitin derivatives. Inter. Ocean. 76, 1160-1170.

Ashie, I.N.A., Smith, J.P. and Simpson, B.K. (1996). Spoilage and shelf-life extension of fresh fish and shellfish. Crit. Rev. Food Sci. Nutr. 36, 87-121.

Austin, P.R., Brine, C.J., Castle, J.E. and Zikakis, J.P. (1981). Chitin: New facets of research. Science 212, 749-753.

Averbach, B.C. (1981). Chitin and chitosan production for utilization shellfish wastes. In Seafood Waste Management in the 1980s: Conference proceedings, September 23-25, Orlando, Florida. ed. W.S. Otwell, Gainesville, Florida Marine Advisory Program, Florida Co-operative Extension Service, University of Florida, FL. pp. 285-300.

Bade, M.L. and Wick, R.L. (1988). Protecting crops and wildlife with chitin and chitosan. In Biologically Active Natural Products: Potential use in Agriculture. ed. H.G. Cutler, ACS Symposium series. 380, American Chemical Society, Washington, DC. pp. 450-468.

Bade, M.L.(1997). Structure and isolation of native animal chitins. In Application of Chitin and Chitosans. ed. Goosan, M.F.A. Technomic Publishing Company, Inc. Lancaster, PA. pp. 255-277.

Barica, J., Stainton, M.P. and Hamilton, A.L. (1973). Mobilization of some metals in water and animal tissue by NTA, EDTA and TPP. Water Res. 7, 1791-1804.

Bartnicki-Garcia, S. (1968). Cell wall chemistry, morphogenesis, and taxonomy of fungi. Ann. Rev. Microbiol. 22, 87-108.

Bassi, R., Prasher, S.O. and Simpson, B.K. (1999). Remediation of metal-contaminated leachate using chitosan flakes. Environl. Technol. 20, 1177-1182.

Bassi, R., Prasher, S.O., and Simpson, B.K. (2000). Removal of selected metal ions from aqueous solutions using chitosan flakes. Separation Sci. Technol. 35 (4), 547-560.

Bergkvist, B., (1987). Soil solution chemistry and metal budgets of spruce forest ecosystems in S-Sweden. Water, Air Soil Pollution 33, 131-154. 
Bergkvist, B., Folkeson, L. and Berggren, D. (1989). Fluxes of $\mathrm{Cu}, \mathrm{Zn}, \mathrm{Pb}, \mathrm{Cd}, \mathrm{Cr}$, and $\mathrm{Ni}$ in temperate forest ecosystems. A literature review. Water, Air Soil Pollution $47,217-286$.

Berkeley, R.C.W. (1979). Chitin, chitosan and their degradative enzymes. In Microbial Polysaccharides and Polysaccharides. eds. R.C.W. Berkeley, G.W. Gooday and D.C. Ellwood. Academic Press, London, UK. pp. 174-189.

Betts, W. D. (Ed.) (1991). Biodegradation: Natural and Synthetic Materials. SpringerVerlag, Germany, pp 1-5.

Bligh, E.G. and Dyer, W.J. (1959). A rapid method of total lipid extraction and purification. Can. J. Biochem. Physiol. 37, 911-917.

Bough, W.A. and Londes, D.R. (1976). Recovery and nutritional evaluation of proteinaceous solids separated from whey by coagulation of chitosan. J. Dairy Sci. 59, 1874-1880.

Bough, W.A.V. (1977). Shelfish components could represent future good ingredients. Food Prod. Dev. 11, 90-92.

Bough, W.A., Salter, W.L., Wu, A.C.M. and Perkin, B.E. (1978). Influence of manufacturing variables on the characteristics and effectiveness of chitosan products. Chemical composition, viscosity, and molecular-weight distribution of chitosan products. Biotechnol. Bioeng. 20, 1931-1943.

Brine, C.J. and Austin, P.R. (1981). Chitin variability with species and method of preparation. Comp. Biochem. Physiol. 69B, 283-286.

Brine, C.J. (1984). Introduction chitin: accomplishment and perspectives. In Chitin, Chitosan and Related Enzymes. ed. J.P. Zikakis, Academic Press, New York, NY. pp 17-24.

Brzeski, M.M. (1982). Concept of chitin/chitosan isolation from Antarctic Krill (Euphausia superba) shells on a technical scale. In Proceedings of the Second International Confernce on Chitin and Chitosan. eds. S. Hirano and S. Tokura. The Japan Society of Chitin and Chitosan, Sapporo, Japan. pp. 15.

Brzeski, M.M. (1987). Chitin and chitosan-putting waste to good use. Infofish Int. 5, 3133.

Buckley, E.H. (1982). Accumulation of airborn polychlorinated biphenyl in foliage. Science 216, 520-522.

Canadian water quality guildeline (1999). Canadian council of ministers of the environment, Winnipeg, MB, Canada. pp.1-8. 
Chakrabarty, T., Subrahmanyam, P.V.R. and Sandaresan, B.B. (1998). Biodegradation of recalcitrant industrial wastes. In Bio-treatment Systems Vol 2, ed. D. Wise, CRC Press, Boca Raton, FL. pp. 172-234.

Chen, C., Liau, W. and Tsai, G. (1998). Antibacterial effects of $N$-sulfonated and $N$ sulfobenzoyl chitosan and application to oyster preservation. J. Food Prot. 61, 1124-1228.

Chui, V.W.D., Mok, K.W, Ng, C.Y., Luong, B.P. and Ma, K.K. (1996). Removal and recovery of copper (II), chrominum (III) and nickel (II) from solutions using crude shrimp chitin packed in smalls column. Environ. Int. 22, 463-468.

Claesson, P.M. and Ninham, B.W. (1992). pH-dependent interaction between adsorbed chitosan layers. Langmuir. 8, 1406-1412.

Cohen, E. (1993). Chitin synthesis and degradation as targets for pesticide action. Arch. Insect. Biochem. Physiol. 22, 245-261.

Cosio, I.G., Fisher, R.A. and Carroad, P.A. (1982). Bioconversion of shellfish chitn waste: Waste pretreatment, enzyme production, process design, and economic analysis. J. Food Sci. 47, 901-905.

Coughlin, R.W., Deshaies, M.R. and Davis, E.M. (1990). Chitosan in crab shell wastes purifies electroplating wastewater. Environ. Prog. 9, 35-39.

Davides, D.H., Elson, C.M. and Hayes, E.R. (1989). N,O- chrboxymethylchitosan, a, new water soluble chitin derivatives. In Chitin and Chitosan, eds. G. Skjak-Break, T. Anthon, P. Elsevier Applied Science, London, UK. pp. 467-472

Deans, J.R. and Dixon, B.G. (1992). Uptake of $\mathrm{Pb}^{2+}$ and $\mathrm{Cu}^{2+}$ by novel biopolymers. Water Res. 26, 469-472.

Denaix, L., Semlali, R.M. and Douay, F. (2001). Dissolved and colloidal transport of Cd, $\mathrm{Pb}$, and $\mathrm{Zn}$ in a silt loam soil affected by atmospheric industrial deposition, Environ Pollut. 114, 29-38.

Derome, J. and Nieminen, T. (1998). Metal and macronutrient fluxes in heavy-metal polluted Scots pine ecosystems in SW Finland. Environ. Pollut. 103, 219-228.

Dung, P.L., Milas, M., Rinaudo, M. and Desbrieres, J. (1994). Water soluble derivatives obtained by controlled chemical modifications of chitosan. Carbohydr. Polym. 24, 209-214.

El Ghaouth, A., Ponnampalam, R. and Castaigne, F. (1992). Chitosan coating to extend the storage life of tomatoes, Hort. Sci. 27, 1016-1018. 
Elinder, C-G. and Piscator, M. (1979). Zinc, Chapter 2. In Handbook on the Toxicology of Metals. eds. L. Friberg, G.E.F Norberg and B. Vouk, Elsevier, North Holland Biomedical Press, Amsterdam, The Netherlands. pp. 675-681.

Enriquez, L.G. and Flick, G.I. (1989). Marine colloids. In Developments in Food Science. Food Emulsifiers. eds. G. Charalambous and G. Doxastakis. Elsevier Science Publishing Company Inc., New York, NY. pp. 322-326.

Eurtz, D.A. (1990) Long Range Transport of Pesticides, Lewis Publishers Inc., Chelsea, MI. pp. 161-183.

FAO. (1999). Fishery Statistics (Capture Production), Vol. 84, 1997, Food and Agriculture Organization of the United Nations, Rome, Italy. Pp. 91-92.

Fawell, J.K. and Stanfield, G. (2001). Drinking water quality and health. In Pollution Causes, Effects and Control. ed. R.M. Harrison. The Royal Society of Chemistry, Cambridge, UK. pp. 60-61.

Fergusson, J.E. (1990). The Toxicity of Heavy Elements to Human Beings. Pergamon Press, New York, NY. pp. 533-537.

Fernandez, M. and Fox, P.F. (1997). Fractionation of cheese nitrogen using chitosan. Food Chem. 58, 319-322.

Ferrer, J., Paez, G., Marmol, Z., Ramones, E., Garcia, H. and Forster, C.F. (1996). Acid hydrolysis of shrimp-shell wastes and the production of single cell protein from the hydrolysate. Bioresource Technol. 57, 55-66.

Florence, T.M. (1989). Electrochemical technique for trace element speciation in waters. In Trace Element Speciation: Analytical Methods and Problems, CRC Press, Boca Raton, FL. pp.79-85.

Forstner, U. (1990). Inorganic sediment chemistry and elemental speciation. Chemistry and Toxicity of In-place pollutants. Secta-Europe, Palaza, Italy, pp. 61-105.

Freedman, B. and Hutchinson, T.C. (1981). Effect of Heavy Metal Pollution on Plants. Vol. 2 In Metal in the Environment. ed. N.W. Lepp. Applied Science Publishers, Englewood, NJ. pp. 35-94.

Friberg, L., Nardberg, G.F. and Vouk, V.B. (1986). Handbook on the Toxicity of Metals, Elsevier, North Holland Biomedical Press, Amsterdam, The Netherlands. pp.2590.

Glover-Kerkvliet, J. (1995). Environmental Assault on Immunity. Environmental Health Perspectives. 103, 236-237. 
Godin, P., Feinberg, M. and Ducauze, C. (1985). Modelling of soil contamination by airborne lead and cadmium around several emission sources, Environ. Pollut. 10, $97-114$.

Gonisor, S.J., Sorci, J.J., Zoellner, M.J. and Landenberger, B.D. (1997). The effects of EDTA on metal solubilization in river sediment/water system. Environ. Qual. 26, 957-966.

Gopakumar, K. (1997). Tropical Fishery Products. Science Publishers Inc. Enfield, NH. pp. $28-56$

Green, J.H. and Kramer, A. (1984). Food Processing Management. AVI Publishing Co. Westport, CT. pp. 24-45.

Greger, M. (1999). Metal availability and bioconcentration in plants. In Heavy Metal Stress in Plants from Molecules to Ecosystems. eds. M.N.V. Prasad and J. Hagemeyer. Springer, Berlin. pp. 1-28.

Haard, N.F. (1992). Technological aspects of extending prime quality of seafood: A review. J. Aquatic Food Technol. 1(3/4), 9-27.

Haard, N.F., Simpson, H.B. and Sikorski, Z.E. (1994). Biotechnological applications of seafood p roteins and o ther $n$ itrogen compounds. In Seafood P roteins. e ds. Z.E. Sikorski, B.S. Pan and F. Shahidi. Chapman and Hall, New York, NY. pp. 195216.

Hackman, R.H. (1954). Studies on chitin I. Enzymatic degradation of chitin and chitin esters. Aust. J. Biol. Sci. 7, 168-169.

Hadwiger, L.A., Kendra, D.F., Fristensky, B.W. and Wagoner, W. (1985). Chitosan both activates genes in plants and inhibits RNA synthesis in fungi. In Chitin in Nature and Technology. e ds.R.A.A. Muzzarelli, C. Jeuniax and G.W.Goody. Plenum Press, New York, NY. pp. 209-222.

Hayes, L.A., Richards, R. and Mathur, S.P. 1994. Economic viability of commercial composting of fisheries wastes by passive aeration. In The Compost Council of Canada Symposium. ed. S.P. Mathur. Montreal, PQ, Canada. pp. 1-14.

Hansen, M.E. and Illanes, A. (1994). Application of crustacean waste in biotechnology. In Fisheries Processing Biotechnological Applications. ed. A.M. Martin, Chapman and Hall, London, UK. pp. 175-205.

Harada, H. and Hatanka, T. (1998). Natural background levels of trace elements in wild plants. Soil Sci. Plant Nutr. 44, 443-452. 
Hare, F.K. (1986). Lead in the Canadian environment. Science and regulation final report of the commission on lead in the environment, Royal Society of Canada, Ottawa, ON. pp.1-15.

Harrison, R.M. and Laxen, D.P. (1981). Chemical analysis of lead in the environment. In Lead Pollution and Control. Chapman and Hall, London, UK. pp. 160-164.

Harrison, P.T.C. (2001). Health effects of environmental chemicals. In Pollution, Causes, Effects and Control. Chapter 19, $4^{\text {th }}$ edn. ed. R.M. Harrison, The Royal Soceity of Chemistry, Cambridge, UK. pp. 500-523.

Healy, M.E., Rome, C.R. and Bustons, R. (1994). Bioconversion of marine crustacean shell waste. Resources Conserv. Recyc. 11, 139-147.

Heinrich, H. and Mayer, R. (1980). The role of forest vegetation in the biochemical cycle of heavy metals. J. Environ. Qual. 6, 402-407.

Hellawell, J.M. (1986). Biological Indication of Fresh Water Pollution and Environmental Management. Elsevier Applied Science Publishers, London, UK. Pp. 52-56.

Hirano, S., Ohe, Y. and Ono, H. (1976). Selective $N$-acylation of chitosan. Carbohyd. Res. 47, 315-320.

Hirano, S. (1989). In Chitin and Chitosan. eds. G. Skjak-Braek, T. Anthonsen and P. Sandford. Elsevier Applied Science, New York, NY. pp. 37-43.

Hirano, S., Itakura, C., Seino, H., Akiyama, Y., Nonaka, I, Kanbara, N. and Kawakami, J. (1990).Chitosan as an ingredient for domestic animal feeds. J. Agric. Food Chem. 38, 1214-1217.

Hirano, S. and Akiyama, Y. (1995). Absence of hypocholesteromic action of chitsoan in high-serum- cholesterol rabbits. J. Sci. Food Agric. 69, 91-94.

Hirano, S. (1996). Chitin biotechnological applications. Biotechnol. Ann. Rev. 2, 237258.

Howling, G.I., Dettmar, P.W., Goddard, P.A., Hampson, F.C., Dornish, M. and Wood, E.J., (2001). The effect of chitin and chitosan on the proliferation of human skin fibroblasts and keratinocytes in vitro. Biomaterials 22, 2959-2966. 
Hortan, D. and Lineback, D.R. (1965). $N$-deacetylation: Chtitosan from chitin. In Methods in Carbohydrate Chemsitry: General Polysaccharides. Vol.V eds. R.L. Whistler, J.N., BeMiller and M.L. Wolform, Academic Press, London, UK. pp. 403-406.

Huang, C., Chung, Y-C. and Liou, M-R. (1996). Adsorption of Cu(II) and Ni(II) by pelletized biopolymer. J. Hazardous Materials 45, 265-277.

Hwang, D.C. and Damodaran, S. (1995). Selective precipitation and removal of lipids from cheese whey using chitosan. J. Agric. Food Chem. 43, 33-37.

Illum, L. (1998). Chitosan and its use as a pharmaceutical excipient. Pharmaceut. Res. 15, 1326-1331.

James, A. (2001). The treatment of toxic wastes. In Pollution Causes, Effects and Control, Ch 6, $4^{\text {th }}$ Edn. eds. R.M. Harrison, Royal Society of Chemistry, Cambridge, UK. pp. 145-167.

Jansson-Charrier, M., Guibal, E., Roussy, J., Delanghe, B. and LeCloire, P. (1996). Vanadium (IV) sorption by chitosan: kinetics and equilibrium. Water Res. 30, 465-475.

Jay, J.M. (1986). Modern Food Microbiology. Van Nostrand Reinhold, New York, USA. pp. 24-88.

Jeon, Y-J., Shahidi, F. and Kim, S-K. (2000). Preparation of chitin and chitosan oligomers and their applications in physiological functional foods. Food Rev. Int. $16,159-176$.

Jeuiaux, C. (1986). Chitosan as a tool for the purification of water. In Chitin in Nature and Technology. eds. R.A.A. Muzzaelli, C. Jeuniaux and G.W. Gooday. Plenum Press, New York, NY. pp. 551-570.

Jha, I.N., Iyengar, L. and Prabhakara, Rao, A.V.S. (1988). Removal of cadmium using chitosan. J. Environ. Eng. 114, 962-974.

Johnes, E.L., Stratford, J.A., Tidridge, P., Waterhase, K.S. and Johston, A.E. (1989). Polynuclear a romatic h ydrocarbons in an agricultural soil: longterm changes in profile distribution. Environ. Pollut. 56, 337-351.

Johnson, E.L. and Peniston, Q.P. (1982). Utilization of shellfish waste for chitin and chitosan production. eds. R.E. Martin, G.J. Flick, C.E. Hebard and D.R. Ward. AVI Publishing Co., Westport, CT. pp. 415-418. 
Juang, R-S, Wu, F-C and Tseng, R-L. (1999). Adsorption removal of copper(II) using chitosan from simulated rinse solutions containing chelating agents. Water Res. 33, 2403-2409.

Jun, H.K., Kim, J.S., No, H.K. and Meyers, S.P. 1994. Chitosan as a coagulant for recovery of proteinaceous solids from tofu wastewater, J. Agric. Food Chem. 42, 1834-1838.

Kabata-Pendias, A (1993). Behavioral properties of trace metals in soils. Appl. Geochem. 17, 763-770.

Katz, S.A. and Salem, H. (1994). Analytical methodologies for chromium. In The Biological and Environmental Chemistry of Chromium. Ch 7. VCH Publishers, New York, NY. pp 153-176.

Kawashima, Y., Lin, S.Y. Kasa, A., Handa, T. and Takenaka, H. (1985). Preparation of prolonged release tablets of aspirin with chitosan. Chem. Pharm. Bull. 33, 21072113.

Kaye, R. (1985). Chitosan markets and quality go hand-in-hand. In Biotechnology of Marine Polysaccharides, Proceedings of the Third Annual MIT Sea Grant College Programme Lecture and Seminar. eds. R.R. Cowell, E.R. Pariser and A.J. Sinskey, Hemisphere Publishing Corporation, New York, NY. pp. 333-342.

Kester, J.J. and Fennema, O.R. (1986). Edible films and coatings, a review. Food Technol. 40 (12), 47-59.

Kishi, Y. (1997). A benchtop inductively coupled plasma-mass spectrometer, HewlettPackard Journal, August. pp. 3-10.

Knorr, D. (1983). Dye binding properties of chitin and chitosan. J. Food Sci. 48, 36-37, 41.

Knorr, D. (1984). Use of chitinous polymers in food- A challenge for food research and Development. Food Technol. 38(1), 85-97, 92-97.

Knorr, D. (1986). Nutritional quality, food processing, and biotechnology aspects of chitin and chitosan: A review. Proc. Biochem. 6, 90-92.

Knorr, D. (1991). Recovery and utilization of chitin and chitosan in food processing waste management. Food Technol. 45(1), 114, 116-120, 122.

Koga, D. (1998). Chitin Enzymology-chitinase. In Advances in Chitin and Chitin Science. vol 111, Third Asia-Pacific Chitin and Chitosan Symposium, Rita Advertising Co. Ltd., Keelung, Taiwan. pp. 16-23. 
Kohn, R. and Furda, I. (1967). Interaction of calcium and potassium ions with carboxyl groups of pectin. Collect. Czech. Chem. Commum. 32, 4470-4484.

Kokalis-Burelle, N. (2001). Chitin amendments for suppression of plant nematodes and fungal pathogens. Phytopathology 91, 5168-5171.

Koljonen, T. (1992). Results of the mapping. In The Geochemical Atlas of Finland, Part 2. ed. T.Koljonen. Geological Survey of Finland. Espoo. pp. 106-218.

Kono, M., Matsui, T., and Shimizu, C., 1987. Effect of chitin, chitosan and cellulose on diet supplement on the growth of cultured fish. Nippon Suisan Gakkaishi. 53, 125-129.

Kumar, K.R. and Jayachandran, P. (1993). Chitin - A versatile biopolymer from crustacean wastes. Seafood Expo. J. 25, 19-21.

Kurita, K., Sannan, T. and Iwakura, Y. (1979). Studies on chitin VI binding of metal cations. J. Appl. Poly. Sci. 23, 511-515.

Kurita, K., Ishiguro, M. and Kitajima, T. (1988). Studies on chitin: 17. Introduction of long alkylidene groups and the influence of the properties. Int. J. Biol. Macromol. 10, 24-125.

Kurita, K., Tomita, K., Tada, T., Ishii, S., Nishimura, S.I. and Shimada, K. (1993). Squid chitin as a potential alternative chitin source: Deacytylation behaviour and characteristic properties. J. Polym. Sci. Part A, 31, 485-488.

Kurita, K. (1997). $\beta$-chitin and reactivity characteristics. In Applications of Chitin and Chitosan. ed. M.F.A. Gossen. Technomic Publishing Company, Inc., Lancaster, PA. pp. 79-87.

Lahiji, A., Sohrabi, A., Hungerford, D.S., and Frondosa, C.E.(2000). Chitosan supports the expression of exracellular matrix proteins in human osteoblasts and chondrocytes. J. Biomed. Mater. Res. 51:586-588.

Lasko, C.L. and Hurst, M.P. (1999). An investigattion into the use of chitosan for the removal of soluble silver from industrial wastewater. Environ. Sci. Technol. 33, 3622-3626.

Lee, K-H., Oshima, M., Takayanagi, T. and Motomizu, S. (2000). Simultaneous determinations of trace elements in river-water samples by ICP-MS in combination with a discrete $m$ icro s ampling technique, a fter enrichment with a chitosan based chelating resin. Anal. Sci. 16, 731-738. 
Li, Q., Dunn, E.T., Grandmaison, S.W. and Goosen, M.F.A. (1997). Applications and properties of chitosan. In Applications of Chitin and Chitosan. ed. M.F.A. Goosen. Technomic Publishing Co. Inc., Lancaster, PA. pp. 1-21.

Li, Q., Dunn, E.T., Grandmaison, E.W. and Goosen, M.F.A. (1992). Applications and properties of chitosan. J. Bioac. Comp. Polym. 7, 370-397.

Lindberg, S. E. and Turner, R.R. (1988). Factors influencing atmospheric depositions, steam expert, and landscape accumulation of trace metals in forested watersheds. Water, Air Soil Pollution 39, 123-156.

Lock, K. and Janssen, C.R. (2002). The effect of ageing on the toxicity of zinc for the potworm Enchytraeus albidus. Environ. Pollut. 116, 289-292.

Lower, E.S. (1984). Polymers from the sea. Chitin Chtiosan Manufac. Chem. 55, 4775.

Lowry, O.H., Rosebrough, N.J., Farr, A.L., and Randall, R.J. (1951). Protein measurement with the Folin phenol reagent. J. Biol. Chem. 193, 265-275.

Lubian, L.M. (1989). Concentrating cultured marine microalgae with chitosan. Agric. Eng. 8, 257-259.

Madhaven, P. and Ramachandran, N.K.G. (1974). Utilization of prawn waste isolation of chitin and its conversion to chitosan. Fish Technol. 11, 50-53.

Maghami, G.G. and Roberts, G.A.F. (1988). Evaluation of the viscometric constants of chitosan. Macromol. Chem. 189, 195-200.

Martin, M.H. and Coughtrey, P.J. (1981). In Effect of Heavy Metal Pollution on Plants, Vol. 2, Metals in the Environment. ed. N.W. Lepp. Applied Science Publishers, Englewood, NJ. pp. 119-158.

Martin, A.M. (1998). Fisheries waste biomass: bioconversion alternatives. In Bioconverion of Waste Material to Industrial Products. ed. A.M. Martin, Blackie Academic and Professional, London, UK. pp. 449-479.

Mason, C.F. (2000). Water pollution biology. In Pollution Courses Effects and Control $4^{\text {th }}$ Ed. ed. R.M. Harrison. The Royal Society of Chemistry, Cambridge, UK. pp. $82-112$.

Masri, M.S. and Randell, V.G. (1978). In Proceedings of the First International Conference on Chitin/Chitosan; MIT sea grant report MITSG, 78-7. eds. R.A.A. Muzzarelli and E. Pariser. Cambridge, MA. pp. 277-287. 
Mckay, G., Blair, H.S. and Gardner, J.R. (1982). Adsorption of dyes of chitin.I. Equilibrium studies. J. Appl. Polym. Sci. 27, 3043-3046.

Merck Index (1996). The Encyclopedia of Chemicals, Drugs and Biochemicals. $12^{\text {th }}$ Ed. eds. Budvarts, S., O’Neil, M.J., Smith, A., Heckelman, P.E. and Kinneary, J.F. Merck Research Labratories, Rahway, NJ. pp. 17, 719.

Micera, G., Deiana, S., Dessi, A., Decock, P, Dubois, B. and Kozlowski, H. (1986). Copper and vanadium complex of chitosan. In Chitin in Nature and Technology, eds. R.A.A. Muzzarelli, C. Jeuniaux and G.W.Goody. Plenum Press, New York, NY.pp. 565-567.

Mima, S., Miya, M., Iwasmoto, R. and Yoshikawa, S. (1983). Highly deacetylated chitosan and properties. J. Appl. Polym. Sci. 28, 1909-1911.

Miyazaki, S., Ishii, K. and Nadai, T. (1981). The use of chitin and chitosan as drug carriers. Chem. Pharm. Bull. 29, 3067-3069.

Moffat, A.S. (1995). Plants proving their worth in toxic metal. Cleanup Sci. 269, 302-303.

Moore, J.W. and Ramamoorthy, S. (1984). Heavy Metals in Natural Waters. Applied Monitoring and Impact Assessment, Spinger-Verlag, New York. NY. pp. 198199.

Moser, T. T., Barker, J. R., and Tingey, D.T. (1992). Anthropogenic contaminants, atmospheric transport, deposition and potential effects as terrestrial ecosystems. In The Science of Global Change, The Impact of Human Activities on the Environment. eds. D .A. D unnette and R.J. O' Brien. ACS S ymposium S eries 483, American Chemical Society, Washington, DC. pp. 23-35

Muzzarelli, R.A.A. and Tubertini, O. (1969). Chitin and chitosan as chromatographic supports and adsorbents for collection of metal ions from organic an aqueous solutions and sea water. Talanta $16,1571-1573$.

Muzzarelli, R.A.A. (1973). Natural Chelating Polymers: Alginic Acid, Chitin and Chitosan. Pergamon Press, Oxford, UK. pp 20-23.

Muzzarelli, R.A.A. (1977). Chitin. Pergamon Press, Oxford, UK. pp 1-4; 47-50; 257-264.

Muzzarelli, R.A.A. (1985). Chitin. In The Polysaccharides, vol 3. ed. G.O. Aspinall, Academic Press Inc., New York, NY. pp. 417-450.

Muzzarelli, R.A.A., Lough, C. and Emanuelli, M. (1987). The molecular weight of chitosans studied by laser light-scattering. Carbohyd. Res. 164, 433-442. 
Muzzzarelli, R.A.A., Weckx, M. and Filippini, O. (1989). Removal of trace metal ions from industrial waters, nuclear effluents and drinking water, with the aid of crosslinked $N$-carboxymethyl chitosan. Carobohyd. Polym. 11, 293-306.

Muzzarilli, R.A.A. (1996). Chitosan-based dietary foods. Carbohyd. Polym. 29, 309-316.

Muzzarilli, R.A.A.(1997). Chitosan as dietary food additives. In Application of Chitin and Chitosans. ed. M.T.A. Goosen. Techonmic, Lancaster, PA. pp. 115-127.

Muzzarelli, R.A.A. (1999). Native industrial and fossil chitins. In Chitin and Chitinases. eds. P. Jolles and R.A.A. Muzzarelli, Birhhauser Velag, Basel, Switzerland. pp 16.

Neugebauer, W.A., Neugebauer, E. and Brzeinski, K. (1989). Determination of the degree of $\mathrm{N}$-acetylation of chitin-chitosan with picric acid. Carbohyd. Res. 189, 363-367.

Nieminen, T. M., Derome, J. and Helmisaari, H.S. (1999). Interactions between precipitation and Scots pine canopies along a heavy-metal pollution gradient. Environ. Pollt. 106, 129-137.

No, H.K., Meyers, S.P. and Lee, K.S. (1989). Isolation and characterization of chitin from crawfish shell waste. J. Agric. Food Chem. 37, 575-579.

No, H.K. and Meyers, S.P. (1989). Crawfish chitosan as a coagulant in recovery of organic compounds from seafood processing streams. J. Agric. Food Chem. 37, 580-583.

No, H.K. and Meyers, S.P. (1992). Utilization of crawfish processing wastes as carotenoids, chitin and chitosan. J. Korean Soc. Food Nutr. 21, 319-326.

No, H.K. and Meyers, S.P. (1995). Preparation and characterization of chitin and chitosan: A review. J. Aquatic Food Product.. Technol. 4 (2) 27-52.

Nriagu, J.O. (1988). A silent epidemic environmental metal poisoning? Environ. Pollut. $50,139-161$.

Nriagu, J.O., Wang, H.K.T., Lawson, G. and Daniel, P. (1998). Saturation of ecosystems with toxic metals in Sudbury basin Ontario, Canada. Sci. Total Environ. 233, 99117.

Ornum, J.V. (1992). Shrimp waste- must it be wasted? Infofish Int. 6, 48-52.

OSHA. (2001). Computerized information system. US Department of Labor, Occupational Safety and Health Administration. Washington, DC. pp. 2-13. 
Pagliai, M., Guildi, G., La Marca, M., Giachetti, M., Lucamente, M. (1981). Effects of sewage sludge and composts on soil porosity and aggregation. J. Environ. Qual. $10,556-561$.

Papp, R.B. (1994). Atomic absorption spectrometry. Ch 3. In Instrumental Methods of Determining elements: Selection and Application. ed.L.R. Taylor, Papp, R.B. and pollard, B.D. VCH Publishing, Inc., New York, NY. pp.16-61.

Pelletier, A., Lemire, J., Sygusch, J., Chornet, E. and Overend, R.P. (1990).

Chitin/chitosan transformation by thermo-mechano-chemical treatment including characterization by enzymatic depolymerization. Biotechnol. Bioeng. 36, 310-313.

Peniche-Covas, C., Alvarez, L.W. and Arguelles-Monal, W. (1992). The adsorption of mercuric ions by chitosan. J. Appl. Polym. Sci. 46, 1147-1149

Peniston, P.Q. and Johnson, E.L. (1970). Methods for treating an aqueous medium with chitosan and derivatives of chitin to remove an impurity. US. Patent. 3,533, 940.

Peter, M.G. (1995). Applications and environmental aspects of chitin and chitosan. $J$. Macro. Mol. Sci.-Pure Appl. Chem. 4, 629-640.

Phillippy, B.Q. (1984). Characterization of the in situ TMA System of Red Hake Muscle, Ph.D. Thesis, University of Massachusetts, Amherst, MA.

Phillips, D.J.H. (1980). Quantitative aquatic biological indicators. Applied Science Publishers Ltd., London. UK. pp. 34-45.

Pirrone, N., Keeler, G. J. and Nriagu, J.O. (1996). Regional differences in worldwide emissions of mercury to the atmosphere. Atmospheric Environ. 301, 2981-2987.

Piscator, M. and Vouk, V. (1979). Sampling and analytical methods. In Handbook on the Toxicology of Metals. ch 3. eds. L. Friberg, F. Nordberg and V.B. Vouk. Elsevier/North Holland Biochemical Press, Amsterdam, The Netherlands. pp. 3345 .

Pollard, B.D. (1994). Atomic emission method. Ch 4. In Instrumental Methods of Determining Elements: Selection and Application. ed.L.R. Taylor, Papp, R.B. and pollard, B.D. VCH Publishing, Inc. New York, NY. pp.61-84.

Prasad M.N.V. and Hagemeyer, J. (1999). Heavy Metal Stress in Plants from Molecules to Ecosystems. Springer, Berlin. pp. 22-51.

Rahn, K.A. and Lowenthal, D.H. (1984). Elemental traces of distant regional aerosol. Science 223, 132-139. 
Ramaswamy, H.S., Simpson, B.K., Ya, T.U. and Yaylayan, V. (1991). Tray-drying of carotenoproteins recovered from lobster waste. J. Food Proc. Pres. 15, 273-284.

Razdan, A. and Petersson, D. 1994. Effect of chitin and chitosan on nutrient digestibility and plasma lipid concentrations in broiler chickens. Brit. J. Nutr. 72, 277-288.

Revah-Moiseer and Carroad, P.A. (1981). Conversion of the enzymatic hydrolysate of shellfish waste chitin to single-cell processing. Biotechnol. Bioeng. 23, 10671073.

Rha, C. (1984). Chitosan as a biomaterial. In Biotechnology in the Marine Sciences. Proceedings of the First Annual MIT Sea Grant Lecture and Seminar. Eds. R.A. Colwell, A.J. Sinskey and E.R. Pariser, John Wiley and Sons, New York, NY. pp. 177-189.

Ritthidej, G.C., Chomto, P., Pummangura, S. and Menasveta, P. (1994). Chitin and chitosan as disintegrants in paracetamol tablets. Drug Devel. Ind. Pharm.20, 2109-2134.

Roberts, G.A.F. and Domszy, J.G. (1982). Determination of the viscometric constants for chitosan. Int. J. Biol. Macromol. 4, 375-377.

Roberts, G.A.F. (1992). Chitin Chemistry, The McMillan Press Ltd., Hampshire, UK. pp.54-84.

Ross, S.M. (1994). Toxic Metals in Soil Plant Systems. John Wiley and sons, Chichester, UK. pp. 20-35.

Rorrer, G.L. and Hsien, T.Y. (1993). Synthesis of porous-magnetic chitosan beads for removal of cadmium ions from waste water. Ind. Eng. Chem. Res. 32, 2170-2178.

Rutherford, F.A. and Austin, P.R. (1978). Marine chitin properties and solvents. In Proceedings of the First International Conference on Chitin/Chitosan. eds. R.A.A. Muzzarelli and E.R. Pariser. MIT Sea Grabt Programme. Cambridge, MA. pp. 182-185.

Salemaa, M., Majamaa-Vanha, I. and Derome, J. (2001). Understorey vegetation along a heavy-metal pollution gradient in SW Finland. Environ. Pollut. 112, 339-350.

SAS (1990). SAS User's Guide: Statistics, $6^{\text {th }}$ ed. SAS Institute Inc. Cay, NC.

Sawayanagi, Y., Nambu, N. and Nagai, T. (1982). Directly compressed tablets containing chitin or chitosan in addition to lactose or potato starch. Chem. Pharm. Bull. 30, 2935-2940. 
Schoemaker, R. (1991). Shrimp waste utilization. In Infofish Technical Hand book No. 4, Infofish Technical handbook Series, Infofish, Kualallumpur, Malaysia. pp.1-10.

Seiler, H.G., Sigel, H. and Sigel, A. (1988). Handbook on the Toxicity of Inorganic Compounds. Marcel Dekker, Inc., New York, NY. pp 200-201.

Selmer-Olsen, E., Ratnaweera, H.C. and Pehrson, R. (1996). A novel treatment process for dairy wastewater with chitosan produced from shrimp-shell waste. Water Sci. Tech. 34, 33-40.

Senstand, C. and Mattiasson, B. (1989). Purification of wheat germ aglutin using affinity flocculation with chitosan and subsequent centrifugation of floatation step. Biotechnol. Bioeng. 34, 387-393.

Shahidi, F. and Synowiecki, J. (1991). Isolation and characterization of nutrients and value-added products from snow crab (Chinoecetes opilio) and shrimp (Pandalus borealis) processing discards. J. Agric. Food Chem. 39, 1527-1532.

Shahidi, F. and Synowiecki, J. (1992). Quality and compositional characteristics of Newfoundland shellfish Processing discards. In Advances in Chtin and Chitosan. eds. C.J. Brine, P.A. Sandford and J.P. Zikakis. Elseveir Applied Science, Essex, UK. pp. 617-626.

Shahidi, F., Synowiecki, J. and Naczk, M. (1992). Utilization of shellfish processing. In Seafood Science and Technology. ed. E.G. B ligh, Fishing N ew Books, Oxford, UK. pp. 300-304.

Shahidi, F. (1994). Seafood Processing by products. In Seafood Chemistry, Processing Technology and Quality. eds. F.Shahidi and J.R.Botta. Blackie Academic and Professional, Glasgow, UK. Pp. 320-334.

Shahidi, F. (1995). Role of chemistry and biotechnology in value-added utilization of shellfish processing discards. Can. Chem. News. 47, 25-29.

Shahidi, F., Kamil, J.V.A., and Jeon, Y-J. (1999). Food applications of chitin and Chitosans. Trends. Food Sci. Technol. 10. 37-51.

Shallari, S., Schwaitz, C., Hasko, A. and Morel, J.L. (1998). Heavy metals in soils and plants of serpentine and industrial sites of Albania. Sci. Total Environ. 209, 133142.

Snedecor, G.W. and Cochran, W.G. (1980). Statistical Methods, $7^{\text {th }}$ ed. The Iowa State Unviesity Press, Ames, IA. 
Sheppard, S.C., Gauder, C., Sheppard, M.I., Cureton, P.M. and Wong, M.P. (1992). The development of assessment and remediation guidelines for contaminated soils; a review of the science. Can. J. Soil Sci. 72, 359-394.

Shimojoh, M., Fukushima, K. and Kurita, K. (1998). Low-molecula- weight chitosans derived from $\beta$-chitin: preparation, molecular characteristics and aggregation activity. Carbohydr. Polym. 35, 223-231.

Siegel, F.R. (2002). Environmental Geochemistry of Potentially Toxic Metals. SpringerVerlag, Berlin, Germany. pp. 100-106.

Sikorski, Z., Olley, J. and Kostuch, S. (1976). Protein change in frozen fish. Crit. Rev. Food Sci. Nutr. 8 , 97-99.

Silva, A.M.M., Novelli, E.L.B., Fascineli, M.L. and Almeida, J.A. (1999). Impact of an environmentally realistic intake of water contaminants and superoxide formation on tissues of rats. Environ. Pollut. 105, 243-249.

Simpson, B.K. and Haard, N.F. (1985). The use of proteolytic enzymes to extract carotenoproteins from shrimp wastes J. Appl. Biochem. 7, 212-222.

Simpson, B.K., Gagne, N. and Simpson, M.V. (1994). Bioprocessing of chitin and chitosan. In Fisheries Processing: Biotechnological Applications. eds. A.M. Martin. Chapman and Hall, London, UK. pp. 155-173.

Simther-Kopperl, M.C. (2001). Chitin as biomass, its origin and role in nutrient cycling. Phytopathology 91, 5167-5170.

Singh, R.P. and Heldman, D.R. (1993). Introduction to Food Engineering. Academic Press, San Diego, CA. pp. 34-41.

Sittig, M. (1991). Handbook of Toxic and Hazardous Chemicals. $3^{\text {rd }}$ ed. Park Ridge, Noyes Publications, NJ. pp.1-6.

Smith, S. R., Hall, J.E. and Hadley, P.H. (1989). Composting sewage sludge wastes in relation to their suitability for use as fertilizer materials for vegetable crop production.In International Symposium of Compost Recycling of Waste. Athens, Greece. pp. 4-9.

Stickel, W.H. (1975). Effect of heavy metal and organochlorine compounds.In Ecological Toxicology Research. eds. A.D. McIntyre and C.F. Mills. Plenum Press, New York. NY. pp. 25-74.

Subasinghe, S. (1999). Chitin from shellfish waste-health benefits over-shadowing industrial uses. Infofish Int. 3, 58-65. 
Sudharsharshan, N.R., Hoover, D.G. and Knorr, D. (1992). Anti-bacterial action of chitosan. Food Biotechnol. 6, 257-272.

Sugano, M., Fujikawa, T., Hiratsuji, Y., Nakashima, K., Fukuda, N. and Hasegawa, Y. (1980). A novel use of chitosan as a hypocholesterolemic agent in rats. Am. J. Clin. Nutr. 38, 787-793.

Sugimoto, M., Morimoto, M., Sashiwa, H., Saimoto, H. and Shigemasa, Y. (1998). Preparation and characterization of water-soluble chitin and chitosan derivatives. Carbohydr. Polym. 36, 49-59.

Synowiecki, J. and Al-Khteeb, N.A.A.Q. (2000). The recovery of protein hydrolysate during enzymatic isolation of chitin from shrimp (Gangon crangon) processing discards. Food Chem. 68, 147-152.

Synowiecki, J., Sikorski, Z.E. and Naczk, M. (1981). Immobilization of invertase of krill chitin. Biotechnol. Bioeng. 23, 231-233.

Taylor, L.R. (1994). Electrochemical techniques for determining elements. Ch 5. In Instrumental Methods of Determining Elements: Selection and Application. ed. L.R. Taylor, Papp, R.B. and Pollard, B.D. VCH Publishing, Inc. New york, NY. pp. $85-129$

Taylor, L.R. and Pollard, B.D. (1994). Miscellaneous techniques for determining elements. Chapter 10. In Instrumental Methods of Determining elements: Selection and Application. L.R. Taylor, Papp, R.B. and Pollard, B.D. VCH Publishing, Inc. Newyork, NY.pp.300-316.

Tan, S.C., Tan, T.K., Wong, S.M. and Khor, E. (1996). The chitosan yield of zygomycetes at their optimum harvesting time. Carbohyd. Polym. 30, 239-242.

Tersawa, N., Murata, M. and Homma, S. (1991). Separation of model melanoidin into components with copper chelating sepharose 6B column chromatography and comparison of chelating activity. Agric. Biol. Chem. 55, 1507-1514.

Tirmizi, S.A., Iqbal, J. and Isa, M. (1996). Collection of metal ions present in water samples of different sites of Pakistan using biopolymer chitosan. J. Chem. Soc. Pakistan 18, 312-315.

Tozaki, H., Komoike, J., Tada, C., Maruyama, T., Terabe, A., Suzuki, T., Yamamoto, A. and Muranishi, S. (1997). Chitosan capsules for colon-specific drug delivery important of insulin absorption from the rat colon. J. Pharm. Sci. 86, 1016-1021.

Tyler, G. (1978). Leaching rates of heavy metal ions in forest soil. Water, Air Soil Pollution 9, 137-148. 
Udaybhaskar, P., Lyengar, L. and Prabakar, R.A.V.S. (1990). Hexavalent chromium interaction with chitosan. J. Appl. Polym. Sci. 39, 739-741.

Venkatrao, B., Baradarajan, A. and Sastry, C.A. (1986). Adsorption of dye stuffs on chitosan. In Chitin in Nature and Technology. eds. R.A.A. Muzzarelli, C. Jeuniax and G.W. Gooday, Plenum Press, New York. NY. pp. 554-559.

Volesky, B. (1987). Biosorbents for metal recovery. Trends Biotechnol. 5, 96-97.

Voutsa, D., Grimanis, A. and Samara, C. (1996). Trace elements in vegetables grown in an industrial area in relation to soil and air particulate matter. Environ. Polltu. 94, 325-335.

Waddel, T. E. and Bower, B.T. (1988). Managing agricultural chemicals. In The Environment the Case for a Multimedia Approach, The Conservation Foundation, Washington, D.C. pp. 42-43.

Wang, G. (1992). Introduction and inactivation of five species of food born pathogens by chitosan. J. Food Prot. 55, 916-919.

Webber, J. (1972). Effects of toxic metals in sewage sludge on crops. J. Water Pollu. Control 71, 404-413.

Weist, J.L. and Karel, M. (1992). Development of a fluorescence sensor to monitor lipid oxidation. 1. Fluorescence spectra of chitosan powder and polyamide powder after exposure to volatile lipid oxidation products. J. Agric. Food. Chem. $40,1158-1162$.

Wettasinghe, M. and Shahidi, F. (2002). Iron (II) chelation activity of extracts of borage and evening primrose meals. Food Res. Int. 35, 65-71.

Whisteler, R.S. and BeMiller, J.N. (1962). Chitin. J. Org. Chem. 27, 1161-1163.

Winterowd, J. G. and Sandford, P.A. (1995). Chitin and chitosan. In Food Polysaccharides and Their Applications. ed. A.M. Stephen, Marcel Deckker Inc. New York, NY. pp. 441-462.

Wolfrom, M.L. and ShenHan, T.M. (1959). The sulfonation of chitosan. J. Am. Chem. Soc. 81, 1764-1766.

World Resources Institute, 'World Resources 1994-95. (1994). A Guide to the Global Environment. Oxford University Press, New York.NY. pp.1-5.

Wu, A.C.M.,Bough, W.A., Conrad, E.C. and Aldfen, K.E.J. (1976). Determination of molecular-weight distribution of chitosan by high-performance liquid chromatography. J. Chromatogr. 128, 87-99. 
Wu, A.C.M., Bough, W.A., Holmes, M.R. and Perkins, B.E. (1978). Influence of manufacturing variables on the characteristics and effectiveness of chitosan products. III. Coagulation of cheese whey solids. Biotechnol. Bioeng. 20, 19571959.

Xue, H., Sigg, L. and Kari, F.G. (1995). Speciation of EDTA in natural waters: Exchange kinetics of Fe-EDTA in river water. Environ. Sci. Technol. 29, 59-68.

Yalpani, M., Johnson, F, and Robinson, L.E., (1992). Antimicrobial activity of some chitosan derivatives. In Advances in Chitin and Chitosan. eds. C.J. Brine, P.A. Sandford and J.P. Zikakis. Elsevier Applied Science, London, UK. pp. 543-555.

Yamasaki, S. and Tsmura, Y. (1992). Determination of ultra-trace levels of elements in water by high resolution ICP-MS with and ultrasonic nebulizer. Water Sci. Technol. 25, 205-212.

Yang, J.E., Kim, Y.K., Kim, J.H. and Park, Y.H. (2000). Environmental impacts and management strategies of trace metals in soil and groundwater in the republic of Korea. In Soils and Groundwater Pollution and Remediation Asia, Africa, and Oceania, Ch 11. eds. P.M. Huang and I.K. Iskandar. Lewis Publishers, New York, NY. pp. 284-287.

Zacour, A.C., Silva, M.E., Cecon, P.R., Bumbirra, E.A. and Vieira, E.C. (1992) Effect of dietary chitin on cholesterol absorption and metabolism in rats. J. Nutr. Sci. Vitaminol. 38, 309-316. 
APPENDIX 
Figure A.1 Dependence of the absorbance of diisopropylethylamine (DIPEA)-picrate concentration at $358 \mathrm{~nm}$ on the concentration of DIPEA-picrate.

Correlation coefficient $(r)=0.9945$

Equation of the line was $\mathrm{Y}=\mathrm{aX}+\mathrm{b}$ where, $\mathrm{Y}=$ absorbance at $358 \mathrm{~nm}\left(\mathrm{~A}_{358 \mathrm{~nm}}\right)$

$\mathrm{X}=$ concentration of DIPEA-picrate in $\mathrm{mol} / \mathrm{L}$

$\mathrm{a}=0.0126$

$\mathrm{b}=0.0$

Therefore, $\mathrm{X}=79.37 * \mathrm{~A}_{358 \mathrm{~nm}}$. 


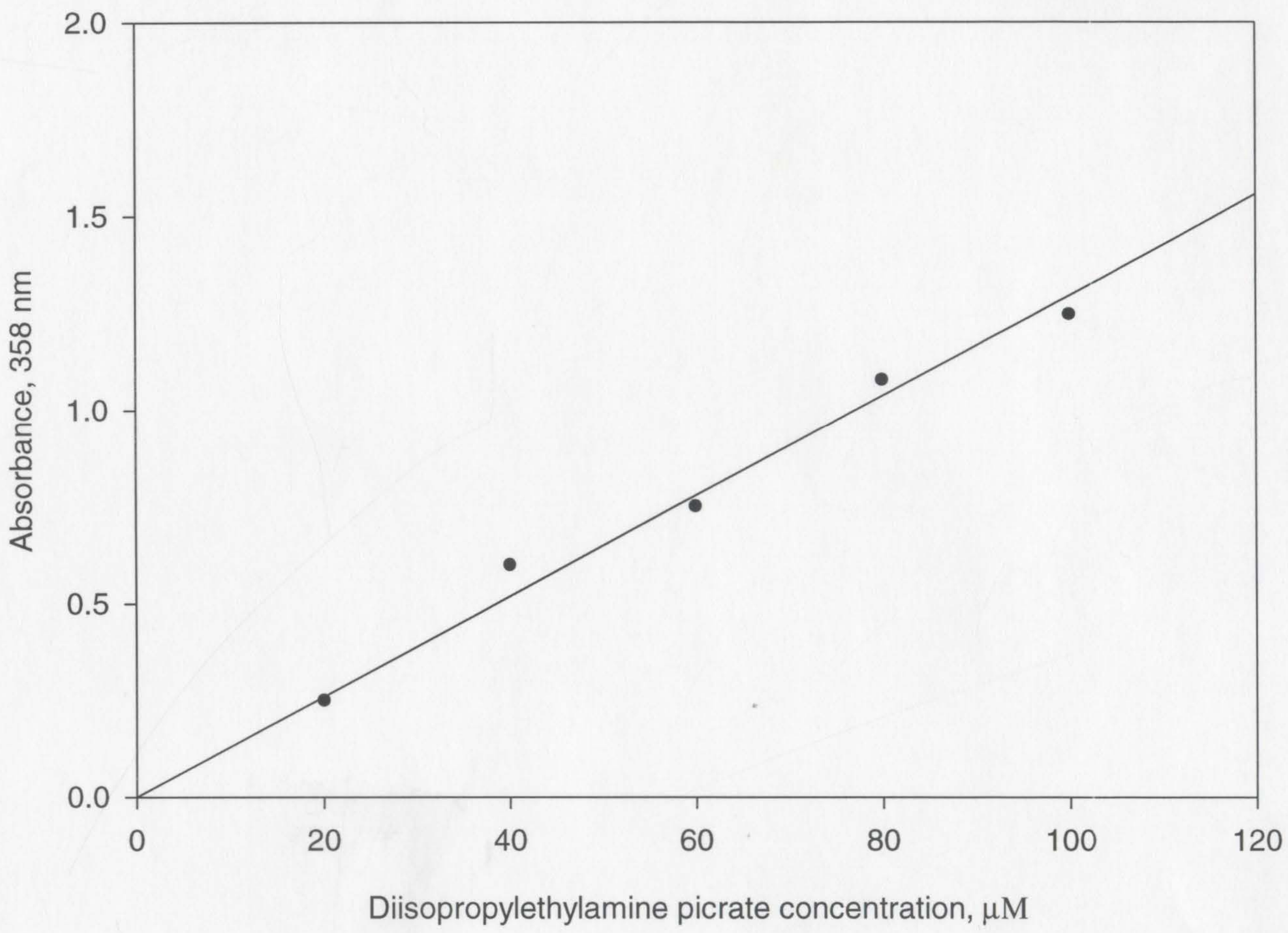


Table A.1 Sensory evaluation of crab waste at cold room temperature $\left(4-7^{\circ} \mathrm{C}\right)$.

\begin{tabular}{|c|c|c|c|c|c|c|}
\hline Days & HCHO & $\mathrm{HCOOH}$ & $\mathrm{CH}_{3} \mathrm{COOH}$ & $\mathrm{NaHCO}_{3}$ & $\mathrm{NaOH}$ & Control \\
\hline \multirow[t]{5}{*}{0} & $1-100$ & $1-100$ & $1-100$ & $1-100$ & $1-100$ & $1-100$ \\
\hline & $2-00$ & $2-00$ & $2-00$ & $2-00$ & $2-00$ & $2-00$ \\
\hline & $3-00$ & $3-00$ & $3-00$ & $3-00$ & $3-00$ & $3-00$ \\
\hline & $4-00$ & $4-00$ & $4-00$ & $4-00$ & $4-00$ & $4-00$ \\
\hline & $5-00$ & $5-00$ & $5-00$ & $5-00$ & $5-00$ & $5-00$ \\
\hline \multirow[t]{5}{*}{1} & $1-85.71$ & $1-57.14$ & $1-57.14$ & $1-28.57$ & $1-28.57$ & $1-00$ \\
\hline & $2-00$ & $2-14.28$ & $2-14.28$ & $2-42.85$ & $2-42.85$ & $2-71.42$ \\
\hline & $3-14.28$ & $3-28.57$ & $3-28.57$ & $3-28.57$ & $3-28.57$ & $3-28.57$ \\
\hline & $4-00$ & $4-00$ & $4-00$ & $4-00$ & $4-00$ & $4-00$ \\
\hline & $5-00$ & $5-00$ & $5-00$ & $5-00$ & $5-00$ & $5-00$ \\
\hline \multirow[t]{5}{*}{2} & $1-57.14$ & $1-57.14$ & $1-57.14$ & $1-57.14$ & $1-71.42$ & $1-57.14$ \\
\hline & $2-42.85$ & $2-42.85$ & $2-42.85$ & $2-42.85$ & $2-28.57$ & $2-28.71$ \\
\hline & $3-00$ & $3-00$ & $3-00$ & $3-00$ & $3-00$ & $3-14.28$ \\
\hline & $4-00$ & $4-00$ & $4-00$ & $4-00$ & $4-00$ & $4-00$ \\
\hline & $5-00$ & $5-00$ & $5-00$ & $5-00$ & $5-00$ & $5-00$ \\
\hline \multirow[t]{5}{*}{3} & $1-57.14$ & $1-42.85$ & $1-57.14$ & $1-57.14$ & $1-14.28$ & $1-14.28$ \\
\hline & $2-42.85$ & 2- 57.14 & $2-28.57$ & $2-14.28$ & $2-42.85$ & $2-57.14$ \\
\hline & $3-00$ & $3-00$ & $3-14.28$ & $3-28.57$ & $3-42.85$ & $3-28.57$ \\
\hline & $4-00$ & $4-00$ & $4-00$ & $4-00$ & $4-00$ & $4-00$ \\
\hline & $5-00$ & $5-00$ & $5-00$ & $5-00$ & $5-00$ & $5-00$ \\
\hline \multirow[t]{5}{*}{4} & $1-00$ & $1-00$ & $1-00$ & $1-00$ & $1-00$ & $1-00$ \\
\hline & $2-100$ & $2-100$ & $2-57.14$ & $2-57.14$ & $2-57.85$ & $2-57.14$ \\
\hline & $3-00$ & $3-00$ & $3-42.85$ & $3-42.85$ & $3-42.85$ & $3-42.85$ \\
\hline & $4-00$ & $4-00$ & $4-00$ & $4-00$ & $4-00$ & $4-00$ \\
\hline & $5-00$ & $5-00$ & $5-00$ & $5-00$ & $5-00$ & $5-00$ \\
\hline \multirow[t]{5}{*}{5} & $1-00$ & $1-00$ & $1-00$ & $1-00$ & $1-00$ & $1-00$ \\
\hline & $2-100$ & $2-100$ & $2-57.14$ & $2-57.14$ & $2-28.57$ & $2-00$ \\
\hline & $3-00$ & $3-00$ & $3-42.85$ & $3-42.85$ & $3-71.42$ & $3-100$ \\
\hline & $4-00$ & $4-00$ & $4-00$ & $4-00$ & $4-00$ & $4-00$ \\
\hline & $5-00$ & $5-00$ & $5-00$ & $5-00$ & $5-00$ & $5-00$ \\
\hline \multirow[t]{5}{*}{6} & $1-00$ & $1-00$ & $1-00$ & $1-00$ & $1-00$ & $1-00$ \\
\hline & $2-100$ & $2-100$ & $2-42.85$ & $2-00$ & $2-57.14$ & $2-00$ \\
\hline & $3-00$ & $3-00$ & $3-57.14$ & $3-42.85$ & $3-42.85$ & $3-42.85$ \\
\hline & $4-00$ & $4-00$ & $4-00$ & $4-57.14$ & $4-00$ & $4-57.14$ \\
\hline & $5-00$ & $5-00$ & $5-00$ & $5-00$ & $5-00$ & $5-00$ \\
\hline \multirow[t]{5}{*}{7} & $1-00$ & $1-00$ & $1-00$ & $1-00$ & $1-00$ & $1-00$ \\
\hline & $2-100$ & $2-28.57$ & $2-57.14$ & $2-00$ & $2-57.14$ & $2-00$ \\
\hline & $3-00$ & $3-71.42$ & $3-42.85$ & $3-57.14$ & $3-00$ & $3-28.57$ \\
\hline & $4-00$ & $4-00$ & $4-00$ & $4-42.85$ & $4-42.85$ & $4-71.42$ \\
\hline & $5-00$ & $5-00$ & $5-00$ & $5-00$ & $5-00$ & $5-00$ \\
\hline 8 & $1-00$ & $1-00$ & $1-00$ & $1-00$ & $1-00$ & $1-00$ \\
\hline
\end{tabular}




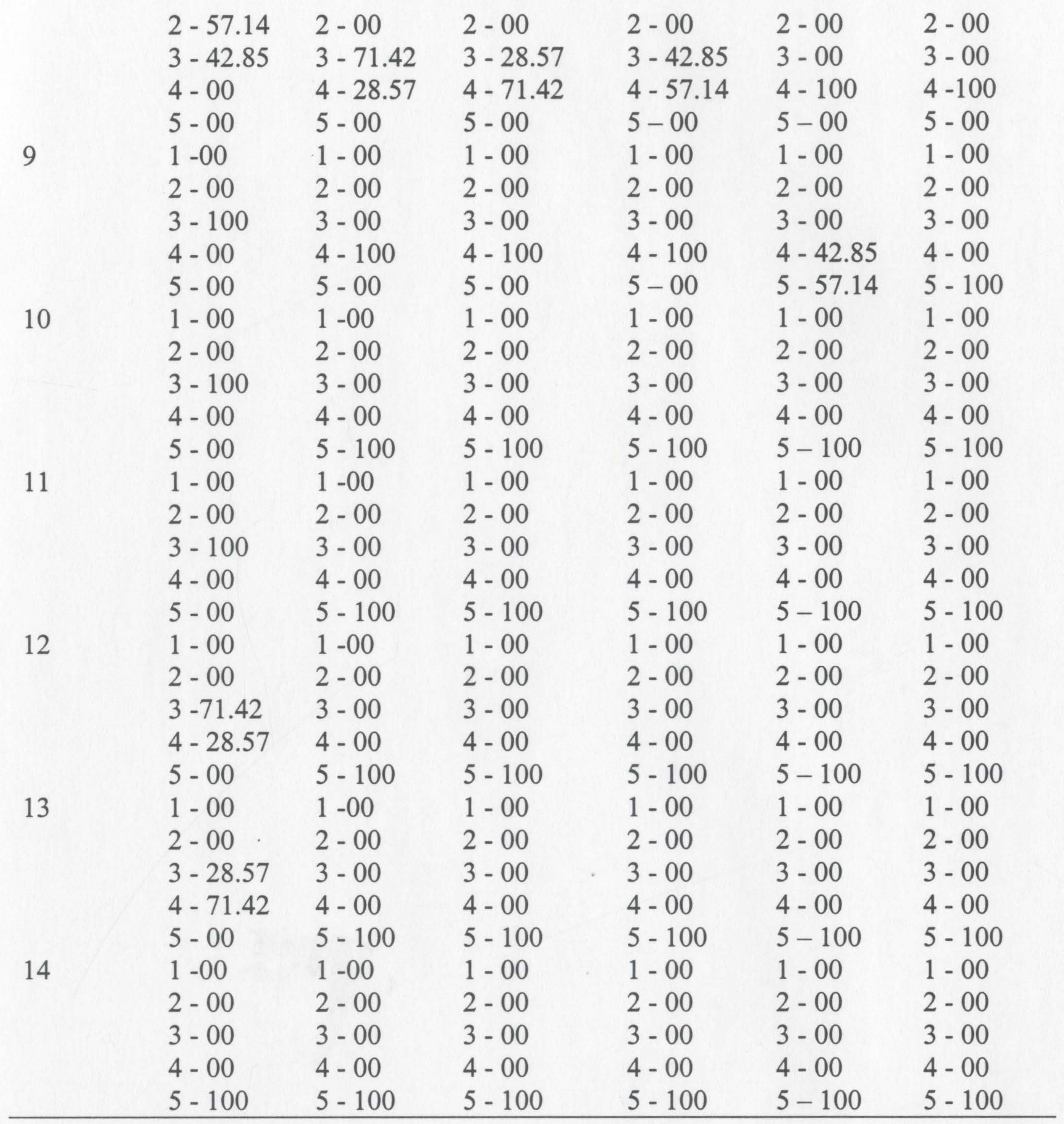

1- Excellent

2- Good

3-Moderate

4-Bad

5- Very bad 
Table A.2 Sensory evaluation of crab wastes at room temperature $\left(20-25^{\circ} \mathrm{C}\right)$.

\begin{tabular}{|c|c|c|c|c|c|c|}
\hline Days & HCHO & НCOOH & $\mathrm{CH}_{3} \mathrm{COOH}$ & $\mathrm{NaHCO}_{3}$ & $\mathrm{NaOH}$ & Control \\
\hline \multirow[t]{5}{*}{0} & $1-100$ & $1-100$ & $1-100$ & $1-100$ & $1-100$ & $1-100$ \\
\hline & $2-00$ & $2-00$ & $2-00$ & $2-00$ & $2-00$ & $2-00$ \\
\hline & $3-00$ & $3-00$ & $3-00$ & $3-00$ & $3-00$ & $3-00$ \\
\hline & $4-00$ & $4-00$ & $4-00$ & $4-00$ & $4-00$ & $4-00$ \\
\hline & $5-00$ & $5-00$ & $5-00$ & $5-00$ & $5-00$ & $5-00$ \\
\hline \multirow[t]{5}{*}{1} & $1-00$ & $1-00$ & $1-00$ & $1-00$ & $1-00$ & $1-00$ \\
\hline & $2-57.14$ & $2-28.57$ & $2-28.57$ & $2-00$ & $2-00$ & $2-00$ \\
\hline & $3-42.85$ & $3-71.42$ & $3-42.85$ & $3-57.85$ & $3-57.14$ & $3-28.57$ \\
\hline & $4-00$ & $4-00$ & $4-00$ & $4-42.85$ & $4-14.28$ & $4-71.42$ \\
\hline & $5-00$ & $5-00$ & $5-28.57$ & $5-00$ & $5-28.57$ & $5-00$ \\
\hline \multirow[t]{5}{*}{2} & $1-00$ & $1-00$ & $1-57.14$ & $1-00$ & $1-00$ & $1-00$ \\
\hline & $2-00$ & $2-00$ & $2-42.85$ & $2-00$ & $2-00$ & $2-00$ \\
\hline & $3-85.71$ & $3-42.85$ & $3-00$ & $3-00$ & $3-00$ & $3-00$ \\
\hline & $4-00$ & $4-57.85$ & $4-00$ & $4-00$ & $4-00$ & $4-00$ \\
\hline & $5-14.28$ & $5-00$ & $5-00$ & $5-100$ & $5-100$ & $5-100$ \\
\hline \multirow[t]{5}{*}{3} & $1-00$ & $1-00$ & $1-00$ & $1-00$ & $1-00$ & $1-00$ \\
\hline & $2-00$ & $2-00$ & $2-00$ & $2-00$ & $2-00$ & $2-00$ \\
\hline & $3-14.28$ & $3-00$ & $3-00$ & $3-00$ & $3-00$ & $3-00$ \\
\hline & $4-85.71$ & $4-100$ & $4-100$ & $4-100$ & $4-100$ & $4-100$ \\
\hline & $5-00$ & $5-00$ & $5-00$ & $5-00$ & $5-00$ & $5-00$ \\
\hline \multirow[t]{5}{*}{4} & $1-00$ & $1-00$ & $1-00$ & $1-00$ & $1-00$ & $1-00$ \\
\hline & $2-00$ & $2-100$ & $2-00$ & $2-00$ & $2-00$ & $2-00$ \\
\hline & $3-00$ & $3-00$ & $3-00$ & $3-00$ & $3-00$ & $3-00$ \\
\hline & $4-100$ & $4-100$ & $4-00$ & $4-00$ & $4-00$ & $4-00$ \\
\hline & $5-00$ & $5-00$ & $5-100$ & $5-100$ & $5-100$ & $5-100$ \\
\hline \multirow[t]{5}{*}{5} & $1-00$ & $1-00$ & $1-00$ & $1-00$ & $1-00$ & $1-00$ \\
\hline & $2-00$ & $2-00$ & $2-00$ & $2-00$ & $2-00$ & $2-00$ \\
\hline & $3-00$ & $3-00$ & $3-00$ & $3-00$ & $3-00$ & $3-00$ \\
\hline & $4-100$ & $4-00$ & $4-00$ & $4-00$ & $4-00$ & $4-00$ \\
\hline & $5-00$ & $5-100$ & $5-100$ & $5-100$ & $5-100$ & $5-100$ \\
\hline \multirow[t]{5}{*}{6} & $1-00$ & $1-00$ & $1-00$ & $1-00$ & $1-00$ & $1-00$ \\
\hline & $2-00$ & $2-00$ & $2-00$ & $2-00$ & $2-00$ & $2-00$ \\
\hline & $3-00$ & $3-00$ & $3-00$ & $3-00$ & $3-00$ & $3-00$ \\
\hline & $4-00$ & $4-00$ & $4-00$ & $4-00$ & $4-00$ & $4-00$ \\
\hline & $5-100$ & $5-100$ & $5-100$ & $5-100$ & $5-100$ & $5-100$ \\
\hline
\end{tabular}

1-Excellent

2-Good

3-Moderate

4-Bad

5 -Very bad 
Table A3 Chelation capacity (\%) of chitosan and EDTA over 24 hour at pH 5.

\begin{tabular}{|c|c|c|c|c|c|c|}
\hline $\begin{array}{l}\text { Metal } \\
\text { ion }\end{array}$ & Chelator & $\mathbf{O h}$ & $1 \mathrm{~h}$ & $\mathbf{3 h}$ & $6 h$ & $24 h$ \\
\hline \multirow[t]{4}{*}{$\mathrm{Fe}^{2+}$} & Type 1 & $46.40 \pm 3.03^{\mathrm{Db}}$ & $25.26 \pm 2.28^{\mathrm{Aa}}$ & $33.12 \pm 0.69^{\mathrm{Ba}}$ & $39.13 \pm 0.79^{\mathrm{Cb}}$ & $27.14 \pm 1.87^{\mathrm{Ab}}$ \\
\hline & Type 2 & $43.85 \pm 0.45^{\mathrm{AbC}}$ & $22.46 \pm 2.62^{\mathrm{aA}}$ & $32.53 \pm 4.90^{\mathrm{aB}}$ & $34.56 \pm 2.11^{\mathrm{aB}}$ & $21.33 \pm 2.52^{\mathrm{aA}}$ \\
\hline & Type 3 & $39.64 \pm 8.03^{\mathrm{aC}}$ & $25.96 \pm 1.59^{\mathrm{aA}}$ & $34.92 \pm 3.96^{\mathrm{aB}}$ & $34.62 \pm 1.59^{\mathrm{aB}}$ & $43.04 \pm 0.95^{\mathrm{cD}}$ \\
\hline & EDTA & $57.69 \pm 1.11^{\mathrm{cA}}$ & $65.59 \pm 1.23^{\mathrm{bB}}$ & $93.63 \pm 0.79^{b C}$ & $92.52 \pm 0.89^{c C}$ & $55.66 \pm 1.93^{\mathrm{dA}}$ \\
\hline \multirow[t]{4}{*}{$\mathrm{Co}^{2+}$} & Type 1 & $49.23 \pm 0.20^{\mathrm{BCb}}$ & $48.50 \pm 1.92^{\mathrm{ABCa}}$ & $44.98 \pm 0.58^{\mathrm{Aa}}$ & $47.77 \pm 0.28^{\mathrm{ABCa}}$ & $50.85 \pm 0.16^{\mathrm{Ca}}$ \\
\hline & Type 2 & $44.79 \pm 3.91^{\mathrm{ABa}}$ & $48.61 \pm 1.36^{\mathrm{BCa}}$ & $44.04 \pm 0.83^{\mathrm{Aa}}$ & $46.91 \pm 0.95^{\mathrm{ABCa}}$ & $49.68 \pm 0.62^{\mathrm{Ca}}$ \\
\hline & Type 3 & $47.36 \pm 0.69^{\mathrm{Bab}}$ & $47.79 \pm 0.37^{\mathrm{Ba}}$ & $41.65 \pm 1.18^{\mathrm{Aa}}$ & $45.75 \pm 1.06^{\mathrm{Ba}}$ & $48.20 \pm 0.42^{\mathrm{Ba}}$ \\
\hline & EDTA & $57.89 \pm 1.08 \mathrm{Ac}$ & $66.96 \pm 2.09^{\mathrm{Ba}}$ & $71.71 \pm 0.97^{\mathrm{Cb}}$ & $94.30 \pm 3.38^{\mathrm{Db}}$ & $98.73 \pm 0.19^{\mathrm{Db}}$ \\
\hline \multirow[t]{4}{*}{$\mathrm{Ni}^{2+}$} & Type 1 & $39.97 \pm 5.90^{\mathrm{Aa}}$ & $43.85 \pm 0.69^{\mathrm{Aa}}$ & $42.83 \pm 0.36^{\mathrm{Aa}}$ & $41.64 \pm 1.12^{\mathrm{Aa}}$ & $42.20 \pm 0.16^{\mathrm{Aa}}$ \\
\hline & Type 2 & $42.98 \pm 0.25^{\mathrm{Aa}}$ & $42.44 \pm 0.41^{\mathrm{Aa}}$ & $42.44 \pm 0.91^{\mathrm{Aa}}$ & $40.91 \pm 0.62^{\mathrm{Aa}}$ & $41.77 \pm 0.32^{\mathrm{Aa}}$ \\
\hline & Type 3 & $44.49 \pm 0.69^{\mathrm{Aa}}$ & $43.68 \pm 0.74^{\mathrm{Aa}}$ & $43.10 \pm 0.47^{\mathrm{Aa}}$ & $44.70 \pm 0.02^{\mathrm{Aa}}$ & $43.03 \pm 0.61^{\mathrm{Aa}}$ \\
\hline & EDTA & $50.96 \pm 0.83^{\mathrm{Ab}}$ & $56.08 \pm 0.63^{\mathrm{Bb}}$ & $61.01 \pm 0.79^{\mathrm{Cb}}$ & $92.70 \pm 0.75^{\mathrm{Db}}$ & $93.42 \pm 0.45^{\mathrm{Db}}$ \\
\hline \multirow[t]{4}{*}{$\mathrm{Mn}^{2+}$} & Type 1 & $71.28 \pm 0.26^{\mathrm{Bc}}$ & $75.94 \pm 0.72^{\mathrm{BCb}}$ & $77.70 \pm 0.00^{\mathrm{Cb}}$ & $82.89 \pm 1.59^{\mathrm{Db}}$ & $43.19 \pm 1.45^{\mathrm{Ac}}$ \\
\hline & Type 2 & $66.72 \pm 0.00^{\mathrm{Bc}}$ & $74.40 \pm 0.58^{\mathrm{Cb}}$ & $72.70 \pm 0.00^{\mathrm{Cb}}$ & $79.64 \pm 0.58^{\mathrm{Db}}$ & $35.68 \pm 3.14^{\mathrm{Ab}}$ \\
\hline & Type 3 & $44.46 \pm 0.00^{\mathrm{Ba}}$ & $69.43 \pm 0.00^{\mathrm{Da}}$ & $55.50 \pm 1.00^{\mathrm{Ca}}$ & $45.94 \pm 0.64^{\mathrm{Ba}}$ & $20.26 \pm 0.01^{\mathrm{Aa}}$ \\
\hline & EDTA & $75.89 \pm 2.56 \mathrm{Ac}$ & $80.76 \pm 0.19 \mathrm{Ac}$ & $87.29 \pm 1.93^{\mathrm{Bc}}$ & $91.00 \pm 0.49^{\mathrm{Bc}}$ & $97.54 \pm 0.66^{\mathrm{Cd}}$ \\
\hline \multirow[t]{4}{*}{$\mathrm{Cu}^{2+}$} & Type 1 & $11.76 \pm 0.19^{\mathrm{Aa}}$ & $21.12 \pm 3.50^{\mathrm{Bb}}$ & $29.63 \pm 1.91^{\mathrm{Cb}}$ & $48.07 \pm 9.25^{\mathrm{Dc}}$ & $79.31 \pm 5.32^{\mathrm{Ec}}$ \\
\hline & Type 2 & $9.59 \pm 0.27^{\mathrm{Aa}}$ & $11.19 \pm 2.89^{\mathrm{ABa}}$ & $15.19 \pm 1.39^{\mathrm{Ba}}$ & $21.40 \pm 4.14^{\mathrm{Ca}}$ & $55.30 \pm 3.24^{\mathrm{Da}}$ \\
\hline & Type 3 & $10.56 \pm 0.22^{\mathrm{Aa}}$ & $19.76 \pm 0.72^{\mathrm{Bb}}$ & $15.22 \pm 3.82^{\mathrm{Ba}}$ & $37.79 \pm 3.83^{\mathrm{Cb}}$ & $71.97 \pm 2.94^{\mathrm{Db}}$ \\
\hline & EDTA & $36.62 \pm 1.80^{\mathrm{Ab}}$ & $44.40 \pm 1.48^{\mathrm{Bc}}$ & $50.83 \pm 0.15^{\mathrm{Cc}}$ & $76.68 \pm 0.93^{\mathrm{Dd}}$ & $91.61 \pm 0.25^{\mathrm{Ed}}$ \\
\hline \multirow[t]{4}{*}{$\mathrm{Zn}^{2+}$} & Type 1 & $49.66 \pm 2.01^{\mathrm{Aa}}$ & $51.28 \pm 0.27^{\mathrm{Ab}}$ & $52.04 \pm 0.00^{\mathrm{Ab}}$ & $52.65 \pm 0.04^{\mathrm{Ab}}$ & $51.48 \pm 0.79^{\mathrm{Ab}}$ \\
\hline & Type 2 & $46.06 \pm 5.39^{\mathrm{Aa}}$ & $49.00 \pm 0.87^{\mathrm{Aba}}$ & $50.32 \pm 0.15^{\text {Bab }}$ & $51.64 \pm 0.81^{\text {Bab }}$ & $50.75 \pm 0.86^{\mathrm{Bab}}$ \\
\hline & Type 3 & $48.24 \pm 0.81^{\mathrm{Aa}}$ & $45.98 \pm 0.70^{\mathrm{Aa}}$ & $46.25 \pm 0.81^{\mathrm{Aa}}$ & $48.20 \pm 0.54^{\mathrm{Aa}}$ & $46.80 \pm 0.36^{\mathrm{Aa}}$ \\
\hline & EDTA & $66.12 \pm 0.59^{\mathrm{Aa}}$ & $71.11 \pm 0.70^{\mathrm{Bc}}$ & $86.15 \pm 1.55^{\mathrm{Cc}}$ & $95.23 \pm 0.77^{\mathrm{Db}}$ & $97.00 \pm 0.30^{\mathrm{Ec}}$ \\
\hline \multirow[t]{4}{*}{$\mathrm{Cd}^{2+}$} & Type 1 & $29.19 \pm 2.02^{\mathrm{Aa}}$ & $42.95 \pm 3.13^{\mathrm{Ca}}$ & $56.69 \pm 1.49^{\mathrm{Da}}$ & $44.29 \pm 3.79^{\mathrm{Cb}}$ & $38.67 \pm 7.78^{\mathrm{Ba}}$ \\
\hline & Type 2 & $52.94 \pm 2.93^{\mathrm{Cc}}$ & $45.18 \pm 5.08^{\mathrm{Bb}}$ & $64.22 \pm 7.51^{\mathrm{Dc}}$ & $40.36 \pm 5.03^{\mathrm{Aa}}$ & $52.25 \pm 8.90^{\mathrm{Cc}}$ \\
\hline & Type 3 & $49.05 \pm 3.04^{\mathrm{BCb}}$ & $52.69 \pm 1.53^{\mathrm{Cc}}$ & $61.00 \pm 10.64^{\mathrm{Db}}$ & $44.54 \pm 6.08^{\mathrm{Ab}}$ & $48.85 \pm 1.21^{\mathrm{Bb}}$ \\
\hline & EDTA & $67.03 \pm 2.35^{\mathrm{Ad}}$ & $75.69 \pm 0.27^{\mathrm{Bd}}$ & $82.55 \pm 1.12^{\mathrm{Cd}}$ & $87.30 \pm 1.94^{\mathrm{Dc}}$ & $90.49 \pm 0.95^{\mathrm{Dd}}$ \\
\hline
\end{tabular}

Types. 1,2 and 3 -Types of chitosan.

Results reported are mean vales of three determinations \pm standard deviation.

Means in each column sharing the same superscript are not significantly $(p>0.05)$ different from one another. 
Table A4 Chelation capacity (\%) of chitosan and EDTA over 24 hour at pH 6.

\begin{tabular}{|c|c|c|c|c|c|c|}
\hline $\begin{array}{l}\text { Metal } \\
\text { ion }\end{array}$ & Chelator & $\mathbf{O h}$ & $1 \mathrm{~h}$ & 3h & $6 h$ & $24 h$ \\
\hline \multirow[t]{4}{*}{$\mathrm{Fe}^{2+}$} & Type 1 & $14.45 \pm 2.53^{\mathrm{Ab}}$ & $33.87 \pm 2.88^{\mathrm{Cb}}$ & $60.14 \pm 2.82^{\mathrm{Da}}$ & $74.63 \pm 2.01^{\mathrm{Ec}}$ & $21.73 \pm 1.57^{\mathrm{Bb}}$ \\
\hline & Type 2 & $13.99 \pm 3.04^{\mathrm{Ab}}$ & $26.01 \pm 2.79^{\mathrm{Db}}$ & $69.86 \pm 3.62^{\mathrm{Db}}$ & $57.90 \pm 1.39^{\mathrm{Cb}}$ & $27.74 \pm 0.71^{\mathrm{Bc}}$ \\
\hline & Type 3 & $9.14 \pm 1.18^{\mathrm{Aa}}$ & $30.15 \pm 4.63^{\mathrm{Ea}}$ & $61.57 \pm 6.64^{\mathrm{Ea}}$ & $51.13 \pm 7.07^{\mathrm{Da}}$ & $17.94 \pm 0.76^{\mathrm{Ba}}$ \\
\hline & EDTA & $30.32 \pm 4.07^{\mathrm{Ac}}$ & $55.19 \pm 2.93^{\mathrm{Cc}}$ & $86.20 \pm 5.56^{\mathrm{Cc}}$ & $90.38 \pm 1.48^{\mathrm{Cd}}$ & $56.67 \pm 1.84^{\mathrm{Bd}}$ \\
\hline \multirow[t]{4}{*}{$\mathrm{Co}^{2+}$} & Type 1 & $2.75 \pm 0.18^{\mathrm{Aa}}$ & $2.26 \pm 0.22^{\mathrm{Aa}}$ & $2.94 \pm 0.00^{\mathrm{Aa}}$ & $2.08 \pm 0.00^{\mathrm{Aa}}$ & $2.23 \pm 0.42^{\mathrm{Aa}}$ \\
\hline & Type 2 & $2.01 \pm 0.71 \mathrm{~A}^{\mathrm{Ba}}$ & $2.21 \pm 0.16^{\mathrm{Ba}}$ & $1.91 \pm 0.06^{\mathrm{Aa}}$ & $1.09 \pm 0.00^{\mathrm{Aa}}$ & $1.32 \pm 0.00^{\mathrm{Aa}}$ \\
\hline & Type 3 & $3.68 \pm 0.10^{\mathrm{Ba}}$ & $1.40 \pm 0.24^{\mathrm{Aa}}$ & $1.19 \pm 0.10^{\mathrm{Aa}}$ & $1.30 \pm 0.20^{\mathrm{Aa}}$ & $1.19 \pm 0.00^{\mathrm{Aa}}$ \\
\hline & EDTA & $49.07 \pm 0.62^{\mathrm{Ab}}$ & $92.90 \pm 4.19^{\mathrm{Bb}}$ & $97.49 \pm 0.99^{\mathrm{BCb}}$ & $96.97 \pm 1.04^{\mathrm{BCb}}$ & $98.69 \pm 0.34^{\mathrm{Cb}}$ \\
\hline \multirow[t]{4}{*}{$\mathrm{Ni}^{2+}$} & Type 1 & $1.12 \pm 0.00^{\mathrm{Aa}}$ & $2.17 \pm 1.07^{\mathrm{Aa}}$ & $5.75 \pm 0.00^{\mathrm{Ba}}$ & $8.31 \pm 1.00^{\mathrm{Bb}}$ & $7.83 \pm 0.67^{\mathrm{Bc}}$ \\
\hline & Type 2 & $1.74 \pm 0.00^{\mathrm{Aa}}$ & $1.72 \pm 0.00^{\mathrm{Aa}}$ & $5.35 \pm 0.00^{\mathrm{Ba}}$ & $5.80 \pm 0.63^{\mathrm{ba}}$ & $4.48 \pm 1.27^{\mathrm{Ba}}$ \\
\hline & Type 3 & $1.33 \pm 0.00^{\mathrm{Aa}}$ & $1.69 \pm 0.68^{\mathrm{Aa}}$ & $6.80 \pm 0.00^{\mathrm{Ba}}$ & $6.58 \pm 0.96^{\mathrm{Bab}}$ & $6.80 \pm 0.10^{\mathrm{Ba}}$ \\
\hline & EDTA & $25.02 \pm 0.31^{\mathrm{Ab}}$ & $31.92 \pm 1.38^{\mathrm{Bb}}$ & $48.05 \pm 0.00^{\mathrm{Cb}}$ & $90.63 \pm 0.10^{\mathrm{Dc}}$ & $90.87 \pm 0.08^{\mathrm{Dd}}$ \\
\hline \multirow[t]{4}{*}{$\mathrm{Mn}^{2+}$} & Type 1 & $13.56 \pm 3.34^{\mathrm{Ba}}$ & $9.32 \pm 3.64^{\mathrm{Aa}}$ & $8.87 \pm 2.90^{\mathrm{Aa}}$ & $7.19 \pm 2.74^{\mathrm{Ab}}$ & $43.69 \pm 12.16^{\mathrm{Ca}}$ \\
\hline & Type 2 & $19.15 \pm 1.98^{\mathrm{Bb}}$ & $10.08 \pm 3.48^{\mathrm{Aa}}$ & $11.16 \pm 4.52^{\mathrm{Aa}}$ & $10.65 \pm 1.86^{\mathrm{Ac}}$ & $53.03 \pm 5.04^{\mathrm{Cb}}$ \\
\hline & Type 3 & $19.13 \pm 2.93^{\mathrm{Cb}}$ & $10.28 \pm 0.14^{\mathrm{Ba}}$ & $9.82 \pm 1.62^{\mathrm{Ba}}$ & $3.01 \pm 0.00^{\mathrm{Aa}}$ & $44.56 \pm 7.57^{\mathrm{Da}}$ \\
\hline & EDTA & $37.43 \pm 1.95^{\mathrm{Ac}}$ & $36.85 \pm 2.79^{\mathrm{Ab}}$ & $53.04 \pm 3.61^{\mathrm{Bb}}$ & $95.92 \pm 3.08^{\mathrm{Cd}}$ & $99.40 \pm 0.00^{\mathrm{Cc}}$ \\
\hline \multirow[t]{4}{*}{$\mathrm{Cu}^{2+}$} & Type 1 & $9.68 \pm 2.08^{\mathrm{Ab}}$ & $26.38 \pm 1.19^{\mathrm{Cc}}$ & $31.35 \pm 0.80^{\mathrm{Da}}$ & $22.84 \pm 0.08^{\mathrm{Ca}}$ & $18.83 \pm 0.59^{\mathrm{Bb}}$ \\
\hline & Type 2 & $6.95 \pm 0.73^{\mathrm{Aa}}$ & $18.50 \pm 0.69^{\text {ba }}$ & $28.52 \pm 0.41^{\mathrm{Da}}$ & $22.44 \pm 0.57^{\mathrm{Ca}}$ & $9.59 \pm 1.04^{\mathrm{Aa}}$ \\
\hline & Type 3 & $6.46 \pm 0.60^{\mathrm{Aa}}$ & $22.05 \pm 1.10^{\mathrm{Cb}}$ & $32.00 \pm 0.07^{\mathrm{Da}}$ & $25.34 \pm 0.59^{\mathrm{Cb}}$ & $16.73 \pm 0.66^{\mathrm{Bb}}$ \\
\hline & EDTA & $24.20 \pm 1.04^{\mathrm{Ac}}$ & $44.30 \pm 1.51^{\mathrm{Bd}}$ & $72.32 \pm 0.44^{\mathrm{Cb}}$ & $79.14 \pm 0.94^{\mathrm{Dc}}$ & $91.60 \pm 0.76^{\mathrm{Ec}}$ \\
\hline \multirow[t]{4}{*}{$\mathrm{Zn}^{2+}$} & Type 1 & $2.64 \pm 0.34^{\mathrm{Aa}}$ & $3.75 \pm 0.49^{\mathrm{Aba}}$ & $4.39 \pm 0.36^{\mathrm{Ba}}$ & $4.08 \pm 0.67^{\mathrm{Bb}}$ & $5.88 \pm 0.82^{\mathrm{Bb}}$ \\
\hline & Type 2 & $1.93 \pm 0.31^{\mathrm{Aa}}$ & $2.81 \pm 0.44^{\mathrm{Aa}}$ & $3.31 \pm 0.45^{\mathrm{Ba}}$ & $2.63 \pm 0.26^{\mathrm{Aa}}$ & $3.59 \pm 0.36^{\mathrm{Ba}}$ \\
\hline & Type 3 & $1.96 \pm 0.49^{\mathrm{Aa}}$ & $2.67 \pm 0.09^{\mathrm{Aa}}$ & $3.66 \pm 0.42^{\mathrm{Ba}}$ & $2.43 \pm 0.37^{\mathrm{Aa}}$ & $3.07 \pm 0.25^{\mathrm{Aa}}$ \\
\hline & EDTA & $20.56 \pm 1.31^{\mathrm{Ab}}$ & $58.14 \pm 0.04^{\mathrm{Bb}}$ & $72.37 \pm 0.00^{\mathrm{Cb}}$ & $92.94 \pm 0.33^{D c}$ & $94.02 \pm 0.24^{\mathrm{Dc}}$ \\
\hline \multirow[t]{4}{*}{$\mathrm{Cd}^{2+}$} & Type 1 & $22.18 \pm 0.21^{\mathrm{Aa}}$ & $22.60 \pm 0.11^{\mathrm{Aa}}$ & $23.62 \pm 0.28^{\mathrm{Aa}}$ & $23.82 \pm 0.08^{\mathrm{Aa}}$ & $23.90 \pm 0.69^{\mathrm{Aa}}$ \\
\hline & Type 2 & $21.78 \pm 0.25^{\mathrm{Aa}}$ & $22.36 \pm 0.11^{\mathrm{Aa}}$ & $23.19 \pm 0.35^{\mathrm{Aa}}$ & $23.02 \pm 0.08^{\mathrm{Aa}}$ & $22.50 \pm 0.15^{\mathrm{Aa}}$ \\
\hline & Type 3 & $21.70 \pm 0.19^{\mathrm{Aa}}$ & $22.39 \pm 0.26^{\mathrm{Aa}}$ & $22.85 \pm 0.22^{\mathrm{Aa}}$ & $23.05 \pm 0.28^{\mathrm{Aa}}$ & $22.48 \pm 0.11^{\mathrm{Aa}}$ \\
\hline & EDTA & $24.41 \pm 5.11^{\mathrm{Ab}}$ & $32.54 \pm 0.16^{\mathrm{Bb}}$ & $47.79 \pm 0.65^{\mathrm{Cb}}$ & $49.43 \pm 1.25^{\mathrm{Cb}}$ & $76.60 \pm 1.05^{\mathrm{Db}}$ \\
\hline
\end{tabular}

Types 1,2 and 3 -Types of chitosan.

Results reported are mean vales of three determinations \pm standard deviation.

Means in each column sharing the same superscript are not significantly $(\mathrm{p}>0.05)$ different from one another. 
Table A5 Chelation capacity (\%) of chitosan and EDTA over 24 hour at pH 7.

\begin{tabular}{|c|c|c|c|c|c|c|}
\hline $\begin{array}{l}\text { Metal } \\
\text { ion }\end{array}$ & Chelator & $\mathbf{O h}$ & $1 \mathrm{~h}$ & $3 h$ & $6 h$ & $24 h$ \\
\hline \multirow[t]{4}{*}{$\mathrm{Fe}^{2+}$} & Type 1 & $2.09 \pm 0.15^{\mathrm{Bb}}$ & $11.99 \pm 0.29^{\mathrm{Cb}}$ & $55.62 \pm 7.08^{\mathrm{Da}}$ & $0.38 \pm 0.16^{\mathrm{Aa}}$ & $0.09 \pm 0.03^{\mathrm{Aa}}$ \\
\hline & Type 2 & $0.94 \pm 0.79^{\mathrm{Aa}}$ & $6.57 \pm 0.00^{\mathrm{Ba}}$ & $53.53 \pm 7.64^{\mathrm{Ca}}$ & $0.60 \pm 0.02^{\mathrm{Aa}}$ & $0.14 \pm 0.06^{\mathrm{Aa}}$ \\
\hline & Type 3 & $0.97 \pm 0.08^{\mathrm{Aa}}$ & $5.29 \pm 0.93^{\mathrm{Ba}}$ & $50.32 \pm 10.01^{\mathrm{Ca}}$ & $0.85 \pm 0.05^{\mathrm{Ab}}$ & $0.25 \pm 0.00^{\mathrm{Ab}}$ \\
\hline & EDTA & $2.55 \pm 0.29^{\mathrm{Bb}}$ & $22.23 \pm 0.12^{\mathrm{Cc}}$ & $67.36 \pm 0.89^{\mathrm{Db}}$ & $2.15 \pm 0.08^{\mathrm{Bc}}$ & $1.82 \pm 0.00^{\mathrm{Ab}}$ \\
\hline \multirow[t]{4}{*}{$\mathrm{Co}^{2+}$} & Type 1 & $13.74 \pm 0.37^{\mathrm{Aa}}$ & $15.15 \pm 0.71^{\mathrm{Ba}}$ & $17.31 \pm 3.59^{\mathrm{Cb}}$ & $14.38 \pm 0.07^{\mathrm{Aa}}$ & $14.69 \pm 0.28^{\mathrm{Aa}}$ \\
\hline & Type 2 & $14.41 \pm 1.77^{\mathrm{Aa}}$ & $14.52 \pm 0.14^{\mathrm{Aa}}$ & $14.22 \pm 0.26^{\mathrm{Aa}}$ & $14.27 \pm 0.25^{\mathrm{Aa}}$ & $13.75 \pm 0.27^{\mathrm{Aa}}$ \\
\hline & Type 3 & $14.12 \pm 0.16^{\mathrm{Aa}}$ & $15.16 \pm 0.10^{\mathrm{Aa}}$ & $14.63 \pm 0.19^{\mathrm{Aa}}$ & $15.17 \pm 0.29^{\mathrm{Aa}}$ & $14.34 \pm 0.14^{\mathrm{Aa}}$ \\
\hline & EDTA & $35.18 \pm 3.24^{\mathrm{Ab}}$ & $55.51 \pm 1.71^{\mathrm{Bb}}$ & $83.81 \pm 2.71^{\mathrm{Cc}}$ & $82.51 \pm 1.31^{\mathrm{Cb}}$ & $89.96 \pm 1.83^{\mathrm{Db}}$ \\
\hline \multirow[t]{4}{*}{$\mathrm{Ni}^{2+}$} & Type 1 & $2.19 \pm 0.22^{\mathrm{Ab}}$ & $2.86 \pm 0.08^{\mathrm{Ab}}$ & $3.57 \pm 0.09^{\mathrm{Ab}}$ & $5.15 \pm 0.53^{\mathrm{Bc}}$ & $6.17 \pm 0.72^{\mathrm{Bb}}$ \\
\hline & Type 2 & $0.62 \pm 0.35^{\mathrm{Ba}}$ & $0.59 \pm 0.03^{\mathrm{Ba}}$ & $0.24 \pm 0.06^{\mathrm{Aa}}$ & $0.89 \pm 0.52^{\mathrm{Ba}}$ & $1.76 \pm 0.23^{\mathrm{Ca}}$ \\
\hline & Type 3 & $0.23 \pm 0.12^{\mathrm{Aa}}$ & $1.23 \pm 0.06 \mathrm{~A}^{\mathrm{Ba}}$ & $2.17 \pm 0.21^{\mathrm{Bb}}$ & $3.32 \pm 0.89^{\mathrm{Cb}}$ & $5.04 \pm 0.04^{\mathrm{Db}}$ \\
\hline & EDTA & $50.27 \pm 1.49^{\mathrm{Ac}}$ & $53.26 \pm 0.34^{\mathrm{Ac}}$ & $76.81 \pm 0.02^{\mathrm{Bc}}$ & $77.04 \pm 0.12^{\mathrm{Bd}}$ & $76.80 \pm 0.21^{\mathrm{Bc}}$ \\
\hline \multirow[t]{4}{*}{$\mathrm{Mn}^{2+}$} & Type 1 & $0.27 \pm 0.03^{\mathrm{Aa}}$ & $1.09 \pm 0.46^{\mathrm{Cb}}$ & $0.67 \pm 0.08^{\mathrm{Bb}}$ & $2.25 \pm 0.07^{\mathrm{Db}}$ & $0.62 \pm 0.09^{\mathrm{ABa}}$ \\
\hline & Type 2 & $0.62 \pm 0.49^{\mathrm{Ab}}$ & $1.29 \pm 0.04^{\mathrm{Bb}}$ & $0.58 \pm 0.00^{\mathrm{Ab}}$ & $1.69 \pm 0.89^{\mathrm{Ba}}$ & $0.58 \pm 0.07^{\mathrm{Aa}}$ \\
\hline & Type 3 & $0.17 \pm 0.00^{\mathrm{Ba}}$ & $0.56 \pm 0.02^{\mathrm{Ba}}$ & $0.06 \pm 0.01^{\mathrm{Aa}}$ & $1.07 \pm 0.49^{\mathrm{Ca}}$ & $0.63 \pm 0.08^{\mathrm{Ba}}$ \\
\hline & EDTA & $42.38 \pm 4.17^{\mathrm{Bc}}$ & $43.82 \pm 0.32^{\mathrm{Bc}}$ & $52.74 \pm 3.19^{\mathrm{Cc}}$ & $51.91 \pm 0.51^{\mathrm{Cc}}$ & $0.84 \pm 0.09^{\mathrm{Ab}}$ \\
\hline \multirow[t]{4}{*}{$\mathrm{Cu}^{2+}$} & Type 1 & $3.47 \pm 0.83^{\mathrm{Ba}}$ & $2.74 \pm 0.04^{\mathrm{Ba}}$ & $0.76 \pm 0.52^{\mathrm{Aa}}$ & $0.62 \pm 0.25^{\mathrm{Aa}}$ & $8.14 \pm 1.84^{\mathrm{Cb}}$ \\
\hline & Type 2 & $3.37 \pm 0.21^{\mathrm{Ca}}$ & $1.38 \pm 0.82^{\mathrm{Ba}}$ & $0.43 \pm 0.26^{\mathrm{Aa}}$ & $0.53 \pm 0.02^{\mathrm{Aa}}$ & $1.53 \pm 0.85^{\mathrm{Ba}}$ \\
\hline & Type 3 & $4.97 \pm 0.53^{\mathrm{Cd}}$ & $2.33 \pm 0.19^{\mathrm{Ba}}$ & $0.57 \pm 0.22^{\mathrm{Aa}}$ & $0.51 \pm 0.01^{\mathrm{Aa}}$ & $5.17 \pm 1.26^{\mathrm{Cb}}$ \\
\hline & EDTA & $21.66 \pm 1.23^{\mathrm{Ab}}$ & $22.01 \pm 1.88^{\mathrm{Ab}}$ & $26.19 \pm 0.65^{\mathrm{Bb}}$ & $45.05 \pm 1.48^{\mathrm{Cb}}$ & $90.63 \pm 0.72^{D c}$ \\
\hline \multirow[t]{4}{*}{$\mathrm{Zn}^{2+}$} & Type 1 & $0.68 \pm 0.09^{\mathrm{Bb}}$ & $1.44 \pm 0.32^{\mathrm{Cb}}$ & $1.33 \pm 0.05^{\mathrm{Cb}}$ & $2.20 \pm 0.00^{\mathrm{Da}}$ & $0.18 \pm 0.13^{\mathrm{Aa}}$ \\
\hline & Type 2 & $1.38 \pm 0.13^{\mathrm{Bb}}$ & $1.28 \pm 0.08^{\mathrm{Bba}}$ & $0.40 \pm 0.01^{\mathrm{Aa}}$ & $1.93 \pm 0.03^{\mathrm{Ca}}$ & $0.85 \pm 0.09^{\mathrm{Ab}}$ \\
\hline & Type 3 & $0.14 \pm 0.00^{\mathrm{Aa}}$ & $0.74 \pm 0.39^{\mathrm{Ba}}$ & $0.17 \pm 0.01^{\mathrm{Aa}}$ & $2.18 \pm 0.03^{\mathrm{Da}}$ & $1.94 \pm 0.15^{\mathrm{Cc}}$ \\
\hline & EDTA & $21.48 \pm 1.08^{\mathrm{Ac}}$ & $42.11 \pm 0.03^{\mathrm{Bc}}$ & $58.63 \pm 4.46^{\mathrm{Cc}}$ & $99.00 \pm 0.05^{\mathrm{Eb}}$ & $93.36 \pm 0.19^{\mathrm{Dd}}$ \\
\hline \multirow[t]{4}{*}{$\mathrm{Cd}^{2+}$} & Type 1 & $5.76 \pm 0.26^{\mathrm{Aa}}$ & $5.87 \pm 0.15 \mathrm{Aa}$ & $6.55 \pm 0.05 \mathrm{Aa}$ & $5.78 \pm 0.05 \mathrm{Aa}$ & $6.29 \pm 0.16^{A}$ \\
\hline & Type 2 & $5.20 \pm 0.12^{\mathrm{Aa}}$ & $5.29 \pm 0.05 \mathrm{Aa}$ & $6.08 \pm 0.06 \mathrm{Aa}$ & $5.28 \pm 0.12 \mathrm{Aa}$ & $5.04 \pm 0.02^{\mathrm{A}}$ \\
\hline & Type 3 & $5.20 \pm 0.00^{\mathrm{Aa}}$ & $5.26 \pm 0.19 \mathrm{aa}$ & $6.05 \pm 0.33 \mathrm{Ba}$ & $4.87 \pm 0.33 \mathrm{Aa}$ & $4.68 \pm 0.55^{\mathrm{A}}$ \\
\hline & EDTA & $9.40 \pm 0.09^{\mathrm{Ab}}$ & $11.60 \pm 0.58^{\mathrm{Ab}}$ & $19.76 \pm 0.43^{\mathrm{Bb}}$ & $67.62 \pm 11.73^{\mathrm{D}}$ & $52.05 \pm 0.13^{\mathrm{C}}$ \\
\hline
\end{tabular}

Types 1, 2 and 3 -Types of chitosan.

Results reported are mean vales of three determinations \pm standard deviation.

Means in each column sharing the same superscript are not significantly $(p>0.05)$ different from one another. 
Figure A.2 Dependence of the absorbance ration of (A) $\mathrm{Fe}^{2+}$ and (B) $\mathrm{Co}^{2+}$ concentration at $460 \mathrm{~nm} / 530 \mathrm{~nm}$ on the concentration of metal solutions $\mathrm{pH} 5$

(A) Regression coefficient $\left(\mathrm{r}^{2}\right)=0.9901$

Equation of the line was $\mathrm{Y}=\mathrm{aX}+\mathrm{b}$ where,

$\mathrm{Y}=$ absorbance at $\mathrm{A}_{460 \mathrm{~nm} / 530 \mathrm{~nm}}$

$\mathrm{X}=$ concentration of $\mathrm{Fe}^{2+}$ in $\mu \mathrm{M}$

$\mathrm{a}=6.156 \times 10^{-4}$

$\mathrm{b}=0$

Therefore, $X=1624.43 *$ A $_{460} \mathrm{~nm} / 530 \mathrm{~nm}$

(B) Regression coefficient $\left(\mathrm{r}^{2}\right)=0.9994$

Equation of the line was $\mathrm{Y}=\mathrm{aX}+\mathrm{b}$ where,

$\mathrm{Y}=$ absorbance at $\mathrm{A}_{460 \mathrm{~nm} / 530 \mathrm{~nm}}$

$\mathrm{X}=$ concentration of $\mathrm{Co}^{2+}$ in $\mu \mathrm{M}$

$\mathrm{a}=1.3347 \times 10^{-3}$

$\mathrm{b}=0$

Therefore, $X=749.23 * A_{460} \mathrm{~nm} / 530 \mathrm{~nm}$ 

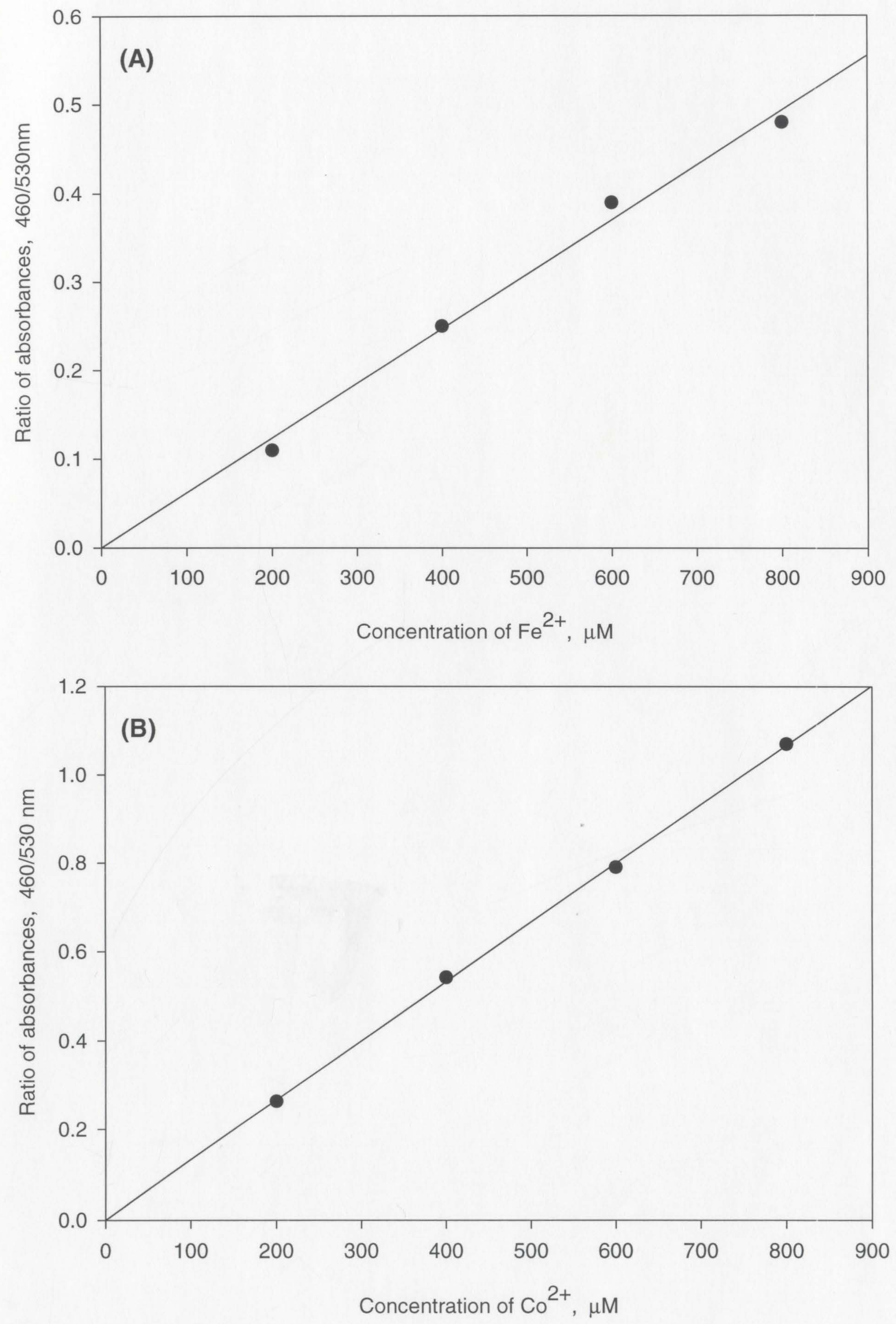
Figure A.3 Dependence of the absorbance ratio of (A) $\mathrm{Ni}^{2+}$ and (B) $\mathrm{Mn}^{2+}$ concentration at $460 \mathrm{~nm} / 530 \mathrm{~nm}$ on the concentration of metal solutions$\mathrm{pH} 5$

(A) Regression coefficient $\left(\mathrm{r}^{2}\right)=0.9956$

Equation of the line was $\mathrm{Y}=\mathrm{aX}+\mathrm{b}$ where,

$\mathrm{Y}=$ absorbance at $\mathrm{A}_{460 \mathrm{~nm} / 530 \mathrm{~nm}}$

$\mathrm{X}=$ concentration of $\mathrm{Ni}^{2+}$ in $\mu \mathrm{M}$

$\mathrm{a}=9.93 \times 10^{-3}$

$\mathrm{b}=0$

Therefore, $X=100.70 *$ A $_{460} \mathrm{~nm} / 530 \mathrm{~nm}$

(B) Regression coefficient $\left(\mathrm{r}^{2}\right)=0.9989$

Equation of the line was $\mathrm{Y}=\mathrm{aX}+\mathrm{b}$ where,

$\mathrm{Y}=$ absorbance at $\mathrm{A}_{460 \mathrm{~nm} / 530 \mathrm{~nm}}$

$\mathrm{X}=$ concentration of in $\mathrm{Mn}^{2+} \mu \mathrm{mol}(\mathrm{C})$

$\mathrm{a}=2.221 \times 10^{-4}$

$\mathrm{b}=0$

Therefore, $\mathrm{C}=4524.88^{*} \mathrm{~A}_{460 \mathrm{~nm} / 530 \mathrm{~nm}}$ 

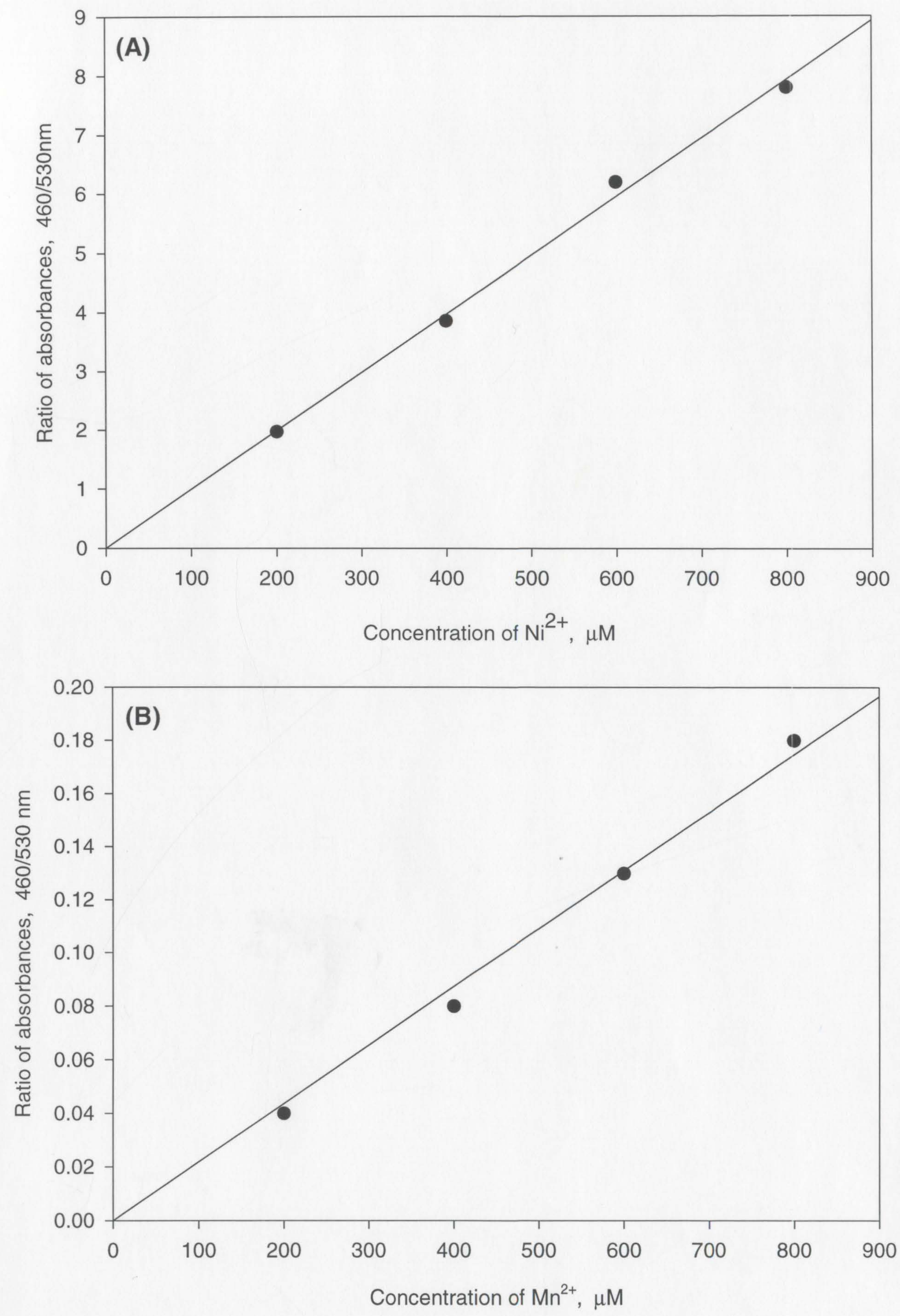
Figure A.4 Dependence of the absorbance ratio of (A) $\mathrm{Cu}^{2+}$ and (B) $\mathrm{Zn}^{2+}$ concentration at $460 \mathrm{~nm} / 530 \mathrm{~nm}$ on the concentration of metal solutions $\mathrm{pH} 5$

(A) Regression coefficient $\left(\mathrm{r}^{2}\right)=0.99966$

Equation of the line was $\mathrm{Y}=\mathrm{aX}+\mathrm{b}$ where,

$\mathrm{Y}=$ absorbance at $\mathrm{A}_{460 \mathrm{~nm} / 530 \mathrm{~nm}}$

$\mathrm{X}=$ concentration of $\mathrm{Cu}^{2+}$ in $\mu \mathrm{M}$

$\mathrm{a}=9.99 \times 10^{-4}$

$\mathrm{b}=0$

Therefore, $X=1010.10 * A_{460 \mathrm{~nm} / 530 \mathrm{~nm}}$

(B) Regression coefficient $\left(\mathrm{r}^{2}\right)=0.9969$

Equation of the line was $\mathrm{Y}=\mathrm{aX}+\mathrm{b}$ where,

$\mathrm{Y}=$ absorbance at $\mathrm{A}_{460 \mathrm{~nm} / 530 \mathrm{~nm}}$

$\mathrm{X}=$ concentration of in $\mathrm{Zn}^{2+} \mu \mathrm{M}$

$\mathrm{a}=4.21 \times 10^{-3}$

$\mathrm{b}=0$

Therefore, $X=237.52 * A_{460 \mathrm{~nm} / 530 \mathrm{~nm}}$ 

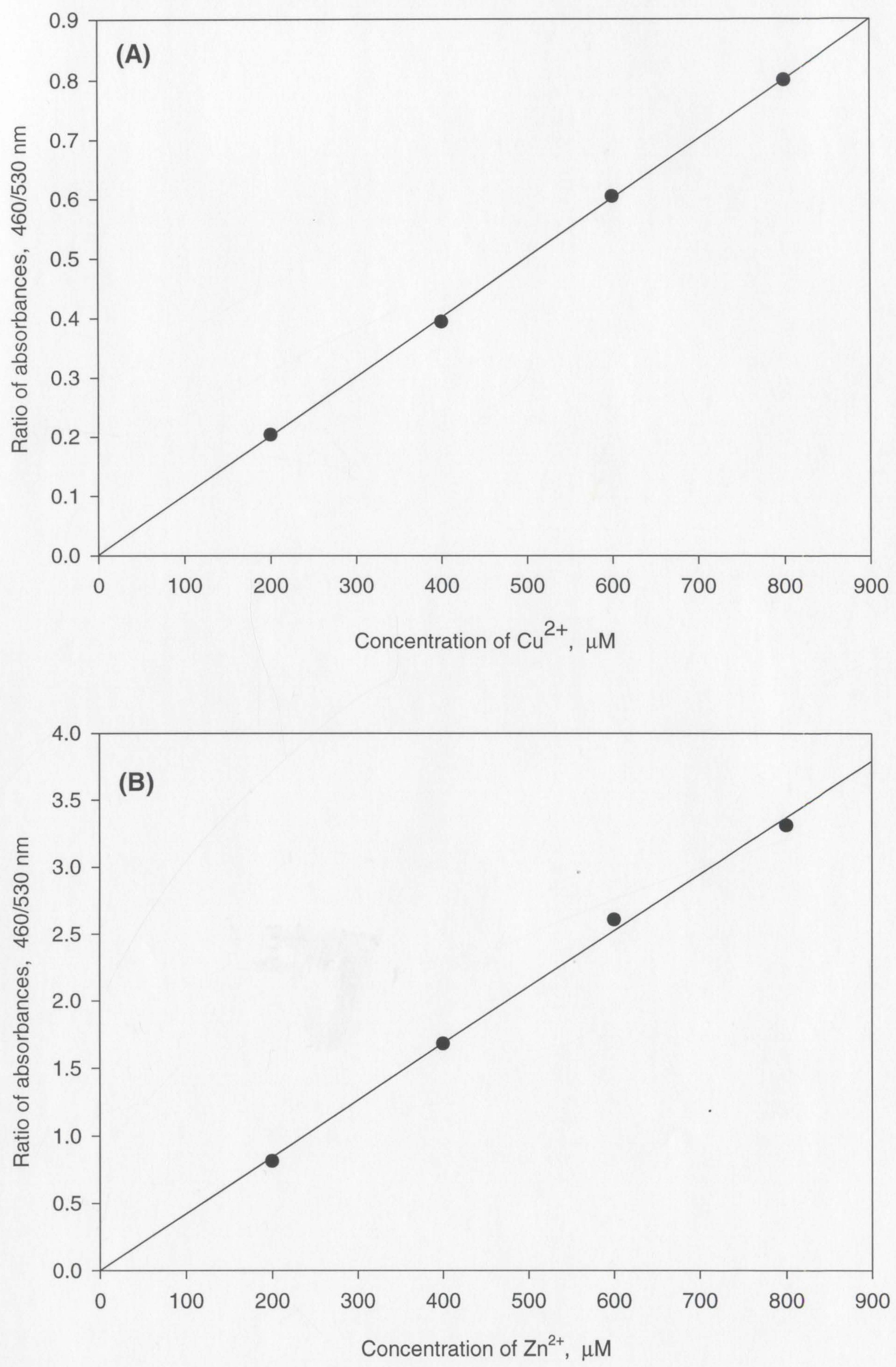
Figure A.5 Dependence of the absorbance ratio of $\mathrm{Cd}^{2+}$ concentration at $460 \mathrm{~nm} / 530 \mathrm{~nm}$ on the concentration of metal solutions- $\mathrm{pH} 5$

Regression coefficient $\left(\mathrm{r}^{2}\right)=0.9962$

Equation of the line was $\mathrm{Y}=\mathrm{aX}+\mathrm{b}$ where,

$\mathrm{Y}=$ absorbance at $\mathrm{A}_{460 \mathrm{~nm} / 530 \mathrm{~nm}}$

$\mathrm{X}=$ concentration of $\mathrm{Ca}^{2+}$ in $\mu \mathrm{M}$

$\mathrm{a}=5.016 \times 10^{-4}$

$\mathrm{b}=0$

Therefore, $\mathrm{C}=1993.62 * \mathrm{~A}_{460 \mathrm{~nm} / 530 \mathrm{~nm}}$ 


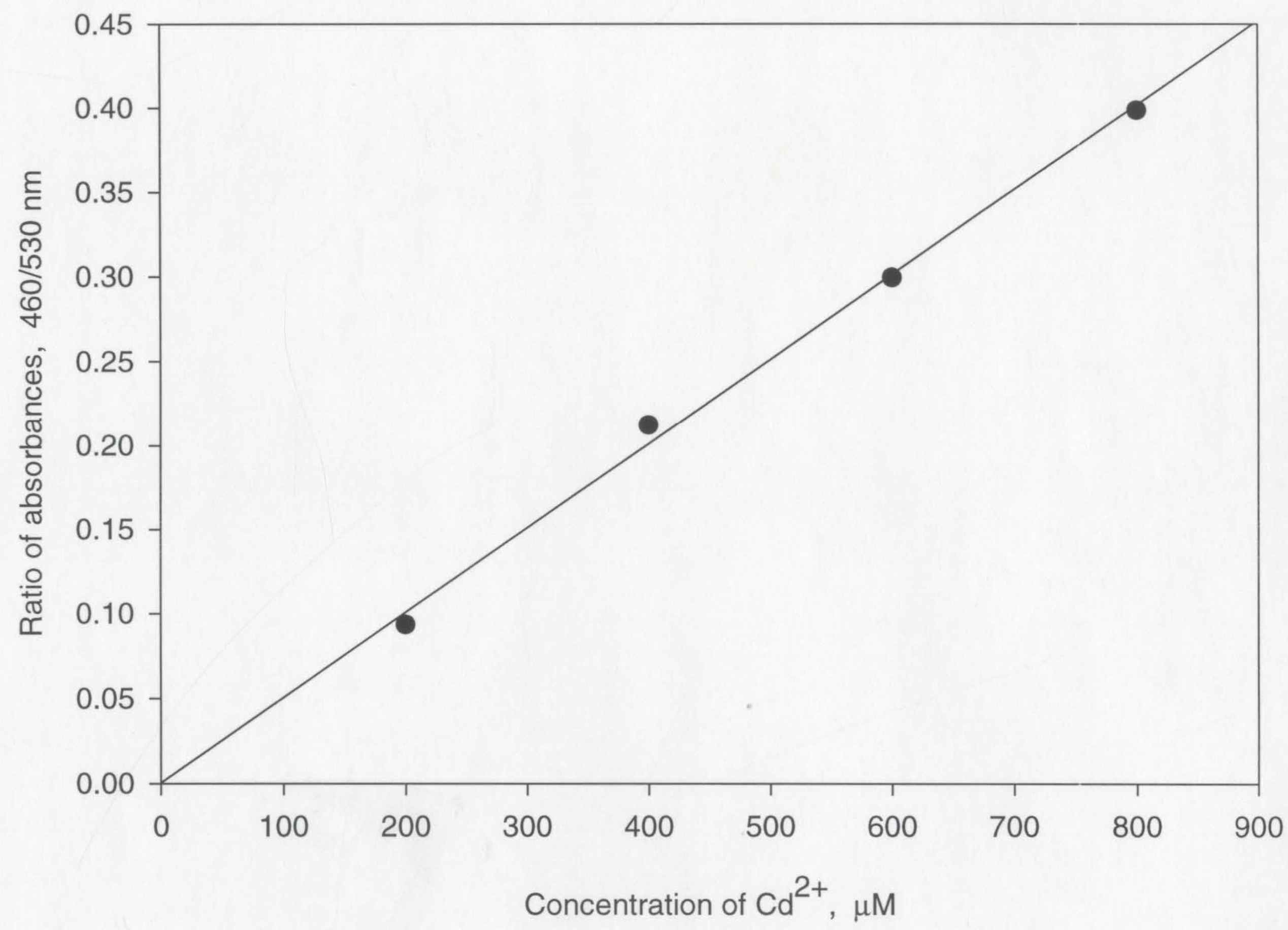


Figure A.6 Dependence of the absorbance ratio of (A) $\mathrm{Ni}^{2+}$ and (B) $\mathrm{Zn}^{2+}$ concentration at $460 \mathrm{~nm} / 530 \mathrm{~nm}$ on the concentration of metal solutions $\mathrm{pH} 6$

(A) Regression coefficient $\left(\mathrm{r}^{2}\right)=0.99779$

Equation of the line was $\mathrm{Y}=\mathrm{aX}+\mathrm{b}$ where,

$\mathrm{Y}=$ absorbance at $\mathrm{A}_{460 \mathrm{~nm} / 530 \mathrm{~nm}}$

$\mathrm{X}=$ concentration of $\mathrm{Ni}^{2+}$ in $\mu \mathrm{M}$

$\mathrm{a}=9.144 \times 10^{-3}$

$\mathrm{b}=0$

Therefore, $\mathrm{X}=109.35 * \mathrm{~A}_{460 \mathrm{~nm} / 530 \mathrm{~nm}}$

(B) Regression coefficient $\left(\mathrm{r}^{2}\right)=0.99915$

Equation of the line was $\mathrm{Y}=\mathrm{aX}+\mathrm{b}$ where, $\mathrm{Y}=$ absorbance at $\mathrm{A}_{460 \mathrm{~nm} / 530 \mathrm{~nm}}$

$\mathrm{X}=$ concentration of in $\mathrm{Zn}^{2+} \mu \mathrm{M}$

$\mathrm{a}=4.180 \times 10^{-3}$

$\mathrm{b}=0$

Therefore, $X=239.21$ 

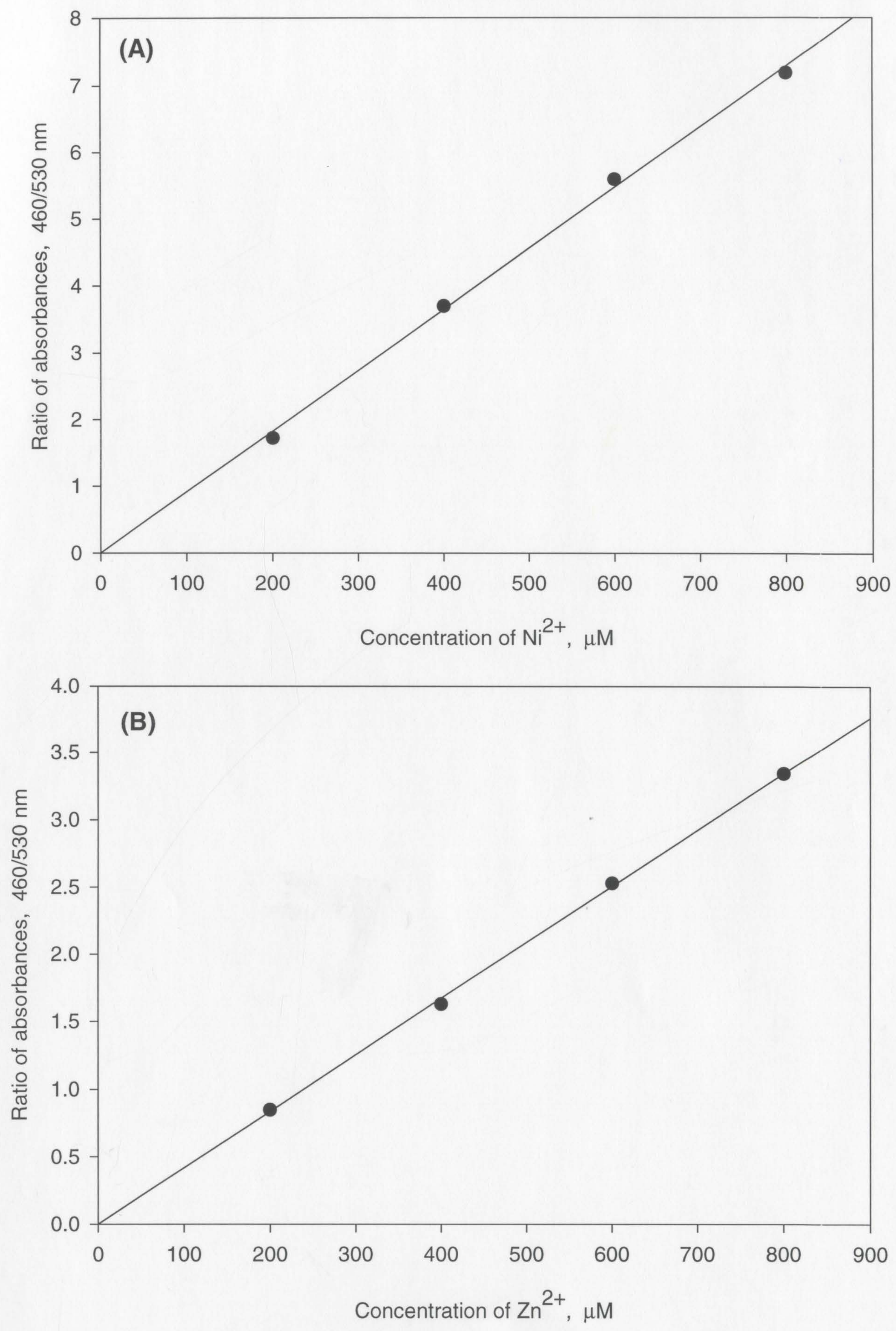
Figure A.7 Dependence of the absorbance ratio of (A) $\mathrm{Mn}^{2+}$ and (B) $\mathrm{Cd}^{2+}$ concentration at $460 \mathrm{~nm} / 530 \mathrm{~nm}$ on the concentration of metal solutions - pH 6

(A) Regression coefficient $\left(\mathrm{r}^{2}\right)=0.9933$

Equation of the line was $\mathrm{Y}=\mathrm{aX}+\mathrm{b}$ where,

$\mathrm{Y}=$ absorbance at $\mathrm{A}_{460 \mathrm{~nm} / 530 \mathrm{~nm}}$

$\mathrm{X}=$ concentration of $\mathrm{Mn}^{2+}$ in $\mu \mathrm{M}$

$\mathrm{a}=1.836 \times 10^{-4}$

$\mathrm{b}=0$

Therefore, $X=5447.51 * \mathrm{~A}_{460 \mathrm{~nm} / 530 \mathrm{~nm}}$

(B) Regression coefficient $\left(r^{2}\right)=0.9915$

Equation of the line was $\mathrm{Y}=\mathrm{aX}+\mathrm{b}$ where,

$\mathrm{Y}=$ absorbance at $\mathrm{A}_{460 \mathrm{~nm} / 530 \mathrm{~nm}}$

$\mathrm{X}=$ concentration of in $\mathrm{Cd}^{2+} \mu \mathrm{M}$

$\mathrm{a}=2.065 \times 10^{-3}$

$\mathrm{b}=0$

Therefore, $X=485.43 * \mathrm{~A}_{460 \mathrm{~nm} / 530 \mathrm{~nm}}$ 

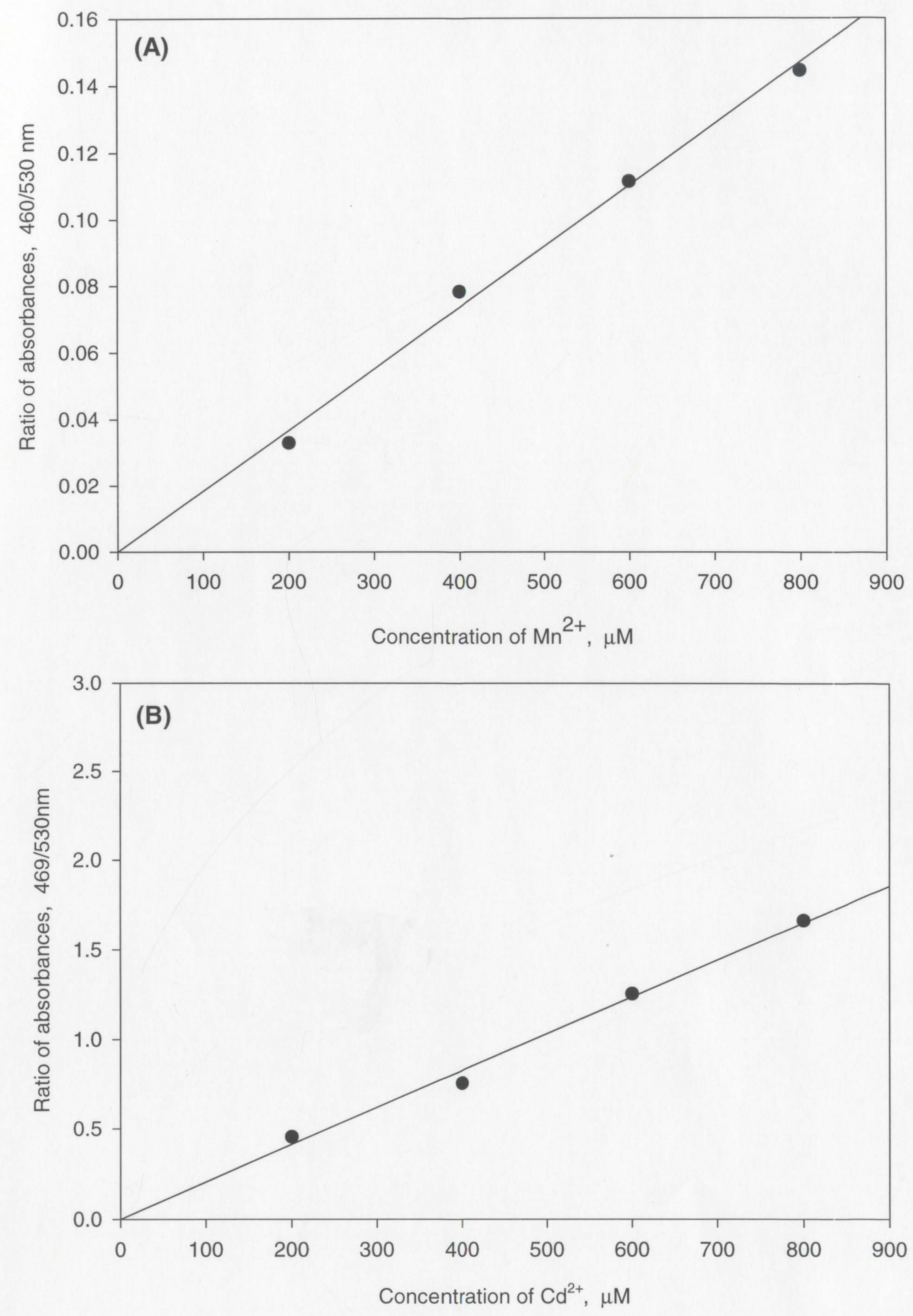
Figure A.8 Dependence of the absorbance ratio of (A) $\mathrm{Cu}^{2+}$ and (B) $\mathrm{Co}^{2+}$ concentration at $460 \mathrm{~nm} / 530 \mathrm{~nm}$ on the concentration of metal solutions - $\mathrm{pH} 6$

(A) Regression coefficient $\left(r^{2}\right)=0.9937$

Equation of the line was $\mathrm{Y}=\mathrm{aX}+\mathrm{b}$ where, $\mathrm{Y}=$ absorbance at $\mathrm{A}_{460 \mathrm{~nm} / 530 \mathrm{~nm}}$ $\mathrm{X}=$ concentration of $\mathrm{Cu}^{2+}$ in $\mu \mathrm{M}$

$\mathrm{a}=1.16 \times 10^{-3}$

$\mathrm{b}=0$

Therefore, $X=862.06 * A_{460 \mathrm{~nm} / 530 \mathrm{~nm}}$

(B) Regression coefficient $\left(\mathrm{r}^{2}\right)=0.9939$

Equation of the line was $\mathrm{Y}=\mathrm{aX}+\mathrm{b}$ where, $\mathrm{Y}=$ absorbance at $\mathrm{A}_{460 \mathrm{~nm} / 530 \mathrm{~nm}}$ $\mathrm{X}=$ concentration of in $\mathrm{Co}^{2+} \mu \mathrm{M}$ $\mathrm{a}=7.7 \times 10^{-4}$ $\mathrm{b}=0$

Therefore, $X=1298.70 * \mathrm{~A}_{460 \mathrm{~nm} / 530 \mathrm{~nm}}$ 

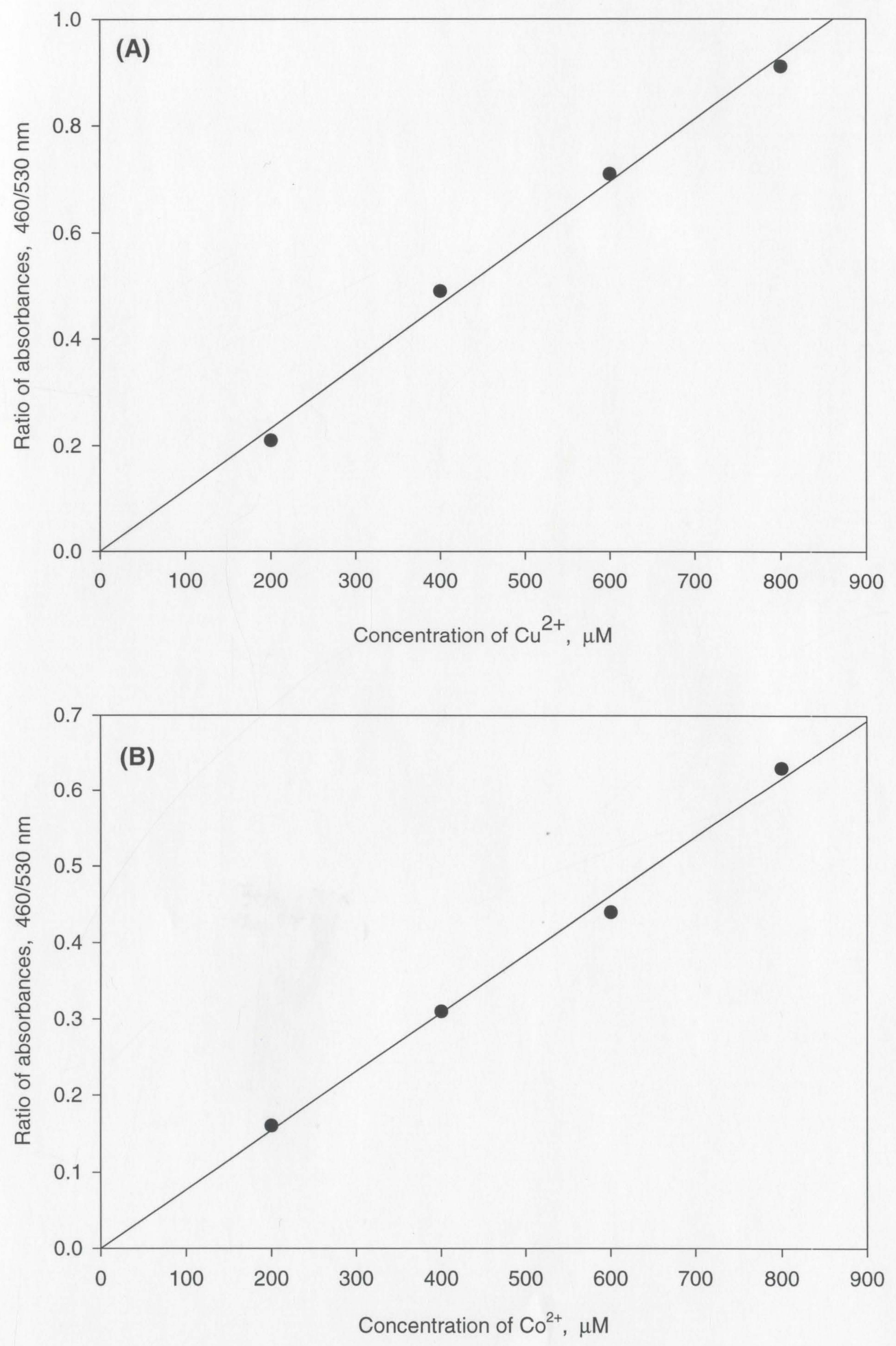
Figure A.9 Dependence of the absorbance ratio of $\mathrm{Fe}^{2+}$ concentration at $460 \mathrm{~nm} / 530 \mathrm{~nm}$ on the concentration of metal solutions - $\mathrm{pH} 6$

Regression coefficient $\left(\mathrm{r}^{2}\right)=0.9977$

Equation of the line was $\mathrm{Y}=\mathrm{aX}+\mathrm{b}$ where,

$\mathrm{Y}=$ absorbance at $\mathrm{A}_{460 \mathrm{~nm} / 530 \mathrm{~nm}}$

$\mathrm{X}=$ concentration of $\mathrm{Fe}^{2+}$ in $\mu \mathrm{M}$

$\mathrm{a}=7.9 \times 10^{-4}$

$\mathrm{b}=0$

Therefore, $X=1265.82 * A_{460 \mathrm{~nm} / 530 \mathrm{~nm}}$ 


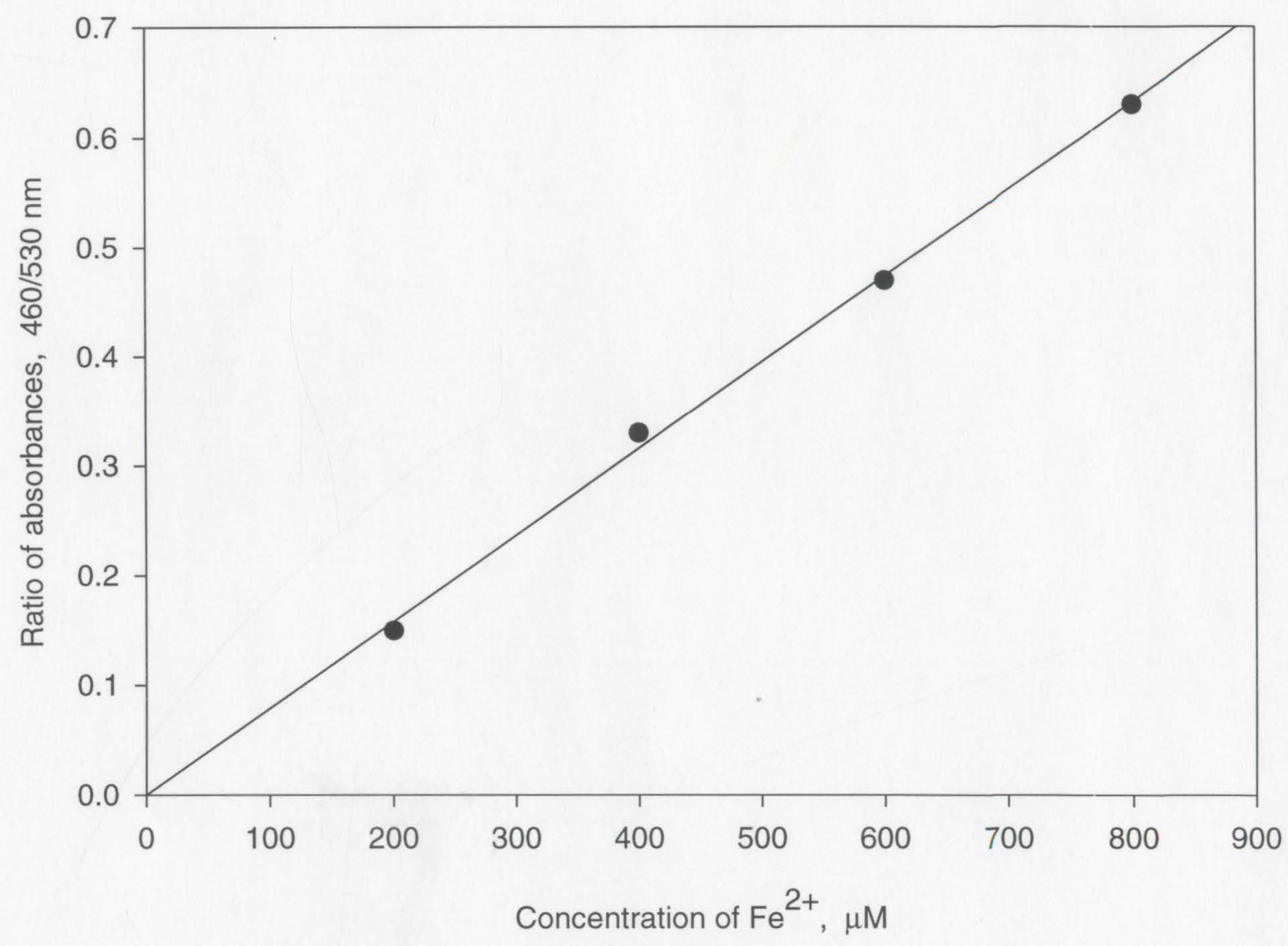


Figure A.10 Dependence of the absorbance ratio of (A) $\mathrm{Ni}^{2+}$ and (B) $\mathrm{Mn}^{2+}$ concentration at $460 \mathrm{~nm} / 530 \mathrm{~nm}$ on the concentration of metal solutions $-\mathrm{pH} 7$

(A )Regression coefficient $\left(\mathrm{r}^{2}\right)=0.9921$

Equation of the line was $\mathrm{Y}=\mathrm{aX}+\mathrm{b}$ where,

$\mathrm{Y}=$ absorbance at $\mathrm{A}_{460 \mathrm{~nm} / 530 \mathrm{~nm}}$

$\mathrm{X}=$ concentration of $\mathrm{Ni}^{2+}$ in $\mu \mathrm{M}$

$\mathrm{a}=8.95 \times 10^{-3}$

$\mathrm{b}=0$

Therefore, $X=111.73 * A$ A $460 \mathrm{~nm} / 530 \mathrm{~nm}$

(B)Regression coefficient $\left(\mathrm{r}^{2}\right)=0.9939$

Equation of the line was $\mathrm{Y}=\mathrm{aX}+\mathrm{b}$ where,

$\mathrm{Y}=$ absorbance at $\mathrm{A}_{460 \mathrm{~nm} / 530 \mathrm{~nm}}$

$\mathrm{X}=$ concentration of in $\mathrm{Mn}^{2+} \mu \mathrm{M}$

$\mathrm{a}=2.8676 \times 10^{-4}$

$\mathrm{b}=0$

Therefore, $X=3487.23 * \mathrm{~A}_{460} \mathrm{~nm} / 530 \mathrm{~nm}$ 

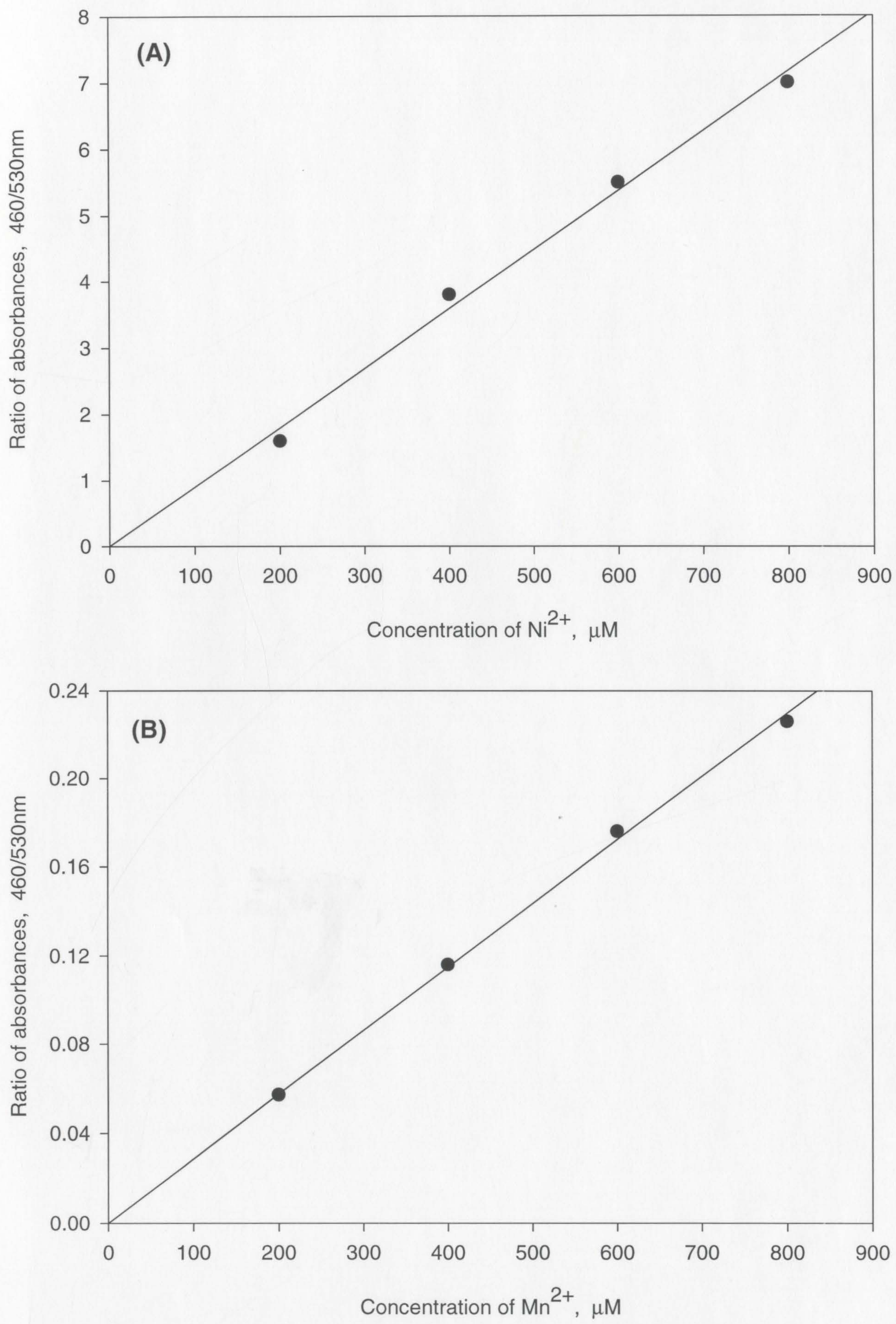
Figure A.11 Dependence of the absorbance ratio of (A) $\mathrm{Cu}^{2+}$ and (B) $\mathrm{Zn}^{2+}$ concentration at $460 \mathrm{~nm} / 530 \mathrm{~nm}$ on the concentration of metal solutions $-\mathrm{pH} 7$

(A )Regression coefficient $\left(\mathrm{r}^{2}\right)=0.9997$

Equation of the line was $\mathrm{Y}=\mathrm{aX}+\mathrm{b}$ where, $\mathrm{Y}=$ absorbance at $\mathrm{A}_{460 \mathrm{~nm} / 530 \mathrm{~nm}}$

$\mathrm{X}=$ concentration of $\mathrm{Cu}^{2+}$ in $\mu \mathrm{M}$

$\mathrm{a}=1.8635 \times 10^{-3}$

$\mathrm{b}=0$

Therefore, $X=536.60 * A_{460} \mathrm{~nm} / 530 \mathrm{~nm}$

(B)Regression coefficient $\left(r^{2}\right)=0.9962$

Equation of the line was $Y=a X+b$ where,

$\mathrm{Y}=$ absorbance at $\mathrm{A}_{460 \mathrm{~nm} / 530 \mathrm{~nm}}$

$\mathrm{X}=$ concentration of in $\mathrm{Zn}^{2+} \mu \mathrm{M}$

$\mathrm{a}=4.42 \times 10^{-3}$

$\mathrm{b}=0$

Therefore, $X=226.24 * A+460 \mathrm{~nm} / 530 \mathrm{~nm}$ 

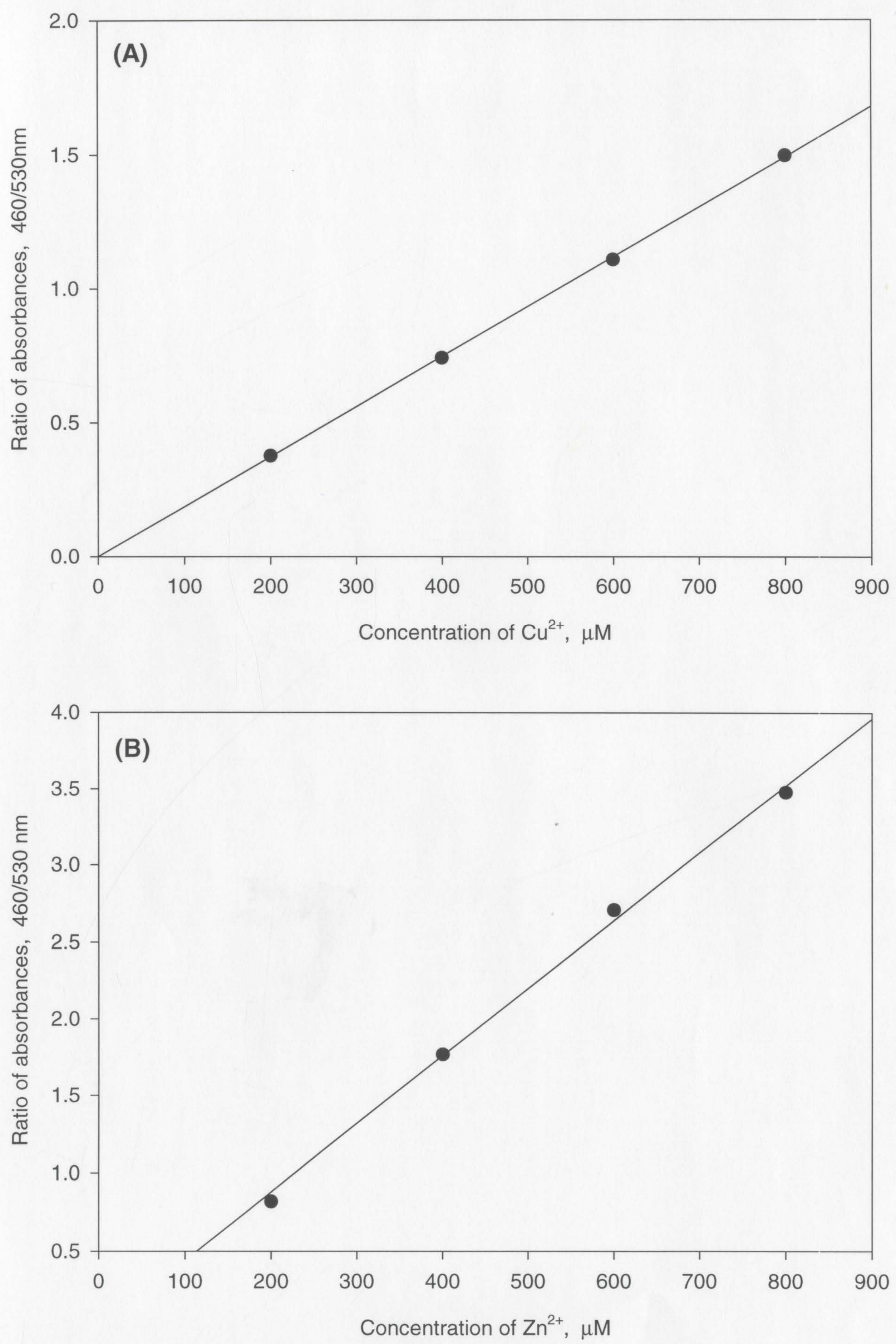
Figure A12 Dependence of the absorbance ratio of (A) $\mathrm{Fe}^{2+}$ and (B) $\mathrm{Co}^{2+}$ concentration at $460 \mathrm{~nm} / 530 \mathrm{~nm}$ on the concentration of metal solutions $-\mathrm{pH} 7$

(A) Regression coefficient $\left(r^{2}\right)=0.9959$

Equation of the line was $\mathrm{Y}=\mathrm{aX}+\mathrm{b}$ where,

$\mathrm{Y}=$ absorbance at $\mathrm{A}_{460 \mathrm{~nm} / 530 \mathrm{~nm}}$

$\mathrm{X}=$ concentration of $\mathrm{Fe}^{2+}$ in $\mu \mathrm{M}$

$\mathrm{a}=1.18 \times 10^{-3}$

$\mathrm{b}=0$

Therefore, $X=847.45 * A_{460} \mathrm{~nm} / 530 \mathrm{~nm}$

(B )Regression coefficient $\left(\mathrm{r}^{2}\right)=0.9975$

Equation of the line was $\mathrm{Y}=\mathrm{aX}+\mathrm{b}$ where,

$\mathrm{Y}=$ absorbance at $\mathrm{A}_{460 \mathrm{~nm} / 530 \mathrm{~nm}}$

$\mathrm{X}=$ concentration of $\mathrm{Co}^{2+}$ in $\mu \mathrm{M}$

$\mathrm{a}=1.26 \times 10^{-3}$

$\mathrm{b}=0$

Therefore, $X=793.65^{*} \mathrm{~A}_{460 \mathrm{~nm} / 530 \mathrm{~nm}}$ 

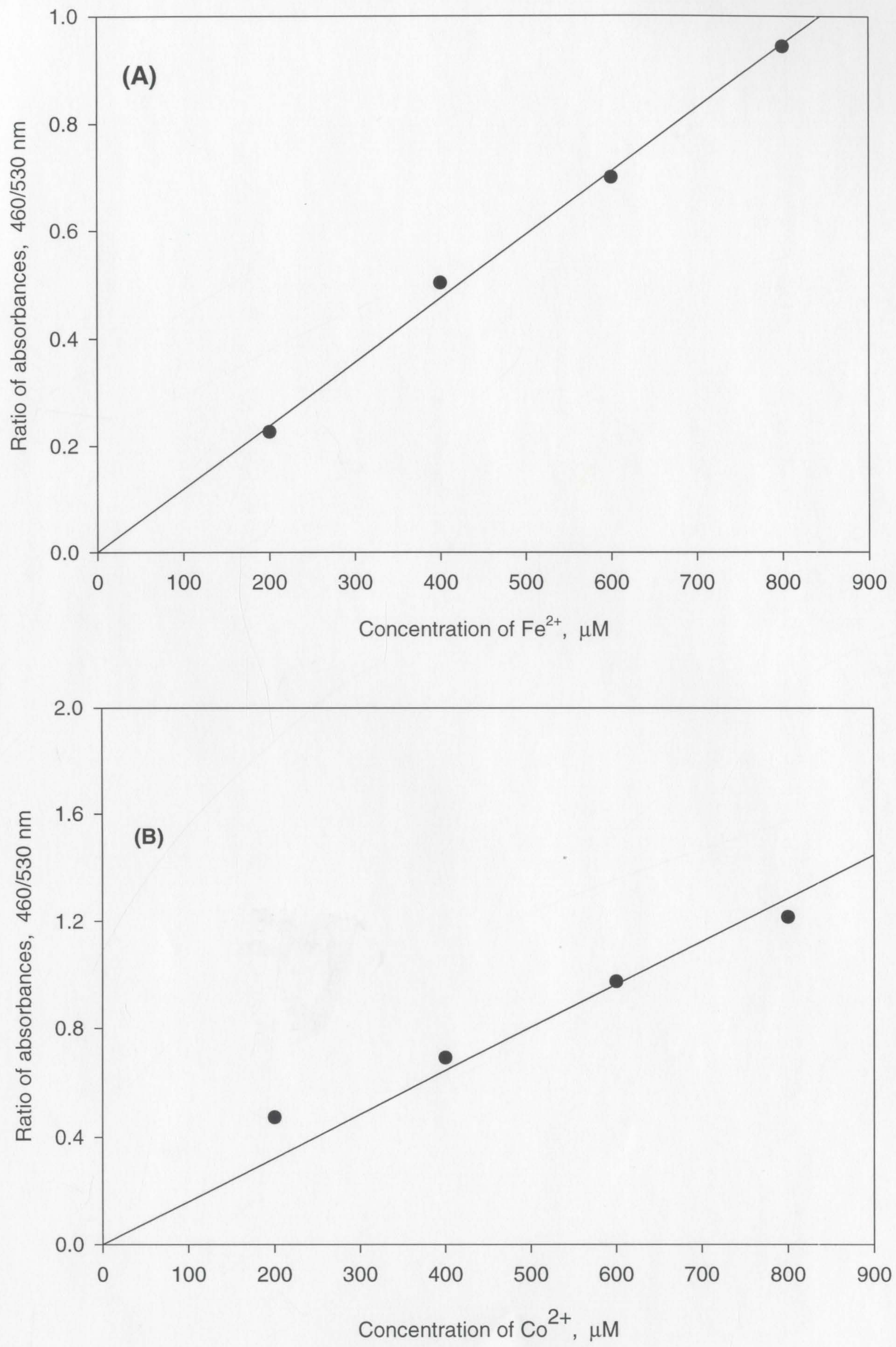
Figure A.13 Dependence of the absorbance ratio of $\mathrm{Cd}^{2+}$ concentration at $460 \mathrm{~nm} / 530 \mathrm{~nm}$ on the concentration of metal solutions - $\mathrm{pH} 7$

(A )Regression coefficient $\left(\mathrm{r}^{2}\right)=0.9992$

Equation of the line was $\mathrm{Y}=\mathrm{aX}+\mathrm{b}$ where,

$\mathrm{Y}=$ absorbance at $\mathrm{A}_{460 \mathrm{~nm} / 530 \mathrm{~nm}}$

$\mathrm{X}=$ concentration of $\mathrm{Cd}^{2+}$ in $\mu \mathrm{M}$

$\mathrm{a}=2.035 \times 10^{-3}$

$\mathrm{b}=0$

Therefore, $X=491.40^{*} \mathrm{~A}_{460 \mathrm{~nm} / 530 \mathrm{~nm}}$ 


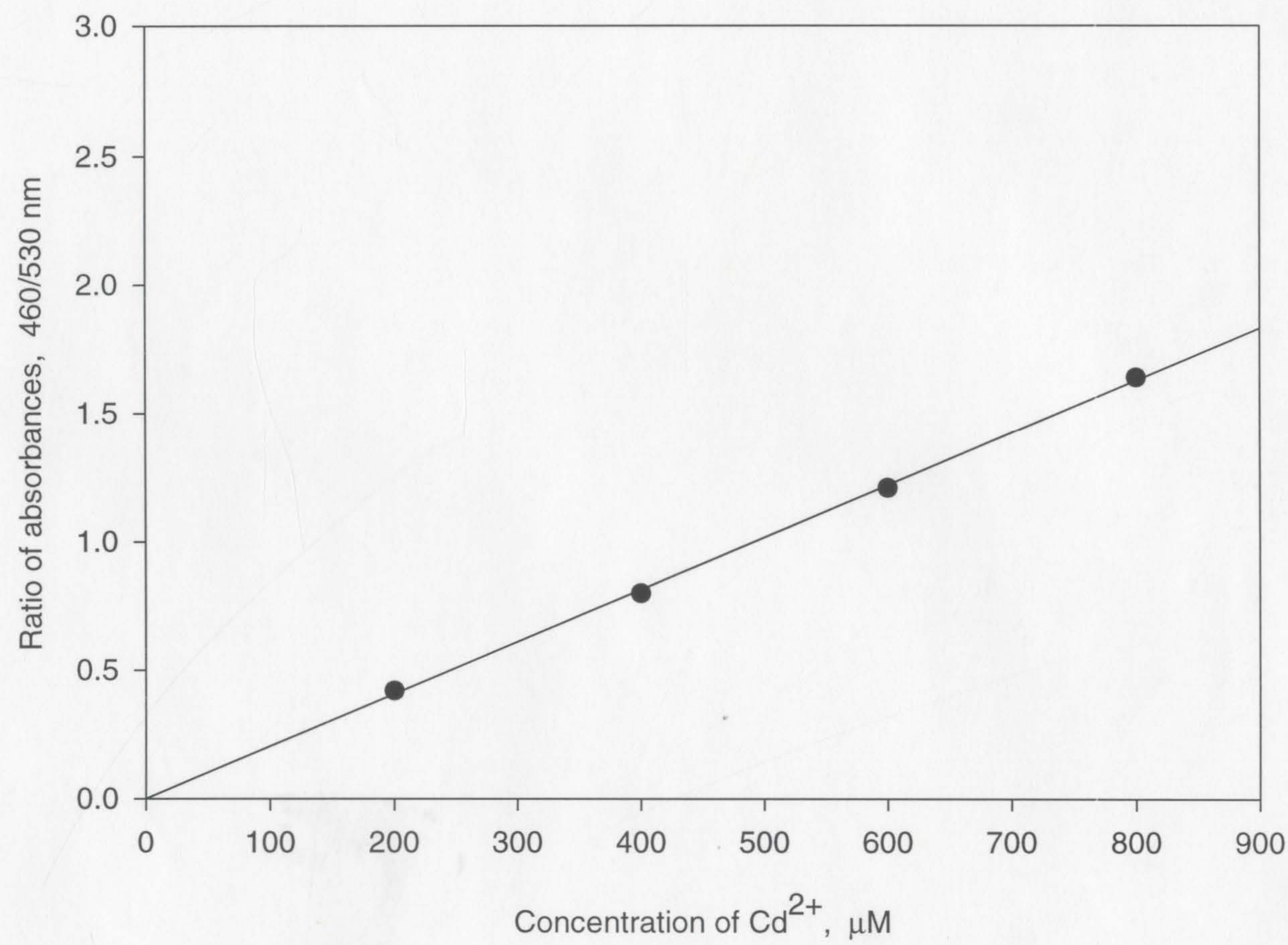


Table A.6 Effectiveness of chitosan in metal ion chelation from industrial wastewater

\begin{tabular}{|c|c|c|c|c|c|}
\hline \multirow{2}{*}{$\begin{array}{l}\text { Heavy } \\
\text { metals }\end{array}$} & \multirow{2}{*}{$\begin{array}{l}\text { Original } \\
\text { Concentration } \\
(\mathrm{ppb})\end{array}$} & \multirow{2}{*}{$\begin{array}{l}\text { Types of } \\
\text { chitosan }\end{array}$} & \multicolumn{3}{|c|}{ Chelation capacity \% } \\
\hline & & & pH 5 & pH 6 & pH 7 \\
\hline $\mathrm{Cr}^{3+}$ & $0.71 \pm 0.01$ & $\begin{array}{l}\text { Type } 1 \\
\text { Type } 2 \\
\text { Type } 3\end{array}$ & $\begin{array}{l}2.08 \pm 0.98^{\mathrm{a}} \\
2.08 \pm 0.98^{\mathrm{a}} \\
0\end{array}$ & $\begin{array}{l}3.52 \pm 0.98^{\mathrm{b}} \\
2.08 \pm 0.98^{\mathrm{a}} \\
0\end{array}$ & $\begin{array}{l}5.06 \pm 0.70^{b} \\
2.08 \pm 0.98^{a} \\
0\end{array}$ \\
\hline $\mathrm{Fe}^{2+}$ & $161.5 \pm 12.0$ & $\begin{array}{l}\text { Type } 1 \\
\text { Type } 2 \\
\text { Type } 3\end{array}$ & $\begin{array}{l}94.1 \pm 0.00^{\mathrm{b}} \\
14.6 \pm 0.00^{\mathrm{a}} \\
15.4 \pm 2.89^{\mathrm{a}}\end{array}$ & $\begin{array}{l}93.8 \pm 0.45^{\mathrm{b}} \\
15.2 \pm 0.07^{\mathrm{a}} \\
14.4 \pm 0.00^{\mathrm{a}}\end{array}$ & $\begin{array}{l}92.2 \pm 6.85^{\mathrm{b}} \\
17.5 \pm 0.24^{\mathrm{a}} \\
15.3 \pm 0.00^{\mathrm{a}}\end{array}$ \\
\hline $\mathrm{Mn}^{2+}$ & $158.5 \pm 0.91$ & $\begin{array}{l}\text { Type } 1 \\
\text { Type } 2 \\
\text { Type } 3\end{array}$ & $\begin{array}{l}2.11 \pm 0.59^{\mathrm{a}} \\
21.2 \pm 1.03^{\mathrm{c}} \\
18.5 \pm 0.82^{\mathrm{b}}\end{array}$ & $\begin{array}{l}8.92 \pm 0.29^{\mathrm{a}} \\
23.4 \pm 1.27^{\mathrm{b}} \\
21.9 \pm 0.85^{\mathrm{b}}\end{array}$ & $\begin{array}{l}11.2 \pm 0.37^{\mathrm{a}} \\
22.9 \pm 3.42^{\mathrm{b}} \\
21.9 \pm 0.83^{\mathrm{b}}\end{array}$ \\
\hline $\mathrm{Co}^{2+}$ & $0.47 \pm 0.00$ & $\begin{array}{l}\text { Type } 1 \\
\text { Type } 2 \\
\text { Type } 3\end{array}$ & $\begin{array}{l}22.1 \pm 1.81^{\mathrm{c}} \\
2.47 \pm 0.50^{\mathrm{b}} \\
2.10 \pm 0.00^{\mathrm{a}}\end{array}$ & $\begin{array}{l}24.2 \pm 1.85^{\mathrm{b}} \\
4.20 \pm 0.06^{\mathrm{a}} \\
2.10 \pm 0.00^{\mathrm{a}}\end{array}$ & $\begin{array}{l}26.3 \pm 1.83^{b} \\
4.20 \pm 0.06^{\mathrm{a}} \\
2.10 \pm 0.00^{\mathrm{a}}\end{array}$ \\
\hline $\mathrm{Ni}^{2+}$ & $1.15 \pm 0.13$ & $\begin{array}{l}\text { Type } 1 \\
\text { Type } 2 \\
\text { Type } 3\end{array}$ & $\begin{array}{l}53.2 \pm 6.15^{\mathrm{b}} \\
11.3 \pm 1.31^{\mathrm{a}} \\
9.04 \pm 0.78^{\mathrm{a}}\end{array}$ & $\begin{array}{l}54.9 \pm 6.36^{\mathrm{b}} \\
12.6 \pm 0.84^{\mathrm{a}} \\
9.51 \pm 0.12^{\mathrm{a}}\end{array}$ & $\begin{array}{l}62.8 \pm 7.29^{b} \\
20.8 \pm 6.76^{a} \\
22.3 \pm 0.09^{a}\end{array}$ \\
\hline $\mathrm{Cu}^{2+}$ & $15.4 \pm 0.47$ & $\begin{array}{l}\text { Type } 1 \\
\text { Type } 2 \\
\text { Type } 3\end{array}$ & $\begin{array}{l}58.3 \pm 1.14^{\mathrm{c}} \\
19.3 \pm 2.07^{\mathrm{b}} \\
12.0 \pm 1.51^{\mathrm{a}}\end{array}$ & $\begin{array}{l}51.8 \pm 0.74^{\mathrm{b}} \\
29.9 \pm 8.08^{\mathrm{a}} \\
35.3 \pm 2.60^{\mathrm{a}}\end{array}$ & $\begin{array}{l}64.9 \pm 1.56^{\mathrm{b}} \\
41.9 \pm 8.21^{\mathrm{a}} \\
38.0 \pm 3.05^{\mathrm{a}}\end{array}$ \\
\hline $\mathrm{Zn}^{2+}$ & $1331 \pm 27.8$ & $\begin{array}{l}\text { Type } 1 \\
\text { Type } 2 \\
\text { Type } 3\end{array}$ & $\begin{array}{l}48.9 \pm 1.01^{\mathrm{b}} \\
34.1 \pm 1.28^{\mathrm{a}} \\
30.9 \pm 1.55^{\mathrm{a}}\end{array}$ & $\begin{array}{l}49.5 \pm 0.96^{\mathrm{b}} \\
34.2 \pm 3.34^{\mathrm{a}} \\
34.5 \pm 1.43^{\mathrm{a}}\end{array}$ & $\begin{array}{l}50.3 \pm 0.88^{b} \\
37.0 \pm 0.98^{a} \\
35.9 \pm 1.17^{a}\end{array}$ \\
\hline $\mathrm{As}^{2+}$ & $0.43 \pm 0.02$ & $\begin{array}{l}\text { Type } 1 \\
\text { Type } 2 \\
\text { Type } 3\end{array}$ & $\begin{array}{l}15.6 \pm 0.00^{\mathrm{b}} \\
4.44 \pm 0.00^{\mathrm{a}} \\
4.44 \pm 0.00^{\mathrm{a}}\end{array}$ & $\begin{array}{l}13.3 \pm 0.00^{\mathrm{b}} \\
4.44 \pm 0.00^{\mathrm{a}} \\
4.44 \pm 0.00^{\mathrm{a}}\end{array}$ & $\begin{array}{l}13.3 \pm 0.00^{\mathrm{b}} \\
4.44 \pm 0.00^{\mathrm{a}} \\
4.44 \pm 0.00^{\mathrm{a}}\end{array}$ \\
\hline
\end{tabular}




\begin{tabular}{|c|c|c|c|c|c|}
\hline $\mathrm{Mo}^{2+}$ & $1.40 \pm 0.05$ & $\begin{array}{l}\text { Type } 1 \\
\text { Type } 2 \\
\text { Type } 3\end{array}$ & $\begin{array}{l}12.9 \pm 0.51^{\mathrm{b}} \\
2.77 \pm 0.01^{\mathrm{a}} \\
2.64 \pm 0.19^{\mathrm{a}}\end{array}$ & $\begin{array}{l}15.7 \pm 1.38^{\mathrm{b}} \\
4.47 \pm 0.43^{\mathrm{a}} \\
2.70 \pm 0.05^{\mathrm{a}}\end{array}$ & $\begin{array}{l}19.9 \pm 2.22^{\mathrm{c}} \\
9.96 \pm 0.03^{\mathrm{b}} \\
2.78 \pm 0.00^{\mathrm{a}}\end{array}$ \\
\hline $\mathrm{Ag}^{+}$ & $0.03 \pm 0.00$ & $\begin{array}{l}\text { Type } 1 \\
\text { Type } 2 \\
\text { Type } 3\end{array}$ & $\begin{array}{l}33.3 \pm 0.00 \\
0 \\
0\end{array}$ & $\begin{array}{l}33.3 \pm 0.00 \\
0 \\
0\end{array}$ & $\begin{array}{l}66.7 \pm 0.00 \\
0 \\
0\end{array}$ \\
\hline $\mathrm{Cd}^{2+}$ & $4.99 \pm 0.08$ & $\begin{array}{l}\text { Type } 1 \\
\text { Type } 2 \\
\text { Type } 3\end{array}$ & $\begin{array}{l}26.9 \pm 5.56 a \\
20.4 \pm 1.07 a \\
25.1 \pm 2.69 a\end{array}$ & $\begin{array}{l}27.5 \pm 4.50 a \\
24.3 \pm 1.14 a \\
26.0 \pm 1.53 a\end{array}$ & $\begin{array}{l}39.1 \pm 0.09 \mathrm{c} \\
30.6 \pm 0.52 \mathrm{a} \\
35.0 \pm 1.38 \mathrm{~b}\end{array}$ \\
\hline $\mathrm{Hg}^{2+}$ & $0.59 \pm 0.02$ & $\begin{array}{l}\text { Type 1 } \\
\text { Type } 2 \\
\text { Type } 3\end{array}$ & $\begin{array}{l}95.8 \pm 0.99 b \\
90.7 \pm 0.75 a \\
89.8 \pm 1.91 a\end{array}$ & $\begin{array}{l}95.8 \pm 0.99 b \\
91.5 \pm 0.41 a \\
90.7 \pm 0.75 a\end{array}$ & $\begin{array}{l}97.5 \pm 1.07 b \\
93.2 \pm 2.80 \mathrm{a} \\
91.5 \pm 0.41 \mathrm{a}\end{array}$ \\
\hline $\mathrm{Pb}^{2+}$ & $32.9 \pm 1.15$ & $\begin{array}{l}\text { Type 1 } \\
\text { Type } 2 \\
\text { Type } 3\end{array}$ & $\begin{array}{l}41.1 \pm 1.43 c \\
8.75 \pm 0.03 b \\
5.94 \pm 1.07 a\end{array}$ & $\begin{array}{l}57.9 \pm 3.24 b \\
14.2 \pm 0.15 a \\
7.26 \pm 0.34 a\end{array}$ & $\begin{array}{l}91.0 \pm 2.33 \mathrm{c} \\
16.9 \pm 0.57 \mathrm{~b} \\
7.91 \pm 0.97 \mathrm{a}\end{array}$ \\
\hline
\end{tabular}


Figure A.14 Dependence of the absorbance of bovine serum albumin protein at $660 \mathrm{~nm}$ on the concentration of protein in the solutions

Regression coefficient $\left(r^{2}\right)=0.9944$

Equation of the line was $\mathrm{Y}=\mathrm{aX}+\mathrm{b}$ where,

$\mathrm{Y}=$ absorbance at $\mathrm{A}_{660 \mathrm{~nm}}$

$\mathrm{X}=$ concentration of protein in $\mu \mathrm{g} / \mathrm{mL}$

$\mathrm{a}=0.0011$

$\mathrm{b}=0.0486$

Therefore, $X=909.04 *$ A $_{660 \mathrm{~nm}}$ 


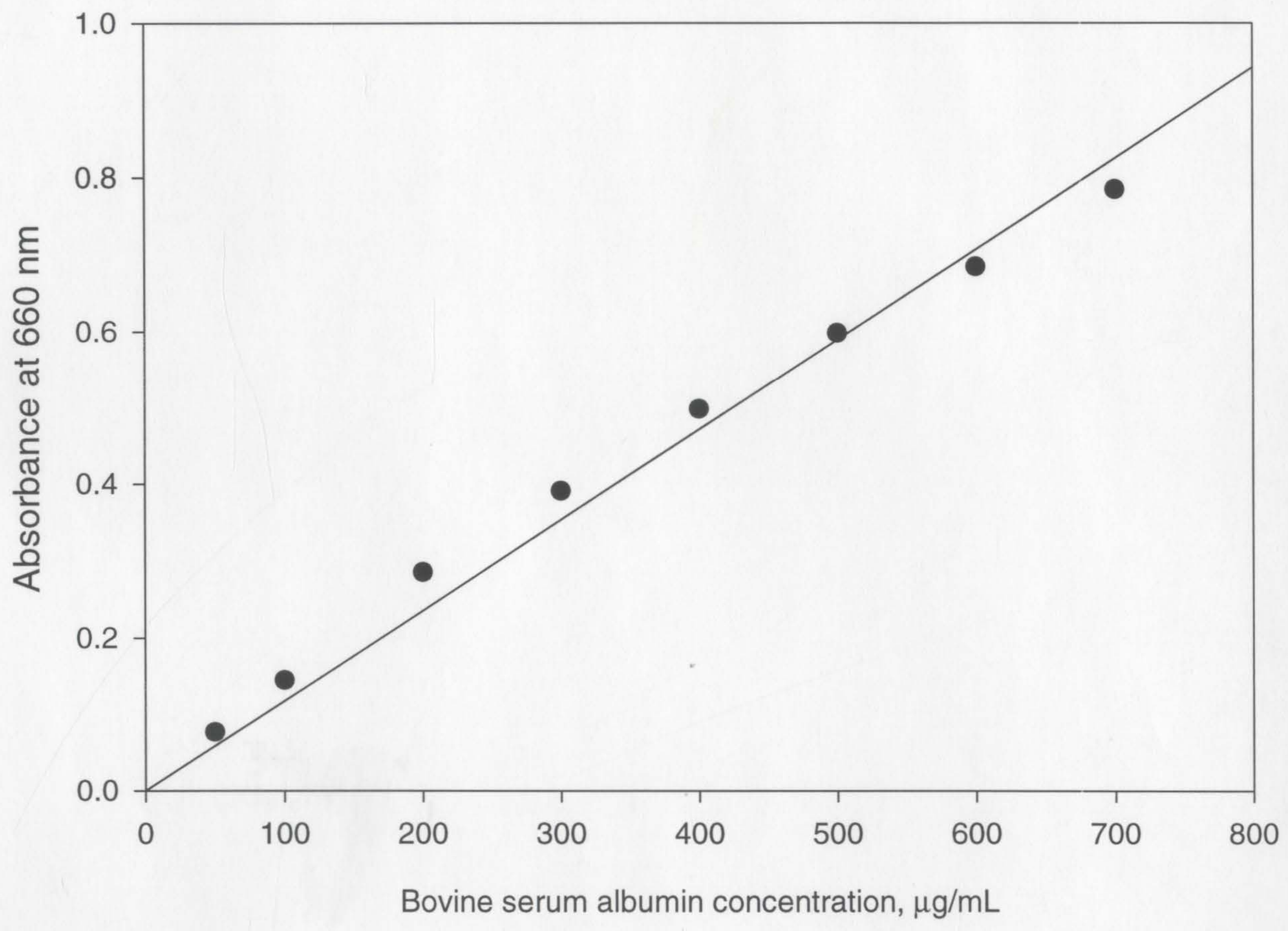


Table A.7 Protein flocculation capacity of chitosan using different concentrations of bovine serum albumin.

\begin{tabular}{llll}
\hline $\begin{array}{l}\text { Protein } \\
\text { concentration } \\
(\mathrm{mg} / \mathrm{mL})\end{array}$ & Type 1 & Type 2 & Type 3 \\
\hline 2 & $100.00 \pm 1.4^{\mathrm{c}}$ & $70.00 \pm 1.2^{\mathrm{a}}$ & $19.55 \pm 1.40^{\mathrm{a}}$ \\
4 & $91.25 \pm 1.2^{\mathrm{b}}$ & $70.00 \pm 1.8^{\mathrm{a}}$ & $22.70 \pm 0.98^{\mathrm{b}}$ \\
6 & $66.83 \pm 1.4^{\mathrm{a}}$ & $74.35 \pm 1.3^{\mathrm{b}}$ & $21.66 \pm 0.88^{\mathrm{a}}$ \\
8 & $65.76 \pm 1.6^{\mathrm{a}}$ & $73.86 \pm 1.1^{\mathrm{b}}$ & $20.26 \pm 0.76^{\mathrm{a}}$ \\
\hline $\begin{array}{l}\text { Results reported are mean vales of three determinations } \pm \text { standard deviation. } \\
\text { Means in each column sharing the same superscript are not significantly }(\mathrm{p}>0.05) \\
\text { different from one another. }\end{array}$
\end{tabular}





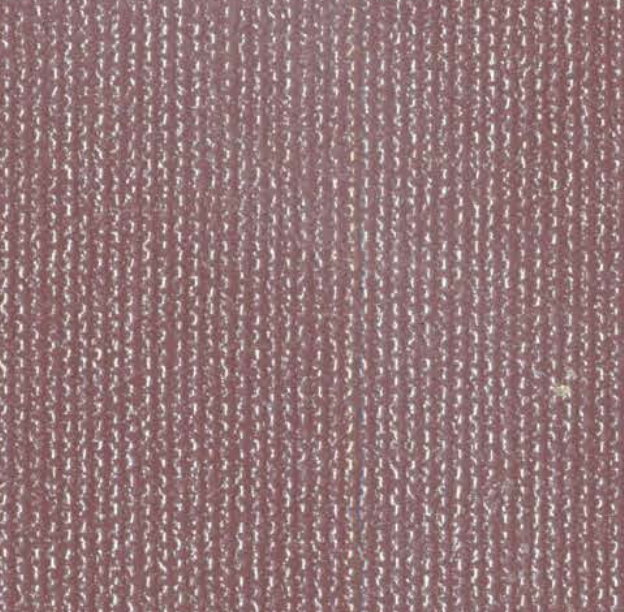

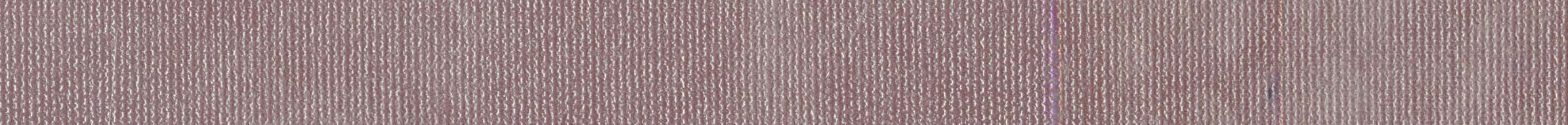
17.

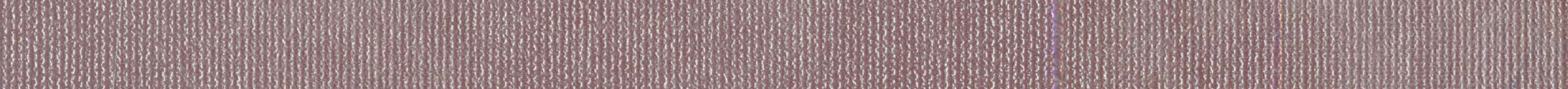

